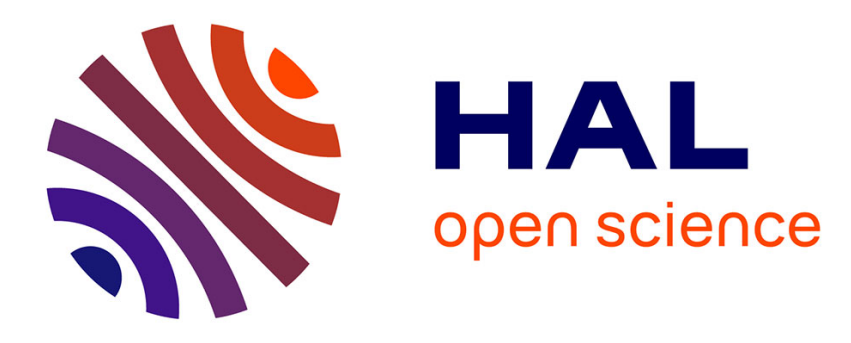

\title{
How do herbivorous mammals adjust their trade-off between food and safety?
}

Francois-René Favreau

\section{To cite this version:}

Francois-René Favreau. How do herbivorous mammals adjust their trade-off between food and safety? Animal biology. Université Claude Bernard - Lyon I; University of Queensland, 2014. English. NNT: 2014LYO10130 . tel-01128307

\section{HAL Id: tel-01128307 https://theses.hal.science/tel-01128307}

Submitted on 9 Mar 2015

HAL is a multi-disciplinary open access archive for the deposit and dissemination of scientific research documents, whether they are published or not. The documents may come from teaching and research institutions in France or abroad, or from public or private research centers.
L'archive ouverte pluridisciplinaire $\mathbf{H A L}$, est destinée au dépôt et à la diffusion de documents scientifiques de niveau recherche, publiés ou non, émanant des établissements d'enseignement et de recherche français ou étrangers, des laboratoires publics ou privés. 


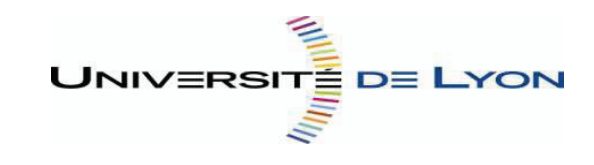

Université Claude Bernard

\section{Lyon 1}

THE UNIVERSITY OF QUEENSLAND

A US T R A L I A

$N^{\circ}$ d'ordre: 130 - 2014

Année 2014

THESE

Réalisée en cotutelle entre

L'UNIVERSITE CLAUDE BERNARD - LYON 1

et

THE UNIVERSITY OF QUEENSLAND

pour obtenir le grade de

DOCTEUR de l'Université Claude Bernard - Lyon 1

et

DOCTOR of PHILOSOPHY of The University of Queensland

Ecole Doctorale : Evolution Ecosystèmes Microbiologie Modélisation (E2M2)

Présenté et soutenue le 10 juillet 2014 à l'Université Claude Bernard - Lyon 1 par

François-René FAVREAU

\section{How do herbivorous mammals adjust their trade-off between food and safety?}

Directeurs de thèse: Hervé FRITZ, D. R. CNRS, Univ. Lyon1

Anne GOLDIZEN, M.C.U, Univ. Queensland

Co-directeur: Olivier PAYS, M.C.U, Univ. Angers

JURY:

Hervé FRITZ, D.R. CNRS, Univ. Lyon1

Directeur

Anne GOLDIZEN, M.C.U, Univ. Queensland

Directeur

Olivier PAYS, M.C.U, Univ. Angers

Co-directeur

Odile PETIT, D.R. CNRS, Univ. Strasbourg

Rapporteur

Clare McARTHUR, M.C.U, Univ. Sydney

Rapporteur

Anne LOISON, C.R. CNRS, Univ. Savoie

Examinateur

Dominique ALLAINÉ, Prof, Univ. Lyon 1

Examinateur

Craig FRANKLIN, Prof, Univ. Queensland

Examinateur 


\section{Abstract}

Prey species foraging under a risk of predation have to trade between food acquisition and safety from predation in order to increase their fitness. This trade-off is commonly investigated by studying the trade-off between foraging and vigilance activities. However, vigilance and foraging can be affected by numerous environmental, social, and individual parameters which can also vary seasonally and differ between individuals from the same population. In this context, the overall objective of my $\mathrm{PhD}$ was to better understand how herbivorous prey animals manage the feeding/vigilance trade-off at a fine scale, considering the wide range of variables that may affect it, individual variation, and the different functions of vigilance, using female eastern grey kangaroos (Macropus giganteus) and impalas (Aepyceros melampus) as models.

I observed that despite the many factors that shape vigilance and feeding rates over short time scales, these behaviours were mainly driven by variation in food resources over longer temporal scales. I also highlighted that predator and social contexts induced different behavioural responses in relation to this trade-off, and that decisions of prey to adjust their vigilance in terms of function and cost were driven by predation risk, food availability, and competition but varied between seasons. Finally, I observed that between-individual variation occurs for this trade-off but that this variation is context dependant.

This thesis shows that prey animals constantly adapt their behaviour and strategies according to the situation they experience, in order to balance the acquisition of food and social information with staying safe. 


\section{Résumé}

Afin d'accroître leur survie et leur succès reproducteur, les espèces proies tentent de maximiser leur apport énergétique tout en évitant la prédation. Par conséquent, elles sont contraintes à un compromis entre acquisition des ressources alimentaires et détection des prédateurs, deux activités souvent considérées comme antagonistes. En effet, comme la détection du prédateur exige à la proie d'investir du temps dans la surveillance (aussi appelée vigilance), cette activité peut s'avérer particulièrement coûteuse car elle affecte l'approvisionnement notamment quand le risque est élevé.

Bien que le compromis entre vigilance et approvisionnement constitue un thème très étudié en écologie comportementale, la compréhension des mécanismes sous-tendant cet ajustement reste mal connu, en particulier chez les herbivores, et ce pour différentes raisons. Tout d'abord, les ajustements comportementaux des herbivores impliqués dans ce compromis sont influencés par de nombreux paramètres environnementaux, sociaux et individuels rendant les mécanismes assez complexes à décrypter. Par ailleurs, les herbivores ajustent leur approvisionnement à divers échelles temporelles et spatiales, et la variation saisonnière des ressources pourraient aussi jouer un rôle déterminant si durant la saison hivernale (ou sèche) les animaux sont particulièrement contraints par des ressources globalement pauvres. De plus, les herbivores sont capables de modérer le coût de la vigilance sur l'approvisionnement. En effet, lors des périodes de surveillance, les herbivores sont capables de réduire grandement le coût de la surveillance en continuant la mastication (vigilance partagée, contrairement à la vigilance exclusive durant laquelle la mastication est arrêtée) notamment quand le risque de prédation est faible. Enfin, l'existence de variations comportementales entre individus d'une même population, doit être prise en compte dans l'étude de ce compromis afin de détecter d'éventuelles stratégies individuelles maximisant la surveillance et l'approvisionnement.

L'objectif global de ce travail de thèse est donc de mieux comprendre comment les herbivores proies maximisent le compromis entre vigilance et approvisionnement. Pour ce faire, j'ai basé mes recherches sur les comportements de deux herbivores proies de taille moyenne. Dans un premier temps, j'ai suivi le comportement de 34 femelles kangourous gris de l'Est (Macropus giganteus) préalablement identifiées durant une année dans une population faiblement impactée par la prédation au sein du parc national de Sundown dans le Queensland (Australie). J'ai alors étudié comment les individus de cette population ajustaient leur comportement en fonction du risque de prédation, du contexte social et de la disponibilité des ressources alimentaire, et si ces ajustements variaient entre les individus. Dans un second temps, j'ai étudié des femelles d'une population d'impalas (Aepyceros melampus) soumise à la prédation au sein du parc national de Hwange au Zimbabwe en manipulant expérimentalement (émission de vocalisations) le contexte 
social et le risque de prédation. Ces observations m'ont permis d'apporter de nouveaux éléments contribuant à la compréhension du compromis entre vigilance et approvisionnement, chez les herbivores, que je présente ici sous la forme de quatre études

Dans une première étude, j'ai cherché à identifier les principaux facteurs responsables des variations saisonnières de vigilance et de taux de consommation chez le kangourou gris. Mes résultats montrent que le type d'habitat utilisé par l'animal, est le principal facteur régulant les variations saisonnières du taux de consommation alors que la taille du groupe régule les variations saisonnières de vigilance. En revanche, comme l'habitat et la taille des groupes sont également fortement corrélés à la variation saisonnière de la qualité des ressources alimentaires, l'étude montre donc que la ressource alimentaire est le principal facteur expliquant les différences d'investissement entre vigilance et alimentation au sein de cette population faiblement soumise à la prédation. Ainsi, il apparait alors que les effets de la taille du groupe et de l'habitat sur le compromis entre approvisionnement et sécurité, n'agissent que comme des sous-produits de la variation saisonnière des ressources alimentaire dans le système étudié.

Dans une seconde étude, j'ai utilisé une approche expérimentale en diffusant des vocalisations de prédateurs (lions) et sociales (mâles impalas) afin d'étudier comment les impalas modulaient leur investissement dans la vigilance, leur taux de consommation et leur déplacement en réponse à ces changements de contextes environnementaux. En réponse aux vocalisations de lions, les femelles augmentent leur activité de vigilance et leur déplacement mais au dépend de leur taux de consommation. En réponse aux vocalisations de mâles, elles augmentent leur déplacement au dépend du temps passé en vigilance sans pour autant altérer leur taux d'ingestion. Ces résultats suggèrent que chez les espèces fortement soumises à la prédation, la présence des prédateurs peut engendrer une forte augmentation de la vigilance et réduire le taux de consommation, alors que la sollicitation par les congénères semble moins coûteuse car le taux de consommation n'est pas affecté. Cependant, la stimulation sociale tout comme la stimulation anti-prédatrice génère plus de déplacements de la part des individus dont les fonctions restent à identifier.

Dans une troisième étude, j'ai analysé comment le risque de prédation, la disponibilité des ressources et la compétition, affectaient la fonction et le cout de la vigilance chez les kangourous en considérant l'effet saisonnier de la qualité des ressources. J'ai donc testé les effets de la taille de groupe, de la distance au couvert, de la distance entre les individus, et de la qualité du patch alimentaire sur la vigilance anti-prédatrice et la vigilance sociale en dissociant pour chacune d'elle, la vigilance partagée et la vigilance exclusive. Quelle que soit la fonction de la vigilance (sociale ou anti-prédatrice), mes résultats montrent que les animaux investissent principalement dans la vigilance partagée limitant ainsi les coûts de la vigilance sur l'activité alimentaire, et que ce type de 
vigilance est fortement influencé par la qualité des patchs alimentaires quelle que soit la saison. De plus, l'investissement dans la vigilance anti-prédatrice exclusive diminue avec la taille du groupe et la proximité d'autres congénères, et apparait donc fortement influencée par la dilution du risque de prédation. Enfin, l'investissement dans la vigilance sociale exclusive ou partagée est affecté par tous les facteurs testés, et leurs effets varient entre les saisons. Ces résultats suggèrent que les décisions individuelles d'engager certains types de vigilance sont fortement dépendantes des variations de contextes écologiques et sociaux tels que le risque de prédation, la ressource alimentaire et la compétition.

Enfin, dans une quatrième étude, j'ai testé s'il existait, au sein d'une même population de kangourous, des variations de personnalité et de plasticité (ajustement entre deux comportements) chez les individus dont les conditions écologiques (qualité du patch alimentaire), sociales (taille du groupe) et physiologiques (statut reproducteur) variaient au cours de l'année. La première partie de cette étude, montre que, bien que les individus aient différents niveaux de vigilance et de taux d'ingestion (donc différentes personnalités), leurs ajustements aux variations de la taille de groupe et de qualité des ressources sont similaires (donc même plasticité). En revanche, leurs ajustements comportementaux diffèrent en fonction de leur statut reproducteur. La seconde partie de cette étude, montre que, pour le compromis entre vigilance et taux d'ingestion, les individus présentent des différences de personnalités seulement dans les petits groupes et dans les patches de bonne qualité, et que les femelles ajustent différemment leur vigilance à leur taux de consommation lorsqu'elles ont un jeune. D'une manière générale, ces résultats suggèrent que les variations de personnalité et de plasticité entre les individus d'une même population peuvent être plus ou moins exprimées dans différentes conditions et que les femelles peuvent avoir des stratégies maternelles différentes.

En conclusion, ce travail de thèse nous permet de mieux comprendre comment les espèces proies ajustent leur compromis entre vigilance et approvisionnement, en fonction de leur environnement, de la présence des congénères et de leurs caractéristiques individuelles. II apparait que les animaux régulent constamment leur activité de vigilance afin de maximiser l'acquisition de ressources, ou d'informations sociales, tout en assurant leur sécurité. De plus, mes études sur des populations soumises à différentes pressions de prédation suggèrent que lorsque le risque est faible (par exemple chez les kangourous), le compromis entre vigilance et approvisionnement est principalement façonné par les ressources même si d'autres facteurs peuvent moduler cet ajustement. Toutefois, lorsque le risque de prédation est important (chez les impalas), ce risque joue un rôle crucial dans l'ajustement de ce compromis. Ce travail ouvre donc des perspectives sur la compréhension des effets de la prédation et des ressources sur la biologie des populations d'espèces proies. 


\section{Declaration by author}

This thesis is composed of my original work, and contains no material previously published or written by another person except where due reference has been made in the text. I have clearly stated the contribution by others to jointly-authored works that I have included in my thesis.

I have clearly stated the contribution of others to my thesis as a whole, including statistical assistance, survey design, data analysis, significant technical procedures, professional editorial advice, and any other original research work used or reported in my thesis. The content of my thesis is the result of work I have carried out since the commencement of my research higher degree candidature and does not include a substantial part of work that has been submitted to qualify for the award of any other degree or diploma in any university or other tertiary institution. I have clearly stated which parts of my thesis, if any, have been submitted to qualify for another award.

I acknowledge that an electronic copy of my thesis must be lodged with the University Library and, subject to the General Award Rules of The University of Queensland, immediately made available for research and study in accordance with the Copyright Act 1968.

I acknowledge that copyright of all material contained in my thesis resides with the copyright holder(s) of that material. Where appropriate I have obtained copyright permission from the copyright holder to reproduce material in this thesis. 


\section{Publications during candidature}

Rieucau, G., Blanchard, P., Martin, J. G. A., Favreau, F-R., Goldizen, A. W. \& Pays O. 2012. Investigating differences in vigilance tactic use within and between the sexes in eastern grey kangaroos. PLoS ONE, 7: e44801.

Favreau, F-R., Pays, O., Goldizen, A.W. \& Fritz, H. 2013. Short-term behavioural responses of impalas in simulated antipredator and social contexts. PLoS ONE, 8: e84970.

Favreau, F-R., Goldizen, A.W., Fritz, H., Blomberg, S. P., Best, E. C. \& Pays, O. 2014. Withinpopulation differences in personality and plasticity in the trade-off between vigilance and foraging in kangaroos. Animal Behaviour, 92, 175-184.

Favreau, F-R., Goldizen, A.W., Fritz, H. \& Pays, O. Seasonal variation in feeding rates and vigilance time in female kangaroos: the primary role of patch quality. Submitted to Functional Ecology.

Favreau, F-R., Pays, O., Fritz, H., Goulard, M., Best, E. C. \& Goldizen, A.W. Predators, food and social context shape the types of vigilance exhibited by kangaroos. Submitted to Animal Behaviour.

\section{Publications included in this thesis}

Chapters 2 through 5 were written as papers for publication in peer-reviewed journals. All coauthors consented to the manuscripts being included in the thesis.

CHAPTER 2: Favreau, F-R., Goldizen, A.W., Fritz, H. \& Pays, O. Seasonal variation in feeding rates and vigilance time in female kangaroos: the primary role of patch quality. Submitted to Functional Ecology.

\begin{tabular}{|l|l|}
\hline \multicolumn{1}{|c|}{ Contributor } & \multicolumn{1}{|c|}{ Statement of contribution } \\
\hline Favreau, F-R. (Candidate) & $\begin{array}{l}\text { Designed study (50\%) } \\
\text { Field work (100\%) } \\
\text { Wrote the paper (70\%) } \\
\text { Statistical analysis (20\%) }\end{array}$ \\
\hline \multirow{3}{*}{ Goldizen, A. W. } & $\begin{array}{l}\text { Designed study (20\%) } \\
\text { Edited paper (34\%) }\end{array}$ \\
\hline Fritz, H. & Project support (100\%) \\
\hline Pays, O. & Designed study (15\%) \\
& Edited paper (33\%) \\
& Designed study (15\%) \\
Wrote the paper (30\%) \\
Statistical analysis (80\%) \\
Edited paper (33\%)
\end{tabular}


CHAPTER 3: Favreau, F-R., Pays, O., Goldizen, A.W. \& Fritz, H. 2013. Short-term behavioural responses of impalas in simulated antipredator and social contexts. PLOS ONE, 8: e84970.

\begin{tabular}{|l|l|}
\hline \multicolumn{1}{|c|}{ Contributor } & \multicolumn{1}{|c|}{ Statement of contribution } \\
\hline Favreau, F-R. (Candidate) & $\begin{array}{l}\text { Designed experiments (30\%) } \\
\text { Field work (80\%) } \\
\text { Wrote the paper (90\%) } \\
\text { Statistical analysis (60\%) }\end{array}$ \\
\hline \multirow{3}{*}{ Pays, O. } & $\begin{array}{l}\text { Designed experiments (30\%) } \\
\text { Field work (20\%) }\end{array}$ \\
& Wrote the paper (10\%) \\
& Statistical analysis (40\%) \\
& Edited paper (33\%) \\
& Project support (20\%) \\
\hline Goldizen, A. W. & Designed experiments (10\%) \\
& Edited paper (33\%) \\
\hline Fritz, H. & Designed experiments (30\%) \\
& Edited paper (33\%) \\
& Project support (80\%) \\
\hline
\end{tabular}

CHAPTER 4: Favreau, F-R., Pays, O., Fritz, H., Goulard, M., Best, E. C. \& Goldizen, A.W. Predators, food and social context shape the types of vigilance exhibited by kangaroos. Submitted to Animal Behaviour.

\begin{tabular}{|l|l|}
\hline \multicolumn{1}{|c|}{ Contributor } & \multicolumn{1}{|c|}{ Statement of contribution } \\
\hline Favreau, F-R. (Candidate) & $\begin{array}{l}\text { Designed study (50\%) } \\
\text { Field work (90\%) } \\
\text { Wrote the paper (100\%) } \\
\text { Statistical analysis (30\%) }\end{array}$ \\
\hline Pays, O. & $\begin{array}{l}\text { Designed study (15\%) } \\
\text { Statistical analysis (50\%) } \\
\text { Edited paper (30\%) }\end{array}$ \\
\hline Fritz, H. & $\begin{array}{l}\text { Designed study (15\%) } \\
\text { Edited paper (30\%) }\end{array}$ \\
\hline Goulard, M. & Statistical analysis (20\%) \\
\hline Best, E. C. & $\begin{array}{l}\text { Field work (10\%) } \\
\text { Edited paper (10\%) }\end{array}$ \\
\hline Goldizen, A.W. & $\begin{array}{l}\text { Designed study (20\%) } \\
\text { Edited paper (30\%) } \\
\text { Project support (100\%) }\end{array}$ \\
\hline
\end{tabular}


CHAPTER 5: Favreau, F-R., Goldizen, A.W., Fritz, H. Blomberg, S. P., Best, E. C. \& Pays, O. 2014. Within-population differences in personality and plasticity in the trade-off between vigilance and foraging in kangaroos. Animal Behaviour, 92, 175-184.

\begin{tabular}{|l|l|}
\hline \multicolumn{1}{|c|}{ Contributor } & \multicolumn{1}{|c|}{ Statement of contribution } \\
\hline Favreau, F-R. (Candidate) & $\begin{array}{l}\text { Designed study (50\%) } \\
\text { Field work (90\%) } \\
\text { Wrote the paper (90\%) } \\
\text { Statistical analysis }(70 \%)\end{array}$ \\
\hline Goldizen, A.W. & $\begin{array}{l}\text { Designed study (20\%) } \\
\text { Edited paper (30\%) } \\
\text { Project support (100\%) }\end{array}$ \\
\hline Fritz, H. & $\begin{array}{l}\text { Designed study (15\%) } \\
\text { Edited paper (30\%) }\end{array}$ \\
\hline Blomberg, S. P. & Statistical analysis (15\%) \\
\hline Best, E. C. & $\begin{array}{l}\text { Field work (10\%) } \\
\text { Edited paper (10\%) }\end{array}$ \\
\hline Pays, O. & $\begin{array}{l}\text { Designed study (15\%) } \\
\text { Wrote the paper (10\%) } \\
\text { Statistical analysis (15\%) } \\
\text { Edited paper (30\%) }\end{array}$ \\
\hline
\end{tabular}




\section{Contributions by others to the thesis}

Bénédicte Bouvy provided assistance in the field for Chapters 2, 4, and 5. Stéphanie Périquet, Martin Muzamba, Eunice Chapanda, Nobuhle Ndlovu and Cynthia Mapendere provided assistance in the field for Chapter 3. Alecia J. Carter provided advice for Chapter 5.

Statement of parts of the thesis submitted to qualify for the award of another degree

None 


\section{Acknowledgements}

First I would like to gratefully thank my three supervisors who made this PhD possible and guided me during these three and a half years. Thank to Olivier Pays who introduced me to research from my third year of my bachelors degree and never stopped to help and advise me on my work during all these years. Thanks to Anne Goldizen for opening the doors of Australia to me during my Masters and this $\mathrm{PhD}$ and who gave me incredible support during these last years. Finally, thanks to Hervé Firtz for his involvement and advice throughout this $\mathrm{PhD}$, and for allowing me to work in and discover Zimbabwe.

I would also like thank the people that I met and who helped me during my journeys in Australia and Zimbabwe. First I wanted to gratefully thank Emily Best for all her support in the field in Sundown National Park, for all her involvement in teaching me to identify the kangaroos, and for many great moments in the field. Also, thanks to Simone Ludlow and Anita Cosgrove for sharing with me many days in Sundown. Thank to the Department of National Parks, Recreation, Sport and Racing for letting us live in the ranger's house at Sundown, and to park rangers Peter Hasselgrove and Ian Elms. I also wanted to say a special thank you to Joanne Towsey and Charlie who let me stay at their place on many occasions during my trips in Australia and with whom I shared many good moments during my stays. Also, I wanted to thank the people from the BERG lab in Australia for their support and their welcome in Australia, including (in alphabetical order) Simon Blomberg, Kerryn and John Carter, Brett Coghlan, Rebecca Dannock, Amy Edwards, Diana Fisher, Natalie Freeman, Wendy King, Clementine Menz, Anita Murray, Daniela Parra and Luis Verde Arregoitia. Finally, I wanted to thank Craig Franklin and Richard Fuller for having been my readers at the University of Queensland, and for their advice.

During my stay in Zimbabwe, I had the chance to meet many different people that made this trip one of the most amazing experiences. I wanted to gratefully thank Stéphanie Périquet for the great moments that we had and for making me discover the African fauna in her famous "landy", but also Brent Staplekamp and his wife Laurie for their welcome and friendliness, and for giving me the opportunity to have close looks at lions. Also thanks to Alison and Patrick Duncan for their kindness. And finally, thanks to the students and staff that helped me to perform my experiments in the field, especially Martin Muzamba, Nobuhle Ndlovu, Cynthia Mapendere, and Eunice Chapanda.

Finally, I could not have accomplished this $\mathrm{PhD}$ without the support of my family and friends. Therefore I want to thank and dedicate this work to my parents Jean-François and Michèle Favreau for having always respected my choices and for their support during this adventure. I also want to thanks my brothers Jean-Antoine and André-Xavier as well as the many friends who 
always encouraged me, especially Audrey and Elo, Béatrice and Géraldine, Cindy and Franket', Gégé and Annabelle, Isa, Joe and Christina, Laurenz and Nancy, Max and Chloé, Nono, Oliv, Prat and Nico, Sergio, Soso, Zac and Kinsy, and Zaza and Marine. Finally, I want to give the biggest thanks to my wife Bénédicte Bouvy for sharing my life for almost 12 years and for her constant and daily support during this period.

This research was made possible by funding from different sources. I first thank the University of Queensland for their financial support through my scholarships. I also thank Anne Goldizen and the University of Queensland for their financial support during my different stays in Australia including plane tickets and funding for fieldwork. Finally, I thank Hervé Fritz, Olivier Pays, and the Hwange Environmental Research for Development (HERD) project for their financial support during my stay in Zimbabwe. 


\section{Keywords}

Prey, predation, trade-off, vigilance, foraging, social context, individual variation, kangaroos, impala

\section{Australian and New Zealand Standard Research Classifications} (ANZSRC)

ANZSRC code: 060207 Population Ecology, 20\%

ANZSRC code: 060201 Behavioural Ecology, 40\%

ANZSRC code: 060801 Animal Behaviour, 40\%

\section{Fields of Research (FoR) Classification}

FoR code: 0602, Ecology, 60\%

FoR code: 0608, Zoology, 40\% 


\section{Table of contents}

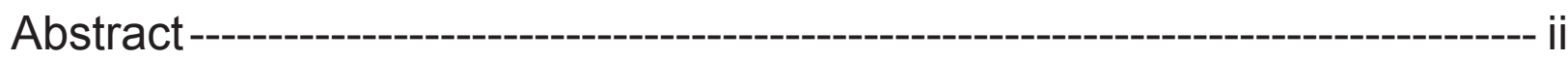

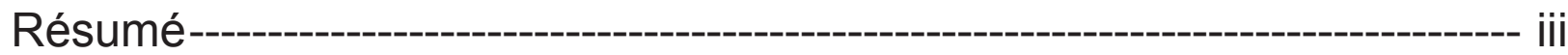

Declaration by author ------------------------------------------------------------------- vi

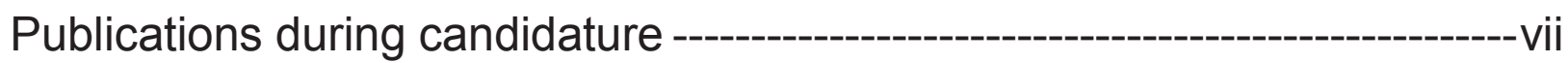

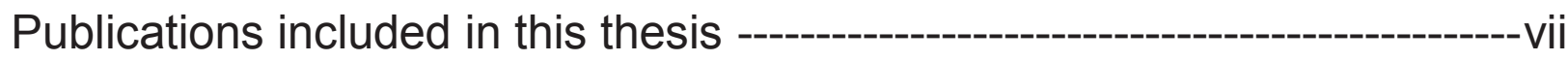

Contributions by others to the thesis -----

Statement of parts of the thesis submitted to qualify for the award of another degree------------------------------------------------------------------------------ $x$

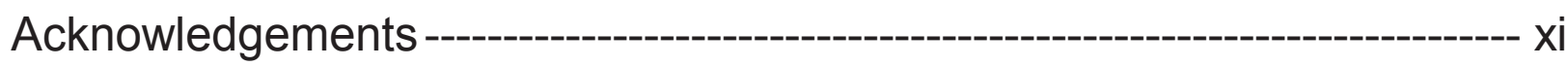

Keywords------- xiii

Australian and New Zealand Standard Research Classifications

(ANZSRC)------ xiii

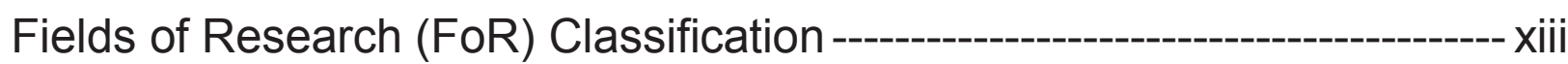

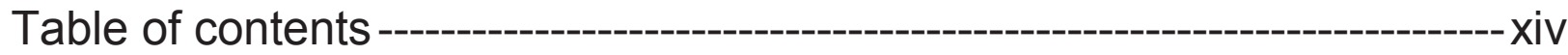

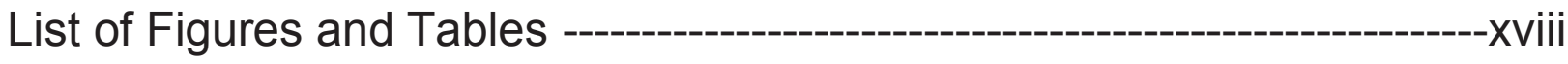

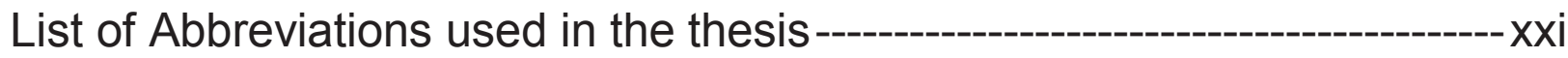

\section{Chapter 1: General introduction ---------------------------------------1}

1 - Trade-off theory ---------------------------------------------------------------------2

1-1 Trade-offs in life history theory -------_on

1-2 Trade-off between food acquisition and safety from predators and its

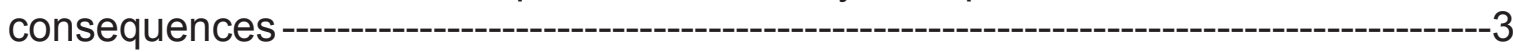

2 - Foraging Behaviour ----------------------------------------------------5

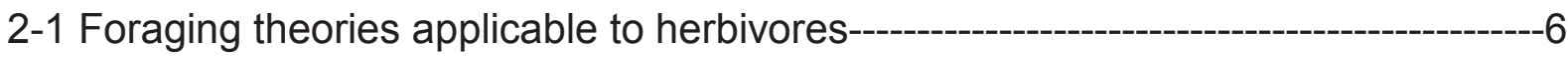

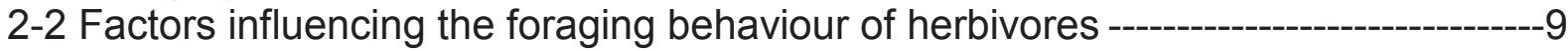

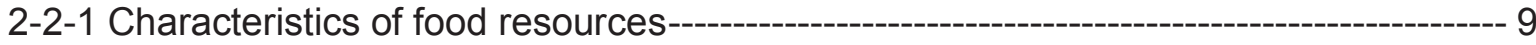

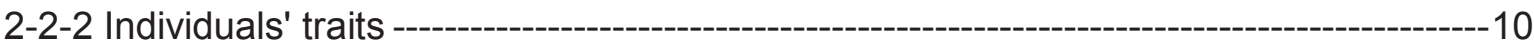

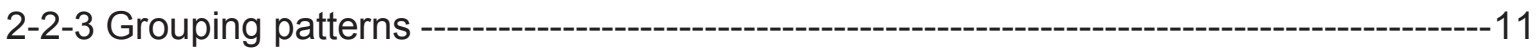

3 - Antipredator vigilance behaviour-- 12

3-1 Factors influencing antipredator vigilance---_-_-_-_-_-_-

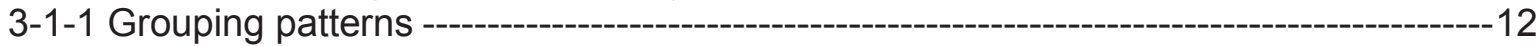

3-1-2 Predation risk and perceived predation risk-------------------------------13

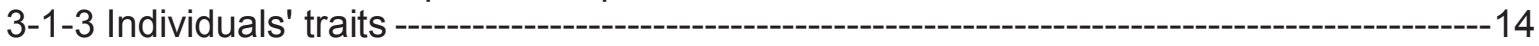

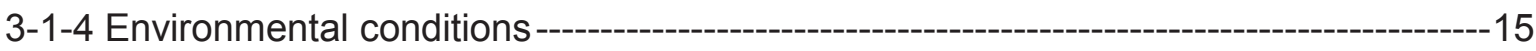

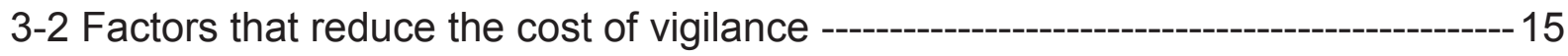




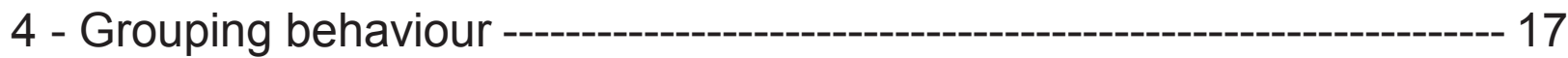

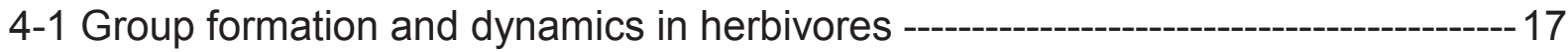

4-2 Benefits and costs of grouping -----_o

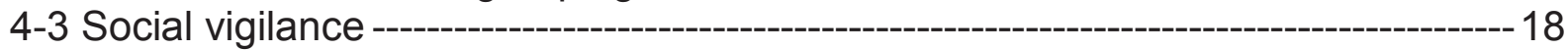

5 - Behavioural variation among individuals--- 20

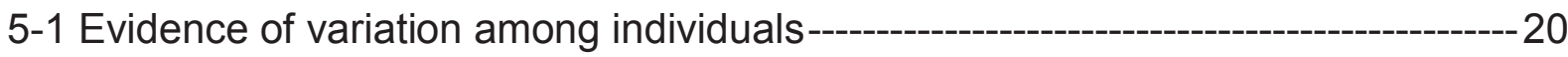

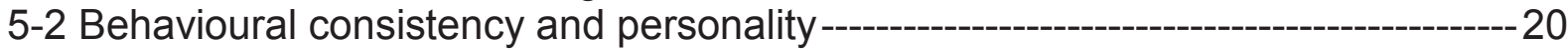

5-3 Behavioural plasticity and the behavioural reaction norm approach ----------------21

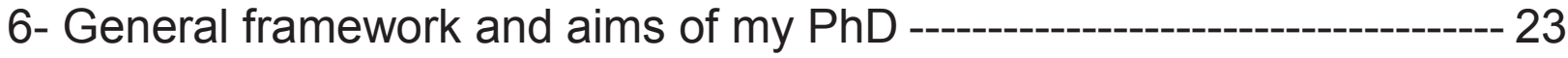

6-1 General framework ---_-

6-2 Aims of the PhD -

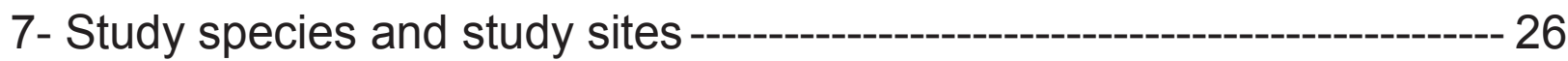

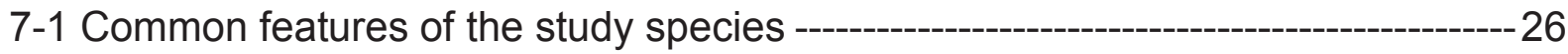

7-2 Study of eastern grey kangaroos at Sundown National Park (Australia)-----------27

7-2-1 Eastern grey kangaroos--------------------------------------------27

7-2-2 Sundown National Park ----------------------------------------------------28

7-3 Study of common impalas in Hwange National Park (Zimbabwe) ----------_-----29

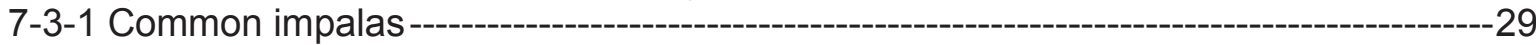

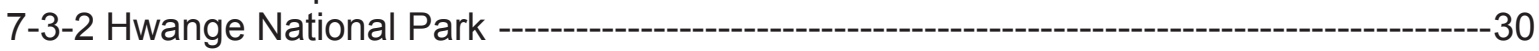

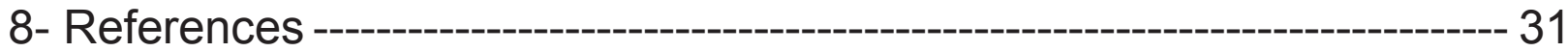

\section{Chapter2: Seasonal variation of feeding rates and vigilance time in female kangaroos: the primary role of patch} quality

Abstract ------- 49

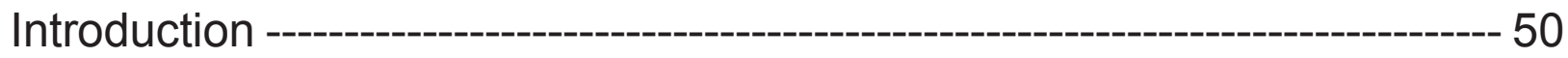

Materials and Methods------------------------------------------------------------------ 52

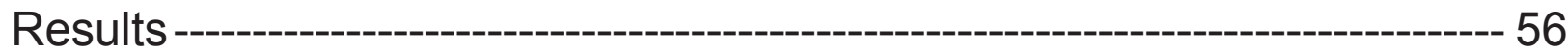

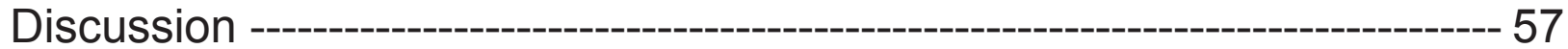

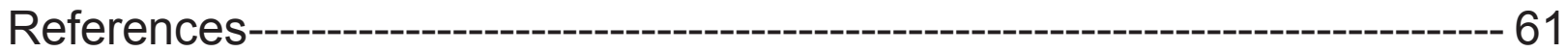

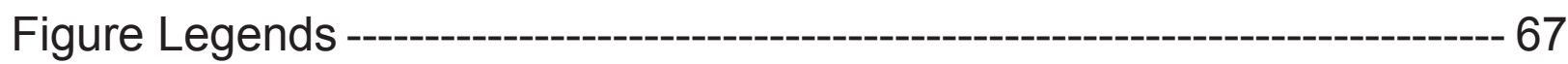

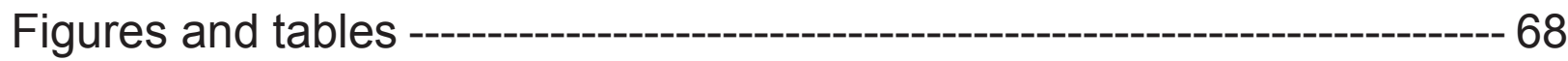


Chapter3: Short-term behavioural responses of impalas in simulated antipredator and social contexts

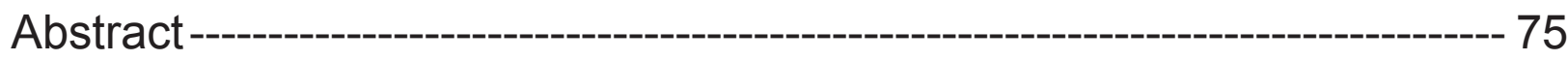

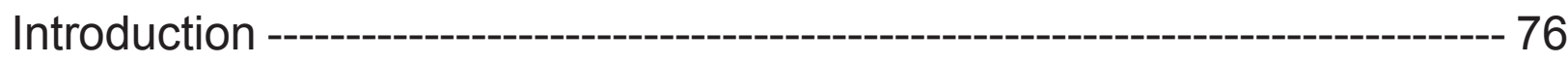

Materials and methods---_- 78

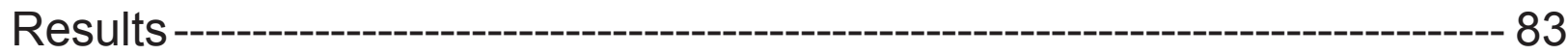

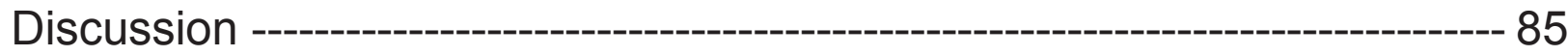

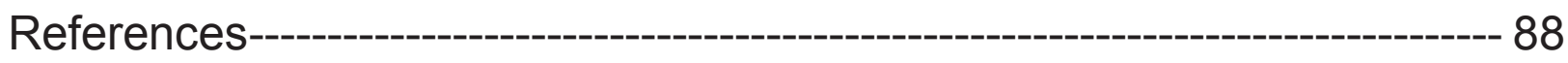

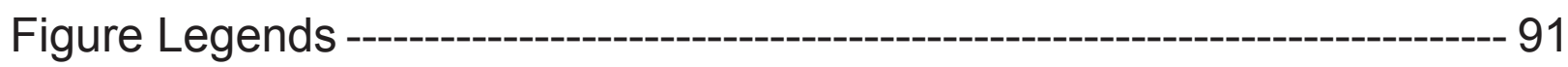

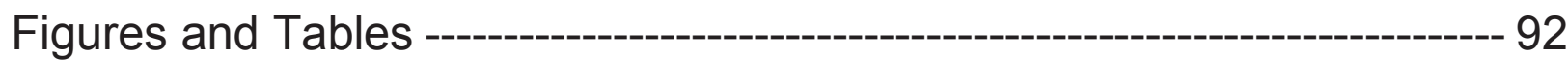

Electronic Supplementary Material --------------------------------------------------- 98

Chapter 4: Predators, food and social context shape the types of vigilance exhibited by kangaroos ------------------ 102

Abstract----_--_--- 102

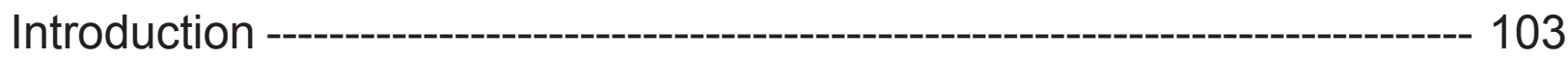

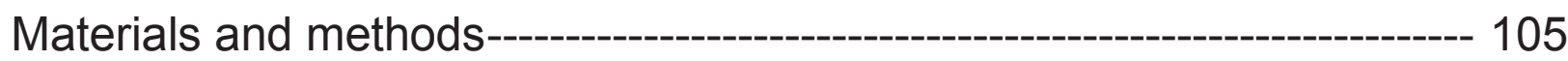

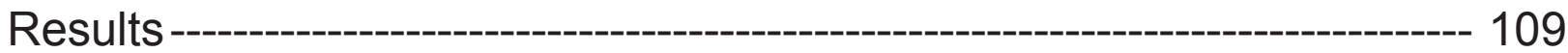

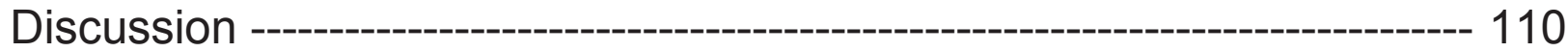

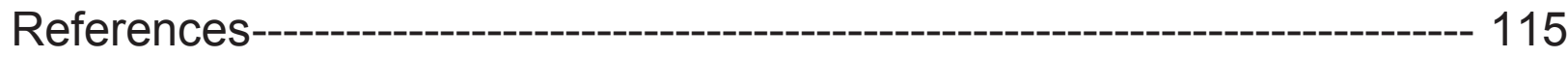

Figure legends ----------------------------------------------------------------------------- 120

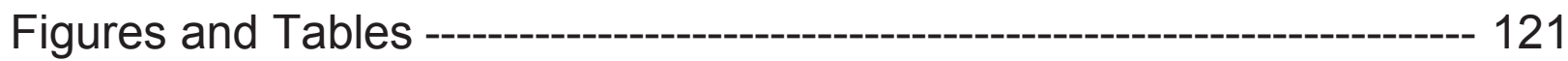

Chapter 5: Within-population differences in personality and plasticity in the trade-off between vigilance and foraging in kangaroos ---------------------------------------------- 125

Abstract ------------------------------------------------------------------------------------------- 125

Introduction ----------------------------------------------------------------------------------- 126

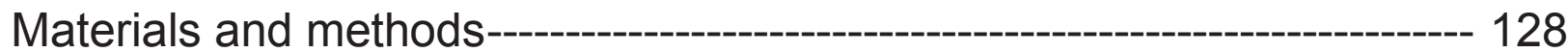

Results ------_--- 132

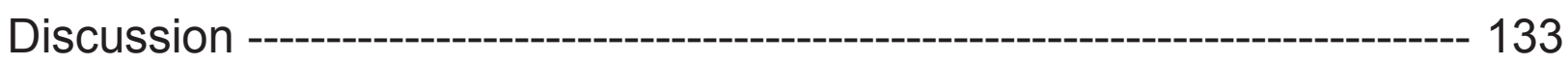

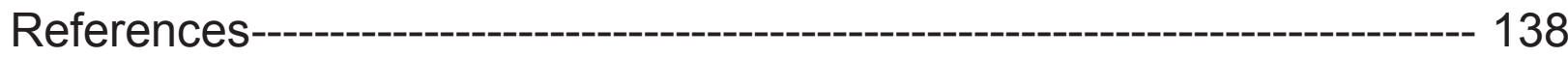


Figure legends

Chapter 6: General discussion

1 - Overview

2 - Causes and consequences of behavioural adjustments of the trade-off between foraging and vigilance in herbivores-

2-1 Food resources and ecological influences

2-2 Predation risk and safety in number

2-3 Social context

2-4 Individuals' traits

2-5 How the vigilance/foraging trade-off and its main drivers might affect population dynamics

3 - Personality and plasticity can vary across contexts.

4 - The significance of considering different temporal scales in the study of the trade-off between vigilance and foraging

5 - Questioning the foraging cost of vigilance

6 - Conclusion

7 - References 


\section{List of Figures and Tables}

\section{Figures:}

- Chapter 1:

Figure 1. Direct and indirect effects of predation and food resources on survival, reproductive success and population dynamics of prey.

Figure 2. The main risks, social, ecological, and individual factors that have been shown to influence vigilance and/or foraging behaviours.

Figure 3. Questions explored in each data chapter of the thesis on vigilance, feeding rates and their trade-off, including the factors tested in the different studies.

\section{- Chapter 2:}

Figure 1. Seasonal variation in (a) observations recorded in the different habitats, (b) patch richness, (c) patch greenness, (d) patch biomass, (e) group size, (f) distance to cover, (g) grass height, and $(\mathrm{h})$ reproductive states of female kangaroos.

Figure 2. Seasonal variation in vigilance and feeding rates of female kangaroos.

Figure 3. Variation in group size and habitat type with patch quality.

Figure 4. Pathways by which season affected the trade-off between vigilance time and feeding rate.

\section{- Chapter 3:}

Figure 1. Effects of playbacks on females' behaviour.

Figure 2. Effects of playbacks on the use of exclusive vigilance and vigilance while chewing.

\section{- Chapter 4:}

Figure 1. Frequencies in winter and summer of (a) percentages of green plants, (b) biomass, and (c) patch quality index of the food patches used by female kangaroos.

\section{- Chapter 5:}

Figure 1. Relationships between female eastern grey kangaroos' vigilance and bite rates and group size $(a, b)$, food patch richness $(c, d)$, and reproductive state $(e, f)$.

Figure 2. Population-level changes in the trade-off between bite rate and the time spent in vigilance in relation to (a) group size, (b) patch richness, and (c) reproductive state for female eastern grey kangaroos. 
Figure 3. Trade-offs between bite rate and the time spent in vigilance for female eastern grey kangaroos (a) in small groups, (b) in rich food patches, and (c) having a young-at-foot.

\section{- Chapter 6:}

Figure 1: Direct and indirect effects of the identified drivers affecting the trade-off between vigilance and feeding rates, and effects of the drivers and the trade-off on population size and dynamics of herbivores.

\section{Tables:}

\section{- Chapter 2:}

Table 1. Details on the distribution of sampling effort during our study across months and seasons

Table 2. Table of patch quality indices for short grass grazers in relation to patch biomass and greenness.

Table 3. Comparison of models for the time spent in vigilance and the feeding rates, using the Akaike information criterion (AIC).

Table 4. Coefficients and P-values for the effect of group size on vigilance time and the effect of habitat on feeding rates of female kangaroos.

\section{- Chapter 3:}

Table 1. Effects of time period, type of playback and their interaction on the proportion of time spent in vigilance, the bite rate, the step rate, the time spent in vigilance while chewing and the time spent in exclusive vigilance, controlling for the effects of date, group size, distance to cover, and grass height.

Table 2. Statistical results of comparisons between playback treatments for the proportion of time spent in vigilance, bite rate and step rate in the pre- and post-playback periods.

Table 3. Statistical results of comparisons between playback treatments for the time spent in vigilance while chewing and exclusive vigilance in the pre- and post-playback periods.

Table 4. Comparisons between the pre- and post-playback periods for the proportion of time spent in vigilance, bite rate and step rate for each experimental treatment.

Table 5. Comparisons between the pre- and post-playback periods for the time spent in vigilance while chewing and exclusive vigilance for each experimental treatment.

Supplementary Table 1. Effects of time period and type of playback on the proportion of time spent in vigilance by female impalas.

Supplementary Table 2. Effects of time period and type of playback on the time spent in vigilance while chewing by female impalas.

Supplementary Table 3. Effects of time period and type of playback on the bite rate of female impalas. 
Supplementary Table 4. Effects of time period and type of playback on the step rate of female impalas.

\section{- Chapter 4:}

Table 1. Summary of hypotheses on the relationships between the functions and costs of vigilance and group size, distance to cover, patch quality and distance to the nearest neighbour

Table 2. Table of patch richness index for short grass grazers in relation to patch biomass and greenness.

Table 3. Coefficients and P-values for the factors influencing the probabilities that foraging female kangaroos use antipredator exclusive vigilance, antipredator vigilance while chewing, social exclusive and social vigilance while chewing.

\section{- Chapter 5:}

Table 1. Table of patch richness index for short grass grazers in relation to patch biomass and greenness.

Table 2. Effects of group size, patch richness and reproductive state on (A) the proportion of time spent in vigilance, and (B) the bite rates of female kangaroos.

Table 3. Comparison of linear models with different random factors for the effects of group size, patch richness and reproductive state on $(A)$ the proportion of time spent in vigilance, and $(B)$ the bite rate of female kangaroos.

Table 4. Comparison of linear models with different random factors for the effects of the proportion of time spent in vigilance on the bite rates of female kangaroos in relation to group size, patch richness and reproductive state.

Table 5. Comparison of linear models with different random factors for the effects of the proportion of time spent in vigilance on the bite rates of female kangaroos in different conditions. 


\section{List of Abbreviations used in the thesis}

$\begin{array}{ll}\text { AAC } & \text { Advanced Audio Coding } \\ \text { AEC } & \text { Animal Ethic Committee } \\ \text { BNR } & \text { Behavioural Reaction Norm } \\ \text { HERD } & \text { Hwange Environmental Research for Development } \\ \text { HNP } & \text { Hwange National park } \\ \text { ID } & \text { Identity } \\ \text { LPY } & \text { Female with large pouch-young } \\ \text { LRT } & \text { Log-likelihood ratio tests } \\ \text { MPY } & \text { Female with medium pouch-young } \\ \text { NPY } & \text { Female with no pouch-young } \\ \text { OFT } & \text { Optimal foraging theory } \\ \text { PM } & \text { Pasture meter } \\ \text { SNP } & \text { Sundown National Park } \\ \text { SPY } & \text { Female with small pouch-young } \\ \text { YAF } & \text { Female with young-at-foot }\end{array}$




\section{Chapter 1: \\ General introduction}

Compared to predators that consume prey of high nutritional value, herbivores exploit food that is often of low or highly variable nutritional quality and widely distributed across the landscape. Consequently, to satisfy their metabolic requirements, herbivores have to spend most of their active time acquiring their food (Senft et al. 1987). In addition, herbivorous prey species are at risk of predation and have to regularly interrupt their foraging activity to watch for predators to minimize the risk of being preyed upon and increase their survival. Individuals thus have to trade off between food acquisition and safety (Brown 1999). As the safety of prey is highly dependent on vigilance behaviour, a classic way to study this trade-off is to study the trade-off between foraging and vigilance activities. Nevertheless, the study of this trade-off in mammalian herbivores is complex for a number of reasons. First, some species are able to carry out multiple tasks without interrupting the foraging process, such as chewing while being vigilant, so these activities are not necessarily mutually exclusive (Spalinger and Hobbs 1992). Second, group formation is common in prey species because aggregations reduce individuals' predation risk, allowing individuals to reduce their time spent in vigilance and increase their foraging time (Pulliam 1973). However, recent studies highlighted that, in such groups, vigilance can be needed to monitor other individuals and this social vigilance may increase with group size (Favreau et al. 2010). Also, forming groups causes competition for food as individuals have to share a common resource (Nicholson 1954). Consequently, the trade-off between foraging and vigilance activities is complex in gregarious prey species, as it is affected by multiple parameters associated with resources, predation risk and grouping patterns. In addition, many recent studies have reported that betweenindividual variation in animals' behaviour exists and needs to be considered in behavioural studies; however, individual variation in the trade-off between vigilance and foraging activities has remained unexplored.

The overall objective of my $\mathrm{PhD}$ was to study different aspects of the trade-off between vigilance and foraging in medium-sized herbivores, as well as individual variation in this trade-off, using the eastern grey kangaroo (Macropus giganteus) and the impala (Aepyceros melampus) as model species. My aims were: (1) to study whether vigilance and foraging vary seasonally over a entire year and identify the main driver(s) responsible for these variations, including ecological, social, and individual parameters; (2) to investigate the effects of predators and social stimuli on vigilance, foraging and on their trade-off; (3) to study the factors affecting the relationships between the functions and the foraging costs of vigilance; and (4) to study between-individual variation in this trade-off. 
To cover the broad background relevant to this objective, the following introduction is divided into seven parts. In the first part, I introduce the concept of trade-offs in life history theory and then focus on the trade-off between food and safety and its consequences at the individual and population levels. In the second part I present the main foraging theories and the factors that have been shown to influence the foraging behaviour of herbivores. In the third part I present the factors that affect antipredator vigilance and how herbivores are able to reduce the cost of this activity. The fourth part discusses the different types of groups formed by herbivores, the benefits and costs of grouping, and the use of social vigilance in these groups. In the fifth part, I cover the evidence for individual variation in animal behaviour and introduce the concepts of behavioural consistency and personality, as well as behavioural plasticity and the behavioural reaction norm approach. The sixth part presents the general framework of my studies and the aims of my PhD, and finally the seventh part introduces the two model species, the eastern grey kangaroo and the common impala, as well as the study sites where I conducted my fieldwork.

\section{1 - Trade-off theory}

\section{1-1 Trade-offs in life history theory}

Trade-offs are at the heart of life history theory, which aims to explain how evolution and natural selection designs organisms to optimize their survival and reproduction (Stearns 1989, 1992, Roff 1992). Life history traits such as growth rate, age, or lifespan vary in response to environmental changes and are limited by various constraints (which can be for example physiological, behavioural or ecological). These constraints limit the simultaneous maximization of different life history traits (Stearns 2000). Therefore, a trade-off exists when an increase in one life history trait is coupled with a decrease in another trait, so that the benefit of increasing a trait is balanced against the cost of decreasing another trait (Stearns 1992). Usually, trade-offs arise when two traits are limited by the same resource such as energy or time, and therefore an increase in the resources allocated to one trait will decrease resources allocated to another trait (Stearns 1992, Zera and Harshman 2001).

There are many kinds of trade-offs, but the most studied trade-offs are associated with organisms' physiology and mostly with the cost of reproduction - for example, trade-offs between an individual's current reproduction vs. its survival, current reproduction vs. future reproduction, or number vs. size of offspring (Stearns 1992, Flatt 2011). However, trade-offs also occur in relation to animals' behaviours that are associated with growth, reproduction and survival. Many such trade-offs occur, such as feeding vs. mating (Griffiths 1996, Köhler et al. 2011), mate attraction vs. parental care (Smith 1995, DeMory et al. 2010), energy intake vs. exposure to parasites (Norris 1999, Lienhard et al. 2010), or nest guarding vs. foraging (Komdeur and Kats 1999). One of the 
trade-offs of central interest in behavioural ecology, which is the focus of my $\mathrm{PhD}$, is the trade-off between energetic gain and the risk of predation (Houston et al. 1993, Bonter et al. 2013).

\section{1-2 Trade-off between food acquisition and safety from predators and its consequences}

Predation and food supplies are recognized as among the major selective forces determining animals' behaviours (Lima and Dill 1990). In addition to predators affecting the demography of prey through direct predation, prey also modify their behaviour in the presence of predators to decrease their chance of being captured. These behavioural modifications can be costly because they take time and energy away from others activities related to fitness, such as parental care, mating and especially food acquisition (Lima and Dill 1990, Lima 1998, Cresswell 2008). Predation risk can force prey to spend large amounts of their time and energy on activities other than resource acquisition, reducing their body condition and consequently their survival and reproductive success (Lima 1998, Hik 1995, Frid and Dill 2002, Creel and Christianson 2008). Direct and indirect effects of predation can therefore both affect population dynamics (Figure 1). The quality and availability of food resources can also either directly or indirectly affect herbivores' population sizes and dynamics (Figure 1). The availability and nutritional quality of food resources often vary seasonally and can alter individuals' energy intake and body conditions, which in turn could increase starvation (thus decreasing survival) and decrease reproductive ability or fecundity (Saether 1997). Food resources also affect herbivores' behavioural adjustments for resource acquisition, such as migration to favourable feeding areas or the time and effort dedicated to feeding (e.g. Fryxell and Sinclair 1988, Clarke et al. 1989). Therefore, prey animals must modify their behaviour to simultaneously to increase their foraging gains and decrease their chance of being killed (Houston et al. 1993). This behavioural trade-off between food acquisition and predation risk can affect many decisions made by animals, such as habitat, patch and food selection, feeding duration, group size, spacing behaviour, fleeing or vigilance activity (Lima and Dill 1990, Houston et al. 1993, Verdolin 2006). 


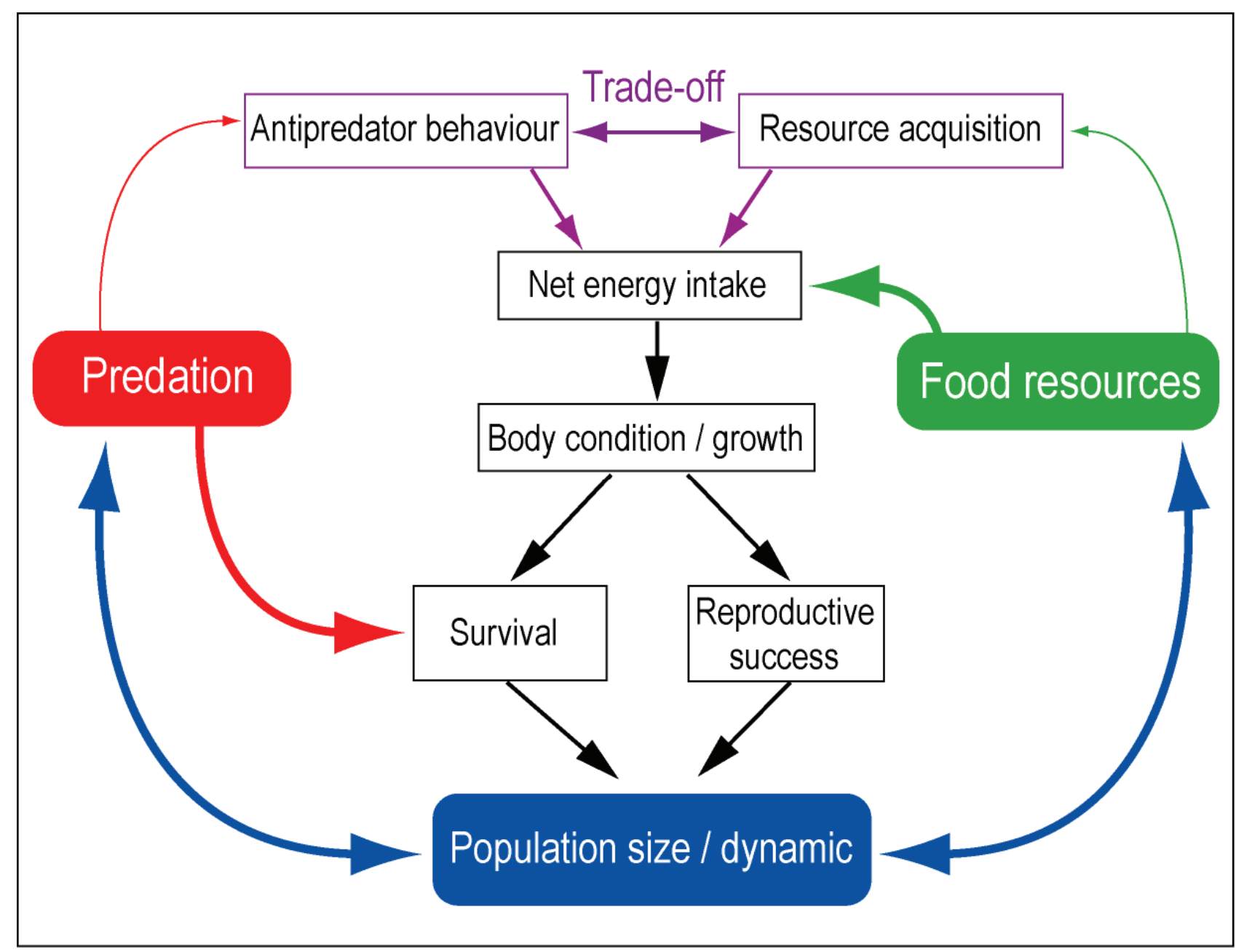

Figure 1: Direct (red and green thick arrows) and indirect effects (red and green fine arrows) of predation and food resources on survival, reproductive success and population dynamics of prey. (Adapted from Frid and Dill (2002) and Creel and Christianson (2008)). The blue thick arrows represent the effects of food resources and predation on herbivores' populations and vice versa.

My $\mathrm{PhD}$ focuses on the general trade-off between food acquisition and safety at a fine behavioural scale: the trade-off between foraging and vigilance activities. As vigilance and foraging activities are considered to be mostly mutually exclusive, time devoted to vigilance is thought to decrease the time available for foraging, and thus reduce energetic gains, making vigilance costly (Barnard 1980, Underwood 1982, McNamara and Houston 1992, Illius and FitzGibbon 1994). While intake rate can decrease simply because an increase in vigilance time decreases foraging time, it has also been shown to decrease during foraging bouts as vigilance increases. For example, Watson et al. (2007) observed that grey partridges (Perdix perdix) decreased their pecking rates during non-vigilant periods as vigilance increased, probably because as individuals interrupted their searching task, they temporarily decreased their probability of success when resuming the search. Reductions in feeding rates have been shown to increase the risk of starvation and mortality (e.g. Watson et al. 2007) and can reduce body condition and affect reproductive success (Lemon and Barth 1992). 
However, this foraging cost of vigilance can vary because animals can adjust the frequency and duration of their vigilance bouts and can sometimes process food while being vigilant. First, the time spent in vigilance results from the combination of the durations and frequencies of vigilance bouts, which can vary independently (Roberts 1995), and can differentially affect the cost of vigilance (See Fritz et al. 2002). Second, many species are able to be vigilant while handling their food (multitasking), which can moderate the foraging cost of vigilance. This has been shown in birds (Lima 1987b, Bednekoff and Lima 2005), rodents (Makowska and Kramer 2007, Unck et al. 2009) and ungulates (Fortin et al. 2004, Pays et al. 2012a). For instance, mammalian herbivores' food intake is usually limited by chewing and swallowing rates and herbivores are able to search for food while chewing the previous bite (Spalinger and Hobbs 1992). Illius and FitzGibbon (1994) suggested that, while chewing between two bites, animals can locate their next bite and then have a period of time to finish chewing before cropping it. This period of chewing has been called "spare time" and could be used for vigilance with a limited impact on intake rates. The different foraging costs of vigilance thus have to be taken into account when studying the trade-off between foraging and vigilance.

Foraging animals have to adjust their foraging and vigilance activities continuously because their immediate environment as well as their individual traits and energetic needs change over time, making the study of this trade-off complex. Understanding this trade-off requires studying the strategies used by individuals to acquire food (foraging) and their behavioural responses to predation risk (in this case, vigilance) and also to the presence of conspecifics. Foraging and vigilance activities are themselves complex behaviours that can be affected by numerous factors associated with patch quality, predation risk, group formation, intra-specific competition, individual traits and environmental conditions. Therefore, in the next three sections I describe the main theories and findings on foraging and vigilance activities, as well as the implications of group formation on those activities.

\section{2 - Foraging Behaviour}

Food acquisition is a primary need for animals to survive, grow and reproduce and therefore maximize their fitness (Illius et al. 2002). However different animals have different food requirements and use different strategies to acquire their food. To try to understand the complexity and diversity of animals' foraging behaviours, different foraging theories have been developed. These theories relate to the general context of foraging, including any type of forager, but some are specific to herbivores, or to gregarious species. In this part I first review the main foraging theories, their limits and their usefulness as a general framework and then I review the main factors observed to affect the foraging behaviour of herbivores in empirical studies. 


\section{2-1 Foraging theories applicable to herbivores}

One of the major foraging theories used to explain animals' foraging behaviours is the optimal foraging theory, which was first developed by Emlen (1966) and MacArthur and Pianka (1966). The basis of this theory is that in order to increase their fitness, animals have to maximize their net rate of energy gain while foraging by making decisions on where and what to eat (Stephens and Krebs 1986). Building on this idea, many complex models have been developed to predict animals' optimal behaviours and patch use (e.g. Schoener 1971, Pulliam 1974, Charnov 1976). All these studies are based on four choices that animals have to make while foraging: (1) which type of food to eat (optimal diet choice theory); (2) which patch to choose (optimal patch choice); (3) how much time to spend in each patch (optimal allocation to patches); and (4) how to move within and between patches (optimal pattern of speed and movement) (reviewed by Pyke et al. 1977). This theory has been widely used and recognized but has also been criticized because numerous assumptions on which the models were based are unrealistic (Reviewed by Pyke 1984). Some of the main criticisms include the following: (1) that this theory assumes that animals are omniscient (i.e. have precise information on the benefits and the costs associated with various behavioural options (Sih 1992)), which seems improbable (Pyke 1984); (2) that increasing foraging efficiency does not necessarily increase individual fitness (Gray 1987); and (3) that foraging behaviour cannot be optimal in nature (Pierce and Ollason 1987). In addition, as optimal foraging theory was initially developed for predators, it was not really applicable to herbivores and further studies were needed to adapt it by incorporating several constraints specific to herbivores in terms of food digestibility, spatial and temporal variation in access to heterogeneous resources, and predation risk (e.g. Sih 1980, Krebs 1980, Pyke 1984, Mangel and Clark 1986).

Alternative theories to the optimal foraging theory have also been proposed, such as the idea that instead of maximising energy gain, foragers should only forage long enough to acquire sufficient energy gain to survive and reproduce (Ward 1992). This idea has been developed as the concept of "energy maximization" and "time-minimization", which differentiates the foraging strategies of animals that maximise their food intake to increase their fitness (energy maximizers) from those who forage long enough to meet their energy needs while saving time for non-foraging activities to increase their fitness (time minimizers) (Hixon 1982, Bergman et al. 2001). In fact these two strategies represent the endpoints of a continuum of foraging behaviour shaped by the contribution of foraging to fitness (Bergman et al. 2001) and can be included in a general optimal foraging theory. It has been assumed that larger species that live in open habitats and form bigger groups would tend to be energy-maximizers as they suffer less from predation than smaller species, which live in more closed habitats and form smaller groups and should be more vigilant and tend to behave more as time-minimizers (Kie 1999). However, even within the same species, foraging strategies can vary along the energy-maximizer/time-minimizer continuum in relation to 
individuals' sex, age, reproductive status or season (reviewed in Kie 1999). Despite being criticized because of unrealistic assumptions or because of their limits, foraging theories in general and optimal foraging theory in particular remain very useful tools as a general framework for testing hypotheses about foraging behaviour. This framework is particularly useful in the understanding of individuals' behavioural decisions to mediate trade-offs between food acquisition and antipredator strategy (McNamara and Houston 1994).

To understand animals' foraging strategies, many studies have been done on the relationships between consumers and their food, using predator/prey models such as functional response models. Functional response models describe changes in a predator's intake rate in response to food density (Solomon 1949, Holling 1959). In these models, an animal's intake rate is dependent on the time spent searching for and handling food. Holling $(1959,1965)$ distinguished between three main types of functional responses to an increase in food density. Among these three main types of functional responses, type I appears to be mainly specific to filter feeders, type II is the most common type, fitting many taxa including invertebrate and vertebrate herbivores and mammalian predators, and type III is the rarest but has been observed in very different taxa such as carnivores, herbivores and filter feeders (reviewed in Jeschke et al. 2004). Most herbivores have been shown to exhibit type II functional responses (e.g. Wickstrom et al. 1984, Short 1985, Hudson and Frank 1987, Spalinger et al. 1988, Gross et al.1993). In the type II response, , predator's consumption increases almost linearly with food density at low food density; as food density increases, searching for prey becomes faster and thus an animal's intake rate is more driven by handling time and starts to decelerate. At very high food density, intake rate can reach a limit determined principally by handling time but also by digestive constraints (Jeschke et al. 2002).

However, herbivores have specific foraging patterns because (1) they have evolved in environments where a large amount of food may be available, but in which patches can also be depleted so that the animal has to move to another patch (Owen-Smith 2002), and (2) in herbivores, searching does not always compete with handling time as animals can chew their food or carry out other activities while searching for a new bite (multitasking). Taking this into account, Spalinger and Hobbs (1992) developed new models of herbivores' foraging with three different "processes" dependant on plant availability (i.e. nonapparent dispersed food items, apparent dispersed food items and apparent concentrated food items) and differentiating two aspects of the handling behaviour of herbivores - cropping and chewing. The models developed by Spalinger and Hobbs confirmed that herbivores showed a type II functional responses, which can be generated by different mechanisms based in particular on food processing and availability. They also showed that herbivores' cropping rates were dependant on bite sizes, and that plant biomass was related to intake rates in grazers but not in browsers, for which intake rates were more related to bite sizes (Spalinger and Hobbs 1992, Gross et al. 1993). 
Finally, as many animals in general and herbivores in particular forage in groups, new models inspired by optimal foraging theory (initially developed for single individuals) have been developed incorporating the advantages and constraints of group formation on foraging behaviour; these models are called "social foraging theory" (Giraldeau and Caraco 2000). The overall concept of social foraging theory is that individuals' foraging behaviours depend on the individuals' own actions as well as others foragers' behaviours (Giraldeau and Caraco 2000). By watching the behaviours of others, foragers can acquire information on when, where, what and how to eat (reviewed in Galef and Giraldeau 2001). For example, an individual can learn about the location of food resources by being attracted to other foragers, which is called "local enhancement" (Thorpe 1963, Galef and Giraldeau 2001). Also, within a patch a forager can estimate patch quality faster and more accurately by watching the activities of others and therefore increase its efficiency at patch exploitation, and waste less time in less profitable food patches (Valone and Templeton 2002). The information about patch quality acquired by monitoring others has been termed "public information" (Valone 1989). Socially acquired information has mainly been reported to be beneficial to social foragers but can also be costly when individual and socially acquired information are not compatible or when social information leads to sub-optimal behaviours (Giraldeau et al. 2002). Two main types of social foraging models have been developed to predict how foragers exploit food discovered by others: the "information-sharing" models and the "producer-scrounger" models. "Information-sharing" models assume that all foragers in a group look for food on their own and simultaneously monitor each other, and that when a food patch is discovered, all the foragers join together to feed there (Clarke and Mangel 1984). "Producer-scrounger" models assume that groups of foragers contain producers, who search for food, and scroungers, who exploit the food discovered by producers (Barnard and Sibly 1981). "Producer-scrounger" models are negatively frequency dependent because scroungers receive larger pay-offs than producers when they are rare, but producers do better when scroungers are common (Vickery et al. 1991).

Foraging theories have thus been widely used as frameworks to better understand animals' foraging behaviour. However, these theories have also been criticized for numerous reasons but especially because of the observation that intra-population variation in foraging strategies occurs even when both phenotypic and environmental variation are controlled for (e.g. Estes et al. 2003, Kurvers et al. 2010). Nevertheless, these theories remain useful for making predictions and testing hypotheses about animals' foraging behaviours. 


\section{2-2 Factors influencing the foraging behaviour of herbivores}

To complement this theoretical framework for understanding herbivores' foraging behaviour, many empirical studies have tried to determine the factors influencing foraging activity in nature. It is possible to group these factors into three main categories: characteristics of food resources, individuals' traits and grouping patterns.

\section{2-2-1 Characteristics of food resources}

First, herbivores are highly constrained by the availability and quality of their food, which can vary spatially and temporally (Senft et al. 1987). In response to spatial variation, herbivores can move in the landscape at small scales between different feeding patches, at medium scales through feeding areas, but also over larger scales through seasonal migrations (Taylor 1984, Senft et al. 1987, Fryxell and Sinclair 1988). In grazing herbivores, intake rates usually increase with plant biomass following the type II functional response (e.g. Wickstrom et al. 1984, Short 1985, Hudson and Frank 1987). This increase arises because grazers tend to take larger bites as biomass increases (Gross et al. 1993), leading to bite sizes exceeding the dimensions of the mouth at high biomass (Illius and Gordon 1987). However, those bigger bites require longer chewing and swallowing times, responsible for the deceleration of grazers' intake rates at high food biomasses (Spalinger and Hobbs 1992). Also, longer periods of time spent processing food decreases feeding rates, which often leads to a negative relationship between bite sizes and feeding rates (e.g. Wickstrom et al. 1984). Grazers are also constrained by forage quality, which usually decreases with sward density because of the maturational accumulation of fibre in grass tissues (Waite 1963). Low quality forage contains more fibre, which reduces its digestibility by herbivores, especially for medium and small-sized herbivores (Wilmshurst et al. 1995), leading to a negative relationship between digestibility and plant biomass (Wilmshurst et al. 1999). Therefore energy intake is limited by grazing rate in low biomass swards and by digestion in high biomass swards (Wilmshurst et al. 1999). Consequently, many grazing herbivores seem to prefer low to intermediate biomass patches where food quality is better compared to high biomass patches (i.e. "forage maturation hypothesis", Fryxell 1991) (e.g. Bell 1973, Wilmshurst et al. 1995, Bergman et al. 2001).

Food availability and quality also vary seasonally, which can influence herbivores' foraging behaviours. For example, in ecosystems exhibiting pronounced seasonal variation in grassland productivity due to periodic variation in rainfall and temperatures, such as African savannas, many herbivorous species migrate to areas of better food quality and availability (Fryxell and Sinclair 1988). The foraging behaviour of non-migratory species can also be altered by seasonal food 
variation. For example, Clarke et al. (1989) observed that eastern grey kangaroos increased their foraging time in winter compared to summer, reflecting their difficulty in finding food items and their need to increase their rate of food intake. Finally, many fairly generalist species such as moose (Alces alces), guanacos (Lama guanicoe) and sheep (Ovis aries) are able to modify their diet according to the season and be less selective in poorer food conditions to satisfy their energetic demands (Reneker and Hudson 1986, Baldi et al. 2004).

Finally, habitat type can affect foraging strategies. Grazing herbivores usually prefer to forage in open grasslands, which are the habitats that offer the better food for the largest part of the year (Moore et al. 2002, Lamoot et al. 2005, Valeix et al. 2009, Schaich et al. 2010). However, Lamoot et al. (2005) reported that donkeys (Equus asinus) could shift from open to more closed habitats when grassland food productivity declined. Also, several herbivores such as donkeys and eastern grey kangaroos have been observed to have higher feeding rates in open habitats compared to more closed habitats (Lamoot et al. 2005, Maguire et al. 2006). Higher bite rates in open habitats could be explained by higher availability of high quality forage but also by the reduced patchiness of resources in open compared to closed habitat types, which allows individuals to move less while foraging and therefore reduce their searching effort between bites (Craighead et al. 1973).

\section{2-2-2 Individuals' traits}

In addition to plant abundance and quality, individual traits also influence the foraging activity of herbivores. The characteristic most reported to influence foraging behaviour is body size (or body mass or body weight). Energetic demands of mammals increase with their body size; however, although larger herbivores need more nutrients and energy than smaller ones, small herbivores need more energy per unit mass (Hopcraft et al. 2010). Smaller herbivores also have smaller gastrointestinal tracks and therefore shorter retention times compared to larger ones (Peters 1983). Consequently, small herbivores cannot process coarse food and have to select high energy forage, whereas large ones can extract their energy from poor quality food if they ingest sufficient quantities (Bell 1971, Hanley 1982, Wilmshurst et al. 2000). Therefore small herbivores are limited by forage quality whereas larger ones are limited by forage quantity (Hopcraft et al. 2010).

Even within the same species, foraging behaviour can differ among individuals due to their different energetic requirements. First, in sexually dimorphic species, the foraging patterns of males and females can differ (Ginnett and Demment 1997). In such species, males are usually larger than females and can therefore accept poorer quality food and be less selective, leading to 
different foraging strategies (e.g., Gross et al. 1995, Main et al. 1996, Ginnett and Demment 1997). Second, reproduction is costly for females and affects their foraging behaviour, especially during lactation periods (Robbins 1983). Therefore lactating female herbivores often increase their time spent foraging as well as their feeding rates compared to non-lactating ones, as for example in eastern grey kangaroos (Cripps et al. 2011), bighorn sheep (Ovis Canadensis) (Ruckstuhl and Festa-Bianchet 1998) and red deer (Cervus elaphus) (Clutton-Brock et al. 1982). Finally, the body conditions of foragers also affect their foraging behaviour, with animals in poor body condition usually spending more time foraging than individuals in good condition, as in Belding's ground squirrels (Spermophilus beldingi) (Bachman 1993).

\section{2-2-3 Grouping patterns}

Finally, the presence of conspecifics also strongly affects the foraging behaviour and tactics of herbivores. As previously discussed, grouping can allow individuals to locate and assess food patches more efficiently (Valone 1989), which decreases individuals' patch discovery time (Caraco 1981). In addition, individuals in groups are less vulnerable to predation and can decrease their antipredator behaviours and thus forage for longer periods of time and increase their feeding rates (Elgar 1989, Lima 1995, Lima et al. 1999). However, foraging in groups also causes competition among foragers as they have to share a common resource (Clarke and Mangel 1986). Nicholson (1954) described two types of competition. First, scramble (or exploitative) competition occurs when several individual have to share the same resource; as the number of individuals increases, the amount of resource available for each competitor decreases. Competition is thus caused indirectly by food depletion. Second, contest (or interference) competition involves direct conflicts among competitors (e.g. aggression, territoriality, dominance). These conflicts cause the "winner" to affect the "loser's" access to resources (Sih 1993). Both types of competition affect individuals' foraging behaviours and fitness, although in different ways. Contest competition causes different intake rates according to individuals' ranks (winner/loser, dominant/subordinate), whereas scramble competition causes different intake rates depending on group sizes and the availability of food resources (van Schaik and van Noordwijk 1988). Interference competition is rare in large gregarious herbivores. As their food resources are usually widely distributed, it would be not advantageous and would be too costly for individuals to engage in direct conflicts. Thus, in these species scramble competition seems to be the main kind of competition (Owen-Smith 2002).

Studying competition among group members is often difficult as competition can affect individuals' foraging behaviours in different ways and is also affected by resource availability. Evidence from field studies suggests that an increase in group size can lead to faster intake rates in order to reduce reductions in food intake associated with competition (Caraco 1979, Shrader et al. 2006), and can even cause the selection of more profitable patches in certain species (Fritz and 
De Garine-Wichatitsky 1996). However, sometimes foraging success cannot increase and may even decrease as group size increases, as a result of food depletion, fights or the displacement of individuals into less preferred areas (Fleischer 1983). Exploitative competition occurs at low food density when food is limiting, and is therefore more pronounced in a seasonal environment during the vegetation's dormant season rather than during the growing season (Beauchamp 2009, OwenSmith 2002).

\section{3 - Antipredator vigilance behaviour}

Prey animals have to avoid being eaten; therefore, prey have developed morphological, physiological and behavioural adaptations to reduce their risk of predation (Barnard 1983). Prey can adopt many different antipredator behaviours such as forming groups, producing auditory and visual signals to warn conspecifics, adopting defensive behaviours, escaping and even attacking predators (Lima and Dill 1990, Caro et al. 2004). However, the most common and best studied antipredator behaviour is vigilance.

\section{3-1 Factors influencing antipredator vigilance}

Vigilance behaviour has been mainly described as an antipredatory strategy and involves an animal monitoring its surroundings to detect a potential threat (Treves 2000). Much research has been conducted on vigilance to try to understand how individuals adjust this behaviour to manage their risk of predation. To summarize the numerous factors affecting vigilance, we can group them in four main categories: (1) grouping patterns, (2) predation risk, (3) individuals' traits and (4) environmental conditions.

\section{3-1-1 Grouping patterns}

The effect of group size on individuals' levels of antipredatory vigilance is the most studied relationship involving vigilance behaviour. This relationship, known as the "group-size effect", predicts a decrease in individual vigilance as group size increases (Pulliam 1973, Lima 1995, Bednekoff and Lima 1998). According to the literature, three main mechanisms could be responsible for this pattern. First, when group size increases, more eyes are available to detect a potential threat and the probability of detecting a predator increases, allowing individuals to reduce their vigilance effort while keeping the same level of safety (many eyes hypothesis or detection effect) (Powell 1974, Dehn 1990, Lima 1990). Second, as group size increases, the chance of a particular individual being captured decreases simply because more prey are available for the 
predator (dilution effect) (Hamilton 1971, Bertram 1978, Dehn 1990). Finally, predators' capture success decreases with group size because a predator may be confused and less able to focus on a single prey animal when many individuals flee in different directions (confusion effect) (Major 1978, Landeau and Terborgh 1986, Schradin 2000). The group size effect has been observed in a wide range of species of birds (Barbosa 2002, Boland 2003, Dias 2006) and mammals (Jarman 1987, Burger and Gochfeld 1992, Shorrocks and Cokayne 2005, Pays et al. 2007, Marino and Baldi 2008). However, several studies failed to observe this pattern, as for example in some studies of impalas (Shorrocks and Cokayne 2005) and eastern grey kangaroos (Colagross and Cockburn 1993), and especially in primates (Rose and Fedigan 1995, Treves 1997, Treves et al. 2001). Other studies found the inverse relationship (an increase in individual vigilance with group size), as in impalas (Underwood 1982), north-western crows (Corvus caurinus) (Robinette and Ha 2001) and wedge-capped capuchin monkeys (Cebus olivaceus) (De Ruiter 1986).

The vigilance of gregarious foragers can also vary with other aspects of group formation. For example, numerous studies have shown that individuals on the periphery of a group exhibit higher vigilance levels than central ones (the "edge effect", e.g. Colagross and Cockburn 1993, Burger et al. 2000, Di Blanco and Hirsh 2006). This pattern has been assumed to reflect a higher risk of predation on a group's periphery because foragers on the edge of the group are more susceptible to an attack from an approaching predator than are central ones (Hamilton 1971). Finally, other factors associated with grouping such as group composition, distance between individuals, group geometry and group density have also been shown to influence individuals' vigilance (e.g. van Schaik and van Noordwijk 1989, Fernández-Juricic et al. 2007, Rolando et al. 2000, Pöysä 1994, Bekoff 1995).

\section{3-1-2 Predation risk and perceived predation risk}

Predators' presence influences behavioural adjustments of prey individuals, such as their spatial distribution in the landscape and vigilance behaviour (Valeix et al. 2009). Assessing predation pressure in the wild is often difficult; however, several studies have shown that foragers increased their vigilance activity as predators' density increased in the area (e.g. Childress and Lung 2003, Lung and Childress 2007). To measure the effect of direct predation pressure on the behaviour of prey, their behaviours have been compared before and after the reintroductions of predators to areas that had been "predator-free" (Hunter and Skinner 1998) or compared in areas known to differ in predator presence (Lung and Childress 2007). In addition, a recent study used satellite-collared predators to study the effects of their spatial proximity on the vigilance levels of prey. This study by Périquet et al. (2010) showed that vigilance in the greater kudu (Tragelaphus strepsiceros) was affected by the presence of lions (Panthera leo) in the vicinity (within $2 \mathrm{~km}$ ). 
As it is often impossible to determine the actual risk of predation, numerous studies have focussed on how vigilance varies in response to individuals' likely perceptions of predation risk, estimated using cues expected to affect predation risk. The most common cue assumed to influence prey animals' perception of predation risk is the distance to cover. The usual observed pattern is that individuals decrease their vigilance near cover as cover is used as a refuge in case of predator attack (Barnard 1980, Colagross and Cockburn 1993). However, some species have been shown to exhibit the inverse pattern (an increase in vigilance near cover), which could be explained by the fact that, depending on the species, cover could be perceived as protective or obstructive, in the case of species whose predators often stalk them within cover (Lazarus and Symonds 1992). This pattern has been observed in both birds and mammals species (e.g. Lima 1987a, Slotow and Rothstein 1995, Burger et al. 2000). Therefore, the effect of distance to cover on species' perceptions of predation risk seems to vary among prey species according to their predators' hunting strategies (i.e. ambush vs. cursorial predators, Loarie et al. 2013), and may not be a useful proxy of predation risk in certain environments (Pays et al. 2012a). Another way to estimate the likely perception of predation risk by grazing animals is to measure grass height, as this can affect individuals' visibility and predator detection. A positive correlation between grass height and vigilance level has been observed in ungulates such as springboks (Burger et al. 2000) and impalas (Pays et al. 2012a) and in marsupials (Blumstein et al. 2003).

\section{3-1-3 Individuals' traits}

Many traits of individuals have also been shown to affect the vigilance behaviour of prey animals, including age, sex, reproductive state and body condition (Alados 1985, Bachman 1993, Alberts 1994, Bednekoff and Ritter 1994, Shorrocks and Cokayne 2005, Lung and Childress 2007, Monclús and Rödel 2009). However, most of these traits (i.e. sex, body condition and reproductive state) are associated with different energy requirements and their effects on vigilance are thus primarily related to foraging requirements (discussed previously). Nevertheless, they can also be directly associated with predation risk. For example, in sexually dimorphic species in which males are bigger than females, females should be more vulnerable to predators and exhibit higher vigilance activity (Pays and Jarman 2008). This pattern has been observed in several species (e.g. Bednekoff and Ritter 1994, Ruckstuhl et al. 2003, Pays and Jarman 2008). However, a higher investment in vigilance by males has also been well documented in primates and ungulates (e.g. Koenig 1998, van Schaik and van Noordwijk 1989, Burger and Gochfeld 1994, Burger et al. 2000). The effect of reproductive state on vigilance can also be associated with predation risk. Females with young are usually more vigilant than females without young because they have to protect 
themselves as well as their young from predators (e.g. Burger and Gochfeld 1994, Childress and Lung 2003).

\section{3-1-4 Environmental conditions}

Many environmental factors, such as time of the day (Bednekoff and Ritter 1994, Pravosudov and Grubb 1998) and temperature (Pravosudov and Grubb 1995, Carter and Goldizen 2003), have been shown to influence vigilance behaviour. In several species, wind speed also has an effect on vigilance activity; individuals are usually more vigilant as wind speed increases. This phenomenon has been described in marsupial species (Johnson 1980, Carter and Goldizen 2003) and is thought to be caused by the sound produced by wind reducing an individual's ability to detect predators (Loughry 1992, 1993). Finally, season and resource quality and quantity influence individual vigilance (Elgar 1989, Underwood 1982), although these environmental characteristics seem to have their primary influence on foraging and consequently an indirect effect on vigilance activity.

\section{3-2 Factors that reduce the cost of vigilance}

Vigilance activity can be costly as it decreases individuals' feeding rates and can thus negatively affect survival and reproductive success (Pulliam 1973, Underwood 1982, McNamara and Houston 1992). However, as mentioned above, the cost of vigilance activity can be reduced when foragers are vigilant while handling food (multi-tasking), such as when birds handle seeds, rodents grasp food and herbivores chew vegetation (e.g. Fortin et al. 2004, Unck et al. 2009, Baker et al. 2011). According to the models developed by Illius and FitzGibbon (1994), animals could spend up to $50 \%$ of their vigilance time without reducing their food intake. Based on this idea, Fortin et al. (2004) studied the cost of vigilance behaviour in bison (Bison bison) and elks (Cervus canadensis) and confirmed that their ability to chew vegetation while being vigilant decreased the cost of vigilance as measured by intake rates. They showed that while spending $31 \%$ of their time in vigilance, bison decreased their bite rates by $20 \%$ and elk did so by $26 \%$, instead of the $31 \%$ expected in the absence of an overlap between chewing and scanning (Fortin et al. 2004). Even though the cost of vigilance can be reduced, this behaviour remains costly because vigilance while chewing does not entirely suppress the cost of vigilance and because herbivores also exhibit periods of vigilance without chewing. Therefore, several recent studies differentiated vigilant bouts when the animal concurrently chewed its food from bouts when the animal was not chewing any food. These two types of vigilance have been given a number of different names in the recent literature. Vigilance of an animal without chewing has been called exclusive, active, induced, highcost vigilance or simply vigilance, whereas vigilance while chewing has been called shared- 
foraging, passive, routine, low-cost vigilance or apprehensive foraging (Lima and Bednekoff 1999, Tchabovsky et al. 2001, Blanchard and Fritz 2007, Unck et al. 2009, Le Roux et al. 2009, Pays et al. 2012a). In this thesis I use the terms "exclusive vigilance" and "vigilance while chewing" to distinguish between these two forms of vigilance.

However, even though vigilance while chewing seems to be advantageous in reducing the foraging cost associated with vigilance activity, Lima and Bednekoff (1999) pointed out that the quality of such vigilance for predator detection is lower compared to that of exclusive vigilance, creating a quality trade-off between vigilance while chewing with low foraging costs but low detection ability, and vigilance without chewing with high foraging costs but high detection ability. Indeed, chewing is noisy and could hinder the ability of prey to evaluate their predation risk (Blanchard and Fritz 2007). In their study, Fortin et al. (2004) observed that bison and elk sometimes stopped chewing while scanning, suggesting that these activities could interfere with each other. Although distinguishing between these two types of vigilance seems to be essential, most studies of vigilance have not taken this into account (e.g. Strirrat 2004, Lung and Childress 2007) or have considered vigilance while chewing as part of foraging activity (e.g. Toïgo 1999). However, this distinction has recently received more attention (Cowlishaw et al. 2004, Fortin et al. 2004, Makowska and Kramer 2007, Unck et al. 2009, Pays et al. 2012a, Meer et al. 2012).

These studies aimed to quantify the amount of time devoted by foragers to each vigilance type and to study the factors responsible for variation in animals' investment in these vigilance types. The average times spent in exclusive vigilance and vigilance while chewing seem to differ among species. In herbivores, most of the studies report that vigilance while chewing is the main type of vigilance exhibited [e.g., plains zebras (Equus quagga) (83.9\% of vigilance time in Périquet et al. 2012), impalas (75.7 and 81\% of vigilance time in Périquet et al. 2012 and Pays et al. 2012a, respectively), and European rabbits (Oryctolagus cuniculus) (62.5\% of vigilance time in Monclús and Rödel 2008)]. Not surprisingly, the main factors driving the investment of foragers in the two types of vigilance relate to their predation risk. For example, impalas spent on average $28 \%$ of their time in exclusive vigilance while drinking compared with 3\% when they foraged (Meer et al. 2012, Pays et al. 2012a). Meer et al. (2012) also observed that kudus strongly increased their level of exclusive vigilance early in the morning when predation risk was the highest. Others studies confirmed than investment in exclusive vigilance increases with predation risk (Monclús and Rödel 2008, Unck et al. 2009, Périquet et al. 2012). Proxies of predation risk such as group size and distance to cover also affect the use of these two types of vigilance (Périquet et al. 2012). Finally, food availability and quality have also been shown to affect the use of vigilance while chewing (Benhaeim et al. 2008, Pays et al. 2012a, Périquet et al. 2012). 


\section{4 - Grouping behaviour}

\section{4-1 Group formation and dynamics in herbivores}

Group living is common in large herbivores, but groups vary in size and composition. Group sizes range from small family units containing only few individuals, such as in Lichtenstein's hartebeests (Alcelaphus lichtensteini) or warthogs (Phacocoerus aethiopicus) (Rodgers 1977), to very large aggregations of hundreds of individuals such as in common elands (Tvagelaphus ovyx), Uganda kobs (Adenota kob thomasi) or common impalas (Jarman 1974). In addition to varying among species, group sizes can also vary within species and many species show highly variable group sizes in nature (Krause and Ruxton 2002). Group sizes usually increase with population density and habitat openness, and can show seasonal variation in relation to reproductive behaviour and fluctuations in food resources (Rodgers 1977, Bergström and Skarpe 1999, Gerard et al. 2002, discussed in Beauchamp 2011).

Groups also vary among species in their stability. Large herbivores can form relatively stable groups such as found in Chacoan peccarys (Catagonus wagneri) (Taber et al. 1994), forest buffaloes (Syncerus caffer nanus) (Melletti et al. 2010) or plains zebras (Neuhaus and Ruckstuhl 2002) or exhibit the opposite pattern, only aggregating on rare occasions, as for example during reproductive periods, which is the case for common wombats (Vombatus ursinus) (Taylor 1993). Between these extremes, many large herbivorous species form groups that are unstable in size and composition, with individuals frequently leaving and joining groups. This social system, called fission-fusion dynamics, was first described in primates and then observed in fishes, cetaceans, bats (see Aureli et al. 2008 for a review), as well as ungulates and marsupials (e.g. Murray 1981, Southwell 1984b, Pépin and Gerard 2008, Fortin et al. 2009, Pays et al. 2012b). Although fissionfusion dynamics are still not completely understood, such patterns have been suggested to be mainly related to population and group sizes, as well as habitat structure, resource availability, predation risk and social interactions (Caughley 1974, Kerth and Koing 1999, Fortin et al. 2009, Pays et al 2012b), and therefore to the balance between the benefits and costs of grouping (Kerth 2010).

\section{4-2 Benefits and costs of grouping}

Group formation confers many benefits to animals. Mainly, grouping reduces prey animals' risk of predation through the detection, dilution and confusion effects described previously. This "safety in number" allows them to decrease their vigilance and therefore increase their foraging 
time and intake rates (Elgar 1989, Treves 2000). Also as previously discussed, feeding in groups can allow individuals to locate and assess the quality of food patches by monitoring their conspecifics' behaviours (Galef and Giraldeau 2001, Valone and Templeton 2002). These are the most reported benefits of group formation for herbivores. However, prey animals living in groups can also defend themselves and their young against predators [e.g., bisons against wolves (Canis lupus) (Carbyn and Trottier 1988), or pronghorn antelopes (Antilocapra americana) cooperating to attack coyotes (Canis latrans) (Berger 1979)].

While the benefits of gregariousness are well established, living in groups can also have costs for individuals. For instance, as a group becomes too large, it is more likely to be detected by predators (Wrona and Dixon 1991, Roberts 1996, Silk 2007). Also, living in groups increase intraspecific competition for resources (Beauchamp 1998, Randler 2005, Rieucau and Giraldeau 2009), intra-sexual competition (Reboreda and Fernández 1997), aggressive behaviours, as well as the transmission of diseases and parasites (reviewed in Krause and Ruxton 2002). Consequently, animals living in groups have to balance the benefits and costs of grouping (Blumstein et al. 2001, Krause and Ruxton 2002). For mammals, it is generally assumed that the main benefit of grouping is protection from predators and the main cost is competition for resource acquisition among group members (Silk 2007).

\section{4-3 Social vigilance}

Although much vigilance done by individuals is devoted to watching their environment, it is now well recognised that vigilance is also used to monitor conspecifics in gregarious species (Artis and Martin 1995). Vigilance toward group members has been assumed to occur for a long time, but the difficulty of assessing the targets of vigilant bouts constrained many researchers to considering vigilance as a general behaviour principally aimed at detecting predators. However, some recent studies have attempted to distinguish between vigilant bouts oriented to the environment, presumably to increase individuals' safety (i.e. antipredator vigilance), and vigilant bouts directed toward conspecifics (i.e. social vigilance or social monitoring) (Treves 2000). Although studies considering vigilance toward conspecifics are rare, social vigilance has been investigated in birds (Artis and Martin 1995, Robinette and Ha 2001) and mammals (Cameron and du Toit 2005, Lung and Childress 2007, Favreau et al. 2010), and particularly in primates (Alberts 1994, Kutsukake 2006).

The amount of vigilance time devoted to social vigilance has received little attention but seems to vary among species, particularly in relation to their degree of sociality. While primate species can dedicate the greatest amount of their vigilance time to monitoring their group mates 
(e.g., 75\% in brown capuchin monkeys (Cebus apella) according to Hirsch 2002), most nonprimate mammals for which this has been estimated spend more time in antipredator vigilance than in social vigilance. For example, Le Roux et al. (2009) reported that yellow mongooses (Cynictis penicillata) and meerkats (Suricata suricatta) spent on average 9.6 and $5 \%$ of their vigilance time monitoring their conspecifics, respectively, and Favreau et al. (2010) found that this proportion was $25 \%$ in eastern grey kangaroos.

Social vigilance has been shown to be used in multiple contexts to obtain information on what others group members are doing, which has been defined as social information (Giraldeau et al. 2002; Valone and Templeton 2002). Public information is a form of indirect social information used by individuals to estimate the quality of environmental parameters (Valone 2007). Thus, via the use of public information, social vigilance allows individuals to detect the locations of food patches and assess their quality by monitoring their group members' behaviours (scrounging tactics) (Smith et al. 1999, Valone and Templeton 2002). Scroungers should therefore exhibit a higher vigilance level than producers (Barnard and Sibly 1981). As this pattern is very difficult to detect in nature, producer-scrounger models have mainly been studied under controlled experimental conditions, although the occurrence of producers and scroungers is suggested to occur in nature (Giraldeau and Beauchamp 1999, Beauchamp 2001, but see Robinette and Ha 2001). Furthermore, scrounging have been shown to increase with group size (Robinette and $\mathrm{Ha}$ 2001), and is assumed to increase when food is scarce and competition strong (Beauchamp 2009). Social information can also be used by individuals to assess predation risk (Ellard and Byers 2005). For example, according to FitzGibbon (1989, 1990), Thomson's gazelles (Gazella thomsoni) should obtain anti-predatory advantages from observing their group mates. A neighbour's alert posture or departure could give information to other individuals on the presence of danger without their having to detect any threat themselves (Pays et al. 2013). Social vigilance has also been demonstrated to be used by individuals to avoid aggression (Knight and Knight 1986, Waite 1987, Slotow and Rothstein 1995) and to protect their young (Caro 2005). This latter type of vigilance is known as maternal vigilance and is used by mothers to protect their offspring from external (predators) and internal group (infanticide) threats (Caro 2005, Kutsukake 2006).

According to the "Within-Group Surveillance Hypothesis" developed by Treves (1999), the fact that many studies of primates failed to find any group size effect on vigilance is likely to be due to social vigilance (or within-group surveillance). This hypothesis suggests that increasing group size should have opposite effects on the two types of vigilance, decreasing anti-predatory vigilance and increasing social vigilance. This could result in a stable level of total vigilance as group size increases. In my master's research, I studied the effects of group size on both social and antipredatory vigilance in eastern grey kangaroos and confirmed the pattern predicted by Treves (1999) (Favreau et al. 2010). Although increasing group size has been shown to be responsible for 
an increase in social vigilance, more field studies are required to investigate other factors affecting this particular activity.

\section{5 - Behavioural variation among individuals}

\section{5-1 Evidence of variation among individuals}

Many studies of how animals modify their behaviour in relation to their environment are focussed at a group or population level, often assuming that every individual from the same population (or group) behaves the same way under the same conditions. While behavioural variation among populations and groups has often been studied (e.g. Hunter and Skinner 1998, Blumstein and Daniel 2003), variation between individuals in the same population or group has received less attention (Bennett 1987, Lott 1991). Although evidence of individual behavioural variation has been observed in many studies, it has often been considered as unwanted noise or random variation, preventing the understanding of typical pattern of groups (Slater 1981).

However, more recent studies have focussed on between-individual behavioural variation in a wide range of behaviours and demonstrated that general patterns observed at the population level can hide a diversity of individuals' strategies within a single population (e.g. Carter et al. 2009a). Different individuals from a single population can exhibit (1) different behaviours that are consistent within individuals across time and contexts (referred as different personalities), and (2) different behavioural adjustments to environmental gradients, thus showing different patterns of behavioural plasticity (Dingemanse et al. 2010). In the next paragraphs, I will focus on these two types of between-individual behavioural variation.

\section{5-2 Behavioural consistency and personality}

Variation in behaviour can be separated into variation between and within individuals (i.e. inter and intra-individual variation) and comparing the extent to which a behaviour varies within and between individuals allows us to study the consistency of a behavioural pattern. Usually, behaviour has been assumed to be highly plastic and to vary with social and ecological conditions (Komers 1997). However, recent studies have argued that behaviour may be constrained within individuals, limiting the phenotypic plasticity of behavioural traits (Pigliucci 2001). For example, in their review, Bell et al. (2009) highlighted that many behavioural traits in a number of taxa showed limited plasticity and tended to differ consistently between individuals. Behavioural consistency has often been quantified by measures of repeatability, which corresponds to the amount of behavioural 
variation that is due to differences between individuals (Hayes and Jenkins 1997). Following this approach, a high repeatability means that within-individual variation is low relative to betweenindividual variation and therefore that individuals' behaviours are consistent while there are differences across individuals. Repeatability has been studied for many behavioural traits such as antipredator behaviour, courtship, foraging, exploration, mating and parental care (Bell et al. 2009).

From this approach, some researchers have developed the concept of animal personality, which is defined as between-individual differences and within-individual consistency in behaviour (Sih and Bell 2008). Personality traits are consistent across time and contexts (Dall et al. 2004). Personality has been studied in many species including primates and non-primate mammals (herbivores and carnivores), reptiles and fishes (see Gosling 2001 for a review), and personality traits have been divided into five categories: activity, boldness, exploration, sociability and aggressiveness (Réale et al. 2007). Correlations between personality traits have also been commonly observed and termed as "behavioural syndromes", as for example the aggressivenessboldness syndrome (Sih et al. 2004), in which bolder individuals also tend to be more aggressive. Finally, some personality traits have been shown to be heritable and linked to fitness (Réale et al. 2007), and to have many implications for the ecology and evolution of animal species (detailed in Wolf and Weissing 2012).

Consistent behavioural differences among individuals have also been observed for other behavioural traits including vigilance and feeding rate, as in nutmeg manikins (Lonchura ponctulata) (Rieucau et al. 2010). Recent studies have linked personality to foraging and antipredator behaviours and the results indicate that, depending on their personalities, individuals use different foraging and anti-predator strategies (Jones and Godin 2010, Kurvers et al. 2010). For example, Kurvers et al. (2010) showed that shy individuals adopted scrounging tactics more than did bold ones and bold individuals tended to spend more time in foraging than shy individuals. Jones and Godin (2010) found that bold individuals spent more time foraging and less time in vigilance than shy ones, which was also observed by Edwards et al. (2013) for eastern grey kangaroos. In Namibian rock agamas (Agama planiceps), bolder male fed more than shy ones (Carter et al. 2010).

\section{5-3 Behavioural plasticity and the behavioural reaction norm approach}

Individuals may not only vary in their average expression of a behavioural trait but could exhibit different plasticity in their responses to environmental variation (Nussey et al. 2007, Dingemanse et al. 2010). For example, in the previously described study by Carter et al. (2009a), 
female eastern grey kangaroos not only differed in their mean levels of vigilance but also differed in their adjustment of vigilance to group size. While kangaroos decreased their vigilance as group size increased at the population level (the classical "group size effect"), at the individual level, only $43 \%$ of the individuals showed this pattern whereas the others showed either no variation or an increase in vigilance levels with group size (Carter et al. 2009a). Examples of individual differences in behavioural plasticity have been observed in several species and for many behavioural traits such as dispersal, startle behaviours, exploration, activity, boldness and aggression (reviewed in Dingemanse et al. 2010). These individual differences in plasticity may have a genetic basis but are also affected by individuals' past experiences (Dingemanse and Wolf 2013).

To study between-individual behavioural differences in consistency (i.e. personality) and plasticity simultaneously, Dingemanse et al. (2010) proposed an adaptive framework called "behavioural reaction norms". In this framework the behavioural response of an individual is viewed as a function of an environmental gradient, and each individual's reaction norm can be statistically characterized by an elevation (or intercept) corresponding to its mean level of behaviour (or personality) and by a linear slope corresponding to its level of plasticity in relation to the environmental gradient (Dingemanse et al. 2010, Dingemanse and Wolf 2013). Therefore the behaviours of individuals from a single population can show (1) no differences in personality (similar intercepts) or plasticity (similar slopes), (2) different personalities (different intercepts) but similar plasticity (same slopes), or (3) different personalities (different intercepts) and plasticity (different slopes).

Although a wide range of behavioural traits have been examined under the behavioural reaction norm framework (reviewed in Mathot et al. 2012), few studies have investigated amongindividual differences in consistency and plasticity of vigilance and foraging activities, although these behaviours are crucial for the survival and fitness of many species. Furthermore, the rare studies that have examined these behaviours reported contrasting results. For example, as previously mentioned, Rieucau et al. (2010) found that nutmeg manikins differed consistently from each other in their levels of vigilance and their feeding rates but showed similar plasticity as group size increased. In contrast, among-individual differences in the plasticity of vigilance behaviour have been shown in eastern grey kangaroos as group size increased (Carter et al. 2009a) and in red knots (Calidris canutus islandica) when predation risk increased (Mathot et al. 2011). Therefore, more studies need to examine the consistency and plasticity of vigilance and foraging behaviours in prey species. Moreover, as foragers' trade off between those activities, this approach could allow us to examine the existence of between-individual behavioural differences in the tradeoff between foraging and vigilance and reasons for such differences. 


\section{6 - General framework and aims of my PhD}

\section{6-1 General framework}

Herbivores are at the interface between plants and predators. Through grazing, browsing, defecation, urination, and trampling, large herbivores cause major changes to the structure and composition of vegetation communities, such as regulating the equilibrium between grass, bushes and trees and maintaining the openness of grasslands (Owen-Smith 1987, McNaughton et al. 1988, Mysterud 2006). In addition to affecting plant communities, large herbivores also impact on predators' populations. As sources of food for carnivores, their abundance determines the abundance of predators under certain conditions (East 1984) (Figure 1). Therefore, communities of large herbivores play a central role in the diversity, dynamics and functioning of ecosystems (Gordon et al. 2004, Danell et al. 2006) and understanding what determines and limits their abundance and diversity is a critical issue in the management of biodiversity and for the conservation of the ecosystems.

Herbivores have to eat and avoid being eaten. Therefore, the abundance and diversity of large herbivores are controlled by food resources (quantity and quality) (Fritz and Duncan 1994) and predation (Sinclair et al. 2003) (Figure 1). These two processes have been termed as "bottomup" and "top-down" processes, respectively (Sinclair et al. 2003), and their effects shown to vary between ecosystems and in relation to herbivores' body sizes (Grange and Duncan 2006, Hopcraft et al. 2010). Herbivores with a body mass lower than $150 \mathrm{~kg}$ are mainly regulated by predation and to a lesser extent by food resources, whereas herbivores with a body mass higher than $150 \mathrm{~kg}$ are mainly regulated by forage quantity (Sinclair et al. 2003, Hopcraft et al. 2010).

The energetic needs and the survival of herbivores not only determine their abundance and diversity but also shape their behaviours at a fine scale. Understanding how their behaviour varies in relation to predation risk and resource availability is therefore crucial for understanding the mechanisms driving their regulation. In my PhD I focused on two medium-sized species of herbivores that are regulated by predation but also by food availability and quality. Studying the trade-off between vigilance and foraging allows us to better understand the strategies used by animals to cope simultaneously with the risks of predation and changes in their resource supply. The study of behavioural strategies can be done at different spatial and temporal scales according to the behaviour studied and the question asked (Bailey et al. 2006). For example, in the study of foraging activity, the different levels can range from the bite level associated with a temporal level of 1 to 2 seconds to the home range level associated with a temporal level of 1 month to 2 years (see Bailey et al. 2006 for details and explanations). When studying the trade-off between vigilance 
and foraging activities, the scales have to be relatively fine; therefore I focused at the "patch" spatial level and at the temporal scale of 10 minute samples, allowing me sufficient time to study behavioural investment and to have precise enough data about food patches. In addition, as during my study of kangaroos, I recorded their behaviour on a monthly basis for an entire year, I was also able to investigate their fine-scale behavioural adjustment over longer periods of time.

\section{6-2 Aims of the PhD}

As described in this introduction, the study of the trade-off between vigilance and foraging is complex because many factors can affect both vigilance and foraging activities (summarized in Figure 2). The overall objective of this $\mathrm{PhD}$ was to study different aspects of the trade-off between vigilance and foraging (via feeding rates) in medium-sized herbivores, as well as variation among individuals in this trade-off, using the eastern grey kangaroo and the impala as model species. My four main chapters examine different questions in relation to this general objective (summarized in Figure 3) and are each formatted in the style of the target journal for publication.

Chapter 2 examines seasonal variation in vigilance and feeding rates in prey species using the eastern grey kangaroo as a model organism. I address whether vigilance and feeding rates of kangaroos varied thoughout the four seasons, and whether ecological, social, or individual characteristics were the main drivers of these variations. This chapter is currently under review by Functional Ecology.

Chapter 3 investigates how predator and social stimuli each affect the trade-off between vigilance and foraging in prey species. To do this, I experimentally simulated the presence of predators and conspecifics to groups of female impalas using playbacks of vocalizations of lions and male impalas. I analyzed and compared the behavioural responses of females in terms of vigilance, separating vigilance while chewing from exclusive vigilance postures, and also their foraging effort and movements. This chapter has been published in PLOS ONE (Favreau et al. 2013).

Chapter 4 studies how prey animals organize their vigilance activity in terms of costs and functions in relation to characteristics of food patches, predation risk and competition using the eastern grey kangaroo as a model species. I describe for the first time the relationship between the targets (anti-predator vs. social vigilance) and the foraging costs (excusive vigilance vs. vigilance while chewing) of vigilance, as well as the effects of patch quality, distance to cover, group size and distance to the nearest neighbour on the decisions of prey animals to use these different types of vigilance. This chapter is currently under review by Animal Behaviour.

Chapter 5 uses the behavioural reaction norm approach to study differences among individuals in the trade-off between vigilance and foraging in eastern grey kangaroos. I investigate whether individuals varied in their personality and plasticity for vigilance, feeding rates and their 
relationship when their group size, patch richness and reproductive state varied. Then I study how the relationship between feeding rate and vigilance varied between individuals in particular contexts relating to group size, patch richness and reproductive state. This chapter has been accepted in Animal Behaviour (Favreau et al. in press).

Chapter 6 provides an overview of the previous chapters to integrate my results in a more general context, discuss several points and questions arising from my results, and highlight areas for future research.

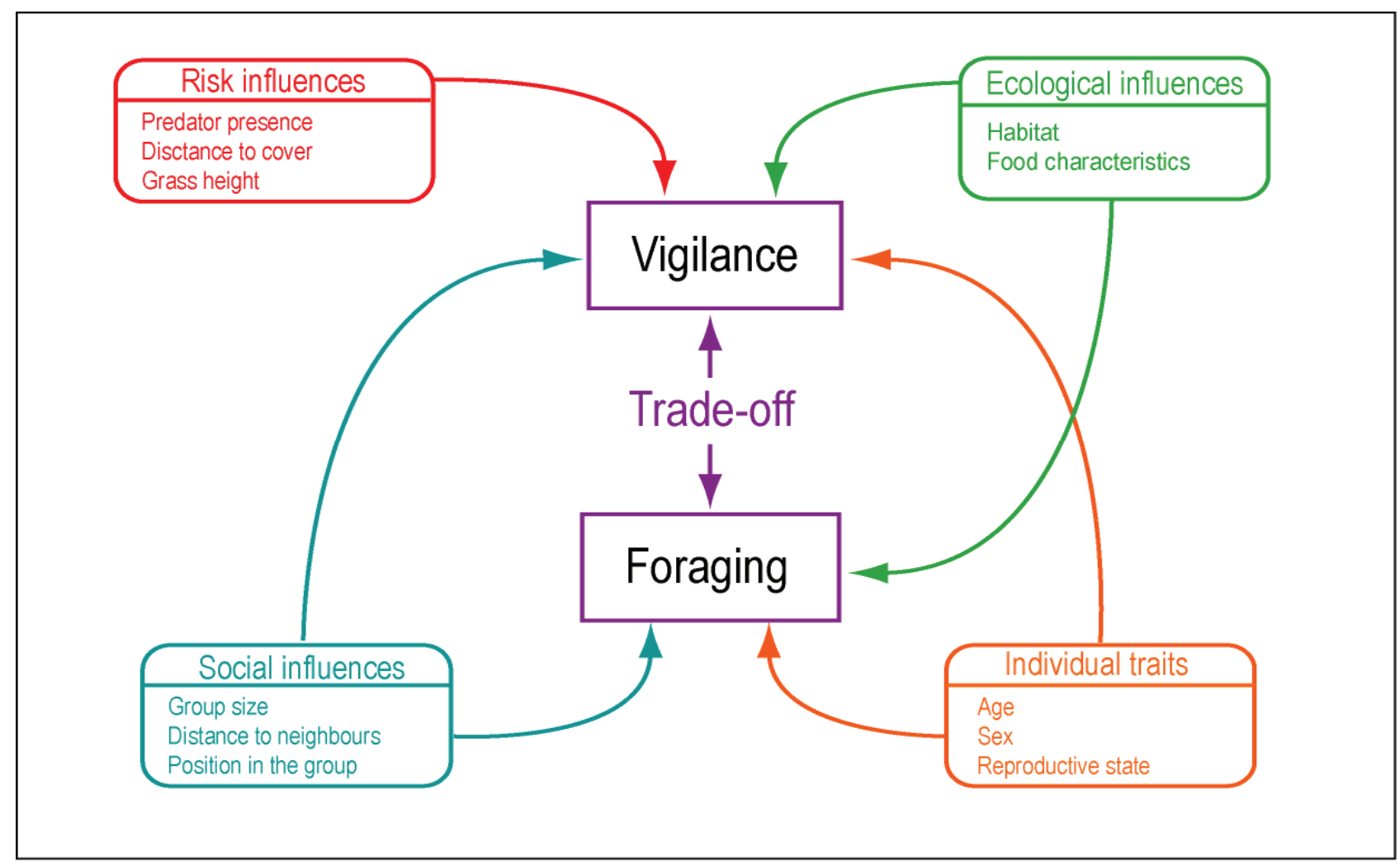

Figure 2: The main risks, social, ecological, and individual factors that have been shown to influence vigilance and/or foraging behaviours. 


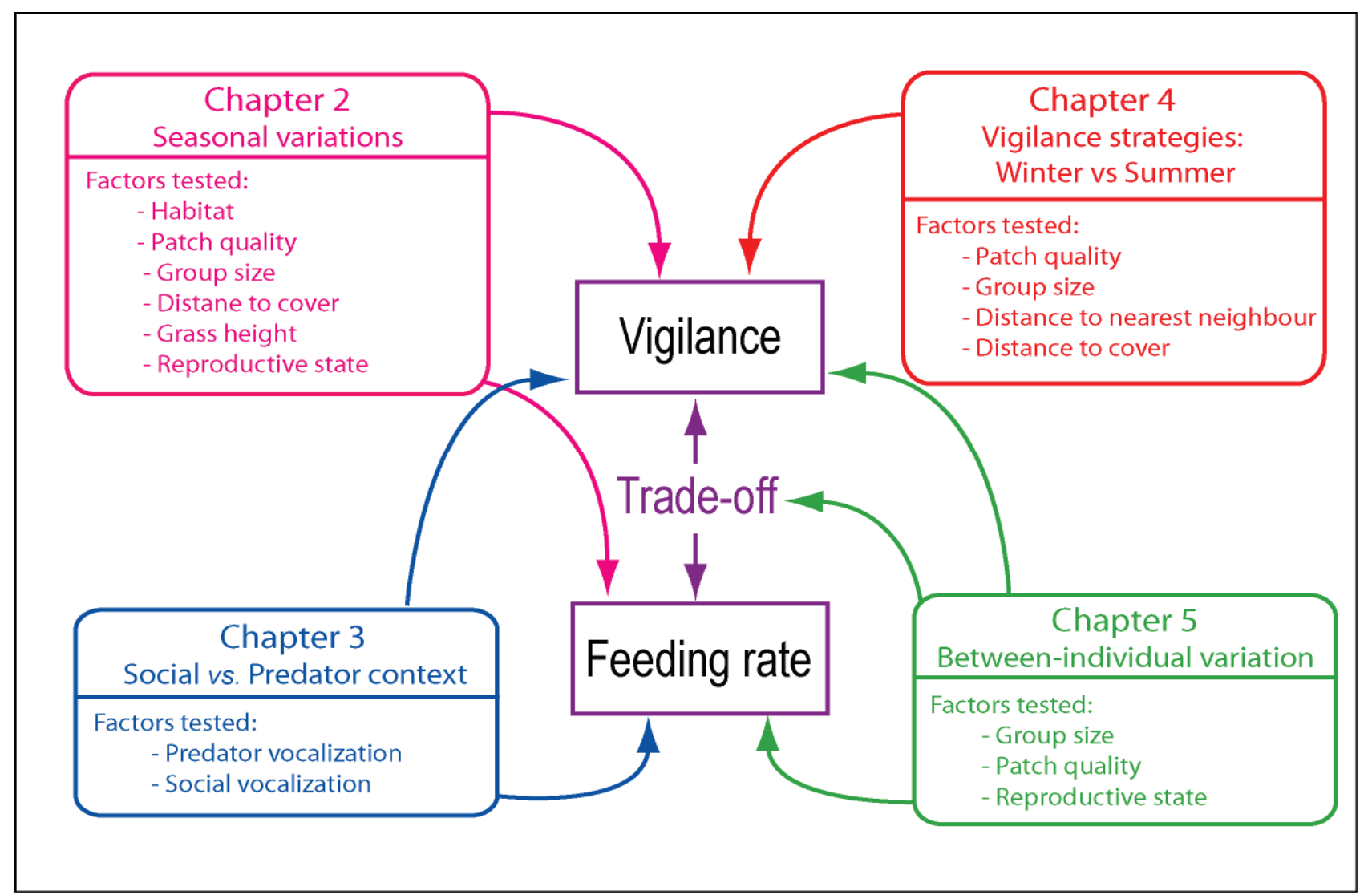

Figure 3: Questions explored in each data chapter of the thesis on vigilance, feeding rates and their trade-off, including the factors tested in the different studies.

\section{7 - Study species and study sites}

\section{7-1 Common features of the study species}

The eastern grey kangaroo and impala have both been subjects of behavioural studies on vigilance and foraging activities and provide good models for the research questions. These two species also exhibit similarities in their foraging behaviour. Their diets are mostly composed of grass and, although their functional responses have not been studied properly, given observations done on very similar species, we assume that they both exhibit a type II functional response [Short 1985 on red kangaroos (Macropus rufus), and Wilmshurst et al. 1999 on Thomson's gazelles]. These species are abundant, identifiable and easy to observe at the different study sites. For both species, the work described here only focussed on females. In kangaroos, vigilance levels differ between the sexes (Pays and Jarman 2008) and males were less numerous at the study site and tended to range over wider areas than females; they were thus much more difficult to find and study compared to females who were abundant and mostly sedentary. In impalas, vigilance patterns also differ between the sexes (Shorrocks and Cokayne 2005) and males are also more 
mobile and compete for access to females. Females are easier to study as they forage in large groups (Jarman and Jarman 1974).

\section{7-2 Study of eastern grey kangaroos at Sundown National Park (Australia)}

\section{7-2-1 Eastern grey kangaroos}

The eastern grey kangaroo is one of the largest marsupials from the family Macropodidae; it is distributed in eastern Australia from Cape York Peninsula to Tasmania (Kaufmann 1975). Eastern grey kangaroos are grazing herbivores that forage in open grasslands at night as well as in the early morning and late afternoon and rest during the remainder of the day (Jarman and Southwell 1986). They are gregarious and defined as one of the most social species of marsupials; they form open-membership mixed-sex groups ranging in size from 2 to over 70 individuals and exhibit a fission-fusion social system (Jarman 1987, Jaremovic and Croft 1991, Clarke et al. 1995). In this species, populations show a strong community structure and associations among individuals are not random (Southwell 1984a, b, Carter et al. 2009b, Best et al. 2013). Eastern grey kangaroos also exhibit a high degree of sexual dimorphism with males being much taller and bigger than females. Neither sex exhibits territoriality. Males travel to find oestrus females to mate with and compete with other males for dominance status, using ritualized displays and fighting; a dominant status then allows them to gain access to females (Jarman 1991). Breeding occurs throughout the year with a seasonal peak, usually in summer (Stuart-Dick 1987, Clarke et al. 1995, Pays and Jarman 2008). The development of young in the pouch has been characterized by different stages. According to Jaremovic and Croft (1991), females have successively (1) a small pouch young (SPY), when the pouch young causes a small distortion of the pouch, (2) a medium pouch young (MPY), with a moderate and visible distortion of the pouch and the head sometimes visible, (3) a large pouch young (LPY), when there is a large distortion of the pouch with the head often out of the pouch and the pouch young making short excursions out of the pouch, and (4) a young at foot (YAF), when the young has permanently left the pouch but is still dependant on the female for lactation (Jaremovic and Croft 1991). Young are weaned around 18 months old and female kangaroos often give birth shortly after their previous young has permanently emerged from the pouch, and can therefore simultaneously have a young-at-foot and a small pouch-young (Poole 1975, Jarman 1994).

Eastern grey kangaroos are almost exclusively grazers and their diet is mostly comprised of grass (between 64 and 98\%, in Kirkpatrick 1965, Taylor 1983). They have been described as selective as they tend to preferentially select green leaves of grass, prefer short grass with high 
nitrogen content and avoid long grass (Bell 1973, Taylor 1984, Clarke et al. 1989). Foraging patterns of kangaroos have been shown to vary seasonally, with longer feeding times and lower bite rates in winter when grass quality is poor compared to summer (Clarke et al. 1989). Although feeding times and bite rates do not seem to vary between males and females, reproductive females have longer feeding periods and higher bite rates than non-reproductive ones and bite rates increase as females' young grow, probably to cope with the cost of lactation (Maguire et al. 2006, Cripps et al. 2011, Gélin et al. 2013).

The vigilance behaviour of eastern grey kangaroos has been well studied. In this species, most studies observed the group-size effect (i.e. a decrease in individuals' vigilance with increasing group size) (Jarman 1987, Heathcote 1987, Pays et al. 2007) but some did not (Colagross and Cockburn 1993). My MSc research showed that the absence of variation in total vigilance with group size in some studies of this species could be explained by the combination of a decrease in anti-predator vigilance and an increase in social vigilance as group size increases (Favreau et al. 2010). Recent studies showed the existence of significant differences among individuals in eastern grey kangaroos' mean vigilance levels and in their adjustment of vigilance as group size increased (Carter et al. 2009a, Dannock et al. 2013). In their study, Carter et al. (2009a) revealed that, among the same population, different females decreased, increased or did not exhibit any variation in their vigilance levels as group size increased. Another recent study observed that kangaroos differed in their vigilance levels in relation to their personality, with shy individuals being more vigilant than bold ones (Edwards et al. 2013). In addition, previous studies have shown that female eastern grey kangaroos were more vigilant than males, reproductive females were more vigilant than non reproductive ones, vigilance increased with distance to cover and peripheral individuals were more vigilant than central ones (Colagross and Cockburn 1993, Pays and Jarman 2008).

\section{7-2-2 Sundown National Park}

Data on eastern grey kangaroos were collected for my $\mathrm{PhD}$ during 11 months from February to December 2011 at Sundown National Park (28 $55^{\prime}$ S, $\left.151^{\circ} 34^{\prime} \mathrm{E}\right)$ in south Queensland (Australia). The study area extended over about 37 ha and was composed of a mosaic of open pastures surrounded by mixed open forests consisting principally of eucalypts (Eucalyptus melanophloia) and pines (Callitris intratropica). All the observations were made during the few hours before sunset and after sunrise within the open pastures or at the edge of the forest where the kangaroos were feeding. The open pastures were mainly composed of grass (principally Brothriochloa decipiens, Austrostipa scabra, Cymbopogon refractus, Eragrostis leptostachya and Enteropogon paucispiceus) and forbs. The study area contained over 240 individuals, with the majority being females, and my study focused on 34 identified females from this population. Prior to my data 
collection, I spent two months learning to identify these 34 females with the help of Emily Best (PhD student at the University of Queensland), who had developed a digital catalogue containing multiple photographs of each female and helped me with individual identification in the field. Female identification was done following the method developed by Jarman et al. (1989), using a combination of personal features such as scars, facial markings, dark patches and ear shapes and tears. After the two month training period, the 34 females were clearly and easily identifiable. Due to the mostly continuous presence of researchers since 2009 and the occasional presence of campers in the area, kangaroos in this population were quite habituated to humans and our presence did not seem to affect their behaviour. Kangaroos' predators in the study area were occasionally observed or heard and included mostly red foxes (Vulpes vulpes) and wedge-tailed eagles (Aquila audax), which are principally a threat to young individuals. Therefore the risk of predation appeared to be relatively low for adult individuals in this population.

\section{7-3 Study of common impalas in Hwange National Park (Zimbabwe)}

\section{7-3-1 Common impalas}

The impala is a medium sized antelope living throughout eastern and southern Africa (Smithers 1983). Impalas are gregarious and sedentary and males are permanently or seasonally territorial (Estes 1991). Female impalas usually form large herds that are at any time divided into a variable number of groups that often change, with individuals joining and leaving those groups (Leuthold 1970, Jarman and Jarman 1974). Males can be found in bachelor herds or as solitary, territorial individuals. Female herds move through males' territories and the territorial males consequently spend much energy trying to keep females within their territories and excluding other males (Jarman and Jarman 1973a). Impalas are sexually dimorphic with only the males having horns (Jarman and Jarman 1973a). The breeding period varies regionally but usually occurs at the end of the rainy season. The birth peak usually occurs at the end of the dry season and weaning is completed after 4 to 5 months (Estes 1999).

Foraging in impalas has been well documented. Impalas are highly selective diurnal herbivores characterized as mixed-feeders, as they alternate between grazing and browsing in relation to the season because of changes in food quality and availability (Jarman 1974, Dunham 1982, Hofmann 1989). Their diet is mostly composed of grass during the wet season (between 75.5 and $90 \%$ ), but this proportion decreases during the dry season (to between 57.8 and $65.0 \%$ ) (Meisner et al. 1996, Wronski 2002). Their daily feeding time ranges from 8 to 11 hours per day and varies seasonally, with an increase in the dry season (Jarman and Jarman 1973b). Finally, 
group size has been shown to have a major influence on foraging activity, determining individuals' patch selection and the number of bites taken from particular bushes (Fritz and De GarineWichatitsky 1996).

The vigilance activity of impala has also been well studied. The relationship between individual vigilance and group size in this species has differed between studies. According to Shorrocks and Cockayne (2005), female impala decreased their vigilance with group size whereas males did not. Smith and Cain (2009) and Pays et al. (2012a) did not find any relationship between vigilance and group size, and Underwood (1982) observed an increase in vigilance with group size and nearest neighbour proximity. The relationship with the proximity to neighbours was tested on the assumption that impalas scan to maintain group cohesion. Although Smith and Cain (2009) did not observe any relationship between group size and vigilance, they observed that vigilance increased with the density of impala, and thus suggested that individuals are more aware of the distribution of group members than of the actual group size. Other studies have shown that males were more vigilant than females, peripheral individuals were more vigilant than central ones, and vigilance increased far from cover and during the afternoon, but did not change with habitat openness (Hunter and Skinner 1998, Shorrocks and Cokayne 2005). Impalas have also been shown to reduce their vigilance when the biomass and quality of food patches increased (Pays et al. 2012a).

\section{7-3-2 Hwange National Park}

Data on impalas were collected over two months from the beginning of March to the end of April 2012 at Hwange National Park (1900'S, 26³0'E) on the north-west border of Zimbabwe. The study area was located around the air strip in the Main Camp region of the park, and composed of an open grassland area of 64 ha surrounded by bushes (Acacia and Combretum). Data were collected at the end of the wet season, which occurs from the end of October to the end of April in this region and is a period during which impalas are mostly grazers. Between 50 and 100 females impalas were observed daily within the study site, mainly foraging in the open grassland. All the females formed a single herd divided into subgroups, and thus exhibited fission-fusion dynamics. The territorial male of the area was observed daily, usually in proximity of the biggest group, and was occasionally observed herding females and defending his territory against other males. About 30 females of this population were ear tagged, allowing us to reduce the risk of pseudoreplication during our experiment. In this area, predation pressure was high and many predators were seen or heard, including spotted hyenas (Crocuta crocuta), lions, leopards (Panthera pardus), cheetahs (Acinonyx jubatus) and African wild dogs (Lycaon pictus) (pays et al. 2012a). 


\section{8 - References}

Alados C.L. 1985. An analysis of vigilance in the Spanish ibex (Capra pyrenaica). Zeitschrift für Tierpsychologie, 68, 59-64.

Alberts S.C. 1994. Vigilance in young baboons: effects of habitat, age sex and maternal rank on glance rate. Animal Behaviour, 47, 749-755.

Artiss T. \& Martin K. 1995. Male vigilance in white-tailed-ptarmigan, Lagopus leucurus: mate guarding or predator detection? Animal Behaviour, 49, 1249-1258.

Aureli F., Schaffner C.M., Boesch C., Bearder S.K., Call J., Chapman C.A., Connor R., Di Fiore A., Dunbar R.I.M., Henzi S.P., Holekamp K.E., Korstjens A.H., Layton R., Lee P., Lehmann J., Manson J.H., Ramos-Fernandez G., Strier K.B. \& van Schaik C.P. 2008. Fission-fusion dynamics. Current Anthropology, 49, 627-654.

Bachman G.C. 1993. The effect of the body condition on the trade-off between vigilance and foraging in Belding's ground squirrels. Animal Behaviour, 46, 233-244.

Bailey D.W., Gross J.E., Laca E.A., Rittenhouse L.R., Coughenour M.B., Swift D.M. \& Sims P.L. 2006. Mechanisms that result in large herbivore grazing distribution patterns. Journal of Range Management, 49, 386-400.

Baker D.J., Stillman R.A., Smart S.L., Bullock J.M. \& Norris K.J. 2011. Are the costs of routine vigilance avoided by granivorous foragers? Functional Ecology, 25, 617-627.

Baldi R., Pelliza-Sbriller A., Elston D. \& Albon S. 2004. High potential for competition between guanacos and sheep in Patagonia. Journal of Wildlife Management, 68, 924-938.

Barbosa A. 2002. Does vigilance always covary negatively with group size? Effects of foraging strategy. Acta ethologica, 5, 51-55.

Barnard C.J. 1980. Factors Affecting Flock Size Mean and Variance in a Winter Population of House Sparrows (Passer domesticus L.). Behaviour, 74, 114-127.

Barnard C.J. 1983. Animal Behaviour: Ecology and Evolution. London: Croom Helm.

Barnard C.J. \& Sibly R.M. 1981. Producers and scroungers: a general model and its application to captive flocks of house sparrows. Animal Behaviour, 29, 543-550.

Beauchamp G. 1998. The effect of group size on mean food intake rate in birds. Biological Reviews, 73, 449-472.

Beauchamp G. 2001. Should vigilance always decrease with group size? Behavioral Ecology and Sociobiology, 51, 473-582.

Beauchamp G. 2009. How does food density influence vigilance in birds and mammals? Animal Behaviour, 78, 223-231.

Beauchamp G. 2011. Functional relationship between group size and population density in Northwest Atlantic seabirds. Marine Ecology Progress Series, 435, 225-233. 
Bednekoff P.A. \& Lima S.L. 1998. Re-examining safety in numbers: interactions between risk dilution and collective detection depend upon predator targeting behaviour. Proceedings of the Royal Society of London B, 265, 2021-2026.

Bednekoff P.A. \& Lima S.L. 2005. Testing for peripheral vigilance: do birds value what they see when not overtly vigilant? Animal Behaviour, 69, 1165-1171.

Bednekoff P.A. \& Ritter R. 1994. Vigilance in nxai pan springbok, Antidorcas marsupialis. Behaviour, 129, 1-11.

Bekoff M. 1995. Cognitive ethology, vigilance, information gathering, representation: Who might know what and why? Behavioural Processes, 35, 225-237.

Bell R.H.V. 1971. A grazing ecosystem in the Serengeti. Scientific American, 224, 86-93.

Bell H.L. 1973. The ecology of three macropod marsupial species in an area of open forest and savannah woodland in north Queensland, Australia. Mammalia, 37, 537-544.

Bell M.B.V., Radford A.N., Rose R., Wade H.M. \& Ridley A.R. 2009. The value of constant surveillance in a risky environment. Proceedings of the Royal Society of London B, 276, 29973005.

Benhaiem S., Delon M., Lourtet B., Cargnelutti B., Aulagnier S. Hewison J.M., Morellet N. \& Verheyden H. 2008. Hunting increases vigilance levels in roe deer and modifies feeding site selection. Animal Behaviour, 76, 611-618.

Bennett A.F. 1987. Interindividual variability. In: New directions in ecological physiology, pp. 147169. Cambridge University Press, New York.

Berger J. 1979. "Predator harassment" as a defensive strategy in ungulates. American Midland Naturalist, 102, 197-199.

Bergman C.M., Fryxell J.M., Gates C.C. \& Fortin D. 2001. Ungulate foraging strategies: energy maximizing or time minimizing? Journal of Animal Ecology, 70, 289-300.

Bergström R. \& Skarpe C. 1999. The abundance of large wild herbivores in a semi-arid savanna in relation to seasons, pans and livestock. African Journal of Zoology, 37, 12-26.

Bertram B.C.R. 1978. Living in groups: predators and prey. In: Behavioural Ecology: an Evolutionary Approach, pp. 64-96. Blackwell, Oxford.

Best E.C., Seddon J.M., Dwyer R.G. \& Goldizen A.W. 2013. Social preference influences female community structure in a population of wild eastern grey kangaroos. Animal Behaviour, 86, 1031-1040.

Blanchard P. \& Fritz H. 2007. Induced or routine vigilance while foraging. Oikos, 116, 1603-1608.

Blumstein D.T. \& Daniel J.C. 2003. Foraging behaviour of three Tasmanian macropodid marsupials in response to present and historical predation threat. Ecography, 26, 585-594.

Blumstein D.T., Daniel J.C. \& McLean I.G. 2001. Yellow-footed rock-wallaby group size effects reflect a trade-off. Ethology, 107, 655-664.

Blumstein D.T., Daniel J.C. \& Sims R.A. 2003. Group size but not distance to cover influences agile wallaby (Macropus agilis) time allocation. Journal of Mammalogy, 84, 197-204. 
Boland C.R.J. 2003. An experimental test of predator detection rates using groups of free-living emus. Ethology, 109, 209-222.

Bonter D.N., Zuckerberg B., Sedgwick C.W. \& Hochachka W.M. 2013. Daily foraging patterns in free-living birds: exploring the predation-starvation trade-off. Proceedings of the Royal Society of London B, 280, 20123087.

Brown J.S. 1999. Vigilance, patch use and habitat selection: Foraging under predation risk. Evolutionary Ecology Research, 1, 49-71.

Brown G.E., Macnaughton C.J., Elvidge C.K., Ramnarine I. \& Godin J.G.J. 2009. Provenance and threat-sensitive predator avoidance patterns in wild-caught Trinidadian guppies. Behavioral Ecology and Sociobiology, 63, 699-706.

Burger J. \& Gochfeld M. 1992. Effect of group size on vigilance while drinking in the coati, Nasua narica in Costa Rica. Animal Behaviour, 43, 1053-1057.

Burger J. \& Gochfeld M. 1994. Vigilance in African mammals: differences among mothers, other females, and males. Behaviour, 131,153-169.

Burger J., Safina C. \& Gochfeld M. 2000. Factors affecting vigilance in springbok: importance of vegetative cover, location in herd, and herd size. Acta ethologica, 25, 97-104.

Cameron E.Z. \& Du Toit J.T. 2005. Social influences on vigilance behaviour in giraffes, Giraffa camelopardalis. Animal Behaviour, 69, 1337-1344.

Caraco T. 1979. Time budgeting and group size: A test of theory. Ecology, 60, 618-627.

Caraco T. 1981. Risk-sensitivity and foraging groups. Ecology, 62, 527-531.

Carbyn L.N. \& Trottier T. 1988. Descriptions of wolf attacks on bison calves in Wood Buffalo National Park. Arctic, 41, 297-302.

Caro T. 2005. Antipredator defenses in birds and mammals. University of Chicago Press, Chicago.

Caro T.M., Graham C.M., Stoner C.J. \& Vargas J.K. 2004. Adaptive significance of antipredator behaviour in artiodactyls. Animal Behaviour, 67, 205-228.

Carter K. \& Glodizen A.W. 2003. Habitat choice and vigilance behaviour of brush-tailed rockwallabies (Petrogale penicillata) within their nocturnal foraging ranges. Wildlife research, $\mathbf{3 0}$, 355-364.

Carter A.J., Pays O. \& Goldizen A.W. 2009a. Individual variation in the relationship between vigilance and group size in eastern grey kangaroos. Behavioral Ecology and Sociobiology, 64, 237-245.

Carter A.J., MacDonald S.L., Thomson V.A. \& Goldizen A.W. 2009b. Structured association patterns and their energetic benefits in female eastern grey kangaroos, Macropus giganteus. Animal Behaviour, 77, 839-846.

Carter A.J. Goldizen, A.W. \& Tromp, S.A. 2010. Agamas exhibit behavioral syndromes: bolder males bask and feed more but may suffer higher predation. Behavioural Ecology, 21, 655-661.

Caughley G. 1974. Bias in aerial survey, Journal of Wildlife Management, 38,921-933. 
Charnov E.L.1976. Optimal foraging, the marginal value theorem. Theoretical Population Biology, 9, 129-136.

Childress L.J. \& Lung M.A. 2003. Predation risk, gender and the group size effect: does elk vigilance depend upon the behaviour of conspecifics? Animal Behaviour, 66, 389-398.

Clarke C.W. \& Mangel M. 1984. Foraging and flocking strategies: information in an uncertain environment. The American Naturalist, 123, 626-641.

Clarke C.W. \& Mangel M. 1986. The evolutionary advantages of group foraging. Theoretical population biology, 30, 45-75.

Clarke J.L., Jones M.E. \& Jarman, P.J.1989. A day in the life of a kangaroo: activities and movements of eastern grey kangaroos Macropus giganteus at Wallaby Creek. In: Kangaroos, wallabies and rat-kangaroos. (Ed. by G. Grigg, P. Jarman \& I. Hume), pp. 611-618. Chipping Norton, United Kingdom: Surrey Beatty.

Clarke J.L., Jones M.E. \& Jarman P.J. 1995. Diurnal and nocturnal grouping and foraging behaviours of free-ranging eastern grey kangaroos. Australian Journal of Zoology, 43, 519529.

Clutton-Brock T.H., lason R., Albona S.D. \& Guinness F.E. 1982. Effects of lactation on feeding behaviour and habitat use in wild Red deer hinds. Journal of Zoology, 198, 227-236.

Colagross A.M.L. \& Cockburn A. 1993. Vigilance and grouping in the eastern grey kangaroo, Macropus giganteus. Australian Journal of Zoology, 41, 325-334.

Cowlishaw G., Lawes M.J., Lightbody M., Martin A., Pettifor R. \& Rowcliffe J.M. 2004. A simple rule for the costs of vigilance: empirical evidence from a social forager. Proceedings of the Royal Society of London B, 271, 27-33.

Craighead J.J., Craighead F.C., Ruff R.L. \& O'Gara B.W. 1973. Home ranges and activity patterns of nonmigratory elk of the madison drainage herd as determined by biotelemetry. Wildlife Monographs, 33, 3-50.

Creel S. \& Christianson D. 2008. Relationships between direct predation and risk effects. Trends in Ecology and Evolution, 23, 194-201.

Cresswell W. 2008. Non-lethal effects of predation in birds. Ibis, 150, 3-17.

Cripps J.K., Wilson M.E., Elgar M.A. \& Coulson G. 2011. Experimental manipulation of fertility reveals potential lactation costs in a free-ranging marsupial. Biology Letters, 7, 859-862.

Dall S.R.X., Houston A.I. \& McNamara J.M. 2004. The behavioural ecology of personality: consistent individual differences from an adaptive perspective. Ecology Letters, 7, 734-739.

Danell K., Bergström R., Duncan P. \& Pastor J. 2006. Large herbivore ecology, ecosystem dynamics and conservation. Cambridge University Press, New York, USA.

Dannock R.J., Blomberg S.P. \& Goldizen A.W. 2013. Individual variation in vigilance in female eastern grey kangaroos. Australian Journal of Zoology, 61, 312-319.

De Ruitier J. 1986. The influence of group size on predation scanning and foraging behaviour of wedge capped capuchin monkeys (Cebus olivaceus). Behaviour, 98, 240-258. 
Dehn M.M. 1990. Vigilance for predators: detection and dilution effects. Behavioral Ecology and Sociobiology, 26, 337-342.

DeMory M.L., Thompson C.F. \& Sakaluk S.K. 2010. Male quality influences male provisioning in house wrens independent of attractiveness. Behavioral Ecology, 21, 1156-164.

Di Blanco Y. \& Hirsch B.T. 2006. Determinants of vigilance in the ring-tailed coati (Nasua nasua): the importance of the within-group spatial position. Behavioral Ecology and Sociobiology, 61, 173-182.

Dias R.I. 2006. Effects of position and flock size on vigilance and foraging behaviour of the scaled dove Columbina squammata. Behavioural Processes, 73, 248-252.

Dingemanse N.J. \& Wolf M. 2013. Between-individual differences in behavioural plasticity within populations: causes and consequences. Animal Behaviour, 85, 1031-1039.

Dingemanse N.J., Kazem A.J.N., Réale D. \& Wright J. 2010. Behavioural reaction norms: where animal personality meets individual plasticity. Trends in Ecology and Evolution, 25, 81-89.

Dunham A.E. 1982. Demographic and life history variation among populations of the iguanid lizard Urosaurus ornatus: implications for the study of life-history phenomena in lizards. Herpetologica, 38, 208-221.

East R. 1984. Rainfall, soil nutrient status and biomass of large African savanna mammals. African Journal of Ecology, 22, 245-270.

Edwards A.M., Best E.C., Blomberg S.P. \& Goldizen A.W. 2013. Individual traits influence vigilance in wild female eastern grey kangaroos. Australian Journal of Zoology, 61, 332-341.

Elgar M.A. 1989.Predator vigilance and group size in mammals and birds: a critical review of the empirical evidence. Biological Reviews, 64, 13-33.

Ellard C.G. \& Byers R.D. 2005. The influence of the behaviour of conspecifics on responses to threat in the Mongolian gerbil, Meriones unguiculatus. Animal Behaviour, 70, 49-58.

Emlen J.M. 1966. The role of time and energy in food preference. The American Naturalist, 100, 611-617.

Estes R.D. 1991. The behavior guide to African mammals. Halfway House, Russel Friedman Books, South Africa.

Estes R.D. 1999. The safari companion: a guide to watching African mammals. Halfway House, Russel Friedman Books. South Africa.

Estes J.A., Riedman M.L., Staedler M.M., Tinker M.T. \& Lyon B.E. 2003. Individual variation in prey selection by sea otters: patterns, causes and implications. Journal of AnimalEcology, 72, 144-155.

Favreau F-R., Goldizen A.W. \& Pays O. 2010. Interactions among social monitoring, anti-predator vigilance and group size in eastern grey kangaroos. Proceedings of the Royal Society $B, \mathbf{2 7 7}$, 2089-2095.

Fernández-Juricic E., Beauchamp G. \& Bastain E. 2007. Group-size and distance-to-neighbour effects on feeding and vigilance in brown-headed cowbirds. Animal Behaviour, 73, 771-778. 
FitzGibbon C.D. 1989. A cost to individuals with reduced vigilance in groups of thomson's gazelles hunted by cheetahs. Animal Behaviour, 37, 508-510.

FitzGibbon C.D. 1990. Mixed-species grouping in Thomson's and Grant's gazelles: the antipredator benefits. Animal Behaviour, 40, 837-845.

Flatt T. 2011. Survival costs of reproduction in Drosophila. Experimental Gerontology, 46, 369-375.

Fleischer R.C. 1983. Relationships between tidal oscillations and ruddy turnstone flocking, foraging, and vigilance behavior. The Condor, 85, 22-29.

Fortin D., Boyce M.S., Merrill E.H. \& Fryxell J.M. 2004. Foraging costs of vigilance in large mammalian herbivores. Oikos, 107, 172-180.

Fortin D., Fortin M.E., Beyer H.L., Duchesne T., Courant S. \& Dancose K. 2009. Group-sizemediated habitat selection and group fusion-fission dynamics of bison under predation risk. Ecology, 90, 2480-2490.

Frid A. \& Dill L. 2002. Human-caused disturbance stimuli as a form of predation risk. Conservation Ecology, 6, 11-26.

Fritz H. \& De Garine-Wichatitsky M. 1996. Foraging in a social antelope: effects of group size on foraging choices and resource perception in impala. Journal of Animal Ecology, 65, 736-742.

Fritz H. \& Duncan P. 1994. On the carrying capacity for large ungulates of African savanna ecosystems. Proceedings of the Royal Society of London B, 256, 77-82.

Fritz H., Guillemain M. \& Durant D. 2002. The cost of vigilance for intake rate in the mallard (Anas platyrhynchos): an approach through foraging experiments. Ethology, Ecology and Evolution, $14,91-97$

Fryxell J.M. 1991. Forage quality and aggregation by large herbivores. The American Naturalist, 138, 478-498.

Fryxell J.M. \& Sinclair A.R.E. 1988. Causes and consequences of migration by large herbivores. TREE, 3, 237-241.

Galef B.G. \& Giraldeau L.C. 2001. Social influences on foraging in vertebrates: causal mechanisms and adaptive functions. Animal Behaviour, 61, 3-15.

Gélin U., Wilson M.E., Coulson G.M. \& Festa-Bianchet M. 2013. Offspring sex, current and previous reproduction affect feeding behaviour in wild eastern grey kangaroos. Animal Behaviour, 86, 885-891.

Gerard J.F., Bideau E., Maublanc M.L., Loisel P. \& Marchal C. Herd size in large herbivores: Encoded in the individual or emergent? The Biological Bulletin, 202, 275-282.

Ginnett T.F. \& Demment M.W. 1997. Sex differences in giraffes foraging behavior at two spatial scales. Oecologia, 110, 291-300.

Giraldeau L.A. \& Beauchamp G.1999. Food exploitation: searching for the optimal joining policy. TREE, 14, 102-106.

Giraldeau L.A. \& Caraco T. 2000. Social Foraging Theory. Princeton, New Jersey: Princeton University Press. 
Giraldeau L.A., Valone T.J. \& Tempelton J.J.2002.Potential disadvantages of using socially acquired information. Phil Trans Royal Society of London B, 357, 1559-1566.

Gordon I.J., Hester A.J. \& Festa-Bianchet M. 2004. The management of wild large herbivores to meet economic, conservation and environmental objectives. Journal of Applied Ecology, 41, 1021-1031.

Gosling S.D. 2001. From mice to men: What can we learn about personality from animal research? Psychological Bulletin, 127, 45-86.

Grange S. \& Duncan P. 2006. Bottom-up and top-down processes in African ungulate communities: resources and predation acting on the relative abundance of zebra and grazing bovids. Ecography, 29, 899-907.

Gray R.D. 1987. Faith and foraging: a critique of the "paradigm argument from design". In: Foraging Behavior. (Kamil, AC, Krebs, JR \& Pulliam, HR Eds.), pp. 69-140.Plenum Press, New York.

Griffiths S.W. 1996. Sex differences in the trade-off between feeding and mating in the guppy. Journal of Fish Biology, 48, 891-898.

Gross J.E., Shipley L.A., Hobbs N.T., Spalinger D.E. \& Wunder B.A. 1993. Functional response of herbivores in food-concentrated patches: tests of a mechanistic model. Ecology, 74, 778-791.

Gross J.E., Demment M.W., Alkon P.U. \& Kotzman M. 1995. Feeding and chewing behaviours of nubian ibex: compensation for sex-related differences in body size. Functional Ecology, 9, 385-393.

Hamilton W.D. 1971. Geometry for the selfish herd. Journal of Theoretical Biology, 31, 295-311.

Hanley T.A. 1982. The Nutritional Basis for Food Selection by Ungulates. Journal of Range Management, 35, 146-151.

Hayes J.P. \& Jenkins S.H. 1997. Individual variation in mammals. Journal of Mammalogy, 78, 274293.

Heathcote C.F. 1987. Grouping of eastern grey kangaroos in open habitat. Australian Wildlife Research, 14, 343-348.

Hik D.S. 1995. Does risk of predation influence population dynamics? Evidence from the cyclic decline of snowshoe hares. Wildlife Research, 22, 115-129.

Hirsch B.T. 2002. Social monitoring and vigilance behavior in brown capuchin monkeys (Cebus apella). Behavioral Ecology and Sociobiology, 52, 458-464.

Hixon M.A. 1982. Energy maximizers and time minimizers: theory and reality. The American Naturalist, 119, 596-599.

Hofmann R.R. 1989. Evolutionary steps of ecophysiological adaptation and diversification of ruminants: a comparative view of their digestive system. Oecologia, 78, 443-457.

Holling C.S. 1959. Some characteristics of simple types of predation and parasitism. Canadian Entomologist, 91, 385-398. 
Holling C.S. 1965. The Functional Response of Predators to Prey Density and its Role in Mimicry and Population Regulation. Memoirs of the Entemological Society of Canada. 97, 1-60.

Hopcraft J.G.C., Olff H. \& Sinclair A.R.E. Herbivores, resources and risks: alternating regulation along primary environmental gradients in savannas. Trends in Ecology and Evolution, 25, 119128.

Houston A.I., McNamara J.M. Hutchinson J.M.C. 1993. General results concerning the trade-off between gaining energy and avoiding predation. Biological Sciences, 341, 375-397.

Hudson R.J. \& Frank S. 1987. Foraging ecology of bison in aspen boreal habitats. Journal of Range Management, 40, 71-75.

Hunter T.B. \& Skinner J.D. 1998. Vigilance behaviour in African ungulates: the role of predation pressure. Behaviour, 135, 195-211.

Illius A.W. \& FitzGibbon C.1994. Costs of vigilance in foraging ungulates. Animal Behaviour, 47, 481-484.

Illius A.W. \& Gordon I.J. 1987. The allometry of food intake in grazing ruminants. Journal of Animal Ecology, 56, 989-999.

Illius A.W., Tolkamp B.J. \& Yearsley J. 2002. Symposium on 'Perspectives in the study of food intake' The evolution of the control of food intake. Proceedings of the Nutrition Society, 61, 465-472.

Jaremovic R.V. \& Croft D.B. 1991. Social organization of the eastern grey kangaroo (Macropodidae, Marsupialia) in southeastern New South Wales. I Groups and group home ranges. Mammalia, 55, 169-185.

Jarman P.J. 1974. The social organisation of antelope in relation to their ecology. Behaviour, 48, 215-267.

Jarman P.J. 1987. Group-size and activity in eastern grey kangaroos. Animal Behaviour, 35, 10441050.

Jarman P.J. 1991. Social Behavior and Organization in the Macropodoidea. In: Advances in the Study of Behavior (Ed. by J.S.R.C.B. Peter, J.B. Slater \& M. Manfred), pp. 1-50: Academic Press.

Jarman P.J. 1994. Individual behaviour and social organisation of kangaroos. In: Animal Societies. Individuals, Interactions and Organisation (Ed. by P.J. Jarman \& A. Rossiter). Kyoto: Kyoto University Press.

Jarman P.V. \& Jarman M.V. 1973a. Social behaviour, population structure and reproductive potential in impala. East African Wildlife Journal, 11, 329-338.

Jarman M.V. \& Jarman P.J. 1973b. Daily activity of impala. East African Wildlife Journal, 11, 75-92. Jarman P.J. \& Jarman M.V. 1974. Impala behaviour and its relevance to management. In: The Behaviour of Ungulates and its Relation to Management, pp. 871-881. Eds V. Geist \& F. Walther. IUCN New Series, No. 24, Morges, Switzerlan. 
Jarman P.J. \& Southwell C.J. 1986. Grouping, associations and reproductive strategies in eastern grey kangaroos. In: Ecological Aspects of Social Evolution: Birds and Mammals. (Ed Rubenstein D.I.\& Wrangham R.Wpp), 399-428. Princeton University Press: Princeton,

Jeschke J.M., Kopp M. \& Tollrian R. 2002. Predator functional responses: discriminating between handling and digesting prey. Ecological Monographs, 72, 95-112.

Jeschke J.M., Kopp M. \& Tollrian R. 2004. Consumer-food systems: why type I functional responses are exclusive to filter feeders. Biological Review, 79, 337-349.

Johnson K.A. 1980. Spatial and temporal use of habitat by the red-necked pademelon, Thylogale thetis (marsupialia: macropodidae). Australian Wildlife Research, 7, 157-166.

Jones K.A. \& Godin J-G.J. 2010. Are fast explorers slow reactors? Linking personality type and anti-predator behaviour. Proceedings of the Royal Society of London B, 277, 625-632.

Kaufmann J.H. 1975. Field observations of the social behaviour of the eastern grey kangaroo, Macropus giganteus. Animal Behaviour, 23, 214-221.

Kerth G. 2010. Group decision-making in fission-fusion societies. Behavioural Processes, 84, 662663.

Kerth G. \& König B. 1999. Fission, fusion and nonrandom associations in female Bechstein's bats (myotis bechsteinii). Behaviour, 136, 1187-1202.

Kie J.G. 1999. Optimal foraging and risk of predation: effects on behavior and social structure in ungulates. Journal of Mammalogy, 80, 1114-1129.

Kirkpatrick T.H. 1965. Studies of the Macropodidae in Queensland. I. Food preferences of the grey kangaroo (Macropus major Shaw). Queensland Journal of Agricultural and Animal sciences, 22, 89-93.

Knight S.K. \& Knight R.L. 1986. Vigilance patterns of bald eagles feeding in groups. The Auk, 103, 263-272.

Koenig A. 1998. Visual scanning by common marmosets (Callithrix jacchus): functional aspects and the special role of adult males. Primates, 39, 85-90.

Köhler A., Hildenbrand P., Schleucher E., Riesch R., Arias-Rodriguez L., Streit B., Plath M. 2011. Effects of male sexual harassment on female time budgets, feeding behavior, and metabolic rates in a tropical livebearing fish (Poecilia mexicana). Behavioral Ecology and Sociobiology, 65, 1513-1523.

Kojola I., Hella T., Hutha E. \& Niva A. 1998. Foraging conditions, tooth wear and herbivore body reserves: a study of female reindeer. Oecologia, 117, 26-30.

Komdeur J. \& Kats R.K.H. 1999. Predation risk affects trade-off between nest guarding and foraging in Seychelles warblers. Behavioral Ecology, 10, 648-658.

Komers P.E. 1997. Behavioural plasticity in variable environments. Canadian Journal of Zoology, 75, 161-169.

Krause J. \& Ruxton G.D. 2002. Living in groups. Oxford University Press, Oxford

Krebs J.R. 1980. Optimal foraging, predation risk and territory defence. Ardea, 68, 83-90. 
Kurvers R., Prins H., van Wieren S., Van Oers K., Nolet B. \& Ydenberg R. 2010. The effect of personality on social foraging: shy barnacle geese scrounge more. Proceedings of the Royal Society of London B, 277, 601-607.

Kutsukake N. 2006 The context and quality of social relationships affect vigilance behaviour in wild chimpanzees. Ethology, 112, 581-591.

Lamoot I., Callebauta J., Demeulenaerea E., Vandenberghea C. \& Hoffmann M. 2005. Foraging behaviour of donkeys grazing in a coastal dune area in temperate climate conditions. Applied Animal Behaviour Science, 92, 93-112.

Landeau L. \& Terborgh J. 1986. Oddity and the 'confusion effect' in predation. Animal Behaviour, $34,1372-1380$.

Lazarus J. \& Symonds M. 1992. Contrasting effects of protective and obstructive cover on avian vigilance. Animal Behaviour, 43, 519-521.

Le Roux A., Cherry M.I., Gygax L. \& Manser M.B. 2009. Vigilance behaviour and fitness consequences: comparing a solitary foraging and an obligate group-foraging mammal. Behavioral Ecology and Sociobiology, 63, 1097-1107.

Lemon W.C. \& Barth R.H. 1992. The effects of feeding rate on reproductive success in the zebra finch, Taeniopygia guttata. Animal Behaviour, 44, 851-857.

Leuthold W. 1970. Observations on the social organization of impala (Aepyceros melampus). Zeitschrift für Tierpsychologie, 27, 693-721.

Lienhard A., Mirwald L., Hötzl T., Kranner I. \& Kastberger G. 2010. Trade-off between foraging activity and infestation by nest parasites in the primitively eusocial bee Halictus scabiosae. Psyche, 2010, 1-13.

Lima S.L. 1987a. Distance to cover, visual obstructions, and vigilance in house sparrows. Behaviour, 102, 231-237.

Lima S.L. 1987b. Vigilance while feeding and its relation to the risk of predation. Journal of theoretical Biology, 124, 303-316.

Lima S.L. 1990. Protective cover and the use of space: different strategies in finches. Oikos, 58, 151-158

Lima S.L. 1995. Back to the basics of anti-predator vigilance: the group-size effect. Animal Behaviour, 49, 11-20.

Lima S.L. 1998. Nonlethal effects in the ecology of predator-prey interactions. BioScience, 48, 2534.

Lima S.L. \& Bednekoff P.A. 1999. Back to the basics of antipredatory vigilance: can nonvigilant animals detect attack? Animal Behaviour, 58, 537-543.

Lima S.L. \& Dill L.M.1990. Behavioral decisions made under the risk of predation: a review and prospectus. Canadian Journal of Zoology, 68, 619-640. 
Lima S.L., Zollner P.A. \& Bednekoff P.A. 1999. Predation, scramble competition, and the vigilance group size effect in dark-eyed juncos (Junco hyemalis). Behavioral Ecology and Sociobiology, 46, 110-116.

Loarie S.R., Tambling C.J. \& Asner G.P. 2013. Lion hunting behaviour and vegetation structure in an African savanna. Animal Behaviour, 85, 899-906.

Lott D.F. 1991. Intraspecific variation in the social systems of wild vertebrates. Cambridge University Press, Cambridge.

Loughry W.J. 1992. Ontogeny of time allocation in black-tailed prairie dogs. Ethology, 90, 206-224.

Loughry W.J. 1993. Determinants of time allocation by adult and yearling black-tailed prairie dogs. Behaviour, 124, 23-43.

Lung M.A. \& Childress L.J. 2007. The influence of conspecifics and predation risk on the vigilance of elk (Cervus elaphus) in Yellowstone National Parc. Biological Reviews, 18, 12-20.

MacArthur R.H. \& Pianka E.R. 1966. On optimal use of a patchy environment. The American Naturalist, 100, 603-609.

Maguire G., Ramp D. \& Coulson G. 2006. Foraging behaviour and dispersion of eastern grey kangaroos (Macropus giganteus) in an ideal free framework. Journal of Zoology, 268, 261269.

Main M.B., Weckerly F.W. \& Bleich V.C. 1996. Sexual segregation in ungulates: new directions for research. Journal of Mammalogy, 77, 449-461.

Major P.F. 1978. Predator-prey interactions in two schooling fishes, Caranx ignobilis and stolephorus purpureus. Animal Behaviour, 26, 760-777.

Makowska I.J. \& Kramer D.L. 2007. Vigilance during food handling in grey squirrels, Sciurus carolinensis. Animal Behaviour, 74, 153-158.

Mangel M. \& Clark C.W. 1986. Towards a unified foraging theory. Ecology, 67, 1127-1138.

Marino A. \& Baldi R. 2008. Vigilance patterns of territorial Guanacos (Lama guanicoe): the role of reproductive interests and predation risk. Ethology, 114, 413-423.

Mathot K.J., van den Hout P.J., Piersma T., Kempenaers B., Réale D. \& Dingemanse N.J. 2011. Disentangling the roles of frequency-vs. state-dependence in generating individual differences in behavioural plasticity. Ecology Letters, 14, 1254-1262.

Mathot K.J., Wright J., Kempenaers B. \& Dingemanse N.J. 2012. Adaptive strategies for managing uncertainty may explain personality-related differences in behavioural plasticity. Oikos, 121, 1009-1020.

McNamara J.M. \& Houston A.I. 1992. Evolutionarily stable levels of vigilance as a function of group size. Animal Behaviour, 43, 641-658.

McNamara J.M. \& Houston A.I. 1994. The effect of a change in foraging options on intake rate and predation. The American Naturalist, 144, 978-1000.

McNaughton S.J., Ruess R.W., \& Seagle S.W. 1988. Large mammals and process dynamics in african ecosystems. BioScience, 38, 794-800. 
Meer E., Pays O. \& Fritz H. 2012. The effect of simulated African wild dog presence on antipredator behaviour of kudu and impala. Ethology, 118, 1018-1027.

Meissner H.H., Pieterse E. \& Potgieter J.H.J. 1996. Seasonal food selection and intake by male impala Aepyceros melampus in two habitats. South African Journal of Wildlife Research, 26, 56-63.

Melletti M. Penteriani V. Mirabile M. \& Boitani L. 2008. Effects of habitat and season on the grouping of forest buffalo resting places. African Journal of Ecology, 47, 121-124.

Monclùs R. \& Rödel H.G. 2008. Different forms of vigilance in response to the presence of predators and conspecifics in a group-living mammal, the european rabbit. Ethology, 114, 287297.

Monclùs R. \& Rödel H.G. 2009. Influence of different individual traits on vigilance behaviour in european rabbits. Ethology, 115, 758-766.

Moore B.D., Coulson G. \& Way S. 2002. Habitat selection by adult female eastern grey kangaroos. Wildlife research, 29, 439-445.

Murray M.G. 1981. Structure of association in impala, aepyceros melampus. Behavioral Ecology and Sociobiology, 9, 23-33.

Mysterud A. 2006. The concept of overgrazing and its role in management of large herbivores. Wildlife Biology, 12, 129-141.

Neuhaus P. \& Ruckstuhl K.E. 2002. The link between sexual dimorphism, activity budgets, and group cohesion: the case of the plains zebra (Equus burchelli). Canadian Journal of Zoology, 80, 1437-1441.

Nicholson A.J. 1954. An outline of the dynamics of animal populations. Australian Journal of Zoology, 2, 9-65.

Norris K. 1999. A trade-off between energy intake and exposure to parasites in oystercatchers feeding on a bivalve mollusc. Proceedings of the Royal Society of London B, 266, 1703-1709.

Nussey D.H., Wilson A.J. \& Brommer J.E. 2007. The evolutionary ecology of individual phenotypic plasticity in wild populations. Journal of Evolutionary Biology, 20, 831-844.

Owen-Smith N. 1987. Pleistocene extinctions: the pivotal role of megaherbivores. Paleobiology, 13, 351-362.

Owen-Smith N. 2002. Adaptive herbivore ecology. From resources to populations in variable environments. Cambridge University Press, Cambridge, UK.

Pays O. \& Jarman P.J. 2008. Does sex affect both individual and collective vigilance in social mammalian herbivores: the case of the eastern grey kangaroo? Behavioral Ecology and Sociobiology, 62, 757-767.

Pays O., Jarman P.J. \& Gerard J.F. 2007. Coordination, independence or synchronisation of individual vigilance in the eastern grey kangaroo? Animal Behaviour, 73, 595-604.

Pays O., Blanchard P., Valeix M., Chamaillé-Jammes S., Duncan P., Périquet S., Lombard M., Ncube G., Tarakini T., Makuwe E. \& Fritz H. 2012a. Detecting predators and locating 
competitors while foraging: an experimental study of a medium-sized herbivore in an African savanna. Oecologia, 169, 419-430.

Pays O., Fortin D., Gassani J. \& Duchesne J. 2012b. Group dynamics and landscape features constrain the exploration of herds in fusion-fission societies: the case of European roe deer. PLOS ONE, 7, e34678.

Pays O., Beauchamp G., Carter A.J. \& Goldizen A. 2013. Foraging in groups allows collective predator detection in a mammal species without alarm calls. Behavioral Ecology, 24, 12291236.

Pépin D. \& Gerard J.F. 2008. Group dynamics and local population density dependence of group size in the Pyrenean chamois, Rupicapra pyrenaica. Animal Behaviour, 75, 361-369.

Périquet S., Todd-Jones L., Valeix M., Stapelkamp B., Elliot N., Wijers M., Pays O., Fortin D., Madzikanda H., Fritz H., Macdonald D.W. \& Loveridge A.J. 2012. Influence of immediate predation risk by lions on the vigilance of prey of different body size. Behavioral Ecology, 23, 970-976

Peters R.H. 1983. The ecological implications of body size. Cambridge University Press, Cambridge

Pierce G.J. \& Ollason G.J. 1987. Eight reasons why optimal foraging theory is a complete waste of time. Oikos, 49, 111-117.

Pigliucci M. 2001. Phenotypic Plasticity: Beyond Nature and Nurture. Baltimore, MD: Johns Hopkins University Press.

Poole W.E. 1975. Reproduction in the two species of grey kangaroos, Macropus giganteus Shaw and M. fuliginosus (Desmarest) II. Gestation, parturition and pouch life. Australian Journal of Zoology, 23, 333-353.

Powell G.V.N. 1974. Experimental analysis of the social value of flocking by Starlings (sturnus vulgaris) in relation to predation and Foraging. Animal Behaviour, 22, 501-505.

Pöysä H. 1994. Group foraging, distance to cover and vigilance in the teal, Anas crecca. Animal Behaviour, 48, 921-928.

Pravosudov V.V. \& Grubb T.C. 1995. Vigilance in the tufted titmouse varies independently with air temperature and conspecific group size. The Condor, 97, 1064-1067.

Pravosudov V.V. \& Grubb T.C. 1998. Body mass, ambient temperature, time of day, and vigilance in Tufted Titmice. Auk, 115, 221-223.

Pulliam H.R. 1973. On the avantages of flocking. Journal of theoretical Biology, 38, 419-422.

Pulliam H.R. 1974. On the theory of optimal diets. The American Naturalist, 108, 59-74.

Pyke G.H. 1984. Optimal foraging theory: a critical review. Annual Review of Ecology and Systematics, 15, 523-575.

Pyke G.H., Pulliam H.R. \& Charnov E.L. 1977. Optimal Foraging: A selective review of theory and tests. The Quarterly Review of Biology, 52, 137-154. 
Randler C. 2005. Coots Fulica atra reduce their vigilance under increased competition. Behavioural Processes, 68, 173-178.

Réale D., Reader S.M., Sol D., McDougall P.T. \& Dingemanse N.J. 2007. Integrating animal temperament within ecology and evolution. Biological review, 82, 291-318.

Reboreda R.C. \& Fernandez G. 1997. Sexual, seasonal and group size differences in the allocation of time between vigilance and feeding in the greater rhea, Rhea americana. Ethology, 103, 198-207.

Renecker L.A. \& Hudson R.J. 1986. Seasonal foraging rates of free-ranging moose. The Journal of Wildlife Management, 50, 143-147.

Rieucau G. \& Giraldeau L.A. 2009. Group size effect caused by food competition in nutmeg mannikins (Lonchura punctulata). Behavioural Ecology, 20, 421-425.

Rieucau G., Morand-Ferron J. \& Giraldeau L.A. 2010. Group size effect in nutmeg mannikin: between-individual behavioral differences but same plasticity. Behavioral Ecology, 21, 684689.

Robbins C.T.1983. Food resources and their utilization. London: Academic Press.

Roberts G. 1995. A real-time response of vigilance behaviour to change in group size. Animal Behaviour, 50, 1371-1374.

Roberts G. 1996. Why individual vigilance declines as group size increases. Animal Behaviour, 51, 1077-1086.

Robinette R.L. \& Ha J.C. 2001. Social and ecological factors influencing vigilance by northwestern crows, Corvus caurinus. Animal Behavior, 62, 447-452.

Rodgers W.A. 1977. Seasonal change in group size amongst five wild herbivore species. East African Wildlife Journal, 15, 175-190.

Roff D.A. 1992. The evolution of life histories: theory and analysis. Chapman \& Hall, New York.

Rolando A. Caldoni R., De Sanctis A. \& Laiolo P. 2001. Vigilance and neighbour distance in foraging flocks of red-billed choughs, Pyrrhocorax pyrrhocorax. Journal of Zoology, 253, 225232.

Rose L.M. \& Fedigan L.M. 1995. Vigilance in white-faced capuchins, Cebus capucinus, in Costa Rica. Animal Behaviour, 49, 63-70.

Ruckstuhl K.E. \& Festa-Bianchet M. 1998. Do reproductive status and lamb gender affect the foraging behavior of bighorn ewes? Ethology, 104, 941-954.

Ruckstuhl K.E., Festa-Bianchet M. \& Jorgenson J.T. 2003. Bite rates in rocky mountain bighorn sheep (Ovis canadensis): effects of season, age, sex and reproductive status. Behavioural Ecology and Sociobiology, 54, 167-173.

Sæther B.E. 1997. Environmental stochasticity and population dynamics of large herbivores: a search for mechanisms. Trends in Ecology and Evolution, 12, 143-149.

Schaich H., Szabo' S. \& Kaphegyi T.A.M. 2010. Grazing with Galloway cattle for flood plain restoration int he Syr Valley, Luxembourg. Journal for Nature Conservation, 18, 268-277. 
van Schaik C.P. \& van Noordwijk M.A. 1988. Scramble and contest in feeding competition among female long-tailed macaques (Macaca fascicularis). Behaviour, 105, 77-98.

van Schaik C.P. \& van Noordwijk, M.A. 1989. The special role of male Cebus monkeys in predation avoidance and its effects on group composition. Behavioral Ecology and Sociobiology, 24, 265-272.

Schluter D.1995. Adaptive radiation in sticklebacks: trade-offs in feeding performance and growth. Ecology, 76, 82-90.

Schoener T.W. 1971. Theory of feeding strategies. Annual Review of Ecology and Systematics, 2, 369-404.

Schradin C. 2000. Confusion effect in a reptilian and primate predator. Ethology, 106, 691-700.

Senft R.L., Coughenour M.B., Bailey D.W., Ritten-house L.R., Sala O.E., Swift D.M. 1987. Large herbivore foraging and ecological hierarchies. BioScience, 37, 789-799.

Shorrocks B. \& Cokayne, A. 2005. Vigilance and group size in impala (Aepyceros melampus Lichtenstein): a study in Nairobi National Park, Kenya. African Journal of Ecology, 43, 91-96.

Short J. 1985. The functional response of kangaroos, sheep and rabbits in an arid grazing. Journal of Applied Ecology, 22, 435-447.

Shrader A.M., Kerley G.I.H., Kotler B.P. \& Brown J.S. 2006. Social information, social feeding, and competition in group-living goats (Capra hircus). Behavioral Ecology, 18, 103-107.

Sih A. 1980. Optimal foraging: Partial consumption of prey. The American Naturalist, 116, 281-290.

Sih A. 1992. Prey uncertainty and the balancing of antipredator and feeding needs. American Naturalist, 139, 1052-1069.

Sih A. 1993. Effects of ecological interactions on forager diets: competition, predation risk, parasitism and prey behaviour. In: Diet selection: An interdisciplinary approach to foraging behaviour (Eds Hughes, R.N.), pp.182-211. Blackwell scientific publications, Oxford, UK.

Sih A. \& Bell A.M. 2008. Insights for behavioural ecology from behavioural syndromes. Advances in the Study of Behavior, 38, 227-281.

Sih A., Bell A.M., Johnson J.C. \& Ziemba R.E. 2004. Behavioral syndromes: An integrative overview. The Quarterly Review of Biology, 79, 241-277.

Silk J.B. 2007. The adaptive value of sociality in mammalian groups. Philosophical Transaction of the Royal Society of London B, 362, 539-559.

Sinclair A., Mduma S. \& Brashares J. 2003. Patterns of predation in a diverse predator-prey system. Nature, 425, 288-290.

Slater P.J.B. 1981. Individual differences in animal behavior. In: Perspectives in Ethology, Vol. 4, Advantages of Diversity (Editors: Bateson P.P.G. \& Klopfer P.H.), pp. 35-49. Plenum Press, New York,

Slotow R. \& Rothstein S.I. 1995.Influence of social status, distance from cover, and group size on feeding and vigilance in white-crowned sparrows. The Auk, 112, 1024-1031. 
Smith H.G. 1995. Experimental demonstration of a trade-off between mate attraction and paternal care. Proceedings of the Royal Society of London B, 260, 45-51.

Smith S.M. \& Cain J.W. 2009. Foraging efficiency and vigilance behaviour of impala: the influence of herd size and neighbour density. African Journal of Zoology, 47, 109-118.

Smith J.W., Benkman C.W. \& Coffey K. 1999. The use and misuse of public information by foraging red crossbills. Behavioral Ecology, 10, 54-62.

Smithers R.H.N. 1983. The mammals of the Southern African subregion. Pretoria: University of Pretoria.

Solomon M.E. 1949. The Natural Control of Animal Populations. Journal of Animal Ecology, 18, 135.

Southwell C.J. 1984a. Variability variability in grouping in the eastern grey kangaroo, Macropus giganteus I. Group density and group size. Australian Wildlife Research, 11, 423-435.

Southwell C.J. 1984b. Variability in grouping in the eastern grey kangaroo, Macropus giganteus II. Dynamics of Group Formation. Australian Wildlife Research, 11, 437-449

Spalinger D.E. \& Hobbs N.T. 1992. Mechanisms of foraging in mammalian herbivores: new models of functional response. The American Naturalist, 140, 325-348.

Spalinger D.E., Hanley T.A. \& Robbins C.T. 1988. Analysis of the functional response in foraging in the sitka black-tailed deer. Ecology, 69, 1166-1175.

Stearns S.C. 1989. Trade-offs in life-history evolution. Functional Ecology, 3, 259-268.

Stearns S.C. 1992. The evolution of life histories. Oxford University Press, Oxford

Stearns S.C. 2000. Life history evolution: successes, limitations, and prospects. Naturwissenschaften, 87, 476-486.

Stephen D.W. \& Krebs J.R. 1986. Foraging theory. Princeton: Princeton University Press.

Strirrat S.C. 2004. Activity budgets of the agile wallaby, Macropus Agilis. Australian Journal of Zoology, 52, 49-64.

Stuart-Dick R.I. 1987. Parental investment in the eastern grey kangaroo. Ph.D. thesis, University of New England, Australia

Taber A.B., Doncaster C.P., Neris N. \& Colman F. 1994. Ranging behavior and activity patterns of two sympatric peccaries Catagonus wagneri and Tayassu tajacu, in the Paraguayan Chaco. Mammalia, 58, 61-71.

Taylor R.J. 1983. The diet of the eastern grey kangaroo and wallaroo in areas of improved and native pasture in the New England Tablelands. Australian Wildlife Research, 10, 203-211.

Taylor R.J. 1984. Foraging in the eastern grey kangaroo and the wallaroo. Journal of Animal Ecology, 53, 65-74.

Taylor R.J. 1993. Observations on the behaviour and ecology of the common wombat wombatus ursinus in northeast Tasmania. Australian Mammalogy, 16, 1-7. 
Tchabovsky A.V., Popov S.V. \& Krasnov B.R. 2001. Intra and interspecific variation in vigilance and foraging of two gerbillid rodents, Rhombomys opimus and Psammomys obesus: the effect of social environment. Animal Behaviour, 62, 965-972.

Thorpe W.H. 1963. Learning and Instinct in Animals. 2nd edn. London: Methuen.

Toïgo C. 1999. Vigilance behavior in lactating female Alpine ibex. Canadian Journal of Zoology, 77, 1060-1063.

Treves A. 1997. Vigilance and use of micro-habitat in solitary rainforest mammals. Mammalia, 61, 511-525.

Treves A. 1999. Whithin-group vigilance in red colobus and redtail monkeys. American journal or primatology, 48, 113-126.

Treves A. 2000. Theory and method in studies of vigilance and agregation. Animal Behaviour, 50, 711-727.

Treves A., Drescher A. \& Ingrisano N. 2001. Vigilance and aggregation in black howler monkeys (Alouatta pigra). Behavioral Ecology and Sociobiology, 50, 90-95.

Unck C.E., Waterman J.M., Verburgt L. \& Bateman P.W. 2009. Quantity versus quality: how does level of predation threat affect Cape ground squirrel vigilance? Animal Behaviour, 78, 625-632. Underwood R. 1982. Vigilance behaviour in grazing African antelopes. Behaviour, 79, 81-107.

Valeix M., Loveridge A.J., Chamaillé-Jammes S., Davidson Z.,Murindagomo F. Fritz H. \& Macdonald D.W. 2009. Behavioral adjustments of African herbivores to predation risk by lions: Spatiotemporal variations influence habitat use. Ecology, 90, 23-30.

Valone T.J. 1989. Group foraging, public information, and patch estimation. Oikos, 56, 357-363.

Valone T.J. 2007. From eavesdropping on performance to copying the behavior of others: a review of public information use. Behavioral Ecology and Sociobiology, 62, 1-14.

Valone T.J. \& Templeton J.J. 2002. Public information for the assessment of quality: a widespread phenomenon. Philosophical Transaction of the Royal Society of London B, 357, 1549-1557.

Verdolin J.L. 2006. Meta-analysis of foraging and predation risk trade-offs in terrestrial systems. Behavioral Ecology and Sociobiology, 60, 457-464.

Vickery W.L., Giraldeau L.A., Templeton J.J., Kramer D.L. \& Chapman C.A. 1991. Producers, scroungers, and group foraging. American Naturalist, 137, 847-863.

Waite R. 1963. Botanical and chemical changes in maturing grass and their effect on its digestibility. Agricultural Progress, 38, 50-56.

Waite T.A. 1987. Vigilance in the white-breasted nuthatch: effects of dominance and sociality. The Auk, 104, 429-434.

Ward D. 1992. The role of satisficing in foraging theory. Oikos, 63, 312-317.

Watson M., Aebischer N.J. \& Cresswell W. 2007. Vigilance and fitness in Grey Partridges Perdix perdix: the effects of group size and foraging-vigilance trade-offs on predation mortality. Journal or Animal Ecology, 76, 211-221. 
Wickstrom M.L., Robbins C.T., Hanley T.A., Spalinger D.E., Parish S.M. 1984. Food intake and foraging energetics of elk and mule deer. The Journal of Wildlife Management, 48, 1285-1301.

Wilmshurst J.F., Fryxell J.M. \& Hudson R.J. 1995 Forage quality and patch choice by wapiti (Cervus elaphus). Behavioral Ecology, 6, 209-217.

Wilmshurst J.F., Fryxell J.M., Colucci P.E. 1999. What constrains daily intake in Thomson's gazelles? Ecology, 80, 2338-2347.

Wilmshurst J.F., Fryxell J.M. \& Bergman C.M. 2000. The allometry of patch selection in ruminants. Proceedings of the Royal Society of London B, 267, 345-349.

Wolf M. \& Weissing F.J. 2012. Animal personalities: consequences for ecology and evolution. Trends in Ecology and Evolution, 27, 452-461.

Wrona F.J. \& Dixon R.W.J. 1991. Group size and predation risk: a field analysis of encounter and dilution effects. The American Naturalist, 137, 186-201.

Wronski T. 2002. Feeding ecology and foraging behaviour of impala Aepyceros melampus in Lake Mburu National Park, Uganda. African Journal of Ecology, 40, 205-211.

Zera A.J. \& Harshman L.G. 2001. The physiology of life history trade-offs in animals. Annual Review of Ecological Systems, 32, 95-126. 


\title{
Chapter 2:
}

\section{Seasonal variation of feeding rates and vigilance time in female kangaroos: the primary role of patch quality}

\author{
François-René Favreau, Anne W. Goldizen, Hervé Fritz, Olivier Pays
}

\section{Abstract}

Seasonal variation in food resources and predation risk imposes major constraints on herbivores, which have to adjust their behaviour to maximize their energy intake and survival. Behavioural adjustments of vigilance and feeding rates are commonly studied to investigate how herbivores trade off between food acquisition and safety from predators. Vigilance and feeding rates have been shown to vary in relation to various environmental, social and individual factors, but also to vary seasonally. However, many of the factors affecting these behaviours also vary across the year, due to variation in food supply. Therefore, it is not yet clear what the primary drivers of seasonal variation in vigilance and feeding rates are. We studied wild female eastern grey kangaroos (Macropus giganteus) under low predation risk over an entire year to investigate whether vigilance and feeding rates varied seasonally and whether this variation was mainly driven by food resources, habitat, group size, predation risk, or individuals' reproductive states. We used a model selection approach to compare these five hypotheses. Both vigilance and feeding rates varied seasonally, with the main statistical effects associated with this variation being group size and habitat, respectively. Vigilance decreased with increasing group size and feeding rate was higher in open habitats. However, because group size increased with food quality and habitat openness and open habitats contained more food, food resources emerged as the primary driver of variation in vigilance and feeding rates. These results suggest that the observed effects of group size and habitat use on the trade-off between food acquisition and safety are in fact corollaries of the seasonal variation in food supply in our study system, which has a low risk of predation on adults, and hence are by-products of the foraging choices made by kangaroos in response to food patch dynamics.

Key-words: food resources, group size, habitat, Macropus giganteus, reproductive state, tradeoff. 


\section{Introduction}

Most animals live in seasonally changing environments (Bronson 1985) and have to adjust their behaviour accordingly (Nelson 1990). To increase their survival, growth, reproduction and therefore fitness, herbivores have to maximise their food intake (Illius, Tolkamp \& Yearsley 2002). Seasonal behavioural adjustments are particularly pronounced for herbivores, because their food resources can vary greatly in quality and quantity through the year due to fluctuations in temperature and rainfall (Owen-Smith 2008). During summer or wet season months, herbivores' food is generally abundant and nutritious, allowing individuals to select the best quality food items. However, during winter or dry season months, vegetation usually becomes depleted and reduced in quality, forcing individuals to ingest lower quality food to maintain their energy intake (OwenSmith 2008). For instance, snow sometimes makes vegetation partially inaccessible, altering individuals' searching efficiency, as in bison (Bison bison) (Courant \& Fortin 2012). In response to seasonal variation in food resources, herbivores exhibit diverse behavioural adjustments involving movements, habitat selection, diet choices, foraging times, feeding rates and group size changes (e.g. Reneker \& Hudson 1986; Fryxell \& Sinclair 1988; Clarke, Jones \& Jarman 1989; Bergström \& Skarpe 1999).

Because most herbivores are subject to predation, they also have to dedicate a certain amount of time to watching for predators. However, vigilance is time consuming and consequently imposes a cost on individuals by reducing their foraging time and ultimately energetic gains, creating a trade-off between vigilance and foraging (Lima 1998; Brown \& Kotler 2004). Although herbivores can reduce the foraging cost of vigilance by being vigilant while chewing vegetation (Fortin et al. 2004), a negative relationship between vigilance and feeding rate has been observed in many taxa including herbivores, and highlights the trade-off between food acquisition and safety (e.g. Ruckstuhl, Festa-Bianchet, \& Jorgenson 2003; Baker et al. 2011; Favreau et al., in press). Consequently, any increases in antipredator vigilance in prey species might incur foraging costs, and more generally, fitness costs (see antipredator responses and risk effects in Creel \& Christianson 2008). This might be particularly true in a seasonally-driven landscape in which seasonality might constrain animals in their access to high-quality food patches.

The literature shows that it is difficult to assess how vigilance and feeding rates are adjusted to ecological contexts in prey species. Vigilance activity and feeding rates have been shown to be affected by numerous environmental, social, and individual factors including predation risk, group size and reproductive states for vigilance (e.g. Childress \& Lung 2003; Pays et al. 2012a; Périquet et al. 2012; Rieucau et al. 2012; Benoist et al. 2013), and food biomass and greenness, and reproductive states for feeding rates (e.g. Clarke et al. 1989; Wilmshurst, Fryxell \& Colucci 1999; Edouard et al. 2010; Gélin et al. 2013). Moreover, behavioural adjustments to vigilance and/or feeding rates in herbivores may also vary seasonally in response to variation in the abundance and quality of food resources (i.e. winter or dry season vs. summer or wet season, e.g. Cosyns et al. 
2001; Drescher et al. 2006), human disturbances (e.g. hunting vs. non-hunting season, Benaheim et al. 2008), and the reproduction cycle (e.g. breeding vs. non-breeding season, Ruckstuhl et al. 2003). Although these studies highlighted seasonal behavioural adjustments, most of them contrasted two periods only and thus how behavioural patterns vary across entire years remains largely unstudied. Because one of the main constraints that herbivores face is the need to acquire sufficient energetic resources despite resource availability varying across the year, regular behavioural observations over a complete seasonal cycle are needed to understand fine-scale seasonal behavioural adjustments, and identify their ultimate drivers.

Many factors that have been reported to shape vigilance and/or feeding rates, including habitat openness, group size, and reproductive state, are often correlated with variation in food quality and quantity. Whether food is a primary driver and other ecological and social factors are collateral drivers of animals' responses to resource availability, because they themselves are affected by food conditions, is not known, yet this is important for understanding the mechanisms underlying seasonal variation in vigilance investment and feeding rates. For example, the effect of group size on vigilance, which is one of the most reported relationships in the behaviour of prey species, could often mask an effect of food density (Beauchamp 2009). Group size is often correlated with the availability, quality and distribution of food resources, causing social foragers to form bigger groups in areas or periods with better food conditions (e.g. Jarman 1974; Bergström \& Skarpe 1999). As a consequence, animals feeding on good food patches may spend less time in vigilance (Pays et al. 2012a). Group sizes have also been shown to increase with habitat openness (Jarman 1974; Fritz \& Loison 2006; Pays et al. 2007a; Fortin \& Fortin 2009; Fortin et al. 2009; Pays et al. 2012b) as (1) food biomass is usually higher in open habitats, attracting more individuals to such habitats, and (2) predator detection and visual contact between group members are improved (Borkowski \& Furubayashi 1998). Feeding rates often differ in habitats that vary in food characteristics (e.g. Lamoot et al. 2005; Maguire, Ramp \& Coulson 2006). For example, Lamoot et al. (2005) reported that donkeys (Equus asinus) preferentially foraged in grassland as it offered the best food conditions for most of the year, but tended to shift to more closed habitats when grassland productivity declined. Thus seasonal variation in habitat use may mask the direct effects of food characteristics on feeding rates and indirect effect on vigilance activity due to the vigilance/feeding trade-off. Finally, reproductive females often exhibit higher feeding and chewing rates than other females (e.g. Ruckstuhl et al. 2003; Blanchard 2005; Gélin et al. 2013). However, since lactating females may select patches with lower biomass but higher quality (Clutton-Brock et al. 1982), their feeding rates and consequently intake rates may also be affected by seasonal variation in food resources.

We investigated seasonal variation in vigilance and feeding rates in female eastern grey kangaroos (Macropus giganteus) on a monthly basis over a one year period at Sundown National Park (Australia), where environmental conditions vary seasonally. We assumed that predation risk for our focal adult females was relatively low as there were no dingoes within the study area or any 
other large predators that could threaten animals of such body size (20 - $36 \mathrm{~kg}$, Yom-Tov 1986). Previous studies have reported evidence of variation in both vigilance and feeding rates between winter and summer in this species, suggesting that food quality might have a major influence on the vigilance/foraging trade-off (Clarke et al. 1989; Clarke, Jones \& Jarman 1995). To identify the main driver shaping seasonal variation in vigilance and feeding rates, we contrasted a null model (\#1) with the following model sets including factors describing ecological, social and reproductive contexts: Model set 2 ("habitat type") included the type of habitat in which the kangaroos were observed; Model set 3 ("patch quality") included information on the biomass, greenness and overall richness of the food patches exploited by kangaroos; Model set 4 ("group effect") included group size; Model set 5 ("perception of predation risk") included distance to cover and grass height, as this can affect visibility;, and Model set 6 ("reproduction") included the reproductive states of females. All of these factors have been reported to significantly affect vigilance or feeding rates in herbivores.

Based on previous studies of this species, models including group size or predation risk are expected to be best predictor of seasonal variation of vigilance (Jarman 1987; Pays, Jarman \& Gerard 2007b), while habitat type or patch quality (Ramp \& Coulson 2002; Maguire et al. 2006) or reproductive state (Gélin et al. 2013) should be the best predictor of feeding rates. Nevertheless, because adults in this population experienced a low risk of predation (Best et al. 2013), we expected food quality to be the primary driver of the vigilance/feeding rate trade-off of females. As herbivores adjust their feeding rates to food resources (Bradbury et al. 1996; Edouard et al. 2010), and vigilance and feeding rates are negatively related in this species (Favreau et al. in press), food quality should also indirectly affect vigilance (e.g. Pays et al. 2012a). As seasons affect vegetation in most ecosystems in eastern Australia (Mott et al. 1985), we predicted that patch quality should vary seasonally and induce seasonal variation in feeding rates as well as vigilance. In addition, food resources can affect herbivores' group sizes, often leading to larger groups in areas offering the best food (Jarman 1974). Therefore we expected that group size would vary seasonally and that feeding rates would increase and vigilance decrease in large groups foraging on good patches. Finally, because most grazing herbivores preferentially forage in open habitats, which usually contain the best food resources (Lamoot et al. 2005; Maguire et al. 2006), we predicted that feeding rates of female kangaroos should increase in open habitats.

\section{Materials and Methods}

\section{- Study site and species}

Fieldwork was carried out in Sundown National Park (Queensland, Australia, 28 ${ }^{\circ}$ 'S, $\left.151^{\circ} 58^{\prime} \mathrm{E}\right)$ during two weeks per month over 11 consecutive months from February through December 2011 (Table 1). The study area of 37.4 ha was composed of several areas of open 
pasture surrounded by open woodland dominated by eucalypts (Eucalyptus melanophloi) and pines (Callitris intratropica). Eastern grey kangaroos typically forage in groups on open pastures from late afternoon to early morning and rest during most of the day. They form open-membership mixed-sex groups, exhibiting a fission-fusion social system (Jarman 1987; Clarke et al. 1995). Mating behaviour can occur throughout the year but peaks during spring and summer when most females have small/medium sized pouch young and sometimes also a young-at-foot (Jarman 1994; Jaremovic \& Croft 1991). Young-at-foot still nurse from their mother but no longer enter the pouch. The study population contained approximately 240 adult and subadult females and 80 adult and subadult males (Best et al. 2013). Predators were occasionally observed or heard in the study area; red foxes, Vulpes vulpes were common but wedge-tailed eagles, Aquila audax were also present. Predation risk was low for adult kangaroos as red foxes and wedge-tailed eagles predominantly target young individuals (Banks 2001). Despite the apparent low predation risk, Favreau, Goldizen \& Pays (2010) observed that female kangaroos from this area dedicated $75 \%$ of their vigilance time to apparent antipredator vigilance. All field work complied with the laws of Queensland and Australia. This research was conducted with clearance from the University of Queensland's Animal Ethics Committee (AEC Approval Number: SIB/206/09/NF) and a Scientific Purposes Permit from Queensland's Department of Environment and Resource Management.

\section{- Individual sampling}

During the study period, we followed 34 identified female kangaroos on a regular basis for 10 to 15 days per month. Females' identification was done using features such as dark or pale patches on the fur, scars, ear shape, and facial markings, following the method developed by Jarman et al. (1989). This method had already been used in several studies on this species (e.g. Carter, Pays \& Goldizen 2009; Best et al. 2013), and allowed the observer to avoid re-sampling individuals and to include individual identity as a random effect in models. The behavioural data were collected by a single observer (F-RF) by filming (video camera: Sony DCR-SR37, 60× optical zoom, Sony Corporation, Tokyo, Japan) the selected adult focal females for10 minute observation periods during the few hours after dawn and before dusk when the animals foraged in the open. Videos were recorded on foot, at a minimum distance of $30 \mathrm{~m}$ between the focal individual and the observer to minimize disturbance. The kangaroos' behaviour did not seem to be affected by our presence during the study, probably due to the nearly continuous presence of researchers. Samples were only included in the analyses if the group containing the observed focal female remained constant in size and composition during the observation period. We considered individuals within $15 \mathrm{~m}$ of their nearest neighbour to be part of the group, following Jarman's (1987) "chain rule".

We collected 32 to 38 focal samples per female for a total of 1135 behavioural samples over the 11 months of the study (see Table 1 for details). 


\section{- Recording behaviour}

Kangaroos were characterized as vigilant when they raised their head above horizontal while either crouched or standing upright, and looked fixedly in one direction or scanned their surroundings (Jarman 1987; Pays et al. 2007b). We counted bites either by direct observation of bites being taken or based on the quick jerky movements of the head characteristic of the biting of vegetation (Watson \& Dawson 1993). From each video sequence, we extracted the times spent in vigilance and the number of bites taken, and then calculated the proportions of time spent vigilance and the feeding rates (number of bites taken per minute) of kangaroos during each 10 min focal sample.

To quantify seasonal variation in habitat use, food patch characteristics, group size, perception of predation risk and reproductive states, we measured the following variables for each sample. We recorded the habitat type in which the focal animal was foraging based on openness: "woodland" when the female was observed under areas of trees and bushes, "woodland edge" when the female was between 1 and 10 meters from woodland (edge areas that sometimes contained one or two trees or shrubs) and "open" when the female was on pasture more than 10 meters away from the woodland.

To evaluate the characteristics of the patch grazed by a focal kangaroo, we measured the biomass and assigned a greenness index to the vegetation where the individual had spent the majority of its foraging time during the focal sample. After each observation, the observer (F-R F) measured vegetation height using a pasture meter (PM) and converted this into a measure of plant biomass. To make this conversion, we first calibrated the pasture meter in each season (i.e. summer, autumn, winter, and spring) by selecting 60 patches of various heights and measuring the relationship between biomass and vegetation height by clipping, drying and weighing the plant biomass below the pasture meter (Summer: biomass $=4.26+2.29 \times \mathrm{PM}$ height, $\mathrm{P}<0.001$, adjusted $\mathrm{R}^{2}=0.85, \mathrm{~N}=60$; Autumn: biomass $=4.53+2.86 \times \mathrm{PM}$ height, $\mathrm{P}<0.001$, adjusted $\mathrm{R}^{2}=$ 0.87, $\mathrm{N}=60$; Winter: biomass $=12.09+2.66 \times \mathrm{PM}$ height, $\mathrm{P}<0.001$, adjusted $\mathrm{R}^{2}=0.87, \mathrm{~N}=60$; Spring: biomass $=8.34+3.11 \times \mathrm{PM}$ height, $\mathrm{P}<0.001$, adjusted $\mathrm{R}^{2}=0.86, \mathrm{~N}=60$ ). All plants under the 81 grid crossings of a quadrat $(90 \times 90 \mathrm{~cm}$ ) were recorded as brown (plants with low energetic value) or green (plants with high energetic value) (Bradbury et al. 1996) and the percentage of plants that were green was recorded as the "greenness" index for the patch. Patch biomass and greenness were used separately in the analyses. We also assigned patch quality using the single patch richness index described in Favreau et al. (in press). This index considers the complex relationship between greenness, biomass and food intake in short-grass grazers and that kangaroos prefer green grass and avoid long dry grass (Bell 1973; Clarke et al. 1989). Accordingly, each focal animal's feeding patch was characterized as "poor", "medium" or "rich" based on kangaroos' feeding preferences (Table 2).

Other variables were assigned for each focal sample as follows. To measure the effect of groups, we recorded the group size in which the focal animal was observed. To incorporate 
measures of the likely perception of predation risk in our analyses, we measured individuals' distance from cover (woodland) when observations occurred in the "open" or "woodland edge" habitats, and also recorded grass height (using the measure of grass height taken for biomass estimation) as an index of visual obstruction for the animal. Finally, following Jaremovic \& Croft (1991) and Gélin et al. (2013), we recorded females' reproductive states according to the size of their young, differentiating females with no visible pouch-young (NPY), a small pouch-young (SPY, when the pouch-young caused a small distortion of the pouch), a medium pouch-young (MPY, when the pouch-young caused an intermediate distortion of the pouch with the young's head sometimes visible), a large pouch-young (LPY, when the young left the pouch for short periods of time), or a young-at-foot (YAF).

\section{- Data analysis}

To investigate which factors best explained the variation in females' vigilance times and feeding rates (indicated by their bite rates), we built six competing model sets based on the factors described above ("habitat type", "patch quality", "group effect", "perception of predation risk" and "reproduction"), including also a null model. These different models are presented in Table 3. To improve goodness of fit, group size and grass height were log-transformed. Including the null model, which contained only month as a fixed factor, we built eleven different candidate models for each response variable. Each candidate model included month to control for seasonal variation and was run with vigilance time and feeding rates as the response variables. To identify which model best explained the seasonal variation in either vigilance or feeding rates, all candidate models were compared according to their AIC statistics and ranked, where the best fitting model had the lowest AIC (Burnham \& Anderson 2002). We then extracted the coefficients \pm SE and Pvalues for each variable from the best models to investigate how the variables specifically affected the time spent in vigilance and the feeding rates.

We modelled the seasonal variation in vigilance and feeding rates using generalized additive mixed models (GAMM), including female kangaroos' identities as a random factor and month as a fixed factor. We used GAMM rather than standard linear models because GAMMs can more efficiently capture nonlinear temporal variation (Dalla Rosa, Ford \& Trites 2012; Morellet et al. 2013). The smoothed effect of month was based on cubic regression splines (Wood 2006) for modelling vigilance and on P-splines (Eilers \& Marx 1996) for modelling feeding rates. Other smoothed effects of continuous variables in the candidate models were based on P-splines. Due to the tendency of GAMMs to overfit, the argument gamma $=1.4$ was used (Kim \& Gu 2004). We paid special attention to visually examining both residual plots and the similarity between plots representing observed and modelled variation in vigilance and feeding rate with month. We fitted models with the 'gamm' function in the 'mgcv' R package (Wood 2006). 
Because seasonal variation in patch quality might shape variation in group size and habitat use, we explored possible links between patch quality, group size, and habitat type using ANOVA and Spearman rank correlation tests.

All statistical analyses were performed with R 2.13.1 (R Development Core Team 2011).

\section{Results}

\section{- Seasonal variation in environmental, group, and individual factors}

Figure 1 shows how the focal samples on female kangaroos were distributed among habitat types, food patches with different characteristics, group sizes, distances to cover, and females' reproductive states over the 11 month study period covering all four seasons (see Table 1). Most observations were done in the open habitat but numbers of samples conducted in the woodland increased slightly during autumn and winter, and those in woodland edge increased in both summer and winter (Fig. 1a). Rich food patches were more common from summer to autumn and much rarer in winter before increasing again during spring, whereas poor food patches were more common during winter (Fig. 1b). Variation in patch richness involves both biomass and greenness. Rich patches were defined as those where biomass was intermediate and greenness was high, whereas poor patches were defined as those where biomass was high and greenness low (Fig. 1bd). Mean group sizes increased from summer to mid-autumn, decreased to mid-winter and increased again until late spring (Fig. 1e). Distance to cover decreased from late autumn to late winter and increased until mid-spring (Fig. 1f). Grass height decreased gradually from summer to winter and increased slightly from spring to summer (Fig. 1g). Finally, females' reproductive states also appeared to vary seasonally and to be relatively synchronized, with most females having an SPY in late autumn and early winter, followed by an MPY during winter, an LPY during spring and a YAF from mid-spring to mid-autumn (Fig. 1h).

\section{- Seasonal variation in vigilance and feeding rates}

AIC-based model selection showed that the model including group size (model \#4) best explained the variation in vigilance through the year, while the one including habitat (model \#2) best explained the variation in feeding rates (Table 3). Analyses based on model \#4 indicated that vigilance varied significantly with month (Table 4), with the time spent in vigilance decreasing from late summer to early autumn but then strongly increasing until early winter before decreasing again until early spring (Fig. 2a,c). Group size also significantly affected the investment in vigilance (Table 4). Figure 2e depicts how group size affected the deviation of vigilance from the average value, controlling for monthly variation; our results showed that vigilance decreased when group size increased. 
Analyses based on Model \#2 indicated that feeding rate varied significantly with month (Table 4), with feeding rates reaching the highest values in late winter and early spring, decreasing gradually during spring and summer, and reaching their lowest values in early autumn, before increasing again gradually until late winter (Fig. 2b,d). Habitat also significantly affected feeding rates (Table 4). Controlling for monthly variation, female kangaroos had higher feeding rates in open habitats than in woodland or on the woodland edges (Table 4, Fig. 2f). Visual comparisons of the observed and modelled values of vigilance (Fig. $2 a$ vs. $2 c$ ) and feeding rate (Fig. $2 b$ vs. $2 d$ ) in relation to months suggest that the GAMMs successfully modelled these two response variables.

\section{- Links between patch quality, group size and habitat}

Analyses of average values per session revealed that group size and habitat type were both correlated with patch quality. The average group size tended to increase with the average greenness of foraging patches (Spearman's rank correlation: $r s=0.58, P=0.05$, Fig. 3b), while we did not observe any correlation of group size with biomass ( $r s=-0.07, P=0.83$, Fig. $3 a$ ). The average biomass of foraging patches was higher in open habitat than in woodland (coef \pm SE $=$ $5.21 \pm 1.86, P=0.01$ ) but did not differ between woodland and woodland edge (coef $\pm \mathrm{SE}=2.97 \pm$ 1.91, $P=0.13$ ) (ANOVA: F2-29 = 3.94, $P=0.03$, Fig. 3c). We did not detect any differences in greenness between the habitat types $(F 2-29=0.20, P=0.82$, Fig. $3 d)$. Finally, group size was on average larger in open habitat (coef $\pm S E=1.97 \pm 0.45, P<0.001$ ) and also to a lesser extent in woodland edge (coef $\pm \mathrm{SE}=0.95 \pm 0.46, \mathrm{P}=0.05$ ) compared to woodland (ANOVA: F2-29 = 9.85, $P<0.001$, Fig. 3e)

\section{Discussion}

Among all our candidate models based on habitat type, patch quality, group size, likely perception of predation risk and reproductive state, the one including proxies of patch quality was not the best model explaining the variation in feeding rate in female kangaroos. Instead, the model including habitat type best explained the variation in feeding rate, supporting previous observations reported on this species (Maguire et al. 2006). Variation in vigilance was best explained by the model including group size, also supporting previous observations (Jarman 1987; Pays et al. 2007b). While the model including patch quality was not the model that best explained the variation in feeding rates or vigilance (Table 3), our study showed how the seasons affected patch quality and suggests that patch quality shaped both habitat use and group size and consequently appeared to be the main driver underlying how animals traded feeding rate off against vigilance (see Fig. 4 for a synthesis). Patch quality varied seasonally, with the lowest patch quality (in terms of greenness) in winter (Fig 4). Vigilance decreased with increasing group size while group size increased with patch quality (greenness) and feeding rate increased in the open habitat while 
biomass increased with openness (Fig. 4). Therefore, our results suggested that the driving force shaping variation in the investment in vigilance and feeding rate along the year was the seasonal variation in patch quality. The effects of group size and habitat type on the negative trade-off between food acquisition and vigilance appeared to be collateral drivers of the seasonal variation in food resources

As vegetation can vary greatly in biomass and quality across the year due to fluctuations in temperature and rainfall, herbivores exhibit seasonal behavioural adjustments (Owen-Smith 2008). One of the well documented behavioural responses of herbivores to seasonal variation in food resources is the migration of ungulate species in the Serengeti system (Holdo et al. 2011). Wildebeest (Connochaetes taurinus), zebra (Equus burchelli) and Thomson's gazelles (Gazella thomsoni) all undergo an annual migration between the grassland and savanna habitats driven by a marked, highly seasonal rainfall gradient coupled with strong differences in soil fertility and plants' nutritional content (Holdo et al. 2009). While this migration is a behavioural mechanism acting at a broad landscape scale, behavioural adjustments to seasonal variation in food availability can also operate at a finer scale (Fryxell et al. 2008), particularly in seasonally-driven ecosystems (Owen-Smith 2010). For instance, Courant \& Fortin (2012) showed that the search efficiency of female plains bison when vegetation was largely covered by snow was strongly improved by the presence of conspecifics; in this system group dynamics depended on both season and habitat heterogeneity (Fortin et al. 2009).

Group size, which was seasonally constrained, with smaller groups during winter when food resources were scarce, shaped vigilance time in our kangaroos. While earlier studies reported that the average group sizes of eastern grey kangaroos remained stable over seasons in other populations (e.g. Southwell 1984; Clarke et al. 1995), similar trends to our results have been observed in several African ungulates that form smaller groups during the dry season when food conditions are the most unfavourable (Bergström \& Skarpe 1999). According to Jarman (1974), this pattern arises because animals have to move further and in differing directions when food items are scarce, and are thus less able to maintain group cohesion than when food items are abundant. In our study, the sizes of foraging groups also varied between habitats, with kangaroos forming larger groups in open habitats in comparison to woodlands and woodland edges. This pattern has been previously observed in several herbivores but mainly described as an antipredatory strategy adopted by prey as habitat openness can improve their detection of predators (Jarman 1974; Underwood 1982). However, in our study area, open habitats contained higher food biomass than the other habitat types. Consequently, despite aggregation reducing predation risk and allowing individuals to decrease their vigilance levels and increase their foraging time, in our population, the formation and the size of groups may not have been primarily related to predation risk as stated for other populations (Heathcote 1987; Jarman \& Wright 1993). Instead, group size may have been influenced by seasonal variation in food resources. Similar observations have been made on other herbivore populations under low predation risk such as forest buffalos 
(Syncerus caffer nanus), for which grouping behaviour appears not to be used as an antipredator strategy and group size appears to be mainly dependent on food resources (Korte 1998; Melletti et al. 2008). Group size often reflects the cost-benefit trade-off of aggregation in terms of safety, food acquisition and social interactions (Fortin \& Fortin 2009). Therefore, through behavioural adjustments in group sizes across the year, prey can respond to variation in food availability and predation risk, which are both heterogeneously distributed in time and space.

Our results also showed that kangaroos exhibited higher feeding rates in open habitats, which contained higher food biomass than the woodland or woodland edge. Most of our foraging observations were made in the open habitats, suggesting that kangaroos tended to use this habitat more. Many grazing herbivores including kangaroos have been reported to preferentially use grasslands as these habitats often offer the best food for the largest part of the year (Taylor 1984; Ramp \& Coulson 2004; Valeix et al. 2009). The fact that seasonal variation in the feeding rates of female kangaroos was primarily influenced by habitat type rather than being directly affected by patch quality suggests that kangaroos select for resources at the habitat scale rather than the patch scale, as observed by Ramp \& Coulson (2004). They observed that individuals seasonally selected the most favorable habitats but often underused the best food patches within habitats, probably because selection at the patch level was also influenced by the presence of conspecifics, perceived predation risk, and proximity to other resources (Ramp \& Coulson 2002; 2004). The higher feeding rates that we observed in open habitats may simply reflect the higher resource availability in grasslands, but could also occur because resources are often more uniformly distributed than in more closed habitat types and thus individuals may move less while foraging due to reduced search effort between bites (Craighead et al. 1973). Finally, as groups of kangaroos were bigger in open habitats, presumably because of food availability and because larger groups are safer, individuals could increase their foraging effort by reducing their level of vigilance in such habitats.

In our population, adult kangaroos faced a low predation risk, which might explain why the models including proxies of predation risk were not the best explanation of the variation in vigilance and feeding rates. In herbivores, cover is a commonly used proxy of predation risk but can be either protective or obstructive; the effect of distance to cover on vigilance varies according to predators' hunting strategies (i.e. ambush vs. cursorial predators, Loarie et al. 2013). For eastern grey kangaroos, cover is usually considered as protective as they often flee into it when alarmed, rest near cover, and spend more time feeding near cover (Banks 2001). However, several studies have not observed any relationship between vigilance and distance to cover in marsupials including grey kangaroos (e.g. Evans et al. 2005; Favreau et al. 2010), probably because kangaroos can be predated on by terrestrial predators that can hide in cover, but also by aerial predators hunting in the open. Therefore, cover itself may provide safety to kangaroos, but proximity to cover might not (Blumstein \& Daniel, 2002; Blumstein, Daniel, \& Smith, 2003). To our knowledge, the effect of grass height on eastern grey kangaroos' vigilance has never been tested, 
but this has been positively related to vigilance in agile wallabies (Macropus agilis) (Blumstein et al. 2003) and in some African ungulate species (e.g. Burger et al. 2000; Pays et al. 2012a), as it reduces visibility. In an ecosystem in which herbivore populations experience top-down regulation with population dynamics affected directly by predation or indirectly via antipredator responses that incur fitness costs (Creel \& Christianson 2008), proxies of predation risk are likely to influence investment in vigilance, causing foraging costs if prey invest heavily in vigilance. In contrast, our results suggest that behavioural responses in our study population of kangaroos were mainly regulated by bottom-up effects (Fig. 4). It would be interesting to investigate seasonal changes in the behavioral responses of kangaroos (vigilance and feeding rate) in a population experiencing a higher predation pressure.

Reproductive state of females was not one of the factors that best explained the variation in vigilance and feeding rates during the year. Recent studies have reported that reproducing female eastern grey kangaroos increased their feeding rates as lactation demand increased, with the young-at-foot stage assumed to be the most "costly" reproductive state (Gélin et al. 2013). This pattern has not been identified for this population, probably due to individual variation in behavioural strategies masking any general effect at the population level (Favreau et al. in press). Nevertheless, seasonal variation in food resources can have profound effects on the reproduction of herbivores, affecting sexual maturity, breeding age, ovulation and conception (Langvatn et al. 1996). In addition, because reproducing females may select for high-quality forage (Clutton-Brock et al. 1982), seasonal variation in food resources is likely to affect their habitat selection and feeding rates.

\section{Acknowledgements}

We would like to thank Emily Best for her help in the field, especially with the identification of kangaroos. We thank Peter Hasselgrove and Ian Elms, Queensland Parks and Wildlife Service rangers at Sundown National Park, for their support of our work. 


\section{References}

Baker, D.J., Stillman, R.A., Smart, S.L., Bullock, J.M. \& Norris, K.J. (2011) Are the costs of routine vigilance avoided by granivorous foragers? Functional Ecology, 25, 617-627.

Banks, P.B. (2001) Predation-sensitive grouping and habitat use by eastern grey kangaroos: a field experiment. Animal Behaviour, 61, 1013-1021.

Beauchamp, G. (2009) How does food density influence vigilance in birds and mammals? Animal Behaviour, 78, 223-231.

Bell, H.L. (1973) The ecology of three macropod marsupial species in an area of open forest and savannah woodland in north Queensland, Australia. Mammalia, 37, 537-544.

Benhaiem, S., Delon, M., Lourtet, B., Cargnelutti, B., Aulagnier, S. Hewison, J.M., Morellet, N. \& Verheyden, H. (2008) Hunting increases vigilance levels in roe deer and modifies feeding site selection. Animal Behaviour, 76, 611-618.

Benoist, S., Garel, M., Cugnasse, J.M. \& Blanchard, P. (2013) Human disturbances, habitat characteristics and social environment generate sex-specific responses in vigilance of Mediterranean mouflon. PLoS ONE, 8, e82960.

Bergström, R. \& Skarpe, C. (1999) The abundance of large wild herbivores in a semi-arid savanna in relation to seasons, pans and livestock. African Journal of Zoology, 37, 12-26.

Best, E.C., Seddon, J.M., Dwyer, R.G. \& Goldizen, A.W. (2013). Social preference influences female community structure in a population of wild eastern grey kangaroos. Animal Behaviour, 86, 1031-1040.

Blanchard, P. 2005. On lactation and rumination in bighorn ewes (Ovis canadensis). Journal of Zoology, 265, 107-112.

Blumstein, D.T. \& Daniel, J.C. (2002) Isolation from mammalian predators differentially affects two congeners. Behavioral Ecology, 13, 657-663.

Blumstein, D.T., Daniel, J.C. \& Sims, R.A. (2003) Group size but not distance to cover influences agile wallaby (Macropus agilis) time allocation. Journal of Mammalogy, 84, 197-204.

Borkowski, J. \& Furubayashi, K. (1998) Seasonal and diel variation in group size among Japanese sika deer in different habitats. Journal of Zoology, 245, 29-34.

Bradbury, J.W., Vehrencamp, S.L., Clifton, K.E. \& Clifton, L.M. (1996) The relationship between bite rate and local forage abundance in wild Thomson's gazelles. Ecology, 77, 2237-2255.

Bronson, F.H. (1985) Mammalian reproduction: an ecological perspective. Biology of reproduction, $32,1-26$.

Brown, J.S. \& Kotler, B.P. (2004) Hazardous duty pay and foraging cost of predation. Ecology Letters, 7, 999-1014.

Burger, J., Safina, C. \& Gochfeld, M. (2000). Factors affecting vigilance in springbok: importance of vegetative cover, location in herd, and herd size. Acta ethologica, 25, 97-104. 
Burnham, K.P. and Anderson, D.R. (2002) Model Selection and Multimodel Inference: A Practical Information-Theoretic Approach. 2d ed. Springer, New York.

Carter, A.J., Pays, O. \& Goldizen, A.W. (2009) Individual variation in the relationship between vigilance and group size in eastern grey kangaroos. Behavioural Ecology and Sociobiology, 64, 237-245.

Childress, L.J. \& Lung, M.A. (2003) Predation risk, gender and the group size effect: does elk vigilance depend upon the behaviour of conspecifics? Animal Behaviour, 66, 389-398.

Clarke, J.L., Jones, M.E. \& Jarman, P.J. (1995) Diurnal and nocturnal grouping and foraging behaviours of free-ranging eastern grey kangaroos. Australian Journal of Zoology, 43, 519529.

Clarke, J.L., Jones, M.E. \& Jarman, P.J. (1989) A day in the life of a kangaroo: activities and movements of eastern grey kangaroos Macropus giganteus at Wallaby Creek. Kangaroos, wallabies and rat-kangaroos (eds Grigg, G.C., Jarman, P.J. \& Hume, I), pp. 611-618. Surrey, Sydney.

Clutton-Brock, T.H., lason, R.., Albona, S.D., Guinness, F.E. (1982) Effects of lactation on feeding behaviour and habitat use in wild Red deer hinds. Journal of Zoology, 198, 227-236.

Cosyns, E., Degezelle, T., Demeulenaere, E. \& Hoffmann, M. (2001) Feeding ecology of Konik horses and donkeys in Belgian coastal dunes and its implications for nature management. Belagian Journal of Zoology, 131, 111-118.

Courant, S. \& Fortin, D. (2012) Search efficiency of free-ranging plains bison for optimal food items. Animal Behaviour, 84, 1039-1049.

Craighead, J.J., Craighead, F.C., Ruff, R.L. \& O'Gara, B.W. (1973) Home ranges and activity patterns of nonmigratory elk of the madison drainage herd as determined by biotelemetry. Wildlife Monographs, 33, 3-50.

Creel, S. \& Christianson, D. (2008) Relationships between direct predation and risk effects. Trends in Ecology and Evolution, 23, 194-201.

Dalla Rosa, L.D.R., Ford, J.K.B. \& Trites, A.W. (2012) Distribution and relative abundance of humpback whales in relation to environmental variables in coastal British Columbia and adjacent waters. Continental Shelf Research, 36, 89-104.

Drescher, M., Heitkönig, I.M.A., Raats, J.G. \& Prins, H.H.T. (2006) The role of grass stems as structural foraging deterrents and their effects on the foraging behaviour of cattle. Applied Animal Behaviour Science, 1, 10-26.

Edouard, N., Duncan, P., Dumont, B., Baumont, R. \& Fleurance, G. (2010) Foraging in a heterogeneous environment: An experimental study of the trade-off between intake rate and diet quality. Applied Animal Behaviour Science, 126, 27-36.

Eilers, P.H.C., Marx, B.D. (1996) Flexible smoothing with B-splines and penalties. Statistical Science, 11, 89-121. 
Evans, L.N., Elgar, M.A. \& Handasyde, K.A. (2005) Risk sensitive foraging: an experimental study of a solitary marsupial. Australian Journal of Mammalogy, 27, 231-234.

Favreau, F-R., Goldizen, A.W. \& Pays, O. (2010) Interactions among social monitoring, antipredator vigilance and group size in eastern grey kangaroos. Proceedings of the Royal Society B, 277, 2089-2095.

Favreau, F-R., Goldizen, A.W., Fritz, H., Blomberg, S., Best, E.C., \& Pays, O. (in press) Withinpopulation differences in personality and plasticity in the trade-off between vigilance and foraging in kangaroos. Animal Behaviour.

Fortin, D. \& Fortin, M.E. (2009) Group-size-dependent association between food profitability, predation risk and distribution of free-ranging bison. Animal Behaviour, 78, 887-892.

Fortin, D., Fortin, M.E., Beyer, H.L., Duchesne, T., Courant, S. \& Dancose, K. (2009) Group-sizemediated habitat selection and group fusion-fission dynamics of bison under predation risk. Ecology, 90, 2480-2490.

Fortin, D., Boyce, M.S., Merrill, E.H. \& Fryxell, J.M. (2004) Foraging costs of vigilance in large mammalian herbivores. Oikos, 107, 172-180.

Fritz, H. \&Loison, A. (2006) Large herbivores across biomes. In Large herbivore ecology ecosystem dynamics and conservation. (eds K. Danell, R. Bergström, P. Duncan \& J. Pastor), pp. 19-49. Cambridge University Press, Cambridge.

Fryxell, J.M. \& Sinclair, A.R.E. (1988) Causes and consequences of migration by large herbivores. TREE, 3, 237-241.

Fryxell, J.M., Hazell, M., Börger, L., Dalziel, B.D., Haydon, D.T., Morales, J.M., Mclntoshd, T. \& Rosatted, R.C. (2008) Multiple movement modes by large herbivores at multiple spatiotemporal scales. Proceedings of the National Academy of Sciences of the United States of America, 105, 19114-19119.

Gélin, U., Wilson, M.E., Coulson, G.M. \& Festa-Bianchet, M. (2013) Offspring sex, current and previous reproduction affect feeding behaviour in wild eastern grey kangaroos. Animal Behaviour, 86, 885-891.

Heathcote, C.F. (1987) Grouping of eastern grey kangaroos in open habitat. Australian Wildlife Research, 14, 343-348.

Holdo, R.M., Holt, R.D. \& Fryxell, J.M. (2009) Opposing rainfall and nutrient gradients best explain the wildebeest migration in the Serengeti. The American Naturalist, 173, 431-445.

Holdo, R.M., Holt, R.D., Sinclair, A.R.E., Godley, B.J. \& Thirgood, S. (2011) Migration impacts on communities and ecosystems: empirical evidence and theoretical insights. Animal Migration: A Synthesis (eds E. J. Milner-Gulland, J.M. Fryxell \& A.R.E. Sinclair), pp. 131-143. Oxford University Press, Oxford, U.K.

Illius, A.W., Tolkamp, B.J. \& Yearsley, J. (2002) Symposium on 'Perspectives in the study of food intake' The evolution of the control of food intake. Proceedings of the Nutrition Society, 61, 465-472. 
Jaremovic, R.V. \& Croft, D.B. (1991) Social organization of the eastern grey kangaroo (Macropodidae, Marsupialia) in southeastern New South Wales. I Groups and group home ranges. Mammalia, 55, 169-185.

Jarman, P.J. (1974) The social organisation of antelope in relation to their ecology. Behaviour, 48, 215-267.

Jarman, P.J. (1987) Group-size and activity in eastern grey kangaroos. Animal Behaviour, 35, 1044-1050.

Jarman, P.J. (1994) Individual behaviour and social organization of kangaroos. Physiology and Ecology Japan, 29, 70-85.

Jarman, P.J., Jones, M.E., Johnson, C.N., Southwell, C.J., Stuart-Dick, R.I., Higginbottom, K.B., \& Clarke, J.L. (1989) Macropod studies at Wallaby Creek. 8. Individual recognition of kangaroos and wallabies. Australian Wildlife Research, 16, 179-185.

Jarman, P.J. \& Wright, S. (1993) Macropod studies at Wallaby Creek. IX. Exposure and responses of eastern grey kangaroos to dingoes. Wildlife research, 20, 833-843.

Kim, Y. J. and Gu, C. (2004) Smoothing spline Gaussian regression: more scalable computation via efficient approximation. Journal of the Royal Statistical Society: Series B, 66, 337-356.

Korte, L.M. (2008) Variation of group size among African buffalo herds in a forest-savanna mosaic landscape. Journal of Zoology, 275, 229-236.

Lamoot, I., Callebauta, J., Demeulenaerea, E., Vandenberghea, C. \& Hoffmann, M. (2005) Foraging behaviour of donkeys grazing in a coastal dune area in temperate climate conditions. Applied Animal Behaviour Science, 92, 93-112.

Langvatn, R., Ablon, S.D., Burkey, T. \& Clutton-Broch, T.H. (1996) Climate, plant phenology and variation in age of first reproduction in a temperate herbivore. Journal of Animal Ecology, 65, 653-670.

Lima, S.L. (1998) Nonlethal effects in the ecology of predator-prey interactions. BioScience, 48, 25-34

Loarie, S.R., Tambling, C.J. \& Asner, G.P. (2013) Lion hunting behaviour and vegetation structure in an African savanna. Animal Behaviour, 85, 899-906.

Maguire, G., Ramp, D. \& Coulson, G. (2006) Foraging behaviour and dispersion of eastern grey kangaroos (Macropus giganteus) in an ideal free framework. Journal of Zoology, 268, 261 269.

Melletti, M. Penteriani, V. Mirabile, M. \& Boitani, L. (2008) Effects of habitat and season on the grouping of forest buffalo resting places. African Journal of Ecology, 47, 121-124.

Morellet, N., Bonenfant, C., Borger, L., Ossi, F. ,Cagnacci, F., Heurich, M., Kjellander, P., Linnell, J.D.C., Nicoloso, S., Sustr, P., Urbano, F. \& Mysterud, A. (2013) Seasonality, weather and climate affect home range size in roe deer across a wide latitudinal gradient within Europe. Journal of Animal Ecology, 82, 1326-1339. 
Mott, J.J., Williams, J., Andrew, M.H., \& Gillison, A.N. (1985) Australian savanna ecosystems. In Ecology and management of the world's savannas: 56-82. Tothill, J.C. \& Mott J.J. (Eds). Australian Academy of Science, Canberra.

Nelson, J. (1990) Mechanisms of seasonal cycles of behavior. Annual Review of Psychology, 41, 81-108.

Owen Smith, N. (2010) Dynamics of large herbivore populations in changing environments: toward appropriate models. Wiley-Blackwell, Hoboken, New Jersey, USA.

Owen-Smith, N. (2008) Effects of temporal variability in resources on foraging behaviour. Resource ecology: spatial and temporal dynamics of foraging (eds Prins, H.H.T. \& Van Langevelde, F), pp. 159-181. Springer-Verlag, Dordrecht, the Netherlands.

Pays, O., Benhamou, S., Helder, R. \& Gerard, J.F. (2007a) The dynamics of group formation in large mammalian herbivores: an analysis in the European roe deer. Animal Behaviour, 74, $1429-1441$.

Pays, O., Jarman, P.J. \& Gerard, J.F. (2007b) Coordination, independence or synchronisation of individual vigilance in the eastern grey kangaroo? Animal Behaviour, 73, 595-604.

Pays, O., Blanchard, P., Valeix, M., Chamaillé-Jammes, S., Duncan, P., Périquet, S., Lombard, M., Ncube, G., Tarakini, T., Makuwe, E. \& Fritz, H. (2012a) Detecting predators and locating competitors while foraging: an experimental study of a medium-sized herbivore in an African savanna. Oecologia, 169, 419-430.

Pays, O., Fortin, D., Gassani, J. \& Duchesne, J. (2012b) Group dynamics and landscape features constrain the exploration of herds in fusion-fission societies: The case of European roe deer. PLoS ONE, 7, e34678.

Périquet, S., Todd-Jones, L., Valeix, M., Stapelkamp, B., Elliot, N., Wijers, M., Pays, O., Fortin, D., Madzikanda, H., Fritz, H., Macdonald, D.W. \& Loveridge, A.J. (2012) Influence of immediate predation risk by lions on the vigilance of prey with different body-sizes. Behavioral Ecology, 23, 970-976.

Ramp, D. \& Coulson, G. (2004) Small-scale patch selection and consumer-resource dynamics of eastern grey kangaroos. Journal of Mammalogy, 85, 1053-1059.

Ramp, D. \& Coulson, G. (2002) Density Dependence in Foraging Habitat Preference of Eastern Grey Kangaroos. Oikos, 98, 393-402.

Renecker, L.A. \& Hudson, R.J. (1986) Seasonal foraging rates of free-ranging moose. The Journal of Wildlife Management, 50, 143-147.

Rieucau, G., Blanchard, P., Martin, J.G.A., Favreau, FR., Goldizen, A.W. \& Pays, O. (2012) Investigating differences in vigilance tactic use within and between the sexes in eastern grey kangaroos. PLoS ONE, 7, e44801.

Ruckstuhl, K. E., Festa-Bianchet, M. \& Jorgenson, J.T. (2003) Bite rates in Rocky Mountain bighorn sheep (Ovis canadensis): effects of season, age, sex and reproductive status. Behavioural Ecology and Sociobiology, 54, 167-173. 
Southwell, C. J. (1984) Variability in grouping in the eastern grey kangaroo, Macropus giganteus I. Group density and group size. Australian Wildlife Research, 11, 423-435.

Taylor, R.J. (1984) Foraging in the eastern grey kangaroo and the wallaroo. Journal of Animal Ecology, 53, 65-74.

Underwood, R. (1982) Vigilance behaviour in grazing African antelopes. Behaviour, 79, 81-107.

Valeix, M., Loveridge, A.J., Chamaillé-Jammes, S., Davidson, Z.,Murindagomo, F., Fritz, H. \& Macdonald, D.W. (2009) Behavioral adjustments of African herbivores to predation risk by lions: Spatiotemporal variations influence habitat use. Ecology, 90, 23-30.

Watson, D.N. \& Dawson, T.J. (1993) The Effects of age, sex, reproductive status and temporal factors on the time-use of free-ranging red kangaroos (Macropus rufus) in western New South Wales. Wildlife Research, 20, 785-801.

Wilmshurst, J.F., Fryxell, J.M. \& Colucci, P.E. (1999) What Constrains daily intake in Thomson's gazelles? Ecology, 80, 2338-2347.

Wood, S.N. (2006) Generalized additive models: An introduction with R. Chapman and Hall/CRC Press, Boca Raton, FL.

Yom-Tov, Y. (1986) Climatological correlates for body size of five species of Australian mammals. Biological Journal of the Linnean Society,29, 245-262. 


\section{Figure Legends}

Figure 1: Variation across months in (a) the proportions of observations recorded in woodland, woodland edge and open habitats, (b) the proportions of observations in poor, medium, and rich patches, (c) mean patch greenness, (d) mean patch biomass, (e) mean group size, (f) mean distance to cover, (g) mean grass height, and (h) the proportions of identified females having NPY, SPY, MPY, LPY or a YAF.

Figure 2: Seasonal variation in vigilance and feeding rates. Observed seasonal variation in the proportions of time spent in vigilance (a) and in feeding rates (b) of female kangaroos (means \pm $\mathrm{SE}$ ) and modelled deviations from average proportion of time spent in vigilance (c) and feeding rate (d) derived from the GAMM procedure (mean with its 95\% confidence interval are solid and dashed lines respectively). In (e), modelled deviation of the effect of group size on the average proportion of time spent in vigilance, controlling for seasonal variation, derived from the GAMM procedure. In (f), estimates of feeding rates ( \pm SE) in the different habitats derived from the GAMM procedure with the level "open" in the parameter habitat used as the reference and set to 0 .

Figure 3: Variation in group size and habitat type with patch quality. Monthly variation in mean group size with (a) mean biomass and (b) mean greenness of the foraging patches (the dashed line indicates a significant trend). Monthly differences in (c) mean biomass, (d) mean greenness, and (e) mean group size between habitat types (see results for statistical details).

Figure 4: Pathways by which season affected the trade-off between vigilance time and feeding rate. Signs near arrows indicate the strength of the relationship and are extracted from our results (Fig. 1, 2, 3). The negative sign between feeding rate and time spent in vigilance was reported in Favreau et al. in press). 
Figures and tables

Figure 1.
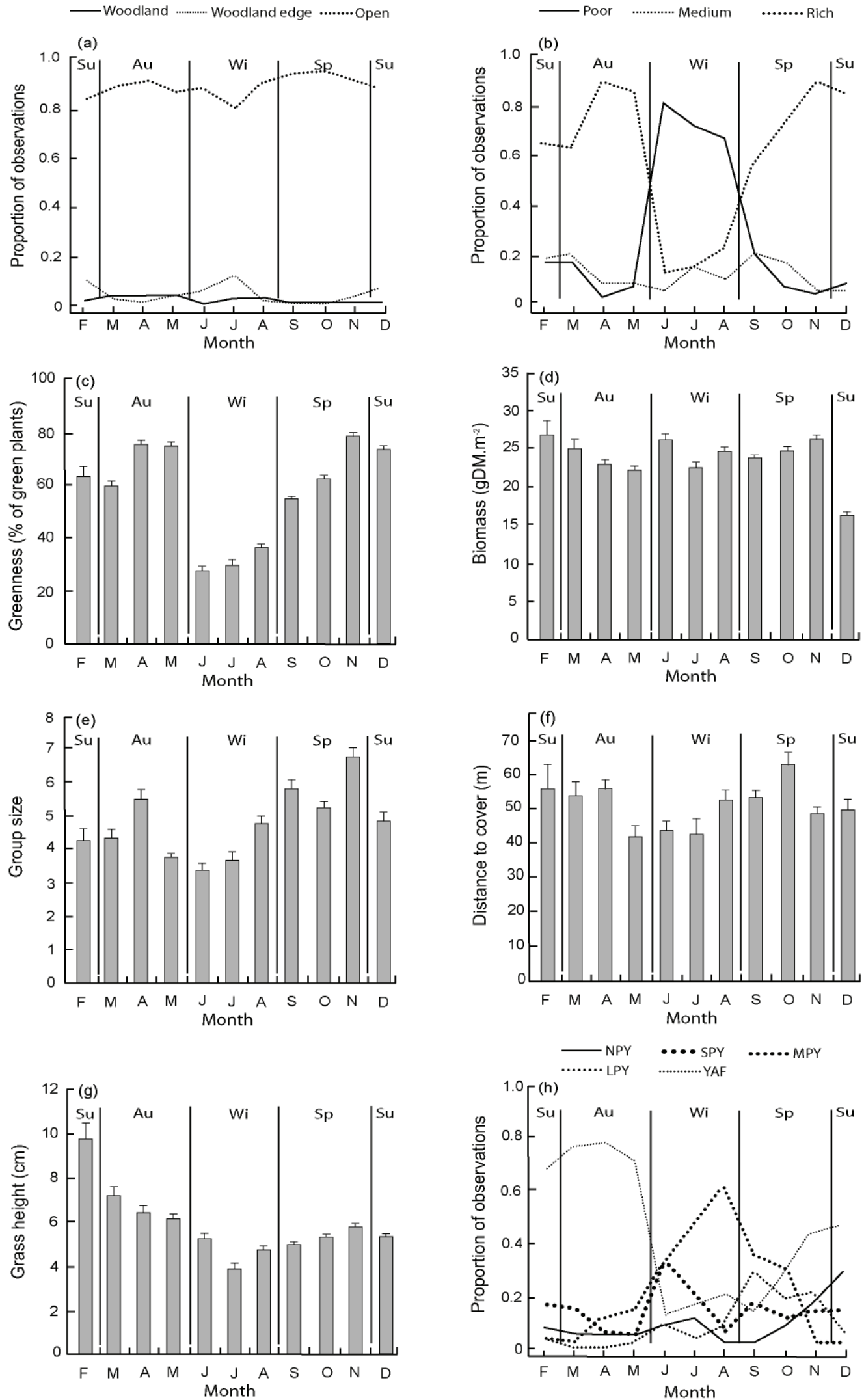
Figure 2.
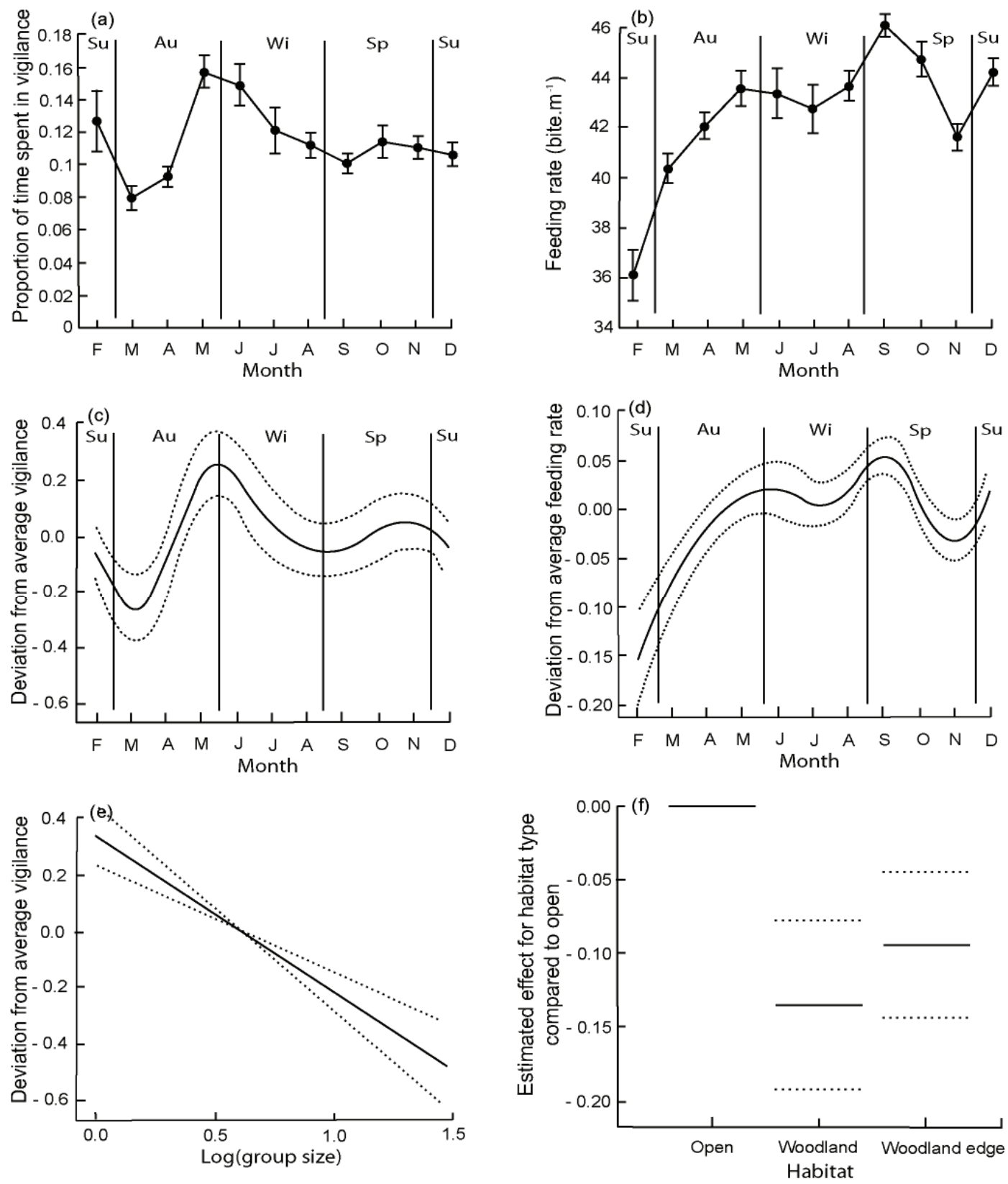
Figure 3.
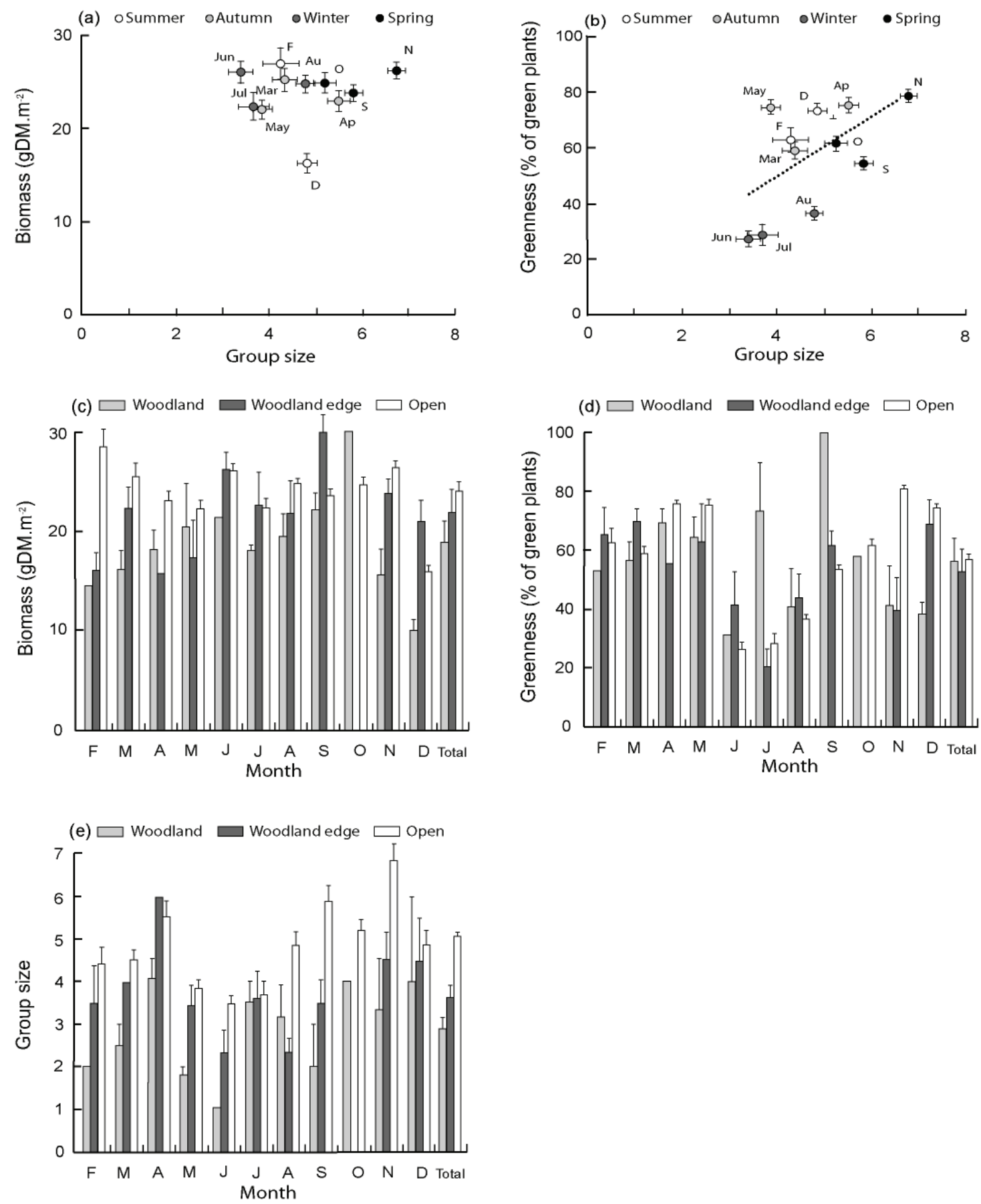
Figure 4.

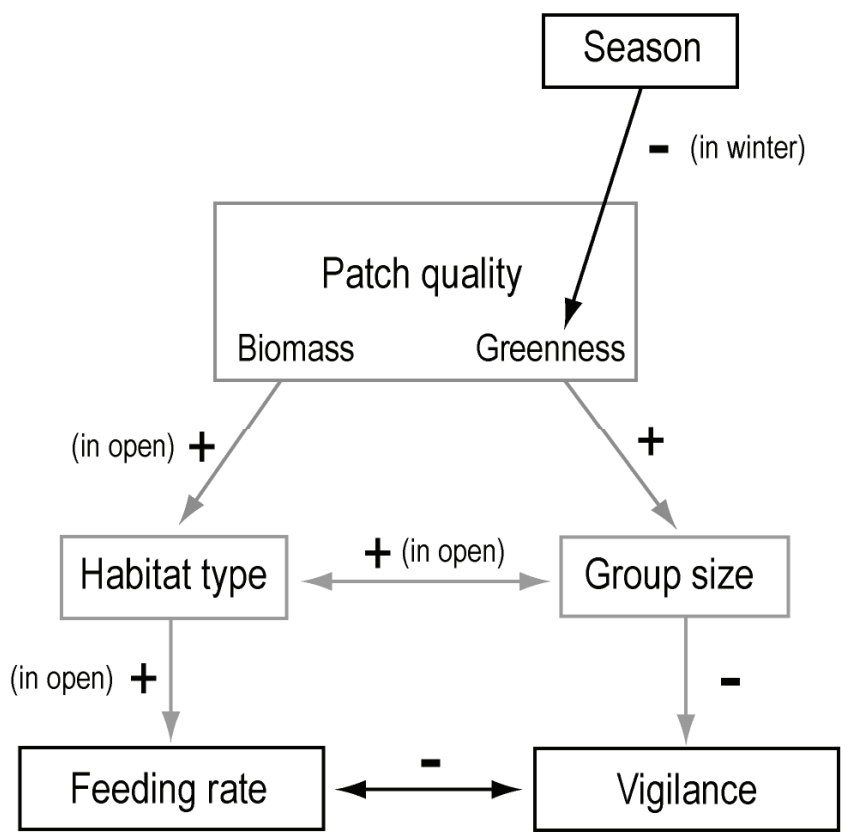


Table 1. Details on the distribution of sampling effort during our study across months and seasons

\begin{tabular}{lccc}
\hline Month & Season & $\begin{array}{c}\text { Number of focal } \\
\text { females observed }\end{array}$ & $\begin{array}{c}\text { Mean number of samples per } \\
\text { focal female }( \pm \text { SE) }\end{array}$ \\
\hline February 2011 & Summer & 34 & $4.50 \pm 0.12$ \\
March 2011 & Autumn & 32 & $2.67 \pm 0.09$ \\
April 2011 & & 34 & $4.15 \pm 0.19$ \\
May 2011 & Winter & 26 & $3.56 \pm 0.09$ \\
June 2011 & & 33 & $1.15 \pm 0.16$ \\
July 2011 & 34 & $2.23 \pm 0.11$ \\
August 2011 & & 34 & $3.35 \pm 0.05$ \\
September 2011 & Spring & 32 & $3.44 \pm 0.07$ \\
October 2011 & & 24 & $1.62 \pm 0.21$ \\
November 2011 & & 33 & $4.23 \pm 0.13$ \\
December 2011 & Summer & & $4.23 \pm 0.13$ \\
\hline
\end{tabular}

Table 2. Table of patch quality indices for short grass grazers in relation to patch biomass and greenness.

\begin{tabular}{|c|c|c|c|c|c|c|c|}
\hline \multirow{2}{*}{$\begin{array}{l}\text { Biomass } \\
\text { (g.m-2) }\end{array}$} & \multicolumn{7}{|c|}{ Percentage of green grass } \\
\hline & $0-40 \%$ & $>40-50 \%$ & $>50-60 \%$ & $>60-70 \%$ & $>70-80 \%$ & $>80-90 \%$ & $>90-100 \%$ \\
\hline $0-5$ & poor & poor & med & med & med & med & med \\
\hline$>5-10$ & poor & poor & med & rich & rich & rich & rich \\
\hline$>10-15$ & poor & med & med & rich & rich & rich & rich \\
\hline$>15-20$ & poor & med & rich & rich & rich & rich & rich \\
\hline$>20-25$ & poor & med & rich & rich & rich & rich & rich \\
\hline$>25-30$ & poor & med & rich & rich & rich & rich & rich \\
\hline$>30-35$ & poor & med & rich & rich & rich & rich & rich \\
\hline$>35-40$ & poor & med & med & rich & rich & rich & rich \\
\hline$>40-45$ & poor & poor & med & rich & rich & rich & rich \\
\hline$>45-50$ & poor & poor & poor & med & med & rich & rich \\
\hline$>50-55$ & poor & poor & poor & med & med & med & med \\
\hline$>55-60$ & poor & poor & poor & med & med & med & med \\
\hline
\end{tabular}

"Poor" means poor patch quality; "med" means medium patch quality and "rich" means rich patch quality. Values for optimal patches are highlighted in grey. 


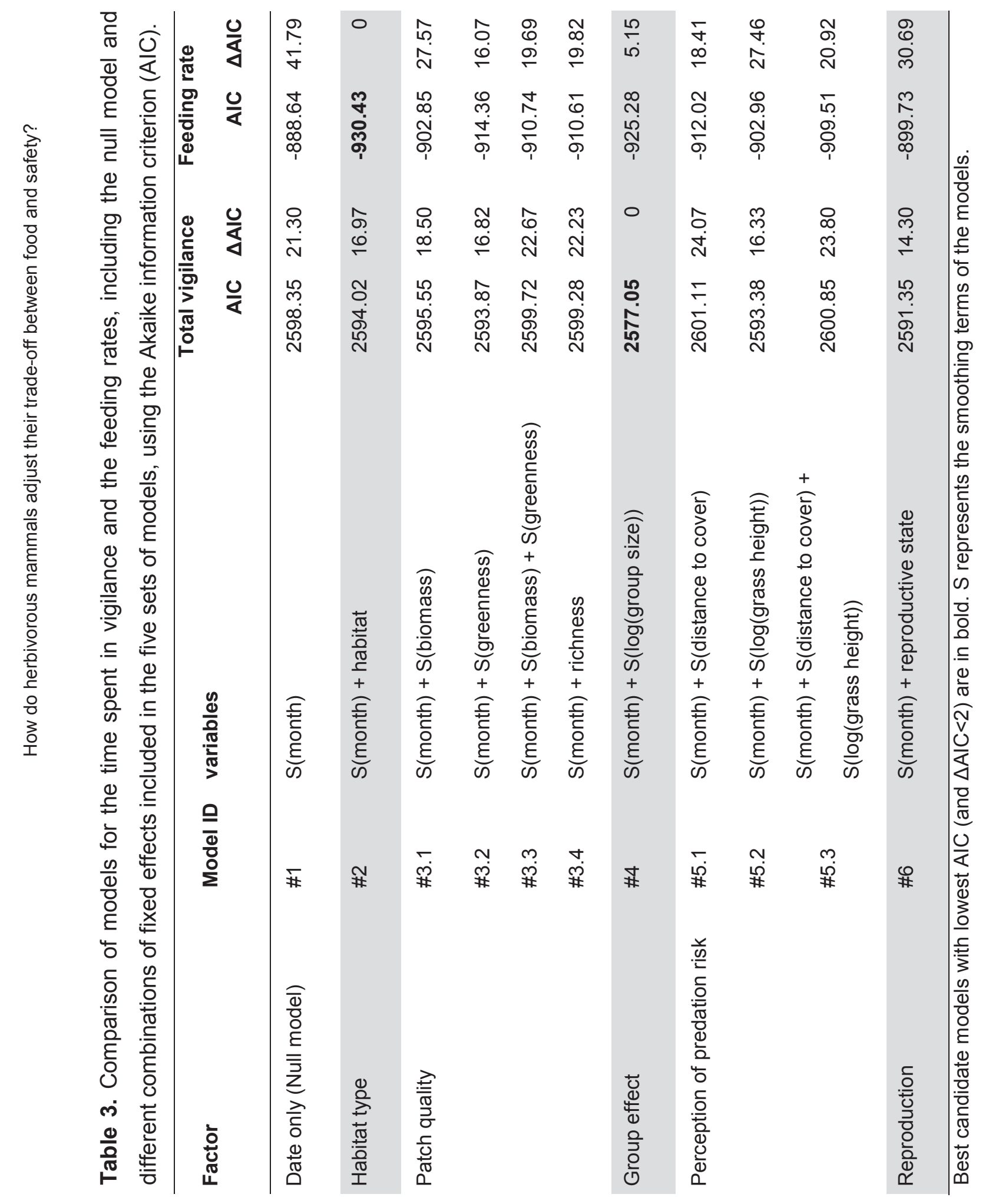


Table 4. Coefficients and P-values for the effect of group size (log-transformed) on vigilance time and the effect of habitat on feeding rates of female kangaroos. Coefficients are extracted for parametric terms only. See Fig. 2 for details on the smooth terms. Both models control for month.

\begin{tabular}{|c|c|c|c|c|c|}
\hline \multirow{2}{*}{ ID Model } & \multirow[t]{2}{*}{ Variables } & \multirow{2}{*}{$\begin{array}{r}\text { Model terms } \\
\text { Parametric coefficients }\end{array}$} & \multicolumn{3}{|c|}{ Model statistics } \\
\hline & & & Coef & SE & $P$ \\
\hline \multirow{4}{*}{ \#4 } & \multirow{4}{*}{ Vigilance time } & Intercept & 4.183 & 0.038 & $<0.001$ \\
\hline & & Smooth terms & est. Df & $F$ & $P$ \\
\hline & & Month & $S(5.41)$ & 4.367 & $<0.001$ \\
\hline & & Log(Group size) & $S(1)$ & 43.651 & $<0.001$ \\
\hline \multirow{6}{*}{ \#2 } & \multirow{6}{*}{ Feeding rate } & Parametric coefficients & Coef & $S E$ & $P$ \\
\hline & & Intercept & 3.770 & 0.008 & $<0.001$ \\
\hline & & Habitat : Woodland & -0.132 & 0.028 & $<0.001$ \\
\hline & & Habitat: Woodland Edge & -0.091 & 0.024 & 0.0002 \\
\hline & & Smooth terms & est. $d f$ & $F$ & $P$ \\
\hline & & Month & $S(6.24)$ & 14.170 & $<0.001$ \\
\hline
\end{tabular}

$\overline{\log (G r o u p ~ s i z e)}$ and month were considered as continuous. Habitat was categorical with the category "open" as the reference. 


\section{Chapter 3:}

\section{Short-term behavioural responses of impalas in simulated antipredator and social contexts}

François-René Favreau, Olivier Pays, Anne W. Goldizen, Hervé Fritz.

\section{Abstract}

Prey animals often have to trade off foraging against vigilance. However, vigilance is costly and individuals are expected to adjust their vigilance and its cost in relation to social cues and their predation risk. To test this, we conducted playback experiments in the field to study how lions' (Panthera leo) roars and male impalas' (Aepyceros melampus) territorial vocalizations affected the vigilance and foraging behaviours as well as movements of female impalas. Our results show that impalas adjusted their activities in different ways depending on the vocalizations broadcast. After lions' roars were played, female impalas increased their vigilance activity (in particular increasing their high-cost vigilance - vigilance without chewing), decreased their bite rates and increased their movements, whereas male impalas' vocalizations caused females to decrease their vigilance (decreasing their low-cost vigilance - vigilance while chewing) and increase their movements without affecting their bite rates. Therefore, it appears that predators' vocalizations stimulate antipredator behaviours such as vigilance and movement at the expense of foraging, whereas males' vocalizations increase individuals' displacements at the expense of vigilance. Overall, this study shows that both predator and social cues have direct effects on the behaviour of gregarious prey and need to be considered in future studies.

Keywords: predator cues; social cues; vigilance; foraging; playback experiment; Aepyceros melampus. 


\section{Introduction}

Predators have profound effects on prey species, affecting their abundance, distribution (e.g., [1, 2]) and many aspects of their behaviour, such as the time spent in vigilance and foraging or movements either within or between foraging areas [3-5]. Prey animals living in groups also adjust their vigilance to the presence of other conspecifics $[6,7]$. Such social monitoring allows prey to assess predation risk from alerted companions [8], monitor competitors [9], gain information about food patches [10] or maintain group cohesion [11]. However, the relative proportions of vigilance time devoted to antipredator versus social vigilance vary among species, probably due to differences in species' vulnerabilities to predation and differences in their social behaviours. In addition, to satisfy their metabolic requirements, prey must also spend most of their active time searching for food [12], creating a trade-off between foraging and vigilance [13]. In the literature, the study of this trade-off has often only considered vigilance as an antipredatory behaviour, thus underestimating the part of this activity that is dedicated to monitoring conspecifics (e.g., [14, 15]). It is thus important to understand how social foragers, such as many herbivores, adjust their tradeoff between foraging and the use of vigilance for antipredator and social purposes.

The cost of vigilance can be reduced when animals are able to be vigilant while handling their food; for example, herbivores can devote a part of their chewing time between bites to vigilance activity and thus limit the reduction of their food intake [16-18]. The ability to be vigilant while chewing could be particularly advantageous to herbivores, as their short-term food intake is often limited by chewing and swallowing rates rather than by the rate of encountering food [19]. Recent studies have thus distinguished between vigilant bouts when the animal is standing alert without chewing its food (hereafter called "exclusive vigilance") and vigilant bouts when the animal is vigilant while chewing its food (hereafter called "vigilance while chewing") (e.g., [16], [17] ). Fortin et al. [16] showed that an increase in the biomass of food decreased herbivores' bite rates because animals took larger bites, which took longer to chew, allowing them to increase their time in vigilance while chewing. However, the immediate benefit of such vigilance/feeding multitasking could be reduced if the quality of predator detection is lower as a result of vigilance while chewing compared to exclusive vigilance [20]. If this was the case, prey would be predicted to use relatively more exclusive vigilance than vigilance while chewing for antipredator versus social vigilance; to date it remains unknown whether this is the case.

The vigilance responses of prey in relation to the risk of predation have often been investigated in relation to predator densities or by using proxies of perception of predation risk (e.g., [17, 21]); such studies have usually shown that foragers increased their vigilance activity when their perceptions of predation risk likely increased. The presence of predators has also been simulated experimentally by exposing prey to predators' vocalizations; even though most predators are silent while hunting, playbacks of their vocalizations have appeared to suggest the predator's 
presence in the surroundings to the prey and led to an increase in the vigilance activity of the prey (reviewed by [22]). Contrasting results have been reported on the effects of predator playbacks on movements of prey within a foraging patch. Caro et al. [23] reviewed the antipredator behaviour of 200 prey species and reported that while some species tend to freeze or remain motionless when a potential predator is detected, many others increase their movements to escape, bunch, inspect, or even to attack predators. Multiple methods have also been used to examine how prey animals adjust their vigilance to the presence of conspecifics. Studies have investigated the relationships between vigilance and distance to the nearest neighbor [24], and the number [25] and behaviours of other group members [26]. Moreover, as many species communicate using vocalizations, playbacks of social calls can be useful for investigating the effects of social events on vigilance and foraging activities. However, the effects of non-alarm social calls on the vigilance of conspecifics have only been demonstrated in a few species, including marmosets (Callithrix kuhlii) [27], meerkats (Suricata suricatta) [28] and topi antelopes (Damaliscus lunatus) [29]. In some ungulate species such as impala (Aepyceros melampus) and red deer (Cervus elaphus), males can be highly vocal when defending their territory or their harems during and prior to the breeding period (e.g., [30], [31]). In this context, McComb (1991) observed that the roars of male red deer, which were displayed during the breeding period when they gathered and defended harems, induced vigilance and attracted females. While conspecifics can clearly disturb foraging activity (e.g., through competition), the foraging costs associated with social vigilance remain largely unknown. The use of comparable playbacks of the calls of predators and of conspecifics provides a strong design for comparing the relative uses of exclusive vigilance and vigilance while chewing in antipredator versus social contexts.

We used playback experiments to investigate how lions' roars and impalas' social vocalizations affect different aspects of female impalas' behaviour. We quantified vigilance (including the separate use of exclusive vigilance and vigilance while chewing), bite rates and step rates of females before and after carrying out playbacks of lions' roars, male impalas' territorial vocalizations and the sounds of common birds of the area as a control. We chose to use playbacks of non-threatening common birds of the area as controls instead white noise at the same intensity as that of the lion and impala playbacks because we wanted the control trials test for responses to the presence of the observers and playback equipment, but without causing significant additional perturbations for the animals. To mimic the natural levels of the particular sounds used, the control playbacks were played at lower intensities compared to the ones of lions and male impalas. If impalas reacted to all three playback types indiscriminately, their postplayback behaviour would be indistinguishable. If they reacted to the volume only, their responses would be greater to the playbacks of lions and impalas but without any difference between those. Finally, if they reacted to the particular calls, they would be expected to respond weakly or not at all to the control playbacks, and to respond to both the lions' and impalas' playbacks but in different ways. 
We predicted that female impalas would react to the particular playbacks played and would increase their time spent in vigilance after both the lion and impala playbacks but with a much stronger response after lions' roars. Indeed, we predicted that they would show an increase in vigilance after lions' roars mainly due to exclusive vigilance as individuals are expected to focus on their survival under such an immediate threat and thus to use the most effective form of vigilance. In addition, after males' vocalizations, female should also increase their vigilance to gather information about the behaviours of conspecifics. However, we predicted that this increase in vigilance would be mainly due to an increase in vigilance while chewing as those vocalizations are not associated with actual danger. We also predicted that after hearing both types of vocalizations, but especially lions' vocalizations, individuals would reduce their bite rates as a consequence of their higher investment in vigilance. Finally, we expected females to increase their movements (measured as step rates) after being exposed to both lion and impala vocalizations as these reactions have been previously reported in other ungulate species.

\section{Materials and methods}

\section{- Study Site, Study Species and Population}

The experiment was conducted around the Main Camp area in Hwange National Park (HNP) $\left(19^{\circ} 00^{\prime} \mathrm{S}, 26^{\circ} 30^{\prime} \mathrm{E}\right)$ on the north-west border of Zimbabwe. The study site is composed of an open grassland area of 64 ha surrounded by bushes (Acacia/Combretum). Data were collected from the beginning of March to the end of April 2012 during the end of the wet season, which occurs from the end of October to the end of April, and prior to the rutting period, which lasts from the beginning of May until mid-June [32, 33]. During this period, impala females occurred in fairly large but regularly changing herds that moved through the territories of dominant males, which consequently spent much energy defending their territories and trying to keep herds within their boundaries [34, 35]. Territoriality was observed prior to the rutting period from February [36]. Territorial males displayed many territorial behaviors; they advertised their presence using static postures, defecating and urinating in dung patches, depositing smelly secretions to mark the area, and using loud territorial vocalizations [37]. Territorial vocalizations are composed of snorts and roars. They are used in various situations, such as indicating to potential rivals the holding of a territory, but also during agonistic interactions against other males or during the chasing of subadult males out of the herd and the chasing of females trying to escape from the male's territory [30, 3234].Female impalas from this area spent on average $14 \%$ of their time in vigilance in a previous study, with $81 \%$ of this in vigilance while chewing; this time allocation was resource-dependent (i.e. varied with grass height) [17]. Impalas are characterized as mixed-feeders, as they alternate between grazing in the wet season and browsing in the dry season because of changes in food quality [38]. During this study (end of the wet season) impalas were mostly grazers. Pays et al. 
[17] reported that the grass biomass available to the impalas on the study area during this season in 2009 varied between 20 and $150 \mathrm{~g} / \mathrm{m}^{2}$. An increase in food biomass within this range of values leads to an increase in intake in selective herbivores of similar body sizes (sheep, Ovis aries, [19]; Thomson's gazelles, Gazella thomsoni [39]). Impalas' bite rates have only been described for limited measures of biomass (or sward height) by Okello et al. [40] but are comparable to those exhibited by Thomson's gazelles [39].

We observed 50 to 100 females daily at the study site, mainly foraging (mostly grazing) in the open field. All female impalas in the study area formed a single clan that was divided into a variable number of herds with marked fusion-fission dynamics; this was known because about 30 adult females were ear-tagged. Although our study was conducted during the two months immediately prior to the rutting period, we observed the territorial male every day, usually with the biggest group of females. The female herds were composed of a majority of females but also included juveniles. We did not observe young males in the herds and supposed that they had already been evicted by the territorial male. The dominant male was occasionally observed or heard displaying territorial behaviours and chasing escaping females. In the Main Camp area, impalas have multiple predators, including lions, spotted hyenas (Crocuta crocuta), leopards (Panthera pardus), cheetahs (Acinonyx jubatus) and African wild dogs (Lycaon pictus).

\section{- Ethics Statement}

Our experiments complied with the current laws of Zimbabwe. They were conducted under permits from the Director General of the Zimbabwe Parks and Wildlife Management Authority and approved by the Native and Exotic Wildlife and Marine Animals Ethics Committee of the University of Queensland (AEC Approval Number: SBS/358/11/HERD). While we wanted a suitable number of observations to achieve robust results, we limited the number of playbacks as much as possible to minimize their impacts on the impala population and on other mammals that were in the area. In savanna ecosystems, it is known that such playbacks can attract resident lions [41], although we never experienced this situation during our experiment.

\section{- Playback Stimuli}

We observed the effects of playbacks of lions' and of male impalas' vocalizations on foraging females. Even though lions are quiet while hunting, we felt that playbacks of lions' roars would simulate their presence in the vicinity, as lions of both sexes usually roar to signal territory occupancy or to contact pride members [42]. To test the reactions of impalas to social stimuli, we exposed females to male impalas' territorial vocalizations, which were composed of snorts and roars as described above. In addition, to control for possible perturbations from the presence of the equipment or the experimental design, we played familiar and non threatening songs of birds as control stimuli. These types of controls are often used in playback experiments (e.g., [43, 44]). We used songs of the red-eyed dove (Streptopelia semitorquata) and the piping cisticola (Cisticola 
fulvicapilla). We checked that there were no differences between the pre- and post-playback phases in the behaviour of impalas to these control playbacks, to determine the robustness of our neutral context control.

To avoid problems of pseudoreplication, we used three different exemplars of each stimulus that were chosen randomly for each trial. Recordings used included our own local recordings and recordings from different commercial sound archives from South Africa and Zimbabwe. Both lions' roars and male impalas' roars can vary in duration; lions' roars have been measured to last from 17 to $90 \mathrm{~s}$ according to Stander and Stander [45]. At our field site, roars by male impalas in the presence of females (mostly chasing females or subadult males) never exceeded one minute and mostly lasted around $20 \mathrm{~s}$ (H.F. and O.P. Pers. Obs.). We chose to standardize our playbacks to a plausible duration, but to make them not too long to minimize disturbance and habituation. Therefore, to have comparable stimuli, we selected and edited 15 seconds of each recording for each type of playback using the software program Audacity 1.2.6. All the playbacks were then transferred to an iPod Classic (Apple Inc., Cupertino, California) in the AAC format and played through a powered portable speaker (Megavox pro 6000, Anchor, Carlsbad, California). All playbacks were calibrated by ear at levels perceived by the experimenters as 'natural' for each source species in order to be perceived as realistic by the animals; this method has been used in several playback experiments done in the field (e.g., [46, 47]). The sound levels of the playbacks of the lions' roars and impalas' territorial vocalizations were quite similar, while the control playbacks had lower intensities.

\section{- Experimental Protocol}

To minimize possible habituation of the animals, we used a random rotation every three days, including two days with playbacks and one day without. We also limited the number of playbacks to two per day: one control stimulus and either one lion's roar or one impala's call. The control playback sequence was always played first, as we assumed that the control playbacks would not (or would only weakly) affect the animals' behaviour. We left about 30 minutes between the end of the control trial and the beginning of the next one. In addition, for each day of playbacks, the type of sound (lion or impala) played after the control and the versions of the sounds were chosen randomly. A previous study reported that different species of ungulates, including impalas, returned to their baseline behaviour within a few seconds to a minute after being exposed to baboons' alarm and contest calls [48]. Therefore, thirty minutes would have been more than sufficient time for the animals to return to normal activity if they had been disturbed by the playbacks of bird songs. To make the behavioural context as realistic as possible, all the observations were made in the late afternoon (17:00 to 19:00), when it is common to hear lions roaring and males displaying territorial vocalizations. However, playbacks were only broadcast if we had not heard either a lion roaring or a male vocalizing on the study site during the 60 minutes preceding the trials. We used one car hidden behind trees or bushes and parked approximately 
100 meters from the focal group to play the sounds, and a second car that was not hidden to film the animals from a distance of 50 to 100 meters. The impalas were habituated to cars in this area as studies had been carried out there for many years, and our presence did not seem to affect their behaviour. In order to improve our sample size and reduce the animals' habituation, two or three observers filmed different focal animals during each trial (video cameras: Sony DCR-SR30, 20x optical zoom; and Sony DCR-HC51E, 40x optical zoom, Sony Corporation, Tokyo, Japan); we dealt with the possible pseudoreplication this may have caused by including the group identity in the analysis. We waited for all group members to be relaxed (defined as the females feeding, grooming or looking around while chewing, and the males not chasing females or making noise), each observer focused on a focal foraging female and then we started the trial. Several individuals were filmed during the same session on some days and not all sampled individuals were marked; however, we took care to avoid filming the same individual twice during the same afternoon. We cannot be sure that we did not film the same individuals on different days. However, as there were over 100 different individuals using the study area we believe that there will have been little pseudo-replication and this would not have affected our results.

We started each trial by filming the animals for 3 minutes before playing the sound (preplayback period) and continued filming during the 15 seconds playbacks and for another 3 minutes immediately after the playbacks (3minutes post-playback period). For the analyses, we retained only the behavioural sequences of females in groups whose sizes and compositions did not vary during the trials. We defined group size using a maximal distance of 50 meters between adjacent individuals and on the basis of the maintenance of social and spatial cohesion of group members during the observation (as in [17] on the same species). The different observers took care not to film the same animal and to switch to another focal animal for the second trial when two sounds were played on the same day. To do so, the observers filmed the impalas in one part of the group during the first trial and then in a different part during the second trial. The observers waited at least 30 minutes before starting a second trial; during these 30 minutes they were watching the group to see if it was moving. On the rare occasions when the group had moved, the observers changed to another group of individuals to perform the second trial.

For each observation, the observers recorded the date, group size and distance to cover (i.e. distance between the focal female and the closest bushes that would have hidden animals of the size of the impalas or their predators: 0-25, 26-50, 51-100, 101-200, more than $200 \mathrm{~m}$ ). The observers also recorded grass height using three categories: short grass (below impala's hooves), medium grass (below the upper part of the metacarpals), and tall grass (when grass height reached the tibia). Trials were not conducted when wind speeds were high, and we positioned the speaker up wind in order to send a clear signal to the animals.

An animal was considered vigilant when it raised its head above the horizontal, looking around without moving its feet. We also distinguished between two types of vigilance. We considered an animal to exhibit vigilance while chewing when it raised its head while chewing and 
exclusive vigilance when it raised its head without chewing. If an animal engaged in both types of vigilance during the same bout, we measured the times allocated to each activity separately. Bites were easily observable and counted through repetitive movements of the head, and steps were counted as forward movements of the left front leg.

We sampled the responses of 31 females to playbacks of lions' roars, 35 females to playbacks of male impalas' calls and 45 females to the control stimuli during 15,15 and 31 playbacks, respectively. These playbacks were done during 29 observation sessions.

\section{- Data Analyses}

To study the responses of the focal female impala to the different stimuli, we extracted from the video sequences the proportions of time spent by females in all vigilance, and in exclusive vigilance and vigilance while chewing separately, during the pre- and the post-playback periods. We also quantified the numbers of bites taken per minute (bite rate), and the numbers of steps per minute (step rate) performed by the focal animals during both periods.

To test the effects of the different stimuli on the vigilance, foraging and movements of female impalas, we used linear mixed-effects models for paired samples with (1) the total proportion of time spent in vigilance, (2) the bite rate, and (3) the step rate as the dependent variables and the time periods (pre-playback and post-playback), the types of playback played (Control, Lion and Impala) and their two-way interactions, as independent variables, and individual identity (to pair the samples) within group identity as two nested random factors. The group identity variable controlled for the pseudoreplication caused by studying multiple focal females in the same group at the same time. We also included date to control for possible habituation, group size, distance to cover and grass height in the models as control factors as they might have influenced impalas' behaviour. To achieve homoscedasticity and normality, the proportions of time spent in vigilance were arcsinesquare-root transformed and the numbers of steps per minute were log-transformed.

We further investigated the effect of the different stimuli on exclusive vigilance and vigilance while chewing separately in order to determine whether the females' short-term responses to the playbacks involved different levels of use of these two types of vigilance. Due to statistical constraints (in particular to fulfill normality of the response variables), we could not examine the proportion of time an impala spent in each type of vigilance (as it was used for the total time spent in vigilance). To test the effects of the stimuli on the vigilance while chewing, we used the logtransformed time that a female impala spent in vigilance while chewing allowing us to use linear mixed-effects models with the procedure as described above. As many females did not exhibit exclusive vigilance, we had many zeros in the data set (for both pre- and post-playback periods) and the log-transformation failed to work. We thus used zero-inflated Poisson mixed-effect models (on non-transformed data) that dealt with the zero-inflated Poisson distribution of the time spent in exclusive vigilance. Here we compared a mixed-effects model including the total time spent in exclusive vigilance as the dependent variable and the time periods and the types of playback 
played as independent variables, including group identity as random factors and the same model including the interaction between the time period and the type of playback played using a loglikelihood ratio test. When an interaction between two variables significantly affected the response variable, we performed a post-hoc test including the Holm correction to counteract the problem of multiple comparisons.

The statistical analyses were performed with R 2.13.1 (R Development Core Team 2011).

\section{Results}

\section{- General Behavioural Responses to the Playbacks}

Overall, we found significant effects of the interactions between the playbacks and the time periods on the total vigilance, vigilance while chewing, exclusive vigilance, bite rates and step rates of female impalas, indicating different behavioural responses before and after the stimuli in relation to the playbacks played (Table 1).

\section{- Behavioural Measures During the Pre-playback Period and Responses to the Control Stimuli.}

We found no differences among the three types of playback experiments in the proportions of time devoted to vigilance, the bite rates, the step rates, or times spent in exclusive vigilance and vigilance while chewing of female impalas during the pre-playback period (Table 2, 3). On average, the females spent ( \pm SE) $9 \pm 0.01 \%$ of their time during these pre-playback observations in vigilance (including $7 \pm 0.01 \%$ in vigilance while chewing and $2 \pm 0.01 \%$ in exclusive vigilance), took $50.93 \pm 1.82$ bites per minute and performed $3.43 \pm 0.46$ steps per minute (Figure 1,2 ). Female impalas did not respond to the control playbacks by changing their proportions of time spent vigilant, their bite or step rates, or their exclusive vigilance and vigilance while chewing, between the pre and post-playback periods (Table 4, 5; Figure 1, 2).

\section{- Effects of Lion and Impala Playbacks on Vigilance}

Female impalas significantly modified their proportions of time spent in vigilance after being exposed to playbacks of both lions' and impalas' vocalizations. In the three minutes following the playbacks of lions' calls, the impalas' proportion of time vigilant was significantly greater than in the pre-playback period, although post-playback vigilance time after lion and control playbacks did not differ significantly $(P=0.120)$ (Tables 2 and 4 , Figure $1 \mathrm{~A})$. After being exposed to males' vocalizations, female impalas significantly decreased their vigilance in comparison with both their responses to the control playbacks during the post-playback period and their level of vigilance during the pre-playback period (Tables 2, and 4, Figure 1A). Group identity did not have a 
significant effect in any of the analyses (Table S1). The results of the effects of the other factors that we controlled for are presented in the Supporting Information (Table S1).

When analyzing in detail the types of vigilance affected by the stimuli, differentiating between exclusive vigilance and vigilance while chewing, we found that after being exposed to lion playbacks, females significantly increased their exclusive vigilance but did not change their level of vigilance while chewing compared to the pre-playback period and to the control playback during the post-playback period (Tables 3 and 5, Figure 2). Also, when exposed to males' territorial vocalizations, females significantly decreased their vigilance while chewing but did not change their level of exclusive vigilance compared to either the pre-playback period or the control playback during the post-playback period (Table 3 and 5, Figure 2). The results of the effects of the other factors that we controlled for in the analyses of vigilance while chewing are presented in the Supporting Information (Table S2).

\section{- Effects of Lion and Impala Playbacks on Bite Rates}

Females significantly decreased their bite rates after the lion stimuli compared to the preplayback period from on average 51 to 40 bites per minutes. During the post-playback period they showed significantly lower bite rates after lions' roars than after males' vocalizations, and nearly significantly lower bite rates compared to the control stimuli $(P=0.065)$. In contrast, there was no effect of playbacks of males' vocalizations on the bite rates of females compared to their bite rates before the playbacks or to those of females exposed to control playbacks (Tables 2 and 4, Figure $1 \mathrm{~B})$. The results of the effects of the factors controlled for are presented in the Supporting Information (Table S3).

\section{- Effects of Lion and Impala Playbacks on Step Rates}

After being exposed to both lion and impala playbacks, female impalas significantly increased their step rates compared to females exposed to control stimuli. However, we found no differences between the step rates of females exposed to lions' roars and females exposed to male impalas' calls. Females increased their step rates from 3.43 to 5.46 steps per minutes on average (an increase of 59\%) in response to these treatments (Tables 2 and 4, Figure 1C). The results of the effects of the factors controlled for are presented in the Supporting Information (Table S4).

\section{- Testing for Effects of Habituation}

While testing for the effects of playbacks, we did not detect any effect of the date of the experiment on either total vigilance $(P=0.19)$, exclusive vigilance $(P=0.22)$, vigilance while chewing ( $P=0.16)$, bite rates $(P=0.15)$ or step rates $(P=0.62)$. Therefore there was no effect of habituation in our experiments. 


\section{Discussion}

The results of this study showed that female impalas did not modify any of the measured aspects of their behaviour after hearing the control playbacks, showing that we controlled for potential biases due to the experimental procedures. Also, the females responded differently in terms of both their vigilance and their foraging behaviour to the playbacks of lions' vocalizations compared with those of male impalas, supporting the hypothesis that they were responding to these particular sounds, rather than just their noise levels. These results show that the female impalas did not react more to the playbacks of lions and impalas than to the control playbacks only because they were louder (loud noise hypothesis, [46]). Because of time constraints and to limit the number of playbacks heard by the impalas (see ethical statement), we did not use a loud noise as a second control; however, given the results we obtained, this form of control was not necessary. In addition, to have comparable playbacks and responses, we only selected and used 15 seconds of each recording. This could be argued to be unrealistic in the case of lions' roars, which can last between 17 and 90 seconds (reviewed by [45]). However, considering the strong responses of female impalas to our playbacks of lions, the duration of playbacks used during this experiment seems to have been enough to realistically mimic lions' presence in the vicinity. We strongly believe that our experiments provided solid data for studying the effects of the lions' and impalas' vocalizations on the behaviour of wild female impalas.

Our results revealed that both predators' and conspecifics' vocalizations altered the behaviours of social prey species but in different ways. The response of female impalas to playbacks of lions' roars, in terms of their movements, vigilance and foraging activities, were as predicted. However, their responses to playbacks of males' vocalizations were strong and not what we had predicted, with animals increasing their movements at the expense of vigilance. These responses highlight the importance of social context to individuals' behaviours. Finally, we observed that a predator stimulus increased the use of exclusive vigilance while a social stimulus decreased the use of vigilance while chewing. Regardless of the type of stimulus, vigilance while chewing was the main type of vigilance exhibited, which is not surprising considering that herbivores need to optimize their energy intake by limiting the cost of vigilance.

As we expected, our experiment suggests that lions' roars strongly affect female impalas' behaviours. After being exposed to the playbacks, females increased their level of vigilance by $40 \%$, on average, with this increase mostly due to an increase in exclusive vigilance. An increase in the vigilance of prey in response to their predators' vocalizations has already been documented in many species of birds and mammals (reviewed by [22]). Similar results were found by Blanchard \& Fritz [20]; although they focused only on the first vigilant bout of impalas in response to playbacks of lions' roars, they found that alarmed impalas increased their use of exclusive vigilance (which they called "induced vigilance") compared to non-alarmed animals. Although exclusive vigilance may be more costly for an animal because it stops the ingestion process, it may 
provide animals with better quality information because chewing is noisy and may reduce the ability of prey to evaluate their predation risk. Thus exclusive vigilance would allow better hearing as well as the stabilization of animals' visual fields [20]. However, although the relative amount of exclusive vigilance increased, vigilance while chewing remained the major type of vigilance exhibited by females during the post-playback period. This result suggests that impala tend to moderate the foraging cost of vigilance by mainly using a "low-cost" posture of vigilance, even in risky situations. In addition to increasing their vigilance, female impalas increased their step rates by $59 \%$ during the post-playback period following lions' roars. We were not able to control for the positions of individuals (whether they were in the centre or on the edge of their groups) as impala groups were dynamic and their geometry changed frequently, and we did not record the directions of their movements. Nevertheless, we never observed females fleeing in response to the playbacks; they increased their step rates but stayed within their foraging patches. Other studies of ungulates' movements in predation contexts have suggested that prey may increase their step rates after hearing a predator's vocalization in order to move to the centre of the group, which is safer ("selfish herd effect" [49]), and bunch together and form denser groups to increase dilution and confusion effects and avoid becoming isolated targets $[5,50]$. We do not have the data to test these hypotheses; other studies are therefore needed to explore the directions and functions of impalas' movements in response to predators' vocalizations.

Finally, female impalas decreased their bite rates after lions' roars. A decrease in foraging effort under high predation risk has already been observed in many prey species (reviewed by [51]), and can be attributed in our case to the increases in both vigilance and step rates as these activities reduce the time available to take bites. A decrease in bite rates from 51 to 40 bites per minute would seem unlikely to have had nutritional consequences for the impalas. However, our playbacks were short (15 s) and played only once per day. As we know that a lion's roar can last up to $90 \mathrm{~s}$ and that a male may roar 38 to 46 times per night [48], multiple roars may cause meaningful foraging costs to impalas during their nocturnal feeding bouts, which represent between 33 and $42 \%$ of their total daily feeding time [52]. Contrary to our expectations, female impalas decreased their vigilance levels by $38 \%$ on average after being exposed to male impalas' territorial vocalizations. This result was unexpected; we had expected females to increase their vigilance to gather information about the males' behaviour and the social context. In addition, the few studies that have investigated non-alarm social calls of mammals have reported positive effects on vigilance (e.g. for phee calls of marmosets [27], close calls of meerkats [28] and sexual calls of red deer [31]). However, all of these studies only recorded vigilance activity in the first minute following the playbacks. In our study, the reduction in vigilance was mainly due to a decrease in vigilance while chewing, probably because, as prey, impalas have to maintain a certain level of exclusive vigilance. Although the female impalas spent less time vigilant, they did not increase their bite rates after the males' vocalizations, but rather increased their movements. We did not record the direction of females' movements, but Schenkel [30] reported that male 
impalas' territorial vocalizations sometimes attracted females but also induced them to bunch together. The decrease in their vigilance may thus have been a result of their increased movements. In addition, it is possible that the impalas' reaction to the playbacks of males' vocalizations was much shorter than their reaction in response to the lion stimuli, so that by the time the post-playback period began after the playbacks of males' vocalizations, the focal males had already stopped being vigilant and were moving to find good feeding positions again, explaining the measured reduction in vigilance. Finally, the males' vocalizations used in this experiment came from commercial sound archives and therefore did not belong to any males from the studied area. We therefore cannot exclude the possibility that females would have reacted in a different way to the calls of local males. Nevertheless this pattern is interesting and future studies should record the directions of females' movements, and compare the effects of vocalizations of local and foreign males.

This study investigated the effects of predator and social stimuli on the behavior of social foragers. Our results showed that female impalas reacted to both types of cues in very different ways. While their response to playbacks of predator vocalizations was as expected, the most interesting result concerned their reactions to playbacks of social calls. Males' territorial vocalizations strongly affected females' time investment in their main activities. Future studies are needed to gain a better understanding of the ways in which social factors influence vigilance activity in gregarious prey species, differentiating social from antipredator vigilance, and considering the costs of these two types of vigilance (i.e. exclusive vigilance and vigilance while chewing). Although we did not control for the directions in which animals moved in response to both stimuli, these results were highly significant and future studies need to investigate this phenomenon more precisely.

\section{Acknowledgments}

The Director General of the Zimbabwe Parks and Wildlife Management Authority is acknowledged for providing us the opportunity to carry out this research. We are particularly grateful to Dr. H. Madzikanda, Mr. A. Musakwa, Mr. G. Mtare and Mr Edwin Makuwe. We would also like to thank Martin Muzamba, Stéphanie Périquet, Eunice Chapanda, Nobuhle Ndlovu and Cynthia Mapendere for assistance in the field as well as the whole HERD team. 


\section{References}

1. Lima SL, Dill LM (1990) Behavioral decisions made under the risk of predation: a review and prospectus. Can J Zool 68: 619-640.

2. Valeix M, Loveridge AJ, Chamaillé-Jammes S, Davidson Z, Murindagomo F, et al. (2009) Behavioral adjustments of African herbivores to predation risk by lions: Spatiotemporal variations influence habitat use. Ecology 90: 23-30.

3. Fortin D, Bayer HL, Boyce HS, Smith DW, Duchesne T, et al. (2005) Wolves influence elk movements: behavior shapes a trophic cascade in Yellowstone National Park. Ecology 86: 1320-1330.

4. Périquet S, Valeix M, Loveridge AJ, Madzikanda H, Macdonald DW, et al. (2010) Individual vigilance of African herbivores while drinking: the role of immediate predation risk and context. Anim Behav 79: 665-671.

5. Lingle S (2001) Anti-predator strategies and grouping patterns in white-tailed deer and mule deer. Ethology 107: 295-314.

6. Childress LJ, Lung MA (2003) Predation risk, gender and the group size effect: does elk vigilance depend upon the behaviour of conspecifics? Anim Behav 66: 389-398.

7. Favreau F-R, Goldizen AW, Pays O (2010) Interactions among social monitoring, anti-predator vigilance and group size in eastern grey kangaroos. Proc R Soc B 277: 2089-2095.

8. FitzGibbon CD (1990) Mixed-species grouping in Thomson's and Grant's gazelles: the antipredator benefits. Anim Behav 40: 837-845.

9. Tchabovsky AV, Popov SV, Krasnov BR (2001) Intra and interspecific variation in vigilance and foraging of two gerbillid rodents, Rhombomys opimus and Psammomys obesus: the effect of social environment. Anim Behav 62: 965-972.

10. Valone TJ, Templeton JJ (2002) Public information for the assessment of quality: a widespread phenomenon. Philos Trans R Soc Lond B 357: 1549-1557.

11. Bekoff M (1996) Cognitive ethology, vigilance, information gathering, representation: Who might know what and why? Behav Process 35: 225-237.

12. Senft RL, Coughenour MB, Bailey DW, Ritten-house LR, Sala OE, et al. (1987) Large herbivore foraging and ecological hierarchies. BioScience 37: 789-799.

13. Fernandez-Juricic E, Erichsen JT, Kacelnik A (2004) Visual perception and social foraging in birds. Trends Ecol Evol 19: 25-31.

14. Roberts G (1996) Why individual vigilance declines as group size increases. Anim Behav 51: 1077-1086.

15. Brown JS (1999) Vigilance, patch use and habitat selection: Foraging under predation risk. Evol Ecol Res 1: 49-71. 
16. Fortin D, Boyce MS, Merrill EH, Fryxell JM (2004) Foraging costs of vigilance in large mammalian herbivores. Oikos 107: 172-180.

17. Pays O, Blanchard P, Valeix M, Chamaillé-Jammes S, Duncan P, et al. (2012) Detecting predators and locating competitors while foraging: an experimental study of a medium-sized herbivore in an African savanna. Oecologia 169: 419-430.

18. Illius AW, FitzGibbon CD (1994) Costs of vigilance in foraging ungulates. Anim Behav 47: 481484.

19. Spalinger DE, Hobbs NT (1992) Mechanisms of foraging in mammalian herbivores: new models of functional response. Am Nat 140: 325-348.

20. Blanchard P, Fritz H (2007) Induced or routine vigilance while foraging. Oikos 116: 1603-1608.

21. Hunter TB, Skinner JD (1998) Vigilance behaviour in African ungulates: the role of predation pressure. Behaviour 135: 195-211.

22. Blumstein DT, Cooley L, Winternitz J, Daniel JC (2008) Do yellow-bellied marmots respond to predator vocalizations? Behav Ecol Sociobiol 62: 457-468.

23. Caro TM, Graham CM, Stoner CJ, Vargas JK (2004) Adaptive significance of antipredator behaviour in artiodactyls. Anim Behav 67: 205-228.

24. Underwood R (1982) Vigilance behaviour in grazing African antelopes. Behaviour 79: 81-107.

25. Di Blanco Y, Hirsch BT (2006) Determinants of vigilance in the ring-tailed coati (Nasua nasua): the importance of the within-group spatial position. Behav Ecol Sociobiol 61: 173-182.

26. Pays O, Goulard M, Blomberg SP, Goldizen AW, Sirot E, et al. (2009) The effect of social facilitation on vigilance in the eastern gray kangaroo, Macropus giganteus. Behav Ecol 20: 469-477.

27. Smith A, Birnie AK, Lane KR, French JA (2009) Production and perception of sex differences in vocalizations of wied's black-tufted-ear marmosets (Callithrix kuhlii). Am J Primatol 71: 324332.

28. Townsend SW Allen C, Manser MB (2011) A simple test of vocal individual recognition in wild meerkats. Biol Lett 8: 179-182.

29. Bro - Jørgensen J, Pangle WM (2010) Male topi antelopes alarm snort deceptively to retain females for mating. Am Nat 176: 33-39.

30. Schenkel R (1966) On sociology and behaviour in impala (Aepyceros melampus linchenstein). Afr J Ecol 4: 99-114.

31. McComb KE (1991) Female choice for high roaring rates in red deer, Cervus elaphus. Anim Behav 41: 79-88.

32. Dasmann RF, Mossman AS (1962) Population studies of impala in southern Rhodesia. $J$ Mammal 43: 375-395.

33. Murray MG (1982) The rut of impala: Aspects of seasonal mating under tropical conditions. $Z$ Tierpsychol 59: 319-337. 
34. Leuthold W (1970) Observations on the social organization of impala (Aepyceros melampus). Z Tierpsychol 27: 693-721.

35. Jarman PV, Jarman MV (1973) Social behaviour, population structure and reproductive potential in impala. E Afr Wild J 11: 329-338.

36. Oliver CM (2005) The role of the ram in the impala (Aepyceros melampus) mating system. MSc Thesis, University of Pretoria, Pretoria.

37. Jarman MV (1979) Impala social behaviour: territory, hierarchy, mating, and the use of space. Z Tierpsychol 21: 1-92.

38. Hofmann RR (1989) Evolutionary steps of ecophysiological adaptation and diversification of ruminants: a comparative view of their digestive system. Oecologia 78: 443-457.

39. Wilmshurst JF, Fryxell JM, Colucci PE (1999) What constrains daily intake in Thomson's gazelles? Ecology 80: 2338-2347.

40. Okello MM, Wishitemi REL, Muhoro $F$ (2002) Forage intake rates and foraging efficiency of free-ranging zebra and impala. S Afr J Wildl Res 32: 93-100.

41. Grinnell J, Packer C, Pusey AE (1995) Cooperation in male lions: kinship, reciprocity or mutualism? Anim Behav 49: 95-105.

42. Grinnell J, McComb K (1995) Maternal grouping as a defense against infanticide by males: evidence from field playback experiments on African lions. Behav Ecol 7: 55-59.

43. Gil-da-Costa R, Palleroni A, Hauser MD, Touchton J, Kelley JP (2003) Rapid acquisition of an alarm response by a neotropical primate to a newly introduced avian predator. Proc $R$ Soc Lond B 270: 605-610.

44. Lea AJ, Barrera JP, Tom LM, Blumstein DT (2008) Heterospecific eavesdropping in a nonsocial species. Behav Ecol 19: 1041-1046.

45. Stander PE, Stander J (1988) Characteristics of lion roars in Etosha National Park. Madoqua 15: 315-318.

46. Durant SM (2000) Living with the enemy: avoidance of hyenas and lions by cheetahs in the Serengeti. Behav Ecol 11: 624-632.

47. Bousquet CAH, Sumpter DJT, Manser MB (2011) Moving calls: a vocal mechanism underlying quorum decisions in cohesive groups. Proc $R$ Soc B 278: 1482-1488.

48. Kitchen DM, Bregman TJ, Cheny DL, Nicholson JR, Seyfarth RM (2010) Comparing responses of four ungulate species to playbacks of baboon alarm calls. Anim Cogn 13: 861-870.

49. Hamilton WD (1971) Geometry for the selfish herd. J Theor Biol 31: 295-311.

50. Mooring MS, Fitzpatrick TA, Nishihira TT, Reisig DD (2004) Vigilance, predation risk, and the allee effect in desert bighorn sheep. J Wild Manag 68: 519-532.

51. Verdolin JL (2006) Meta-analysis of foraging and predation risk trade-offs in terrestrial systems. Behav Ecol Sociobiol 60: 457-464.

52. Jarman MV, Jarman PJ (1973) Daily activity of impala. E Afr Wildl J 11: 75-92. 


\section{Figure Legends}

Figure 1. Effects of playbacks on females' behaviour.

Mean $(A)$ proportions of time spent in vigilance $( \pm S E),(B)$ bite rates $( \pm S E)$ (numbers of bites per minute during foraging), and (C) step rates ( \pm SE) (numbers of steps per minute) of female impalas exposed to control stimuli, playbacks of lions' roars and male impalas' calls during pre- and postplayback periods. ${ }^{*},{ }^{* *}$ and ${ }^{* * *}$ indicate significance at the $p<0.05, p<0.01$ and $p<0.001$ levels, respectively.

Figure 2. Effects of playbacks on the use of exclusive vigilance and vigilance while chewing.

Mean proportions of time ( \pm SE) spent by female impalas in $(A)$ exclusive vigilance and (B) vigilance while chewing during the pre- and post-playback periods after their exposure to playbacks of control stimuli, lions' roars and male impalas' calls. ${ }^{*}{ }^{* *}$ and ${ }^{* * *}$ indicate significance at the $p<0.05, p<0.01$ and $p<0.001$ levels, respectively. 


\section{Figures and Tables}

Figure 1.
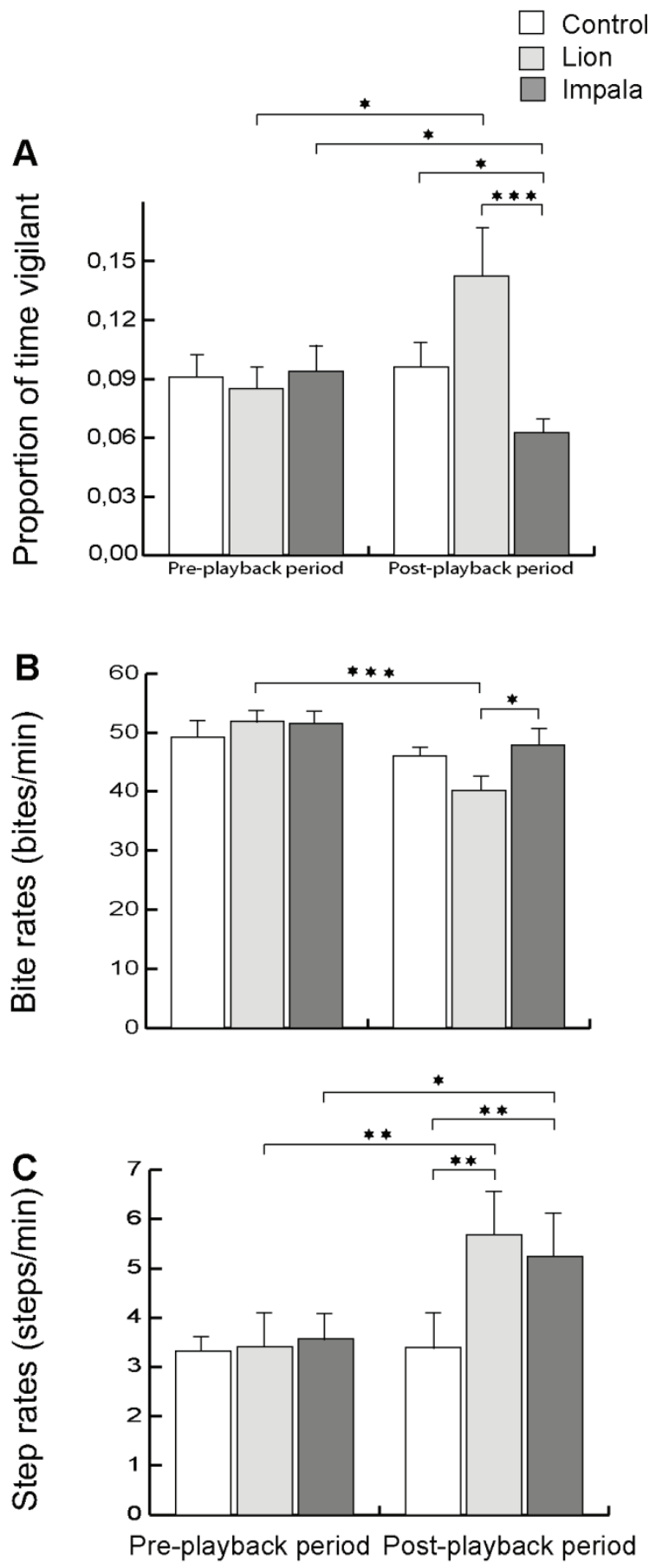
Figure 2.

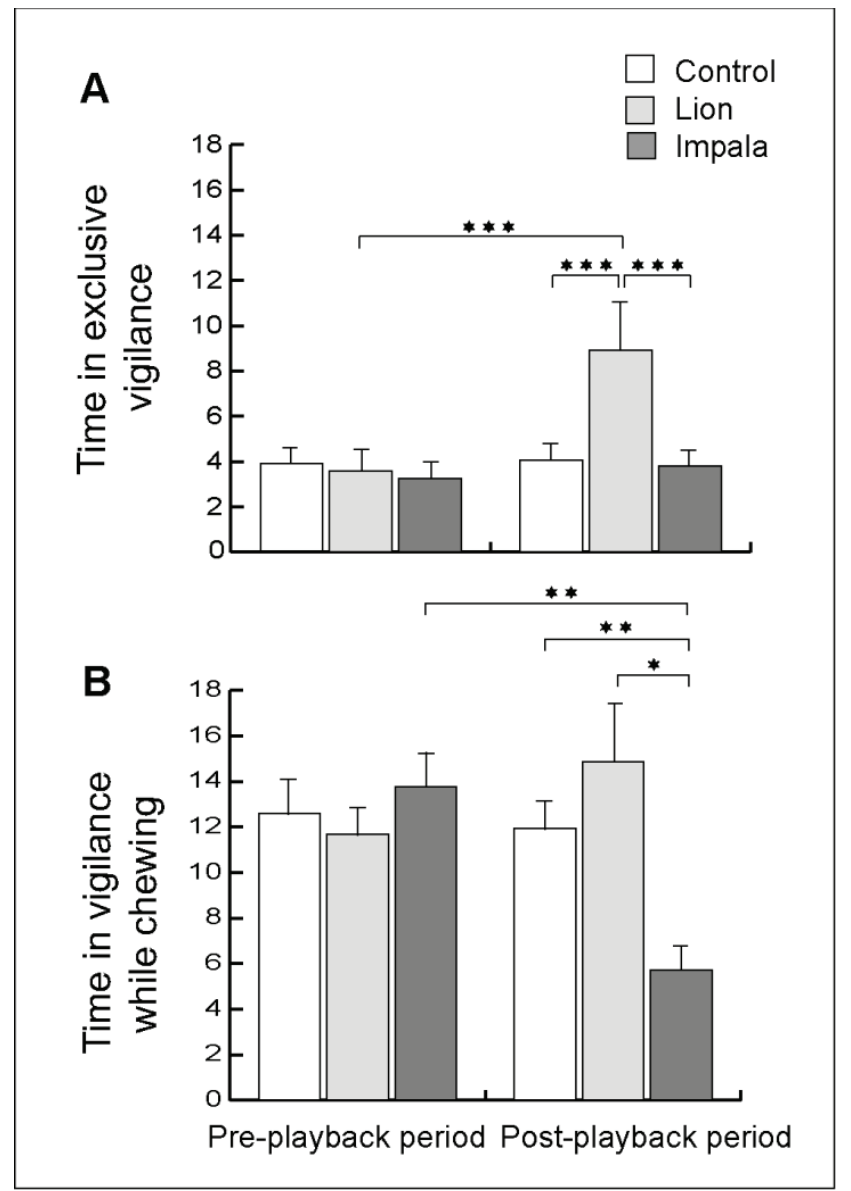


Table 1. Effects of time period, type of playback and their interaction on the proportion of time spent in vigilance, the bite rate, the step rate, the time spent in vigilance while chewing and the time spent in exclusive vigilance, controlling for the effects of date, group size, distance to cover, and grass height.

\begin{tabular}{|c|c|c|c|c|c|c|}
\hline Activity & Variables & numDF & denDF & F-value & $p$-value & Coeff \pm SE \\
\hline \multirow[t]{4}{*}{ Vigilance } & (Intercept) & 1 & 100 & 614.309 & $<0.001$ & $0.288 \pm 0.022$ \\
\hline & Time period & 1 & 100 & 0.028 & 0.867 & See Table 2 \\
\hline & Playback & 2 & 42 & 3.628 & 0.035 & See Table 2 \\
\hline & $\begin{array}{l}\text { Time period } \times \\
\text { Playback }\end{array}$ & 2 & 100 & 4.631 & 0.012 & See Table 2 \\
\hline \multirow[t]{4}{*}{ Bite rate } & (Intercept) & 1 & 92 & 2819.501 & $<0.001$ & $69.279 \pm 7.693$ \\
\hline & Time period & 1 & 92 & 14.795 & $<0.001$ & See Table 2 \\
\hline & Playback & 2 & 42 & 1.750 & 0.186 & See Table 2 \\
\hline & $\begin{array}{l}\text { Time period } \times \\
\text { Playback }\end{array}$ & 2 & 92 & 3.107 & 0.049 & See Table 2 \\
\hline \multirow[t]{4}{*}{ Step rate } & (Intercept) & 1 & 84 & 235.305 & $<0.001$ & $1.104 \pm 0.145$ \\
\hline & Time period & 1 & 84 & 4.194 & 0.044 & See Table 2 \\
\hline & Playback & 2 & 41 & 2.113 & 0.134 & See Table 2 \\
\hline & $\begin{array}{l}\text { Time period } x \\
\text { Playback }\end{array}$ & 2 & 84 & 6.560 & 0.002 & See Table 2 \\
\hline \multirow[t]{5}{*}{ Vigilance while chewing } & (Intercept) & 1 & 75 & 891.392 & $<.0001$ & $0.983 \pm 0.061$ \\
\hline & Time period & 1 & 75 & 1.7833 & 0.1858 & See Table 3 \\
\hline & Playback & 2 & 48 & 0.8319 & 0.4414 & See Table 3 \\
\hline & $\begin{array}{l}\text { Time period } \times \\
\text { Playback }\end{array}$ & 2 & 75 & 5.2121 & 0.0076 & See Table 3 \\
\hline & & & Df & LRT & $p$-value & Coeff \pm SE \\
\hline \multirow[t]{3}{*}{ Exclusive vigilance } & Time period & & 1 & 18.505 & $<0.001$ & See Table 3 \\
\hline & Playback & & 2 & 69.941 & $<0.001$ & See Table 3 \\
\hline & $\begin{array}{l}\text { Time period } \times \\
\text { Playback }\end{array}$ & & 2 & 13.804 & 0.001 & See Table 3 \\
\hline
\end{tabular}

The proportion of time spent in vigilance was ArcSinSqRoot transformed and step rate and the time spent in vigilance while chewing were log-transformed. See Tables S1, S2, S3 and S4 for details on factors that were controlled for. The pre-playback period and the control playback were used as references for the time period and playback variables, respectively. Vigilance, bite rate, step rate and vigilance while chewing were analyzed using linear mixed-effects models and exclusive vigilance using zero inflated Poisson mixed-effects models (see methods). 


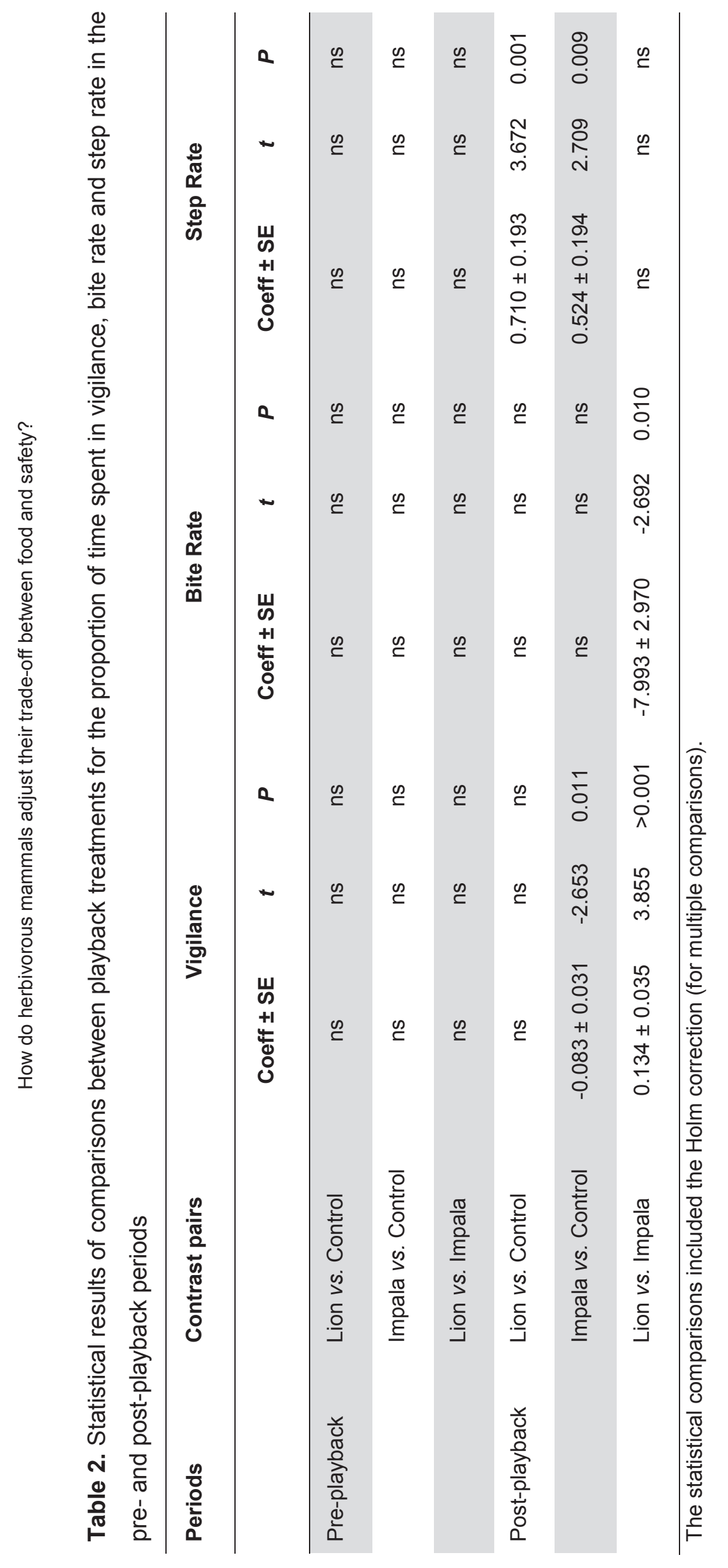




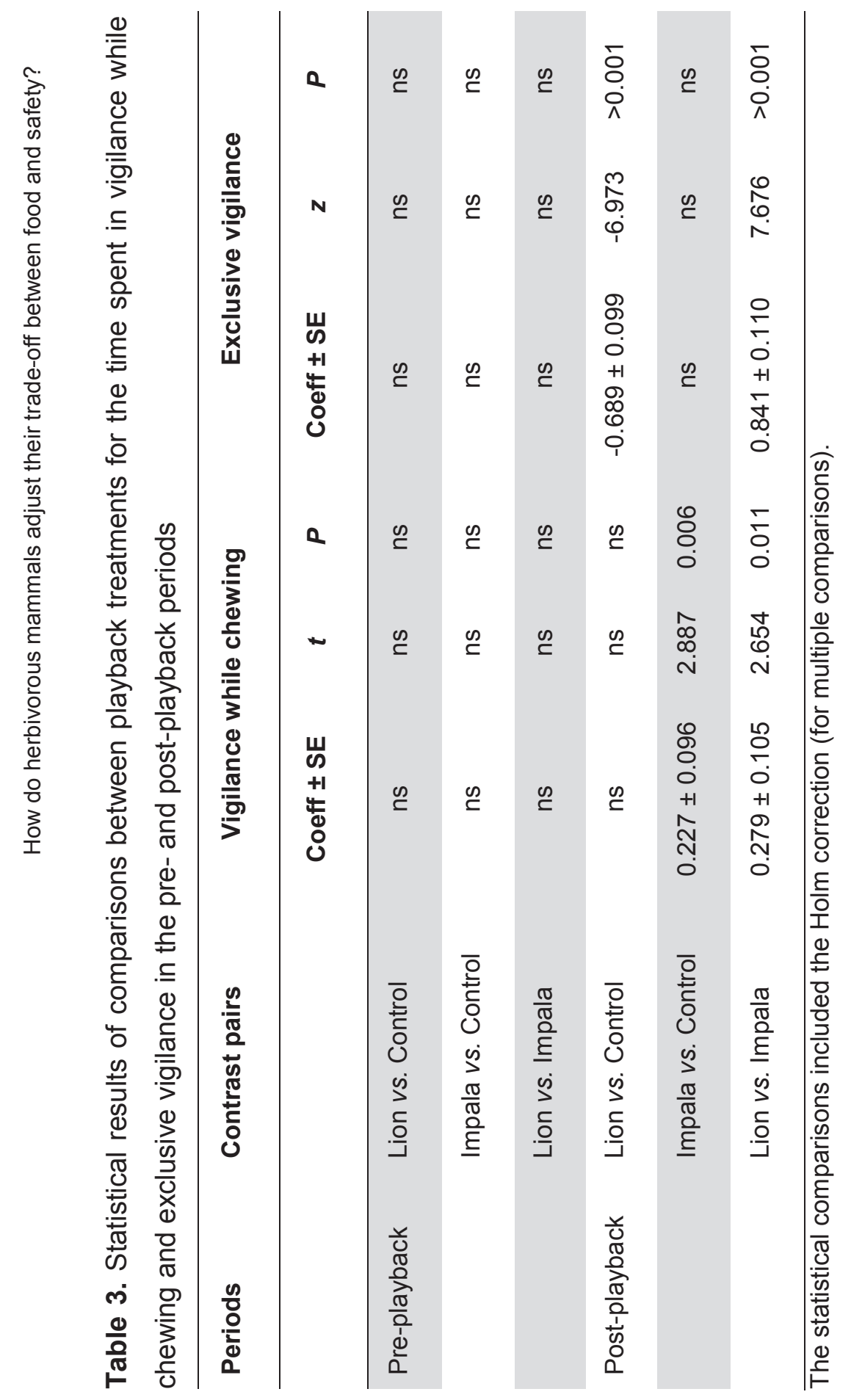




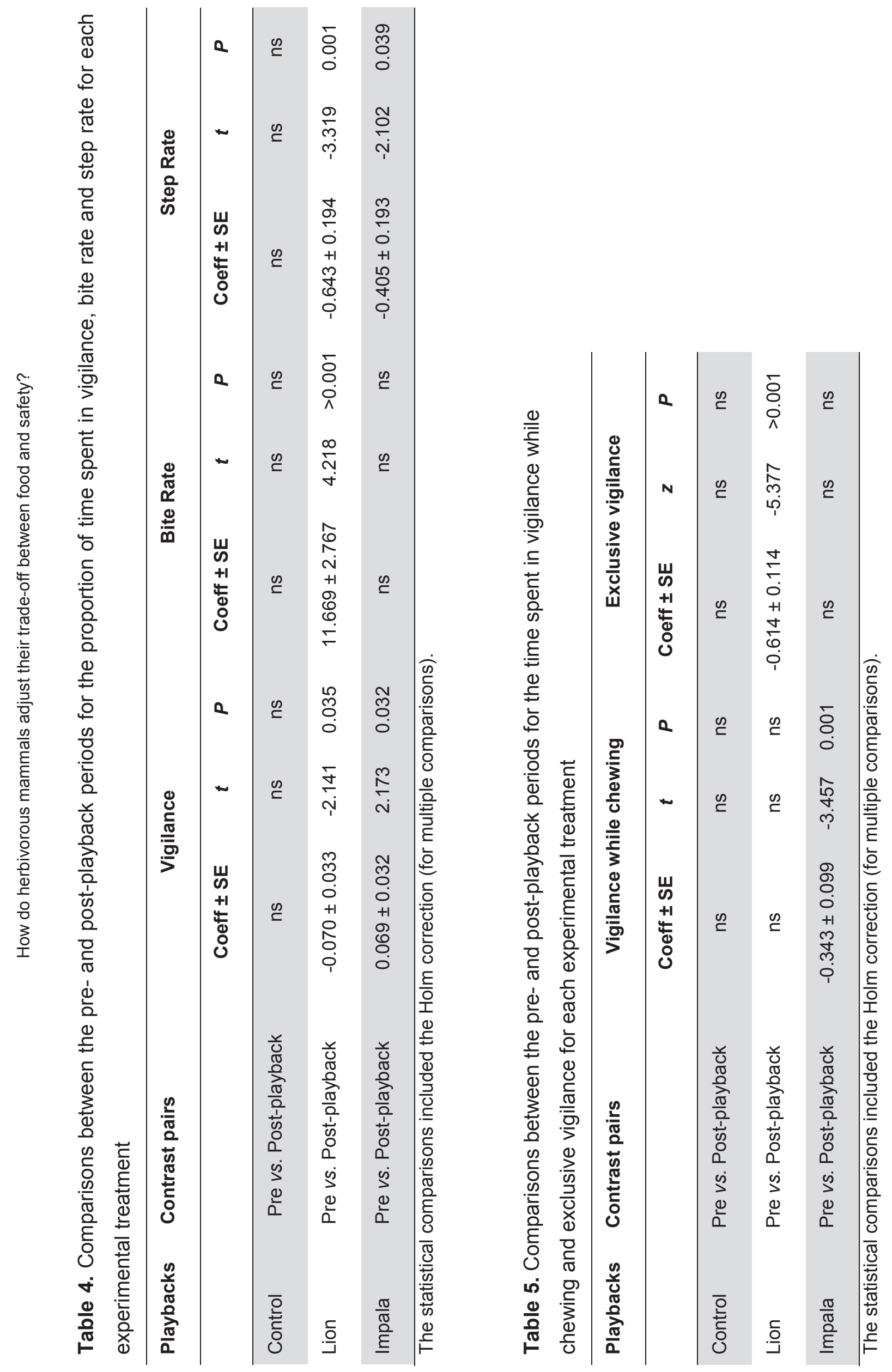

ลิ

. 


\section{Electronic Supplementary Material}

Table S1. Effects of time period and type of playback on the proportion of time spent in vigilance by female impalas (ArcSinSqRoot transformed), controlling for the effects of date, group size (log-transformed), distance to cover and grass height.

\begin{tabular}{|c|c|c|c|c|c|}
\hline Variables & numDF & denDF & F-value & p-value & Coeff \pm SE \\
\hline (Intercept) & 1 & 100 & 614.309 & $<0.001$ & $0.288 \pm 0.022$ \\
\hline Time period & 1 & 100 & 0.028 & 0.867 & See Table 2 \\
\hline Playback & 2 & 42 & 3.628 & 0.035 & See Table 2 \\
\hline Time period $\times$ Playback & 2 & 100 & 4.631 & 0.012 & See Table 2 \\
\hline Date & 1 & 42 & 1.743 & 0.194 & \\
\hline Log group size & 1 & 42 & 2.914 & 0.095 & \\
\hline Distance to cover & 4 & 42 & 0.537 & 0.710 & \\
\hline Grass height & 2 & 42 & 2.651 & 0.082 & \\
\hline
\end{tabular}

Log (Group size) and date were considered as continuous. Time period (Pre-playback, postplayback), playback (Control, Lions' roars, Males' roars), individual identity, distance to cover (0-25, 26-50, 51-100, 101-200, more than 200m), grass height (short, medium, tall), were categorical (classes used as references are italicized in the legends). Two nested random factors were included, individual within group identity (group identity: $P=0.229$; individual identity: $P=0.263$ ). 
Table S2. Effects of time period and type of playback on the time spent in vigilance while chewing by female impalas (log-transformed), controlling for the effects of date, group size (log-transformed), distance to cover and grass height.

\begin{tabular}{|c|c|c|c|c|c|}
\hline Variables & numDF & denDF & F-value & p-value & Coeff \pm SE \\
\hline (Intercept) & 1 & 75 & 891.932 & $<0.001$ & $0.983 \pm 0.061$ \\
\hline Time period & 1 & 75 & 1.783 & 0.186 & See Table 2 \\
\hline Playback & 2 & 48 & 0.831 & 0.441 & See Table 2 \\
\hline Time period $\times$ Playback & 2 & 75 & 5.212 & 0.007 & See Table 2 \\
\hline Date & 1 & 40 & 2.001 & 0.165 & \\
\hline Log group size & 1 & 40 & 7.871 & 0.007 & $0.326 \pm 0.188$ \\
\hline Distance to cover & 4 & 40 & 0.613 & 0.655 & \\
\hline Grass height & 2 & 40 & 3.027 & 0.059 & \\
\hline \multicolumn{6}{|c|}{$\begin{array}{l}\text { Log (Group size) and date were considered as continuous. Time period (Pre-playback, post- } \\
\text { playback), playback (Control, Lions' roars, Males' roars), individual identity, distance to cover } \\
(0-25,26-50,51-100,101-200 \text {, more than } 200 m \text { ), grass height (short, medium, tall), were } \\
\text { categorical (classes used as references are italicized in the legends). Two nested random } \\
\text { factors were included, individual within group identity (group identity: } P=0.481 \text {; individual } \\
\text { identity: } P=0.513 \text { ). }\end{array}$} \\
\hline
\end{tabular}


Table S3. Effects of time period and type of playback on the bite rate of female impalas, controlling for the effects of date, group size (log-transformed), distance to cover and grass height.

\begin{tabular}{|c|c|c|c|c|c|}
\hline Variables & numDF & denDF & F-value & $p$-value & Coeff \pm SE \\
\hline (Intercept) & 1 & 92 & 2819.501 & $<0.001$ & $69.279 \pm 7.693$ \\
\hline Time period & 1 & 92 & 14.795 & $<0.001$ & See Table 2 \\
\hline Playback & 2 & 42 & 1.750 & 0.186 & See Table 2 \\
\hline Time period $\times$ Playback & 2 & 92 & 3.107 & 0.049 & See Table 2 \\
\hline Date & 1 & 42 & 2.143 & 0.151 & \\
\hline Log group size & 1 & 42 & 4.427 & 0.041 & $-7.782 \pm 4.232$ \\
\hline Distance to cover & 4 & 42 & 0.748 & 0.565 & \\
\hline Grass height & 2 & 42 & 5.258 & 0.009 & $\begin{array}{c}\text { Medium: } \\
-7.509 \pm 3.132(P=0.021) \\
\text { High: } \\
-8.194 \pm 3.074(P=0.011)\end{array}$ \\
\hline $\begin{array}{l}\text { Log (Group size) and } \\
\text { playback (Control, Lions } \\
\text { 200, more than 200m), } \\
\text { italicized in the legends } \\
\text { identity: } P=0.152 \text {; indivi }\end{array}$ & $\begin{array}{l}\text { were con } \\
\text { s, Males' } \\
\text { height (s } \\
\text { o nested } \\
\text { dentity: } P=\end{array}$ & $\begin{array}{l}\text { idered as } \\
\text { oars), indi } \\
\text { lort, medit } \\
\text { andom fa } \\
\text {.988). }\end{array}$ & $\begin{array}{l}\text { continuous } \\
\text { idual identit } \\
\mathrm{m} \text {, tall), wer } \\
\text { tors were in }\end{array}$ & $\begin{array}{l}\text { ime peric } \\
\text { distance tc } \\
\text { categorica } \\
\text { uded, indiv }\end{array}$ & $\begin{array}{l}\text { Pre-playback, post-playback), } \\
\text { ver (0-25, 26-50, 51-100, 101- } \\
\text { lasses used as references are } \\
\text { al within group identity (group }\end{array}$ \\
\hline
\end{tabular}


Table S4. Effects of time period and type of playback on the step rate of female impalas (log-transformed), controlling for the effects of individual identity, date, group size (log-transformed), distance to cover and grass height.

\begin{tabular}{|c|c|c|c|c|c|}
\hline Variables & numDF & denDF & F-value & p-value & Coeff \pm SE \\
\hline (Intercept) & 1 & 84 & 235.305 & $<0.001$ & $1.104 \pm 0.145$ \\
\hline Time period & 1 & 84 & 4.194 & 0.044 & See Table 2 \\
\hline Playback & 2 & 41 & 2.113 & 0.134 & See Table 2 \\
\hline Time period $\times$ Playback & 2 & 84 & 6.560 & 0.002 & See Table 2 \\
\hline Date & 1 & 41 & 0.251 & 0.619 & \\
\hline Log group size & 1 & 41 & 1.091 & 0.302 & \\
\hline Distance to cover & 4 & 41 & 0.652 & 0.629 & \\
\hline Grass height & 2 & 41 & 0.972 & 0.387 & \\
\hline \multicolumn{6}{|c|}{$\begin{array}{l}\text { Log (Group size) and date were considered as continuous. Time period (Pre-playback, post- } \\
\text { playback), playback (Control, Lions' roars, Males' roars), individual identity, distance to cover } \\
(0-25,26-50,51-100,101-200 \text {, more than } 200 m) \text {, grass height (short, medium, tall), were } \\
\text { categorical (classes used as references are italicized in the legends). Two nested random } \\
\text { factors were included, individual within group identity (group identity: } P=0.115 \text {; individual } \\
\text { identity: } P=0.270) \text {. }\end{array}$} \\
\hline
\end{tabular}




\title{
Chapter 4:
}

\section{Predators, food and social context shape the types of vigilance exhibited by kangaroos}

\author{
François-René Favreau, Olivier Pays, Hervé Fritz, Michel Goulard, Emily C. Best, Anne
}

W. Goldizen

\section{Abstract}

Vigilance in prey species can serve many purposes, including predator detection and monitoring other group members, but is generally thought to impose a cost due to reduced food intake. However, previous studies have shown that herbivores are able to reduce the foraging cost of vigilance by chewing their food during vigilance bouts ("vigilance while chewing", compared to vigilance without chewing, called "exclusive vigilance"). How predation risk, food availability and competition affect both the functions and the foraging costs of vigilance remains an open question. We studied female eastern grey kangaroos, Macropus giganteus, during winter and summer, when available food supplies were poor and rich, respectively, to investigate how group size, distance to cover, proximity between foragers and food patch quality affected foraging female kangaroos' decisions to exhibit exclusive vigilance or vigilance while chewing and antipredator or social vigilance. The use of antipredator vigilance (particularly antipredator exclusive vigilance) was mainly driven by the perception of predation risk and decreased with increased group size and with decreased nearest neighbour distances but did not vary with distance to cover. An increase in patch quality decreased the use of antipredator vigilance while chewing in winter and antipredator exclusive vigilance in summer and increased the use of social vigilance while chewing in both seasons. Social vigilance while chewing was also affected positively by group size, and distance between foragers affected both types of social vigilance but differently across seasons. This study provides the first findings on how individual animals make decisions about the functions and foraging costs of vigilance and allows a better understanding of how social foragers respond to an ever-changing environment.

Keywords: antipredator vigilance; competition; Macropus giganteus; patch quality; predation risk; social vigilance. 


\section{Introduction}

Vigilance behaviour is crucial for prey in order to increase their safety. In gregarious species, this activity may also serve for the acquisition of social information (Beauchamp, 2001). Whatever its function, vigilance likely reduces the time an individual can allocate to other fitness-enhancing activities such as food acquisition, and may thus reduce energetic gains, particularly when prey have strong time constraints on foraging (McNamara \& Houston, 1992). Therefore, gregarious prey should manage their use of vigilance carefully in order to increase their safety, acquire social information and maximise food acquisition.

Although vigilance is thought to reduce food intake, the foraging cost of vigilance may be reduced because scanning and feeding are not always incompatible (Spalinger \& Hobbs, 1992). In fact, many species of birds and mammals are able to continue food ingestion while vigilant by handling or chewing their food (Baker, Stillman, Smart, Bullock, \& Norris, 2011; Fortin, Boyce, Merrill, \& Fryxell, 2004; Pays et al., 2012). Consequently, recent studies focusing on herbivores' vigilance have differentiated a high intensity form of vigilance in which the animal stops all activities and raises its head (hereafter termed as "exclusive vigilance") from a lower intensity vigilance during which the animal is vigilant while chewing its food (hereafter termed as "vigilance while chewing") (e.g. Meer, Pays, \& Fritz, 2012; Pays et al., 2012; Robinson \& Merrill, 2013; Unck, Waterman, Verburgt, \& Bateman, 2009). However, while differing in terms of their costs to foraging, these two types of vigilance also likely differ in the quality of perception that they offer (Lima \& Bednekoff, 1999), with the chance of detecting a predator reduced during vigilance while chewing because of the noise resulting from the mastication process (Blanchard \& Fritz, 2007; Fortin et al., 2004). Although this distinction between these forms of vigilance is recent, field studies have shown that herbivores' investment in both exclusive vigilance and vigilance while chewing can be driven by predation risk, food resource characteristics and group size (Benhaeim et al., 2008; Meer et al., 2012; Pays et al., 2012; Périquet et al., 2012).

Another aspect of vigilance that has received some attention subdivides vigilance according to its function. While vigilance has been mainly described as an antipredator behaviour, it can also function for the acquisition of social information in gregarious species (Beauchamp, 2001). Vigilance towards conspecifics (or social vigilance) may be used in various contexts such as monitoring competitors, searching for mates, protecting young or indirectly detecting predators (e.g. Burger \& Gochfeld, 1994; Caro, 2005; Ellard \& Byers, 2005; FitzGibbon, 1990; Monclùs \& Rödel, 2008). In addition, social vigilance can also be employed by social foragers to locate and assess the quality of food patches discovered by others in order to detect foraging opportunities (Barnard \& Silby, 1981; Smith, Benkman, \& Coffey, 1999). This behaviour has been described in producer-scrounger models, which suggest that a forager can either search for food by itself (producer mode) or locate and exploit food patches discovered by its companions (scrounger mode) (Giraldeau \& Beauchamp, 1999). The use of scrounging strategies tends to increase when 
food is scarce and competition strong (Beauchamp, 2009). Overall, social vigilance has been shown to be affected by food quality and availability, group size, and the distance between foragers (Beauchamp, 2008; Favreau, Goldizen, \& Pays, 2010; Fernàndez-Juricic \& Kacelnik, 2004).

Vigilance is therefore a complex behaviour that can differ in terms of its foraging costs and be used for safety or social purposes. Foraging herbivores thus have different vigilance options and have to make choices between these in order to maximize both their survival and resource acquisition. While these two aspects of vigilance behaviour (exclusive vigilance vs. vigilance while chewing and antipredator vs. social vigilance) have been studied separately, they have never been investigated simultaneously and the factors that motivate individuals to invest in particular types of vigilance remain poorly understood. To further complicate the situation, an animal exhibiting either antipredator or social vigilance can use either exclusive vigilance or vigilance while chewing. Thus, individuals have the opportunity to moderate the cost of their social or antipredator bouts of vigilance by simultaneously processing their food (vigilance while chewing). It has been assumed that exclusive vigilance is mainly associated with antipredator vigilance, and vigilance while chewing with social vigilance (Monclùs \& Rödel, 2008). However, these assumptions have not yet been tested. Predation risk, food quality and availability, and the occurrence and level of competition should all affect the vigilance tactics employed by foragers. A more nuanced understanding of the relationships between these two aspects of vigilance is therefore needed.

We studied wild female eastern grey kangaroos, Macropus giganteus, in Sundown National Park in southeast Queensland, Australia, to investigate how perceptions of predation risk, food resources and social context affected the decisions made by foraging individuals to exhibit particular types of vigilance (antipredator exclusive vigilance, antipredator vigilance while chewing, social exclusive vigilance, social vigilance while chewing). Using data from detailed behavioural monitoring of foraging females, we developed a statistical approach for modelling the probability of a kangaroo exhibiting a particular type of vigilance that allowed us to consider individuals' choices second by second. We used this procedure to test whether group size, distance between the focal animal and its nearest neighbour, distance to cover, and food patch quality affected the decisions of foraging kangaroos to engage in a particular type of vigilance. We focused on females because (1) they are known to exhibit different vigilance patterns from males (Pays \& Jarman 2008; Rieucau et al., 2012), (2) most males were less regularly observed at our study site, and (3) we wanted to avoid adding gender differences to our already complex analyses. As the grass eaten by kangaroo shows major seasonal variation in abundance and quality in this part of Australia, we also investigated whether overall food conditions affected the behavioural decisions taken by kangaroos by studying their behaviour during two contrasting seasons, winter (offering the worst food conditions) and summer (offering the best food conditions).

Based on theoretical and empirical studies, we made some predictions about how a number of factors might affect the decisions of foraging kangaroos to engage in different types of vigilance 
(refer to Table 1 for hypotheses and references). We predicted that female kangaroos should decrease their probability of using antipredator exclusive vigilance in bigger groups and when foraging closer to another individual, as their predation risk would be decreased, and also when closer to cover, as they seem to use cover as a source of protection against predators (Table 1, Hyp. 1.1, 2.1, 3.1). We also predicted that a greater proportion of social vigilance should involve exclusive vigilance as distance to cover increases as kangaroos should observe conspecifics' reactions more frequently to assess the risk of predation when that risk is greater (Table 1, Hyp. 3.2). In good food conditions (summer) and in better food patches (high quantity and/or quality), we predicted that kangaroos should decrease their vigilance time to increase their investment in food acquisition (Table 1, Hyp 4.1). Better food conditions should lead to an increase in individuals' bite rates and bite sizes, favouring the use of vigilance while chewing over exclusive vigilance (Table 1 , Hyp. 4.2). However, in winter and in poorer food patches (poor quantity and/or quality), competition and scrounging should increase. As scrounging is assumed to involve mainly vigilance while chewing (Monclùs \& Rödel, 2008), we expected the probability of using social vigilance while chewing to increase in poorer food conditions, in larger groups in which scrounging opportunities increase, and when distances between foragers increases, because the quality of social information decreases when foragers are further apart (Table 1, Hyp. 4.3, 1.2, 2.2).

\section{Materials and methods}

\section{- Study site and animals}

The study was conducted in Sundown National Park (Queensland, Australia, 28 9'S, $151^{\circ} 58$ 'E) over two months in winter (July-August 2011) and two months in summer (NovemberDecember 2011). The 37.4 ha study area was composed of a mosaic of open pasture and mixed open forests primarily composed of eucalypts, Eucalyptus melanophloia, and pines, Callitris intratropica. Eastern grey kangaroos are gregarious and one of the most social species of marsupials; they form open-membership mixed-sex groups and exhibit fission-fusion social dynamics (Aureli et al., 2008; Clarke, Jones, \& Jarman, 1995; Jarman, 1987). Kangaroos typically come onto the pasture to forage from the late afternoon to the early morning and rest during the daytime. The study area contained 240 females and notably fewer males (Best, Seddon, Dwyer, \& Goldizen, 2013). Kangaroos' predators were occasionally observed or heard in the study area and included red foxes, Vulpes vulpes, and wedge-tailed eagles, Aquila audax, and possibly dingoes, Canis lupus dingo, although dingoes were rare if present at all. This research was approved by the University of Queensland's Animal Experimentation Ethics Committee, and conducted under a Scientific Purposes Permit from Queensland's Environmental Protection Agency. 


\section{- Recording data}

-Individual sampling

We collected behavioural data by videotaping (video camera: Sony DCR-SR37, 60× optical zoom, Sony Corporation, Tokyo, Japan) selected focal adult females for 10 min periods during the few hours after dawn (summer: 4h30 - 7h30, winter: 6h30 - 10h30) and before dusk (summer. 16h - 18h30, winter: $15 \mathrm{~h} 30$ - 17h30) when the animals came on the pasture to forage. All field data were collected by the same observer (F-RF). Kangaroos in this population had been intensively studied since 2009 and all resident females were identified, which allowed the observer to avoid resampling individuals more than once per day. Individual identification was done using a combination of personal features such as scars, facial markings, dark patches and ear shapes and tears (Best et al., 2013; Coulson, 1997; Jarman et al., 1989). The video sequences were used only if the size and composition of the group in which the focal animal was observed remained constant during the observation and group members stayed in the same location. Following Jarman's "chain rule" (1987), we considered a group as a set of kangaroos who maintained social and spatial cohesion during focal sampling and whose most peripheral associate was within $15 \mathrm{~m}$ of another group member.

We observed 28 identified females in winter and 21 of these in summer and used six randomly selected samples per female per season in our analyses, for a total of 168 focal samples in winter and 126 in summer.

\section{-Recording behaviour}

Data were recorded on foot, keeping a minimum distance of 30 meters between the focal individual and the observer to minimize disturbance; due to the nearly continuous presence of researchers and the occasional campers in the area, kangaroos were habituated to people and easy to approach. We characterized a kangaroo as vigilant if it raised its head above horizontal while either crouched or standing upright, and looked fixedly in one direction or scanned its surroundings (Jarman, 1987; Pays et al., 2007). To determine whether an animal was likely to exhibit antipredator or social vigilance, we used head orientation as an indicator of the target of the individual's visual attention; this method has been used in previous studies, including studies of eastern grey kangaroos (Fernández-Juricic, Erichsen, \& Kacelnik 2004; Fernández-Juricic, Siller \& Kacelnik 2004; Favreau et al. 2010; Quirici, Castro, Oyarzun, \& Ebensperger, 2008). We considered a female to be using antipredator vigilance when it oriented its head away from the group and social vigilance when it was oriented toward other group members. Using this method, we had no difficulty characterizing the orientation of vigilance. In addition, we followed the method developed by Favreau et al. (2010) for this species by only using samples from females located on the periphery of groups in our analyses, as antipredator and social vigilance could not easily be distinguished for central individuals, and by using only groups of at least three individuals. To account for the cost/intensity of vigilance in our study, we distinguished vigilance while chewing 
(when an individual raised its head while chewing) from exclusive vigilance (when it raised its head without chewing) (Lima \& Bednekoff, 1999; Unck et al., 2009). Thus, the function (social or antipredator) and foraging cost (exclusive vigilance or vigilance while chewing) of each bout of vigilance were recorded.

For each focal sample, we measured the following predictor variables. We recorded the group size, including all age-sex classes, and measured the distance between the focal animal and its nearest adult neighbour with a range finder at the beginning of the 10 minute sample. To do this, we measured the distance between the observer and the focal female, the distance between the observer and the female's nearest neighbour and the angle between them using a protractor and then later calculated inter-individual distances with trigonometric formulas. We similarly measured the distance between the focal animal and the nearest cover (i.e. distance to the edge of the forest) at the beginning of the observation. As already mentioned, we only analysed data from groups that stayed relatively immobile; however, if the distance between individuals or the distance to cover changed markedly during the observation period, we took a second measure at the end of the observation and averaged both distances.

At the end of each focal sample, the observer measured characteristics of the patch exploited by the animal to estimate patch characteristics in terms of the quantity and quality of vegetation available on food patches. This procedure has been described in Favreau et al. (2014, in press) and is summarized here. To measure patch quality, the observer put down a quadrat (90 $\times 90 \mathrm{~cm}$ ) with 81 grid crossings and recorded a greenness index for all plants under each grid crossing. This index was comprised of two categories, brown (plants with low energetic value) and green (plants with high energetic value) (Bradbury, Vehrencamp, Clifton, \& Clifton, 1996), and allowed us to estimate the percentage of plant material that was green for each food patch. To measure the quantity of vegetation in patches, we used a pasture meter to estimate vegetation biomass. To convert the vegetation height below the pasture meter (PM) into biomass, we calibrated the pasture meter for each season. The relationship between PM height and biomass was measured by clipping, drying and weighing the plant biomass below the pasture meter (Winter: biomass $=12.09+2.6634 \times \mathrm{PM}$ height, $P<0.001$, adjusted $\mathrm{R}^{2}=0.87, n=50$; Summer: biomass $=8.33+3.1131 \times \mathrm{PM}$ height, $P<0.001$, adjusted $\left.\mathrm{R}^{2}=0.86, n=51\right)$.

However, kangaroos are short-grass grazers, and the relationship between greenness, biomass and food intake in such herbivore species is complex (Wilmshurst, Fryxell, \& Colucci, 1999). According to Clarke, Jones, \& Jarman (1989), kangaroos preferentially select green leaves of grass; therefore patch attractiveness should increase with greenness. In addition, Bell (1973) observed that eastern grey kangaroos strongly preferred short grass and avoided long dry grass. Similar preferences have been observed in other short-grass grazers of similar body size. As an increase in grass biomass generally decreases digestibility, the selection of forage patches is likely to be humped-shaped as a function of biomass (Forage Maturation Hypothesis, Fryxell, 1991). Indeed, Wilmshurst et al. (1999) showed that herbivore species of similar size to the grey kangaroo 
prefer patches of low to intermediate biomass for which forage digestibility remains high. Taking into account studies on short-grass grazers such as sheep, antelopes and other kangaroo species (Bradbury et al., 1996; Short, 1985; Wilmshurst et al., 1999), we established an index of patch quality based on both patch greenness and biomass following predictions derived from Wilmshurst et al. (1999) (Table 2). We then attributed a single patch quality index to the site of each focal observation (i.e. poor patch, medium patch or rich patch), reflecting the quality of the patch exploited by the kangaroo in relation to its digestibility within the forage maturation hypothesis framework (see also Favreau et al., in press). Rich patches were those at and close to the optimum biomass and greenness for herbivores of kangaroo size (within 30\% from the optimal patch), medium patches were those within $60 \%$ from the optimal patch, and poor ones were those further from the optimum.

\section{- Data analyses}

We extracted from our data which activity was exhibited by the focal individual at each second during the $600 \mathrm{~s}$ sequences. Because we wanted to explore how the ecological and social contexts affected the decisions of foraging kangaroos to engage in different types of vigilance, we investigated which factors affected the probability of an individual exhibiting a particular type of vigilance at a given second, by adapting and extending the statistical procedure described in Pays et al. (2009). Pays et al. (2009) developed a statistical procedure to investigate an individual's decisions about whether to be vigilant (thus between two options - vigilant or not). Our procedure allowed us to investigate individuals' decisions among five options (not vigilant or engaged in one of the four types of vigilance). As the response variable was categorical and included five categories (i.e. non-vigilant, antipredator exclusive vigilance, antipredator vigilance while chewing, social exclusive vigilance and social vigilance while chewing), we ran multinomial logistic regression models using the package "nnet" in the R software (Venables \& Ripley, 2002). In this procedure, we fixed the level "non-vigilant" of the response variable (corresponding mainly to foraging activity, see Results) as the reference, allowing us to model the probabilities of a kangaroo exhibiting the four types of vigilance when she was foraging. We included group size, distance between the focal animal and its nearest neighbour, distance to cover, and patch quality (poor, medium, rich) as fixed factors and ran a model for each season.

There were several methodological constraints in our data set that we had to consider. First, Pays et al. (2009) showed that the probability of a kangaroo exhibiting a vigilant behaviour was strongly affected by the behaviour of the focal animal at the previous second. This temporal autocorrelation was controlled for by (1) including the state of the animal (vigilant or not vigilant) at the previous second as a fixed factor in models and (2) checking for the lack of sequential correlation in the residuals (Pays et al., 2009). To simplify the procedure, we grouped the four different types of vigilance together for the focal animal's activity at the previous second to consider only two states (non-vigilant vs. vigilant) and included this variable depicting the behaviour at the 
previous second as a fixed factor (named "Behaviour before" in Table 3). We confirmed the lack of sequential correlation in the residuals of the model run for each season using a partial autocorrelation function (Maindonald \& Braun, 2007). Second, it was not possible to standardize a mixed-effects multinomial regression model to control for the effects of other potential sources of non-independence between observations (particularly because of the complexity of running this complex procedure with the huge number of seconds analyzed: $100800 \mathrm{~s}$ in winter and $75600 \mathrm{~s}$ in summer). Thus, to control for individual identity, we included individual ID as a fixed factor. So that parameters could be estimated, a constraint was imposed for some sets of parameters. Two types of constraints can be used for a set of "effects" $\left(\alpha_{i}\right)$ : the first assumes one element $i_{0}$ as a reference (i.e. one kangaroo) and thus the constraint is $a_{i 0}=0$. The second (the one that we chose) sets that $\Sigma \alpha_{i}=0$, without a reference. Thus, from this latter one, the model's intercept described the overall mean for all identified females (28 in winter and 21 in summer). We standardized the number of focal samples per individual by including only six focal samples for each female in a season (i.e. $6 \times 10 \mathrm{~min}=3600 \mathrm{~s}$ ). Third, we avoided the non-independence that would have been caused by sampling multiple individuals in the same group by including only one individual per group.

The statistical analyses were performed with $\mathrm{R}$ version 3.0.2 ( $\mathrm{R}$ Development Core Team 2013).

\section{Results}

\section{- Seasonal differences in food patch characteristics}

The percentage of vegetation that was green differed significantly between winter and summer (Fig. 1a; Kolmogorov-Smirnov two-sample test: $D=0.73, N_{1}=168, N_{2}=126, P<0.001$ ), as did the biomass of the vegetation at foraging patches (Fig. 1b; Kolmogorov-Smirnov two-sample test: $\left.D=0.29, N_{1}=168, N_{2}=126, P<0.001\right)$. Pastures were much greener but slightly lower in biomass during summer compared to winter. Consequently "poor" patches were dominant in winter and "rich" patches dominant in summer (Fig. 1c).

\section{- Females' investments in vigilance}

Analysis of the 10-min video sequences showed that female kangaroos spent most of their time foraging ( $85.3 \%$ in winter and $86.7 \%$ in summer) and between $10.8 \%$ (in summer) and $12.9 \%$ (in winter) of their time in vigilance. They spent most of their vigilance time in antipredator vigilance (89.2\% of total vigilance on average) and in vigilance while chewing $(65.8 \%$ of total vigilance on average). Finally, vigilance while chewing comprised between $74.5 \%$ (in summer) and $86.3 \%$ (in winter) of social vigilance and between $60.5 \%$ (in winter) and $71.4 \%$ (in summer) of antipredator vigilance. 


\section{- Factors affecting types of vigilance used}

For each season, Table 3 presents the effects of group size, distance between the focal animal and its nearest neighbour, distance to cover, and patch quality on the probability of foraging female kangaroos using each of the four types of vigilance, controlling for whether the animal was already vigilant or not at the previous second. The results are described based on the signs of the coefficients derived for each factor (Table 3).Female kangaroos were more likely to be vigilant when they had already been vigilant at the previous second, whatever the season and the type of vigilance engaged in. As group size increased, the probabilities of females exhibiting antipredator vigilance decreased for both exclusive vigilance and vigilance while chewing in both seasons. The use of social exclusive vigilance also decreased with group size in summer, but increasing group size increased the probability of social vigilance while chewing being used in each season (Table 3). In winter, distance to the nearest neighbour was positively related to the probability that focal females exhibited antipredator exclusive vigilance as well as both types of social vigilance. In summer, it was negatively related to the probability of exhibiting social exclusive vigilance. Distance to cover was not related to the probability of focal females exhibiting either form of antipredator vigilance in either season. In winter, both types of social vigilance decreased with increased distance to cover, whereas in summer this effect only occurred for social exclusive vigilance. Finally, in both seasons, an improvement in patch quality had a significant negative effect on the use of both types of antipredator vigilance. However, this effect was not as clear for antipredator exclusive vigilance in winter and antipredator vigilance while chewing in summer as these were only significant when comparing poor and medium quality patches and not when comparing poor and rich patches. Nevertheless, an increase in patch quality significantly decreased the use of antipredator vigilance while chewing by female kangaroos in winter and the use of antipredator exclusive vigilance in summer. An increase in patch quality was also positively related to the use of social vigilance while chewing in both seasons, with this effect stronger in summer.

\section{Discussion}

Female kangaroos spent most of their vigilance time looking outwards from their foraging groups and thus seemed to focus more on predator detection than on the acquisition of social information, regardless of the season. A similar pattern had already been observed in this species (Favreau et al., 2010) and Le Roux, Cherry, Gygax, \& Manser (2009) reported that yellow mongooses, Cynictis penicillata, and meerkats, Suricata suricatta, spent averages of only 9.6 and $5 \%$ of their vigilance time monitoring their conspecifics, respectively. However, in highly social species such as primates, monitoring conspecifics can be the primary function of vigilance, as for example in brown capuchin monkeys, Cebus apella, for which social vigilance can represent up to 
$75 \%$ of vigilance time (Hirsch, 2002). Female kangaroos mostly used vigilance while chewing, supporting findings from other grazing mammals, including impalas, Aepyceros melampus (Pays et al., 2012), plains zebra, Equus quagga (Périquet et al., 2012) and European rabbits Oryctolagus cuniculus (Monclus \& Rodel 2008). They presumably used more vigilance while chewing than exclusive vigilance to limit the foraging cost of vigilance (Fortin et al., 2004). Thus, both social and antipredator vigilance bouts mainly involved vigilance while chewing, which does not support Monclùs and Rodel's (2008) assumption that social vigilance should mostly involve vigilance while chewing and antipredator vigilance mostly exclusive vigilance.

The probability of a foraging kangaroo exhibiting either form of antipredator vigilance decreased as group size increased, regardless of the season. This result supports the classical "safety in numbers" hypothesis, which states that prey can reduce their vigilance in large groups because of detection (Pulliam, 1973), dilution (Hamilton, 1971) and confusion effects (Landeau \& Terborgh, 1986). This classical "group size effect" has already been observed in many taxa (Elgar, 1989; Roberts, 1996), including eastern grey kangaroos, for both total and antipredator vigilance (Favreau et al., 2010; Jarman, 1987, Pays et al., 2007). We had initially predicted that only antipredator exclusive vigilance would decrease with group size (Table 1, Hyp. 1.1), but our results showed that vigilance while chewing was also affected, although to a lesser extent. Studies on the effect of group size on the cost of vigilance in herbivores have reported contrasting results. For instance, in impalas, while Pays et al. (2012) reported a negative effect of group size on exclusive vigilance only, Périquet et al. (2012) observed this effect for both exclusive vigilance and vigilance while chewing. It seems that prey reduce their antipredator vigilance in larger groups mainly by decreasing their exclusive vigilance and secondarily by reducing their vigilance while chewing.

Although a positive effect of group size on social vigilance had previously been reported in eastern grey kangaroos (Favreau et al., 2010), our study goes a step further by showing that this increase involved vigilance while chewing only, in support of our prediction (Table 1, Hyp. 1.2). This pattern highlights that kangaroos try to limit the cost of vigilance when it is not associated with the detection of danger. Also, we observed that kangaroos did not modify their use of exclusive social vigilance in relation to group size in poor food conditions (i.e. winter), but reduced it in larger groups in better conditions (i.e. summer). This may occur because (1) scrounging usually decreases when food conditions are good (Beauchamp, 2009) or (2) exclusive vigilance is replaced by vigilance while chewing in good conditions as females take bigger bites that require longer to chew (Bergman, Fryxell, \& Gates, 2000; Fortin et al., 2004).

Female kangaroos increased their use of exclusive antipredator vigilance as the distance to their nearest neighbour increased, but in winter only. This result supports the idea that proximity between prey increases the dilution effect, which reduces individuals' predation risk and allows them to decrease their antipredator vigilance to invest more in foraging (Table 1, Hyp. 2.1) (Fernàndez-Juricic \& Kacelnik, 2004; Mooring, Fitzpatrick, Nishihira, \& Reisig, 2004). The fact that this effect was only observed in winter suggests that this strategy is primarily used in poor food 
conditions when foragers need more time to achieve their energetic needs. The effect of distance to the nearest neighbour on the decisions of kangaroos to use different types of vigilance was more pronounced for social vigilance, but showed contrasting patterns between the two seasons. In winter the increase in both forms of social vigilance with nearest neighbour distance supports the hypothesis that individuals increase their use of social vigilance in poor food conditions to locate and assess food patches discovered by others, and that distance between neighbours affects the amount of social vigilance exhibited (Table 1, Hyp. 2.2). Despite most social vigilance being vigilance while chewing, we observed that social exclusive vigilance also increased with distance to the nearest neighbour. This increase in social exclusive vigilance may arise (1) because overall food quality is low in winter, reducing bite sizes and thus the probability of animals exhibiting vigilance while chewing, but also (2) because an increasing distance between animals makes obtaining relevant information more difficult (Fernàndez-Juricic \& Kacelnik, 2004; Poysa, 1994). Given the latter and that vigilance while chewing is assumed to reduce vigilance "quality" (Lima \& Bednekoff, 1999), animals may alternate between exclusive vigilance and vigilance while chewing as distance to their neighbours increases to reduce the cost of vigilance but still obtain more accurate information.

In summer we observed the opposite trend, with an increase in the use of social exclusive vigilance with increasing proximity to the nearest neighbour. An increase in vigilance with increasing proximity between foragers has been observed in several herbivores such as impalas (Underwood, 1982), giraffes, Giraffa camelopardalis (Cameron \& Du Toit, 2005) and European rabbits (Monclùs \& Rodel, 2008); these authors hypothesized that this pattern was due to reproduction or competition. Because food quality was good in summer, we do not believe that the increase of social exclusive vigilance arose because of competition for food. We suggest that this was related to reproduction and/or the protection of young. Although mating in eastern grey kangaroos can occur year round (Jarman, 1994), several studies have reported that it tends to be more frequent during summer (Jaremovic \& Croft, 1991; Stuart-Dick, 1987). During our observations, more females were observed in mixed-sex groups in summer $(25 \%$ of the focal females) than in winter $(13.4 \%)$, and more females had young-at-foot in summer $(49.2 \%$ of the focal females) compared to winter (18.5\%) (F-R. Favreau, unpublished data). Therefore the increase in social vigilance in summer may reflect an increase in time invested by females in monitoring males (to avoid sexual harassment) or monitoring young (Caro, 2005).

Distance to cover, which is often considered as a proxy of prey animals' likely perceptions of predation risk, was not related to antipredator vigilance either in winter or summer. This result did not support our initial prediction that kangaroos would be more vigilant for predators when further from cover, as had been observed in other studies of this species (Table 1, Hyp. 3.1). Several studies have argued that eastern grey kangaroos would use cover for protection because (1) they flee into cover when alarmed, (2) they rest near or in cover, and (3) they spend more time feeding close to cover when in risky habitats (Banks, 2001; Colagross \& Cockburn, 1993). However, the 
lack of a relationship between vigilance and distance to cover has been reported in some studies of eastern grey kangaroos and other macropodid species (e.g. Evans, Elgar, \& Handasyde, 2005; Favreau et al. 2010; Wahungu, Catterall, \& Olsen, 2001). Kangaroos (particularly small individuals) are predated by different predators using different hunting strategies (Evans et al., 2005). Terrestrial predators can hide in cover, whereas raptors' hunting success is greatest in the open. Therefore, cover itself may provide safety to kangaroos, but proximity to cover might not (Blumstein \& Daniel, 2002; Blumstein, Daniel, \& Smith, 2003).

Distance to cover was related to social vigilance but not in the way that we had expected. Contrary to our prediction that kangaroos should increase their social vigilance with distance to cover if they use the vigilance of other group members to assess predation risk (Table 1, Hyp. 3.2), social vigilance decreased as the distance to cover increased, except for social vigilance while chewing in summer. The general decrease in the use of social vigilance far from cover may have been due to the fact that there is less visual obstruction in the open and companions are easier to locate and monitor than in more closed habitats.

Patch quality influenced the type of vigilance exhibited by foraging kangaroos in both seasons. Although in two situations we failed to find a significant difference between the extreme values (i.e. poor vs. rich patches), the four other significant comparisons relating to a patch-quality effect (Table 3) were unambiguous. Female eastern grey kangaroos decreased their use of antipredator vigilance in both seasons as patch quality increased. This pattern supports previous findings in birds and mammals that animals invest more time in food acquisition and less time in predator detection in good patches (Table 1, Hyp. 4.1) (LaGory, 1986; Repasky, 1996). However, these patterns were only clear for antipredator vigilance while chewing in winter and antipredator exclusive vigilance in summer. In winter, kangaroos simultaneously decreased their antipredator vigilance while chewing and increased their social vigilance while chewing. This suggests that when good patches were rare, kangaroos foraging on good patches tended to switch from antipredator to social vigilance during their chewing time, agreeing with our prediction that scrounging behaviour should increase in poor food conditions (Table 1, Hyp. 4.3).

During summer, the females decreased their use of antipredator exclusive vigilance, and increased their social vigilance while chewing, which we did not expect. However, as explained above, the increase in social vigilance while chewing with increasing patch quality may have different functions in different seasons; kangaroos may increase their social vigilance in winter to monitor group mates' patch exploitation as we predicted (i.e. scrounging), but may increase social vigilance in summer to acquire other types of social information related to reproduction or young protection. Overall, our results showed that female kangaroos increased their social vigilance while chewing with food quality in both seasons. This result agrees with the hypothesis that good patches favour bigger bites and higher bite rates (Bergman et al., 2000) and lead to an increase in vigilance while chewing (Fortin et al., 2004) (Table 1, Hyp 4.2). Animals on good patches therefore had more chewing time available and used it to perform social vigilance instead of antipredator 
vigilance. Although we observed several clear patterns regarding vigilance and food patches, others were not that clear. Therefore further studies are needed to better understand the effects of patch quality on the functions and the costs of vigilance behaviour.

To conclude, this study provides the first findings on the associations between the functions and the foraging costs of vigilance in a prey species. Our results show that individuals' decisions to use a particular type of vigilance are based on variation in both ecological and social contexts, including predation risk, competition for food, and food resources, which are at the heart of the trade-off between food acquisition and safety. For methodological reasons, we only focused on peripheral females in foraging groups. To improve our understanding of the adjustment of individuals' decisions in relation to their social context, it would be interesting to test for the effects of the position of individuals within the foraging group or the social network, inter-individual aggression and reproductive status on vigilance strategies. Also, vigilance while chewing was the main type of vigilance used in both social and antipredator contexts. Thus, our study does not support the idea that vigilance is automatically a costly activity.

\section{Acknowledgments}

We thank Bénédicte Bouvy for assistance in the field and the rangers at Sundown National Park for their support. 


\section{References}

Aureli, F., Schaffner, C. M., Boesch, C., Bearder, S. K., Call, J., Chapman, C. A., et al. (2008). Fission-fusion dynamics. Current Anthropology, 49, 627-654.

Baker, D. J., Stillman, R. A., Smart, S. L., Bullock, J.M., \& Norris, K. J. (2011). Are the costs of routine vigilance avoided by granivorous foragers? Functional Ecology, 25, 617-627.

Banks, P. (2001). Predation-sensitive grouping and habitat use by eastern grey kangaroos: a field experiment. Animal Behaviour, 61, 1013-1021.

Barnard, C. J., \& Sibly, R. M. (1981). Producers and scroungers: a general model and its application to captive flocks of house sparrows. Animal Behaviour, 29, 543-550.

Beauchamp, G. (2009). How does food density influence vigilance in birds and mammals? Animal Behaviour, 78, 223-231.

Beauchamp, G. (2008). A spatial model for producing and scrounging. Animal Behaviour, 76, 1935-1942.

Beauchamp, G. (2001). Should vigilance always decrease with group size? Behavioral Ecology and Sociobiology, 51, 47-52.

Bell, H. L. (1973). The ecology of three macropod marsupial species in an area of open forest and savannah woodland in north Queensland, Australia. Mammalia, 37, 537-544.

Benhaiem, S., Delon, M., Lourtet, B., Cargnelutti, B., Aulagnier, S., Hewison, J. M., et al. (2008). Hunting increases vigilance levels in roe deer and modifies feeding site selection. Animal Behaviour, 76, 611-618.

Bergman, C. M., Fryxell, J. M., \& Gates, C. C. (2000). The effect of tissue complexity and sward height on the functional response of wood bison. Functional Ecology, 14, 61-69.

Best, E. C., Seddon, J. M., Dwyer, R. G., \& Goldizen, A. W. (2013). Social preference influences female community structure in a population of wild eastern grey kangaroos. Animal Behaviour, 86, 1031-1040.

Blanchard, P., \& Fritz, H. (2007). Induced or routine vigilance while foraging. Oikos, 116, 16031608.

Blumstein, D. T., Daniel, J.C., \& Sims, R. A. (2003). Group size but not distance to cover influences agile wallaby (Macropus agilis) time allocation. Journal of Mammalogy, 84, 197204.

Blumstein, D. T., \& Daniel, J. C. (2002). Isolation from mammalian predators differentially affects two congeners. Behavioral Ecology, 13, 657-663.

Bradbury, J. W., Vehrencamp, S. L., Clifton, K. E., \& Clifton, L. M. (1996). The relationship between bite rate and local forage abundance in wild Thomson's gazelles. Ecology, 77, 2237-2255. 
Burger, J., \& Gochfeld, M. (1994). Vigilance in African mammals: Differences among mothers, other females, and males. Behaviour, 131,153-169.

Cameron, E. Z., \& Du Toit, J. T. (2005). Social influences on vigilance behaviour in giraffes, Giraffa camelopardalis. Animal Behaviour, 69, 1337-1344.

Caro, T. (2005). Antipredator defenses in birds and mammals. Chicago, USA: University of Chicago Press.

Clarke, J. L., Jones, M. E., \& Jarman, P. J. (1989). A day in the life of a kangaroo: activities and movements of eastern grey kangaroos Macropus giganteus at Wallaby Creek. In: Kangaroos, wallabies and rat-kangaroos. (Ed. by G. Grigg, P. Jarman \& I. Hume), pp. 611618. Chipping Norton, UK: Surrey Beatty.

Clarke, J. L., Jones, M. E., \& Jarman, P. J. (1995). Diurnal and nocturnal grouping and foraging behaviours of free-ranging eastern grey kangaroos. Australian Journal of Zoology, 43, 519529.

Colagross, A. M. L., \& Cockburn, A. (1993). Vigilance and grouping in the eastern grey kangaroo, Macropus giganteus. Australian Journal of Zoology, 41, 325-334.

Coulson, G. (1997). Repertoires of social behaviour in captive and free-ranging grey kangaroos, Macropus giganteus and Macropus fuliginosus (Marsupialia: Macropodidae). Journal of Zoology, 242, 119-130.

Elgar, M. A. (1989). Predator vigilance and group size in mammals and birds: a critical review of the empirical evidence. Biological Reviews, 64, 13-33.

Ellard, C. G., \& Byers, R. D. (2005). The influence of the behaviour of conspecifics on responses to threat in the Mongolian gerbil, Meriones unguiculatus. Animal Behaviour, 70, 49-58.

Evans, L. N., Elgar, M. A., \& Handasyde, K. A. (2005). Risk sensitive foraging: an experimental study of a solitary marsupial. Australian Mammalogy, 27, 231-234.

Favreau, F-R., Goldizen, A.W., \& Pays, O. (2010). Interactions among social monitoring, antipredator vigilance and group size in eastern grey kangaroos. Proceedings of the Royal Society B, 277, 2089-2095.

Favreau, F-R., Goldizen, A.W., Fritz, H., Blomberg, S., Best, E. C., \& Pays, O. (in press) Withinpopulation differences in personality and plasticity in the trade-off between vigilance and foraging in kangaroos. Animal Behaviour.

Fernández-Juricic, E., \& Kacelnik, A. (2004). Information transfer and gain in flocks: the effects of quality and quantity of social information at different neighbour distances. Behavioral Ecology and Sociobiology, 55, 502-511.

Fernández-Juricic, E., Erichsen, J. T., \& Kacelnik, A. (2004). Visual perception and social foraging in birds. Trends in Ecology and Evolution, 19, 25-31.

Fernández-Juricic, E., Siller, S., \& Kacelnik, A. (2004). Flock density, social foraging, and scanning: an experiment with starlings. Behavioral Ecology, 15, 371-379. 
FitzGibbon, C. D. (1990). Mixed-species grouping in Thomson's and Grant's gazelles: the antipredator benefits. Animal Behaviour, 40, 837-845.

Fortin, D., Boyce, M. S., Merrill, E. H., \& Fryxell, J. M. (2004). Foraging costs of vigilance in large mammalian herbivores. Oikos, 107, 172-180.

Fryxell, J. M. (1991). Forage quality and aggregation by large herbivores. American Naturalist, 138, 478-498.

Giraldeau, L. A., \& Beauchamp, G. (1999). Food exploitation: searching for the optimal joining policy. Trends in Ecology and Evolution, 14, 102-106.

Hamilton, W. D. (1971). Geometry for the selfish herd. Journal of Theoretical Biology, 31, 295-311.

Hirsch, B. T. (2002). Social monitoring and vigilance behavior in brown capuchin monkeys (Cebus apella). Behavioral Ecology and Sociobiology, 52, 458-464.

Jaremovic, R. V., \& Croft, D. B. (1991). Social organization of the eastern grey kangaroo (Macropodidae, Marsupialia) in southeastern New South Wales. 1. Groups and group home ranges. Mammalia, 55, 169-185.

Jarman, P. J. (1994) .Individual behaviour and social organization of kangaroos. Physiology and Ecology Japan, 29, 70-85.

Jarman, P. J. (1987). Group size and activity in eastern grey kangaroos. Animal Behaviour, 35, 1044-1050.

Jarman, P. J., Jones, M. E., Johnson, C. N., Southwell, C. J., Stuart Dick, R. I., Higginbottom, K. B., et al.(1989). Macropod studies at Wallaby Creek. 8. Individual recognition of kangaroos and wallabies. Australian Wildlife Research, 16, 179-185.

LaGory, K. E. (1986). Habitat, group size, and the behaviour of white-tailed deer. Behaviour, 98, $168-179$.

Landeau, L., \& Terborgh, J. (1986). Oddity and the confusion effect in predation. Animal Behaviour, 34, 1372-1380.

Le Roux, A., Cherry, M. I., Gygax, L., \& Manser, M. B. (2009). Vigilance behaviour and fitness consequences: comparing a solitary foraging and an obligate group-foraging mammal. Behavioral Ecology and Sociobiology, 63, 1097-1107.

Lima, S. L., \& Bednekoff, P. A. (1999). Back to the basics of antipredatory vigilance: can nonvigilant animals detect attack? Animal Behaviour, 58, 537-543.

Maindonald, J., \& Braun, J. (2007). Data analaysis and graphics using R. An example-based approach. (2nd ed.) Cambridge, UK: Cambridge University Press.

McNamara, J. M., \& Houston, A. I. (1992). Risk-sensitive foraging: a review of the theory. Bulletin of Mathematical Biology, 54, 355-378.

Meer, E., Pays, O., \& Fritz, H. (2012). The effect of simulated African wild dog presence on antipredator behaviour of kudu and impala. Ethology, 118, 1018-1027. 
Monclùs, R., \& Rödel, H. G. (2008). Different forms of vigilance in response to the presence of predators and conspecifics in a group-living mammal, the European rabbit. Ethology, 114, 287-297.

Mooring, M. S., Fitzpatrick, T. A., Nishihira, T. T., \& Reisig, D. D. (2004). Vigilance, predation risk, and the Allee effect in desert bighorn sheep. Journal of Wildlife Management, 68, 519-532.

Pays, O., Renaud, P. C., Loisel, P., Petit, M., Gerard, J. F., \& Jarman, P. J. (2007). Prey synchronize their vigilant behaviour with other group members. Proceedings of the Royal Society $B, 274,1287-1291$.

Pays, O., \& Jarman, P. J. (2008). Does sex affect both individual and collective vigilance in social mammalian herbivores: the case of the eastern grey kangaroo? Behavioral Ecology and Sociobiology, 62, 757-767.

Pays, O., Goulard, M., Blomberg, S. P., Goldizen, A. W., Sirot, E., \& Jarman, P. J. (2009). The effect of social facilitation on vigilance in the eastern grey kangaroo, Macropus giganteus. Behavioral Ecology, 20, 469-477.

Pays, O., Blanchard, P., Valeix, M., Chamaillé-Jammes, S., Duncan, P., Périquet, S., et al. (2012). Detecting predators and locating competitors while foraging: an experimental study of a medium-sized herbivore in an African savanna. Oecologia, 169, 419-430.

Penning, P. D., Parsons, A. J., Orr, R. J., \& Hooper, G. E. (1994). Intake and behaviour responses by sheep to changes in sward characteristics under rotational grazing. Grass and Forage Science, 49, 476-486.

Périquet, S., Todd-Jones, L., Valeix, M., Stapelkamp, B., Elliot, N., Wijers, M., et al. (2012). Influence of immediate predation risk by lions on the vigilance of prey of different body size. Behavioral Ecology, 23, 970-976.

Pöysä, H. (1994). Group foraging, distance to cover and vigilance in the teal, Anas crecca. Animal Behaviour, 48, 921-928.

Pulliam, H. R. (1973). On the advantages of flocking. Journal of Theoretical Biology, 38,419-422.

Quirici, V., Castro, R. A., Oyarzun, J., \& Ebensperger, L. A. (2008). Female degus (Octodon degus) monitor their environment while foraging socially. Animal Cognition, 11, 441-448.

Repasky, R. R. (1996). Using vigilance behavior to test whether predation promotes habitat partitioning. Ecology, 77, 1880-1887.

Rieucau, G., Blanchard, P., Martin, J. G. A., Favreau, F-R., Goldizen, A. W., \& Pays, O. (2012). Investigating differences in vigilance tactic use within and between the sexes in eastern grey kangaroos. PLoS ONE, 7, e44801.

Roberts, G. (1996). Why individual vigilance declines as group size increases. Animal. Behaviour, 51, 1077-1086.

Robinson, B. G., \& Merrill, E. H. (2013). Foraging-vigilance trade-offs in a partially migratory population: comparing migrants and residents on a sympatric range. Animal Behaviour, 85, 849-856. 
Short, J.(1985). The functional response of kangaroos, sheep and rabbits in an arid grazing system. Journal of Applied Ecology, 22, 435-447.

Smith, J. W., Benkman, C. W. \& Coffey, K. (1999) The use and misuse of public information by foraging red crossbills. Behavioral Ecology, 10, 54-62.

Spalinger, D. E., \& Hobbs, N. T. (1992). Mechanisms of foraging in mammalian herbivores: New models of functional response. The American Naturalist, 140, 325-348.

Stuart-Dick, R. I. (1987). Parental investment and rearing schedules in the eastern grey kangaroo. (Doctoral thesis, University of New England, Armidale, NSW).

Unck, C. E., Waterman, J. M., Verburgt, L., \& Bateman, P. W. (2009). Quantity versus quality: how does level of predation threat affect Cape ground squirrel vigilance? Animal Behaviour, $78,625-632$.

Underwood, R. (1982). Vigilance behaviour in grazing African antelopes. Behaviour, 79, 81-107.

Venables, W. N., \& Ripley, B. D. (2002). Modern Applied Statistics with S (4th ed.) New York, USA: Springer.

Wahungu, G. M., Catterall, C. P., \& Olsen, M. F. (2001). Predator avoidance, feeding and habitat use in the red-necked pademelon, Thylogale thetis, at rainforest edges. Australian Journal of Zoology, 49, 45-58.

Wilmshurst, J. F., Fryxell, J. M., \& Colucci, P. E. (1999). What constrains daily intake in Thomson's gazelles? Ecology, 80, 2338-2347. 


\section{Figure legends}

Figure 1. (a) Frequencies of foraging patches with different proportions of green vegetation in winter $(N=168)$ and summer $(N=126)$. (b) Frequencies of biomass categories of foraging patches in winter $(N=168)$ and summer $(N=126)$. (c) Frequencies of patches used by female kangaroos in winter $(N=168)$ and summer $(N=126)$ that were poor, medium or rich 


\section{Figures and Tables}

Figure 1.
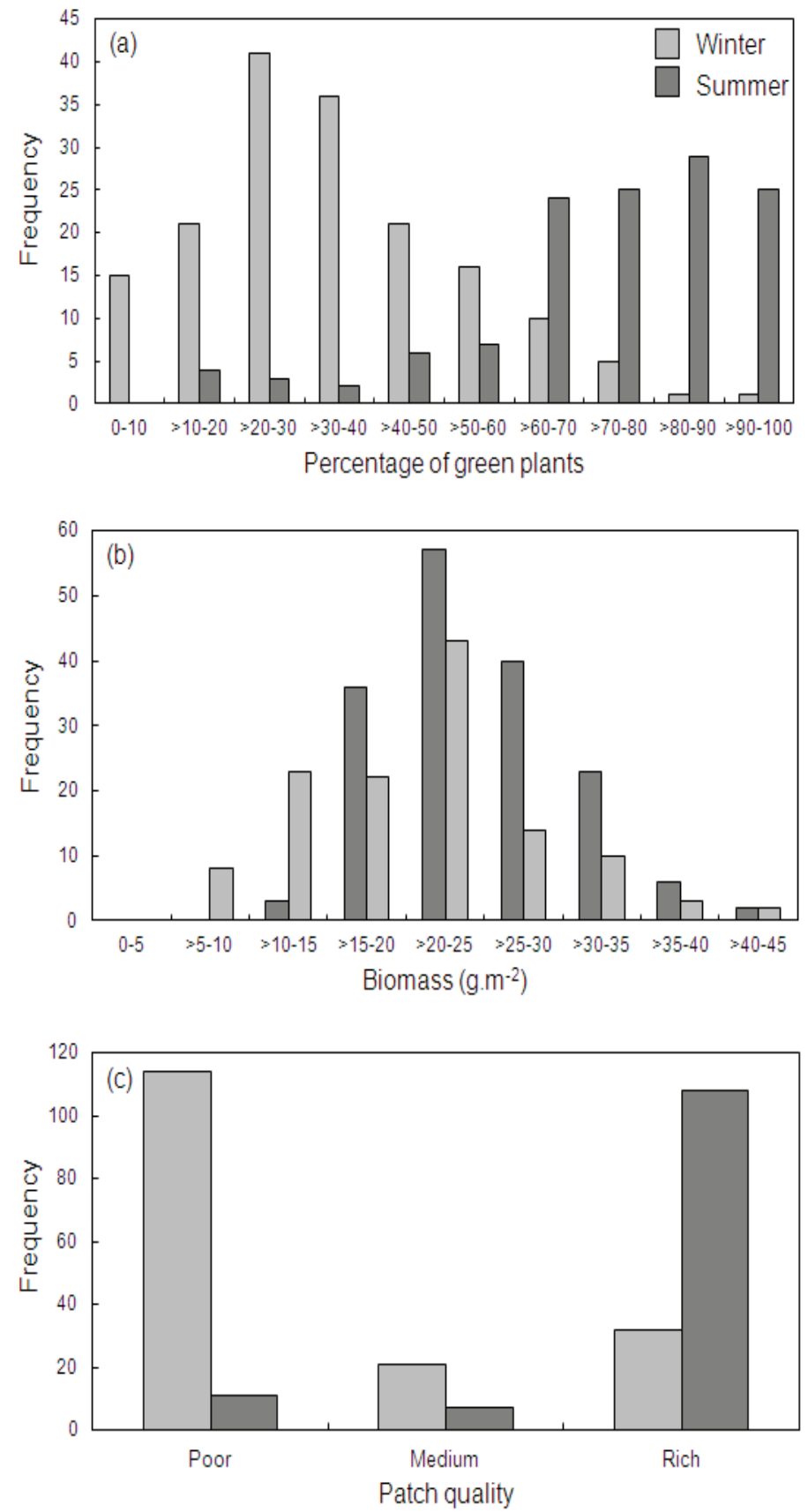


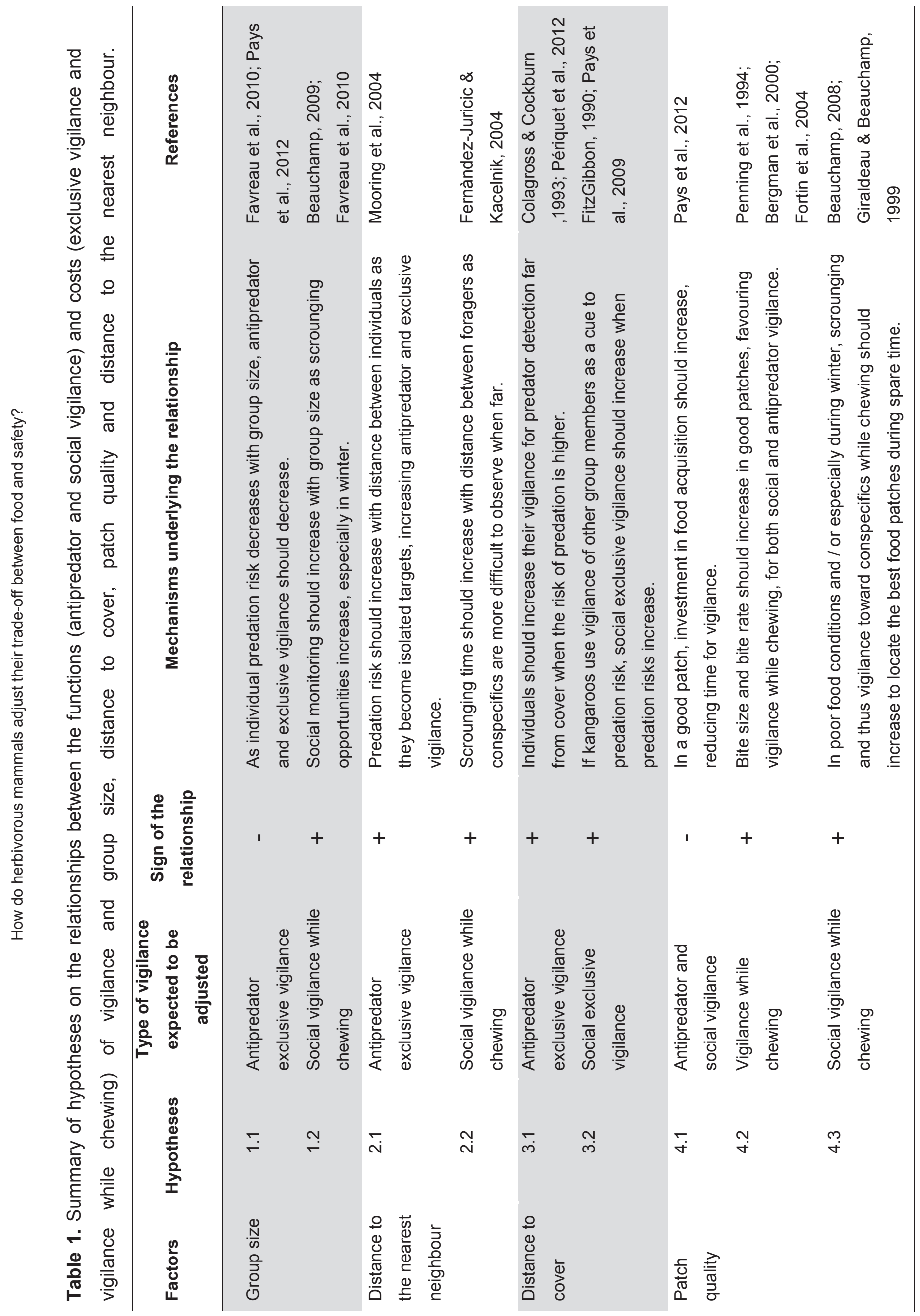


Table 2. Table of patch quality indices for short grass grazers in relation to patch biomass and greenness.

\begin{tabular}{|c|c|c|c|c|c|c|c|}
\hline \multirow{2}{*}{$\begin{array}{l}\text { Biomass } \\
\text { (g.m-2) }\end{array}$} & \multicolumn{7}{|c|}{ Percentage of green grass } \\
\hline & $0-40 \%$ & $>40-50 \%$ & $>50-60 \%$ & $>60-70 \%$ & $>70-80 \%$ & $>80-90 \%$ & $>90-100 \%$ \\
\hline $0-5$ & poor & poor & med & med & med & med & med \\
\hline$>5-10$ & poor & poor & med & rich & rich & rich & rich \\
\hline$>10-15$ & poor & med & med & rich & rich & rich & rich \\
\hline$>15-20$ & poor & med & rich & rich & rich & rich & rich \\
\hline$>20-25$ & poor & med & rich & rich & rich & rich & rich \\
\hline$>25-30$ & poor & med & rich & rich & rich & rich & rich \\
\hline$>30-35$ & poor & med & rich & rich & rich & rich & rich \\
\hline$>35-40$ & poor & med & med & rich & rich & rich & rich \\
\hline$>40-45$ & poor & poor & med & rich & rich & rich & rich \\
\hline$>45-50$ & poor & poor & poor & med & med & rich & rich \\
\hline$>50-55$ & poor & poor & poor & med & med & med & med \\
\hline$>55-60$ & poor & poor & poor & med & med & med & med \\
\hline
\end{tabular}




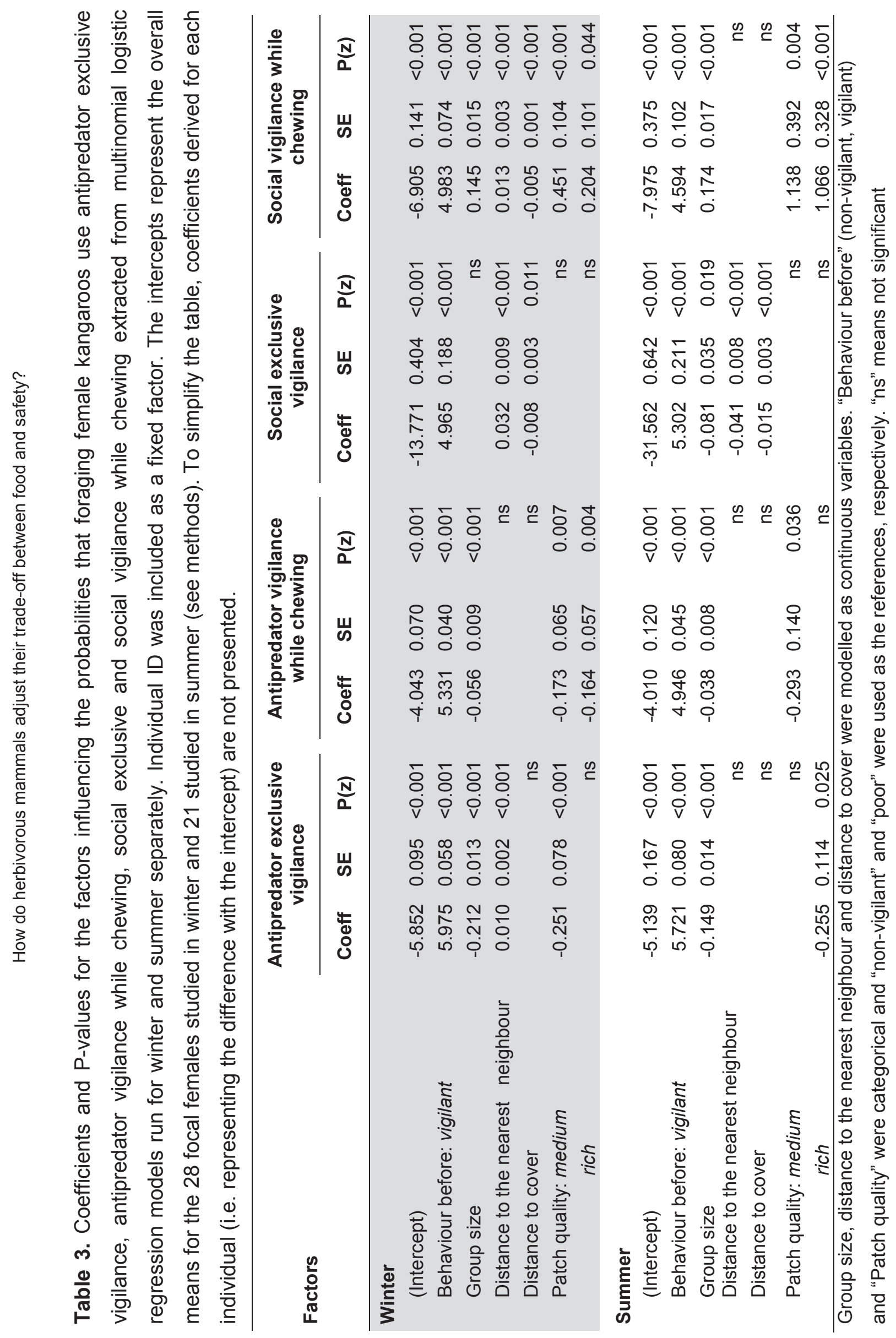




\title{
Chapter 5:
}

\section{Within-population differences in personality and plasticity in the trade-off between vigilance and foraging in kangaroos}

\author{
François-René Favreau, Anne W. Goldizen, Hervé Fritz, Simon P. Blomberg, Emily C. \\ Best, Olivier Pays
}

\section{Abstract}

Behavioural traits can vary between individuals from the same population. These differences can involve consistent variation in the level of a particular behaviour (personality) or differences in the way individuals adjust their behaviour to environmental gradients (plasticity). In prey species, feeding rates and vigilance vary with environmental, social and individual factors and the feeding rate/vigilance relationship reflects the trade-off between food acquisition and safety. While feeding rates and vigilance have been shown to vary between individuals in relation to group size and predation risk, how they relate to other factors has not yet been investigated, nor has betweenindividual variation in this trade-off. We studied between-individual variation in vigilance, feeding rates and their trade-off in female eastern grey kangaroos, Macropus giganteus, to see whether females showed consistent behavioural differences and different plasticity in relation to ecological (food patch richness), social (group sizes) and physiological (reproductive states) conditions. We addressed two contrasting hypotheses: an "ecological" hypothesis under which individuals facing the same conditions should behave similarly, and a "behavioural" hypothesis under which they should behave differently because of their own personality or plasticity. Female kangaroos tended to adjust their behaviours similarly in relation to ecological and social conditions, supporting the ecological hypothesis. However, they also showed differences in personality and plasticity in relation to their reproductive states that could not be explained by energetic demand alone; this was suggestive of different maternal strategies, thus supporting the behavioural hypothesis. Altogether these results suggest that consistent differences in animals' personality and behavioural plasticity can be promoted by physiological conditions and are not necessarily repeatable across different ecological contexts.

Keywords: behavioural plasticity; feeding rate; herbivore; kangaroo; Macropus giganteus; personality; vigilance. 


\section{Introduction}

Many behavioural traits are considered to be plastic, allowing individuals to adjust their responses to temporal variation in extrinsic and intrinsic factors (Briffa, Rundle, \& Fryer, 2008; Hazlett, 1995). For instance, many prey animals have been shown to adjust their time allocated to vigilance and their feeding rate as group sizes vary (e.g. Lima, 1995; Rieucau \& Giraldeau, 2009). Because numerous empirical studies have demonstrated that ecological drivers strongly affect behavioural adjustments, animals from the same population have often been assumed to behave similarly and many studies have considered unexpected individual variation in behaviour as "noise" (reviewed by Lott, 1991). However, more recent studies have focussed on between-individual behavioural variation in a wide range of behaviours and demonstrated that a general pattern observed at the population level can hide a diversity of individuals' strategies (e.g. Carter, Pays, \& Goldizen 2009). Different individuals from a single population can exhibit (1) consistent behavioural differences in their mean levels of a behaviour (personality) (Briffa et al., 2008; Dall, Houston, \& McNamara, 2004; Dingemanse et al., 2007; Sih, Bell, Johnson, \& Ziemba, 2004), but also (2) different behavioural adjustments in response to environmental gradients (plasticity) (Dingemanse, Kazem, Réale, \& Wright, 2010). Two alternative hypotheses can be proposed to explain patterns of within-population behavioural differences. Under an "ecological hypothesis", individuals who experience similar ecological or social conditions (e.g. patch quality, predation risk, or group size) and have similar traits (e.g. age-sex class, body size, or reproductive state) should experience the same ecological constraints and behave in the same way. In contrast, under a "behavioural hypothesis", individuals should exhibit behavioural variation (different personalities) even when experiencing similar conditions and having similar characteristics, and may also show different behavioural adjustments to environmental conditions (different patterns of plasticity).

Between-individual variation has recently received considerable attention and has been shown to have both genetic and non-genetic bases (Nussey, Wilson, \& Brommer, 2007), with the latter including individuals' past experiences (Stamps \& Groothuis, 2010) or differing ecological and social niche specializations (Montiglio, Ferrari, \& Réale, 2013). To investigate the existence of between-individual variation in personality and plasticity, recent studies have adopted a single framework called "behavioural reaction norms". This framework can be graphically represented by plotting an individual's behavioural response (y-axis) as a function of an environmental gradient ( $x$ axis). The individual can be characterised by the intercept and the slope of its response, representing personality and plasticity respectively (Dingemanse et al., 2010; Nussey et al., 2007). Therefore, under this framework, when individuals' behavioural responses do not differ in their intercepts and slopes, they do not exhibit different personalities or plasticity, when only the intercepts differ they show different personalities but similar plasticity in relation to the environmental gradient, and when both intercepts and slopes differ, they show different personalities and plasticity (Dingemanse et al., 2010). 
Although a wide range of behavioural traits have been examined under this framework (reviewed by Mathot, Wright, Kempenaers, \& Dingemanse, 2012), between-individual differences in vigilance and foraging activities have received little attention, despite these activities being crucial for the survival and fitness of many species. Indeed, vigilance is often assumed to incur foraging costs by limiting time available for feeding and by decreasing feeding rates, leading ultimately to a potential trade-off between foraging and vigilance activities (Lima \& Dill, 1990). Negative relationships between vigilance time and feeding rate have been reported in many taxa (e.g. Cowlishaw et al., 2004; Fritz, Guillemain, \& Durant, 2002; Ruckstuhl, Festa-Bianchet, \& Jorgenson, 2003) and provide information on both the impact of a high investment in vigilance in terms of feeding rate and the ability of individuals to adjust their feeding rate with vigilance.

Despite vigilance, feeding rates and their trade-off not being considered as personality traits themselves, they have recently been shown to reflect animals' boldness in different species, with bolder individuals spending less time in vigilance and exhibiting higher feeding rates (e.g. Bergvall, Schäpers, Kjellander, \& Weiss, 2011; Carter, Goldizen, \& Heinsohn, 2012; Edwards, Best, Blomberg, \& Goldizen, 2013). In addition, while vigilance and feeding rates are known to be affected by ecological drivers and individual traits such as group size (e.g. Rieucau \& Giraldeau, 2009), food patch characteristics (e.g. Beauchamp, 2009; Pays et al., 2012) and reproductive state, including the presence of dependent young (e.g. Childress \& Lung, 2003; Ruckstuhl et al., 2003), these behaviours have been shown to vary between individuals. For example, Rieucau, Morand-Ferron, \& Giraldeau (2010) studied vigilance levels and feeding rates in nutmeg manakins, Lonchura punctulata, in relation to group size and found that individuals differed in their mean response levels but showed similar adjustments as group size increased. In contrast, Carter, Pays, et al. (2009) found that eastern grey kangaroos, Macropus giganteus, exhibited significant differences in their mean levels of vigilance and also differed in their responses to an increase in group size. Finally, Mathot et al. (2011) showed that red knots, Calidris canutus islandica, varied in their adjustment of vigilance when predation risk increased. While these studies showed that patterns of vigilance and feeding rates can vary between individuals in relation to group size and predation risk, it is not known how they vary in relation to other environmental or individual conditions. In addition, it is not known whether between-individual variation exists in the trade-off between feeding rates and vigilance and if this variation varies in different contexts.

We studied wild female eastern grey kangaroos to test whether patterns of individual variation in vigilance, feeding rate, and in the feeding rate/vigilance trade-off fitted the predictions of the ecological or behavioural hypotheses in relation to three environmental, social and physiological conditions. To do this, we used the behavioural reaction norm approach to test (1) whether there were overall adjustments of vigilance and feeding rates to changes in group size, patch richness and reproductive state across the population, (2) whether individuals differed in their responses to these factors, (3) whether group size, patch richness, and reproductive state affected the trade-off between feeding rate and vigilance across the population, and (4) whether 
individuals experiencing similar environmental or social conditions (food patch richness or group size) or reproductive states differed in their trade-off between feeding rate and vigilance. Eastern grey kangaroos exhibit a fission-fusion social system, forming open-membership mixed-sex groups with individuals frequently joining and leaving groups (Clarke, Jones, \& Jarman, 1995; Jarman, 1987). We focussed on females as they have been shown to be more vigilant than males (Pays \& Jarman, 2008), and as males were far less common in our population, collecting enough data for our analyses would have been challenging. Associations between females have been shown to be non-random (Best, Seddon, Dwyer, \& Goldizen, 2013), with some females having preferred associates (Best, Dwyer, Seddon, \& Goldizen, 2014; Carter, MacDonald, Thomson, \& Goldizen, 2009), showing that females differ in their patterns of sociability. In addition, between-individual variation in vigilance has been previously described (Carter, Pays, et al. 2009; Dannock, Blomberg, \& Goldizen, 2013) and related to boldness in eastern grey kangaroos, tending to support the behavioural hypothesis (Edwards et al., 2013). Ecological drivers and individuals' characteristics such as group size, patch attractiveness and reproductive states have also been reported to shape feeding rates and/or vigilance in this species (e.g. Favreau, Goldizen, \& Pays, 2010; Garnick, Elgar, Beveridge, \& Coulson, 2010; Gélin, Wilson, Coulson, \& Festa-Bianchet, 2013; Pays, Jarman, Loisel, \& Gerard, 2007).

\section{Materials and methods}

\section{- Study site and animals}

Data collection was conducted in Sundown National Park (Queensland, Australia, 289'S, $151^{\circ} 58$ 'E) for two weeks per month from January until December 2011. The study site was composed of open pastures surrounded by mixed open forests predominantly containing eucalypts, Eucalyptus melanophloia, and pines, Callitris intratropica. The study area contained 240 females and approximately 80 males (Best et al., 2013). Predators included red foxes, Vulpes vulpes, wedge-tailed eagles, Aquila audax, and possibly dingoes, Canis lupus dingo. All field work complied with the current laws of Queensland and Australia. This research was conducted with clearance from the University of Queensland's Animal Ethics Committee (AEC Approval Number: SIB/206/09/NF) and a Scientific Purposes Permit from Queensland's Department of Environment and Resource Management.

\section{- Sampling of individuals}

We followed 34 identified adult female kangaroos of similar body size over the year. Identification of focal females was done using features such as ear shape, dark or pale patches on the fur and facial markings and scars, and allowed the observer to follow specific females and avoid re-sampling individuals on the same day (Best et al., 2013; Coulson, 1997; Jarman et al., 
1989). Since eastern grey kangaroos mainly forage at night, dawn and dusk and rest during the hot part of the day (Clarke, Jones, \& Jarman, 1989), the observations were conducted during late afternoons and early mornings when light intensity was sufficient for accurate observations. The observer (F-RF) collected behavioural data by filming (video camera: Sony DCR-SR37, 60× optical zoom, Sony Corporation, Tokyo, Japan) the focal adult females for 10 minutes while they foraged in groups on the pasture. Videos were recorded by an observer on foot, keeping a minimum distance of $30 \mathrm{~m}$ between the focal individual and the observer to minimize disturbance. Because of the nearly continuous presence of researchers in the area, the kangaroos' behaviour did not seem to be affected by our presence during the study. The video sequences were used only if the group in which the focal animal was observed remained constant in size and composition during the observation period. To determine which individuals were included in a group, we used Jarman's "chain rule" (1987), considering individuals who were within $15 \mathrm{~m}$ of their nearest neighbour to be part of the group. The observer never sampled a female more than once per observation session, and so individuals were sampled twice a day at the most. However, on some occasions several focal females were sampled consecutively in the same group. We collected between 32 and 38 focal samples per female, resulting in a total of 1135 behavioural observations from 962 groups.

\section{- Quantifying behaviour}

Vigilance bouts were defined as when kangaroos raised their head above horizontal while either crouched or standing upright, and looked fixedly in one direction or scanned their surroundings (Jarman, 1987; Pays, Renaud, et al. 2007b). We quantified bites either by direct observation of bites being taken or based on the quick jerky movements of the head characteristic of the biting of vegetation (Watson \& Dawson, 1993). From each video sequence, we extracted the time spent in vigilance and the number of bites taken. We then calculated the proportions of time spent by kangaroos in vigilance and their bite rates (number of bites taken per minute) for each 10 min focal sample.

To study individuals in similar conditions, we measured the following variables for each focal sample. We recorded the group sizes and then categorized them into "small" groups (from 1 to 4 individuals) and "large" groups (from 5 to 30 individuals). We chose these categories because the mean \pm SD group size during our observation was $4.64 \pm 3.5$. We also measured characteristics of the patches exploited by focal individuals in terms of the quantity and quality of vegetation available. To do this, the observer estimated the height of the vegetation where the animal had spent most of its time feeding during the observation. Vegetation height was measured with a pasture meter (PM) and converted into biomass of plants. For the conversion, we calibrated the pasture meter for each season (i.e. summer, autumn, winter, and spring) by selecting 60 patches of different heights. The relationship between vegetation height and biomass was measured by clipping, drying and weighing the plant biomass below the pasture meter (Summer: biomass $=4.26$ 
$+2.29 \times \mathrm{PM}$ height, $P<0.001$, adjusted $\mathrm{R}^{2}=0.85, N=60 ;$ Autumn: biomass $=4.53+2.86 \times \mathrm{PM}$ height, $P<0.001$, adjusted $\mathrm{R}^{2}=0.87, N=60$; Winter: biomass $=12.09+2.66 \times \mathrm{PM}$ height, $P<$ 0.001 , adjusted $\mathrm{R}^{2}=0.87, N=60$; Spring: biomass $=8.34+3.11 \times \mathrm{PM}$ height, $P<0.001$, adjusted $\left.\mathrm{R}^{2}=0.86, N=60\right)$. To record the quality of the patches, the observer used a quadrat $(90 \times 90 \mathrm{~cm})$ with 81 grid crossings, and assigned a greenness index for all plants under each grid crossing. This index was comprised of two categories, brown (plants with low energetic value) and green (plants with high energetic value) (Bradbury, Vehrencamp, Clifton, \& Clifton, 1996), and allowed us to estimate the percentage of plants that were green for each food patch.

These two characteristics of food patches allowed us to attribute a single patch richness index (i.e. poor patch, medium patch, rich patch) to each focal animal's feeding patch. As kangaroos prefer green grass and tend to avoid long dry grass (Bell, 1973; Clarke et al., 1989), the relationship between greenness, biomass and food intake is complex. Studies on the feeding preferences of other short-grass grazers of similar body size to the eastern grey kangaroo, such as sheep, Ovis aries, Thomson's gazelles, Gazella thomsoni, and red kangaroos, Macropus rufus, have shown that increasing grass biomass generally decreased digestibility (Fryxell, 1991). Such herbivores therefore tended to preferentially exploit patches of low to intermediate biomass for which forage digestibility remained high (Bradbury et al., 1996; Short, 1985; Wilmshurst, Fryxell, \& Colucci, 1999). Under this framework we established an index of patch richness, in which rich patches were those at or within $30 \%$ of the optimum biomass and greenness for herbivores of kangaroo size, medium patches of intermediate richness were those from 31 to $60 \%$ from the optimal patch characteristics, and the poor patches were those furthest from the optimum (Table $1)$.

Following Jaremovic and Croft (1991) and Gélin et al. (2013), we recorded the presence and the size of pouch young and young-at-foot of females (hereafter termed "reproductive states"), as these should reflect the females' energetic needs due to lactation demand. We differentiated females with no visible pouch-young (NPY), a small pouch-young (SPY), a medium pouch-young (MPY; when the young's head was sometimes visible), a large pouch-young (LPY; when the young left the pouch for short periods of time), or a young-at-foot (YAF; when the young was permanently out of the pouch but still nursing). In cases where a female had both a YAF and a SPY this was classified as YAF since the energetic demands of the SPY would have been much smaller than those of the YAF.

\section{- Statistical analyses}

To test for the effect of time of the day on vigilance, feeding rates and their trade-off, we included this variable in our preliminary analyses. As it was never significant, we excluded time of the day from subsequent analyses. To test for the effects of group size, patch richness, and reproductive state on the vigilance and feeding rates of female kangaroos, we used linear mixed effect models with the proportion of time spent in vigilance and bite rate as the response variables, 
respectively, and group size category (small and large), patch richness (poor, medium and rich) and reproductive state (NPY, SPY, MPY, LPY, and YAF) as fixed effects, including individual identity as a random effect.

To test for between-individual variation in the levels and plasticity of the behavioural responses (vigilance and bite rates) to changes in group size, patch richness and reproductive state, we used linear random regressions following the reaction norm approach (Dingemanse et al., 2010; Nussey et al., 2007). We tested for consistent individual differences (i.e. individual variation in intercepts) in how vigilance and feeding rates were affected by each factor (group size, patch richness and reproductive state) separately. To achieve this we compared simple linear models with vigilance or bite rate as the response variables and the factor as a fixed effect, to the same models but also including individual identity as a random effect. Then to test for betweenindividual differences in the plasticity of individual responses (i.e. individual variation in slopes), we compared each previous mixed effects model with a model including the interaction between the factor tested and female identity as a random effect.

To test for behavioural differences in the trade-off between vigilance and feeding rates across conditions, we first adapted the reaction norm approach described previously to compare the average responses across all individuals to each particular condition for each factor tested (group size, patch richness, reproductive state). We thus compared for each factor a model containing bite rate as the response variable and the proportion of time spent in vigilance as a fixed effect to the same models but also including the factor tested as a random effect to test for consistent differences between conditions. Then to test for between-condition differences in plasticity, we compared the previous mixed effects model to a model including the interaction between the proportion of time spent in vigilance and the factor tested as a random effect.

Finally, to test for between-individual variation in the trade-off between vigilance and feeding rates in each particular condition, we adapted the same method by first comparing a model including bite rate as the response variable and the proportion of time spent in vigilance as a fixed effect to the same model but also including individual identity as a random effect. We then compared that last model to a model also including the interaction between the proportion of time spent in vigilance and the individual identity as a random effect.

We performed comparisons of models using R ( $R$ Development Core Team 2013) and the Ime function from the nlme package in R 3.0.1 (Pinheiro et al., 2013), which allowed us to compare models with and without random effects. To satisfy assumptions of normality and to achieve linearity between bite rate and vigilance, the proportion of time spent in vigilance was arcsine square-root transformed in all models. The model comparisons were done with a likelihood ratio test (following Rieucau et al., 2010) investigating the effect of adding one random effect to a model (Pinheiro \& Bates, 2000). Based on simulations, Martin, Nussey, Wilson, and Réale (2011) argued that to test for individual variation using random regression models, the minimum sample size should be 200 observations and the ratio between the number of individuals and the number of 
observations per individual should be at least 0.5 . In our study we made 1135 observations on 34 females sampled between 32 and 38 times each, giving a ratio between 0.89 and 1.06. Therefore this sample size should provide enough power to detect potential between-individual variation in personality and plasticity.

\section{Results}

\section{- Factors influencing vigilance and feeding rate}

On average, individuals decreased their vigilance and increased their feeding rates as group size increased (Table 2, Figure 1a, b). Neither patch richness nor reproductive state significantly affected either vigilance or feeding rates (Table 2, Figure 1c-f).

\section{- Individual differences of vigilance and feeding rate}

For each of the three factors tested, the addition of individual identity as a random effect in our models of both vigilance and feeding rates significantly improved their fits (Table 3 ). The addition of the interaction between individual identity and the factor tested only improved the fits of the models for reproductive state for both vigilance and feeding rates (Table 3). This suggests that individuals exhibited consistent behavioural variation but similar plasticity in vigilance and feeding rates as group size and patch richness varied (i.e. different intercepts, equal slopes), and consistent behavioural variation as well as different patterns of plasticity as reproductive state varied (i.e. different intercepts and slopes) (Figures 1a-f).

\section{- Factor influencing the feeding rate/vigilance trade-off}

The addition of the factors tested as a random effect in the models of the trade-off between feeding rates and vigilance was only significant for reproductive state, as was the addition of the interaction between the proportion of time spent in vigilance and reproductive state as a random effect (Table 4). Therefore, on average individuals adjusted their feeding rate/vigilance trade-off similarly in different group sizes and in patches of different richness, but exhibited different adjustments in relation to their reproductive states (Figures 2a-c).

\section{- Individual differences in the feeding rate/vigilance trade-off}

When we fitted models for each specific condition within each factor, the addition of individual identity as a random effect in the models was significant for small groups, rich food patches and all reproductive states. The addition of the interaction between the proportion of time spent in vigilance and individual identity as a random effect was significant only for females with a young-at-foot (Table 5). Therefore, individuals in large groups, as well as in poor and medium food patches, did not differ consistently in their levels of the vigilance/feeding trade-off or their patterns 
of plasticity for this trait (i.e. no differences in intercept or slopes). Individuals in small groups, rich food patches, and without an apparent pouch young, or with a small, medium or large pouch young, consistently differed in their trade-off between feeding rates and vigilance but showed similar plasticity (i.e. different intercepts but similar slopes) in this trade-off. Individuals with a young-at-foot exhibited both consistent variation in their levels of the trade-off and different patterns of plasticity (i.e. different intercepts and slopes) (Figures 3a-c).

\section{Discussion}

We used the reaction norm approach to investigate whether the mean levels and plasticity of vigilance, feeding rates and the trade-off between them varied between individuals as a function of group size, food patch richness and reproductive states for female eastern grey kangaroos. Our results highlighted that different patterns occurred for the factors considered. Behavioural adjustments in different group sizes and food patches of different richness seemed to be mainly affected by ecological drivers and thus supported the ecological hypothesis, with some support also for the behavioural hypothesis, whereas adjustments in relation to females' reproductive states seemed to strongly support the behavioural hypothesis.

Group size affected vigilance negatively and feeding rates positively at the population level, and although all individuals showed the same patterns of plasticity for these traits, they exhibited consistent variation in their levels of vigilance and feeding rates. It is well known that larger groups are safer and thus allow individuals to reduce their time spent in vigilance to the benefit of foraging, explaining the higher foraging rates often observed in large groups (Lima, 1995). The decrease in vigilance with group size has been observed in eastern grey kangaroos (e.g. Jarman, 1987; Pays, Jarman, et al., 2007), as was between-individual variation in this pattern (Carter, Pays, et al., 2009). However, while we only observed between-individual variation in vigilance levels, Carter, Pays, et al. (2009) reported both variations in levels as well as in the adjustments to vigilance as group size increased. These differences may have been due to differences in predation risk or levels of competition between the populations studied. Our results are consistent with the findings of Rieucau et al. (2010), who observed consistent between-individual differences but similar plasticity for vigilance and feeding rates in nutmeg manakins as group size increased. Overall, female kangaroos did not differ in their feeding rate/vigilance trade-off as group size increased, whereas within the different group sizes, the patterns differed. Female kangaroos showed consistent individual variation in this trade-off in small groups but this was not quite significant in larger groups. Large groups have been shown to induce scramble competition between foragers and several studies have supported the idea that the increase in foraging effort in such groups is mainly due to the increasing competition rather than the decrease in predation risk (e.g. Randler, 2005; Rieucau \& Giraldeau, 2009). Therefore, increasing competition in large groups could be 
responsible for the greater standardization of feeding rates as all the individuals would tend to increase their foraging effort to their maximum capacity.

Surprisingly, patch richness did not affect either vigilance or feeding rates, although individuals consistently displayed different levels for both behaviours. We expected patch richness to affect kangaroos' behaviour and especially their feeding rates. Garnick et al. (2010) observed that kangaroos had lower feeding rates in tall swards compared to short swards. This pattern is common in herbivores and arises because they usually take larger bites in tall swards, which require longer chewing time, leading to an inverse relationship between bite rate and bite mass (Spalinger \& Hobbs, 1992). Clarke et al. (1989) argued that the lower feeding rates and vigilance levels that they observed in winter compared to summer occurred because patch quality declined in this season and kangaroos took more time to select food items, which suggests that patch richness should affect vigilance and feeding rates. The absence of an effect of patch richness on individual feeding rates may suggest that, during our study, the range of variation in patch quality in the study area might have been insufficient to force individuals to be more selective at some times than others. Overall, patch richness had no effect on the feeding rate/vigilance trade-off, but individuals in rich food patches showed consistent inter-individual differences in this trade-off. In poor and medium patches individuals did not differ in their feeding rate/vigilance trade-offs, probably because they were relatively constrained in terms of food acquisition compared to individuals in rich food patches and needed to maximize their intakes, and maybe also because scramble competition is usually higher when food quality and density are low (Beauchamp, 2009).

Two possible explanations for consistent individual variation in feeding rates, vigilance and their trade-off involve females' ages and personalities. According to Nielsen (1999), consistent differences in feeding rates between individuals under similar conditions may be due to age differences, because age is known to cause changes in body size and the capacity of the mouth in terms of bite sizes (Illius \& Gordon, 1987; Shipley, Gross, Spalinger, Hobbs, \& Wunder, 1994). Old animals are also usually more vulnerable to predation (e.g. Peterson, Woolington, \& Bailey, 1984), which should affect their vigilance patterns. We did not know the actual age of each focal female, but we only studied individuals that were adults and of apparently similar body sizes and ages. Thus the effect of potential differences in the ages of adult females was expected to be limited.

We therefore suggest that the consistent individual differences in feeding rates, vigilance and their trade-off may reflect aspects of female kangaroos' personalities. Indeed, personality has been shown to be related to foraging tactics in some taxa, with bolder animals feeding for longer and exhibiting higher feeding rates and intake rates than shy individuals (Bergvall et al., 2011; Carter, Goldizen, \& Tromp, 2010; Kurvers et al., 2010). Although the possibility of a relationship between foraging and boldness has not yet been tested in eastern grey kangaroos, recent studies have shown that females exhibit different personalities along a bold-shy continuum and that shyer individuals are more vigilant than bolder ones (Best, 2013; Edwards et al., 2013). In addition, Webster and Ward (2011) developed the idea that increases in conformity (i.e. the tendency of 
individuals to adopt the behaviour of the majority of their group mates) and social facilitation (i.e. the changing of behaviours by individuals due to the presence of group mates) in large groups could be responsible for a decrease in the expression of personality types. Our results are consistent with this hypothesis as individual differences in the feeding rate/vigilance trade-off occurred in small groups but not in large ones.

While we suggest that individual variation in vigilance and feeding rates reflects kangaroos' personalities, our results suggest that consistent behavioural differences (or personalities) in the feeding rate/vigilance trade-off may only occur when constraints on foraging are low (i.e. in small groups and rich food patches). When individuals were constrained by food acquisition, they seemed to exhibit similar adjustments, probably to optimize their food intake, mainly supporting the ecological hypothesis. In addition, there were no significant individual differences in patterns of plasticity in feeding rates, vigilance or the trade-off between these behaviours when group sizes and food patches varied, nor for any of the different conditions tested. Therefore, food availability and competition appear to be strong drivers of feeding rate and vigilance, causing animals to exhibit similar patterns of plasticity, in accordance with the ecological hypotheses.

The effects of reproductive state on vigilance, feeding rates and their trade-off were different to those of group size and patch richness. At the population level, the presence of pouch-young of different sizes and of young-at-foot had no effect on either vigilance or feeding rates. The presence of young has been shown to affect mothers' vigilance levels in some species because they have to protect themselves as well as their young from predators (e.g. Burger \& Gochfeld, 1994; Childress \& Lung, 2003). However, in eastern grey kangaroos, several studies have not observed this relationship; instead of modifying their vigilance time, mothers adapted their time budgets by reducing their time resting, increasing their foraging time and increasing their feeding rates (Cripps, Wilson, Elgar, \& Coulson, 2011; Gélin et al., 2013). Reproduction is costly for females because gestation and lactation have high energetic requirements (Robbins, 1983), often leading to higher bite rates for reproducing females compared to other individuals (e.g. Neuhaus \& Ruckstuhl, 2002; Ruckstuh et al., 2003). We did not find any effect of reproductive state on feeding rates at the population level, but at the individual level, females showed consistent differences in how their feeding rates and vigilance adjusted to reproductive state. It appears that the diversity of behavioural strategies displayed by the different individuals masked any general effect at the population level. As we suggest above, differences in vigilance and feeding rates are probably related to individual personalities. In addition, differences in patterns of plasticity between individuals have been shown to be related to genetics, past experiences and interactions between these (Dingemanse \& Wolf, 2013). In the case of reproductive state, we suggest that females' past breeding experiences (e.g. the number of young previously raised and/or lost) could partly explain differences in their behavioural plasticity.

Overall, the adjustment of feeding rates to vigilance varied among reproductive states. Therefore, the potential cost of vigilance to feeding rates seemed to vary with lactation demand. At 
low vigilance levels, females exhibited higher feeding rates as reproductive state progressed from females having no pouch-young to females having large pouch-young. However, as vigilance increased, the diminution of feeding rates was more severe when females had pouch-young than when they did not. Surprisingly, females with young-at-foot and females with no pouch-young exhibited similar trade-offs between feeding rates and vigilance, which was not expected as the young-at-foot stage is assumed to be the more "costly" reproductive state due to higher lactation demand (Gélin et al., 2013). Because we observed that the cost of vigilance increased with reproductive state, we would assume that females with young-at-foot would exhibit higher feeding rates at low vigilance levels and incur the severest foraging cost as vigilance increased. Nevertheless, when we investigated females' adjustments within the different reproductive states, we observed consistent differences between individuals in all reproductive states, but different patterns of plasticity only for females with a young-at-foot. We suggest that, as for the variation observed at the individual level for vigilance and feeding rates, described above, the diversity of strategies employed by the different individuals with a young-at-foot may explain this unexpected observation at the population level.

The fact that only females with young-at-foot exhibited different patterns of plasticity in this trade-off could have several explanations. First, although we did not control for the sex of the young-at-foot, part of the plasticity observed in behavioural adjustments may reflect different investment and behavioural strategies of females according to the sex of their offspring. In many species, the cost of reproduction differs in relation to the sex of the offspring produced (Gélin et al., 2013). Sons are usually costlier than daughters to produce because they are larger and tend to suckle more and because they usually impose greater delays on their mother's return to oestrus (e.g. Hogg, Hass, \& Jenni, 1992). Second, differences in behavioural adjustments may reflect differences in maternal care displayed by females. Consistent differences in maternal care, termed "maternal styles" (Hill, Greer, Solangi, \& Kuczaj, 1997), have been documented in many primates, including humans, and in other mammals (see Fairbanks, 1996 for a review) such as eastern grey kangaroos (Stuart-Dick, 1987). Maternal care in eastern grey kangaroos involves behaviours such as grooming, protection, playing and lactation (Kaufmann, 1975; Cripps et al., 2011), and could therefore affect vigilance and foraging behaviours. Flexibility in maternal care has been associated with mothers' personalities and could be related to their previous maternal experiences (Bard, 2002; Fleming \& Li, 2002). Our results on females in different reproductive states indicate that the ecological hypothesis is not sufficient to explain the variation in females' feeding rates, vigilance and their trade-offs because individuals showed (1) consistent differences and differing patterns of plasticity in vigilance and feeding rates when their reproductive states varied, (2) consistent differences in their trade-off between these behaviours in all reproductive states and (3) different patterns of plasticity in this trade-off in the most energetically demanding condition. Therefore individuals' characteristics appear to induce more complex and diverse behaviours than do external and social factors, which appears to support the behavioural hypothesis. 
In summary, herbivorous prey species have to adjust their behaviour to maximize their fitness and survival. Individuals' adjustments of foraging and vigilance would therefore be expected to be comparable when individuals face similar conditions. We found that the effects of factors external to the individuals (group size and patch richness) might reflect certain aspect of individuals' personalities that were more likely to be expressed when foraging constraints were low, and did not induce differences in plasticity. We also observed a high degree of between-individual differences in personalities and plasticity in relation to reproductive state for vigilance and feeding rates as well as in the trade-off between these behaviours when females had a young-at-foot. Therefore individual differences in the levels and plasticity of vigilance and foraging behaviour appear to be specific to different situations and not necessarily repeatable across contexts. More studies are required to examine the effects of these factors on personality and plasticity in the behaviour of wild animals under different conditions.

\section{Acknowledgments}

We thank Bénédicte Bouvy for assistance in the field, and Alecia Carter for comments on a draft of this paper. We also thank the rangers at Sundown National Park for their support. Finally, we are grateful to Alexander Weiss and an anonymous referee for their valuable comments on previous versions of the manuscript. 


\section{References}

Bard, K. (2002). Primate parenting. In: Handbook of parenting, Biology and ecology of parenting Vol. 2 (Ed. by M. Bornstein), pp. 99-140. Mahwah, New Jersey: Lawrence Erlbaum Associates publishers.

Beauchamp, G. (2009). How does food density influence vigilance in birds and mammals? Animal Behaviour, 78, 223-231.

Bell, H. L. (1973). The ecology of three macropod marsupial species in an area of open forest and savannah woodland in north Queensland, Australia. Mammalia, 37, 537-544.

Bergvall, U. A. , Schäpers, A., Kjellander, P. \& Weiss, A. (2011). Personality and foraging decisions in fallow deer, Dama dama. Animal Behaviour, 81, 101-112.

Best, E. C. (2013). Network analysis of the social structure of female eastern grey kangaroos (Macropus giganteus). Ph.D. Thesis, University of Queensland, Brisbane.

Best, E. C., Seddon, J. M., Dwyer, R. G. \& Goldizen, A. W. (2013). Social preference influences female community structure in a population of wild eastern grey kangaroos. Animal Behaviour, 86, 1031-1040.

Best, E. C., Dwyer, R. G., Seddon, J. M. \& Goldizen, A. W. (2014). Associations are more strongly correlated with space use than kinship in female eastern grey kangaroos. Animal Behaviour, 89, 1-10.

Bradbury, J. W., Vehrencamp, S. L., Clifton, K. E. \& Clifton, L. M. (1996). The relationship between bite rate and local forage abundance in wild Thomson's gazelles. Ecology, 77, 2237-2255.

Briffa, M., Rundle, S. D. \& Fryer, A. (2008). Comparing the strength of behavioural plasticity and consistency across situations: animal personalities in the hermit crab Pagurus bernhardus. Proceedings of the Royal Society B, 275, 1305-1311.

Burger, J. \& Gochfeld, M. (1994). Vigilance in African mammals: Differences among mothers, other females, and males. Behaviour, 131,153-169.

Carter, A. J., MacDonald, S. L., Thomson, V. A. \& Goldizen, A. W. (2009). Structured association patterns and their energetic benefits in female eastern grey kangaroos, Macropus giganteus. Animal Behaviour, 77, 839-846.

Carter, A. J., Pays, O. \& Goldizen, A. W. (2009). Individual variation in the relationship between vigilance and group size in eastern grey kangaroos. Behavioural Ecology and Sociobiology, 64, 237-245.

Carter, A. J., Goldizen, A. W. \& Tromp, S. A. (2010). Agamas exhibit behavioral syndromes: bolder males bask and feed more but may suffer higher predation. Behavioural Ecology, 21, 655661. 
Carter, A. J., Goldizen, A. W. \& Heinsohn, R. (2012). Personality and plasticity: temporal behavioural reaction norms in a lizard, the Namibian rock agama. Animal Behaviour, 84, 471-477.

Childress, L. J. \& Lung, M. A. (2003). Predation risk, gender and the group size effect: does elk vigilance depend upon the behaviour of conspecifics? Animal Behaviour, 66, 389-398.

Clarke, J. L., Jones, M. E. \& Jarman, P. J.(1989). A day in the life of a kangaroo: activities and movements of eastern grey kangaroos Macropus giganteus at Wallaby Creek. In: Kangaroos, wallabies and rat-kangaroos. (Ed. by G. Grigg, P. Jarman \& I. Hume), pp. 611618. Chipping Norton, United Kingdom: Surrey Beatty.

Clarke, J. L., Jones, M. E. \& Jarman, P. J.(1995). Diurnal and nocturnal grouping and foraging behaviours of free-ranging eastern grey kangaroos. Australian Journal of Zoology, 43, 519529.

Coulson, G. (1997). Repertoires of social behaviour in captive and free-ranging grey kangaroos, Macropus giganteus and Macropus fuliginosus (Marsupialia: Macropodidae). Journal of Zoology, 242, 119-130.

Cowlishaw, G., Lawes, M. J., Lightbody, M., Martin, A., Pettifor, R. \& Rowcliffe, J. M. (2004). A simple rule for the costs of vigilance: empirical evidence from a social forager Proceedings of the Royal Society B, 271, 27-33.

Cripps, J. K., Wilson, M. E., Elgar, M. A. \& Coulson, G. (2011). Experimental manipulation of fertility reveals potential lactation costs in a free-ranging marsupial. Biology Letters, 7, 859862.

Dall, S. R. X., Houston, A. I. \& McNamara, J. M. (2004). The behavioural ecology of personality: consistent individual differences from an adaptive perspective. Ecology Letters, 7, 734-739.

Dannock, R. J., Blomberg, S. P. \& Goldizen, A. W. (2013). Individual variation in vigilance in female eastern grey kangaroos. Australian Journal of Zoology, 61, 312-319.

Dingemanse, N. J., Wright, J., Kazem, A. J. N., Thomas, D. K., Hickling, R. \& Dawnay, N. (2007). Behavioural syndromes differ predictably between 12 populations of stickleback. Journal of Animal Ecology, 76, 1128-1138.

Dingemanse, N. J., Kazem, A. J. N., Réale, D. \& Wright, J. (2010). Behavioural reaction norms: where animal personality meets individual plasticity. Trends in Ecology and Evolution, 25, 81-89.

Dingemanse, N. J. \& Wolf, M. (2013). Between-individual differences in behavioural plasticity within populations: causes and consequences. Animal Behaviour, 85, 1031-1039.

Edwards, A. M., Best, E. C., Blomberg, S. P. \& Goldizen, A. W. (2013). Individual traits influence vigilance in wild female eastern grey kangaroos. Australian Journal of Zoology, 61, 332-341.

Fairbanks, L. A. (1996). Individual differences in maternal style: Causes and consequences for mothers and offspring. Advances in the Study of Behavior, 25, 579-611. 
Favreau, F-R., Goldizen, A.W. \& Pays, O. (2010). Interactions among social monitoring, antipredator vigilance and group size in eastern grey kangaroos. Proceedings of the Royal Society B, 277, 2089-2095.

Fleming, A. S. \& Li, M. (2002). Psychobiology of maternal behavior and its early determinants in nonhuman mammals. In: Handbook of parenting, Biology and ecology of parenting Vol. 2 (Ed. by M. Bornstein), pp. 61-97. Mahwah, New Jersey: Lawrence Erlbaum Associates publishers.

Fritz, H., Guillemain, M. \& Durant, D. (2002). The cost of vigilance for intake rate in the mallard (Anas platyrhynchos): an approach through foraging experiments. Ethology, Ecology and Evolution, 14, 91-97.

Fryxell, J. M. (1991). Forage quality and aggregation by large herbivores. American Naturalist, 138, 478-498.

Garnick, S. W., Elgar, M. A., Beveridge, I. \& Coulson, G. (2010). Foraging efficiency and parasite risk in eastern grey kangaroos (Macropus giganteus). Behavioural Ecology, 21, 129-137.

Gélin, U., Wilson, M. E., Coulson, G. M. \& Festa-Bianchet, M. (2013). Offspring sex, current and previous reproduction affect feeding behaviour in wild eastern grey kangaroos. Animal Behaviour, 86, 885-891.

Hazlett, B. A. (1995). Behavioral plasticity in crustacea: why not more? Journal of Experimental Marine Biology and Ecology, 193, 57-66.

Hill, H. M., Greer, T., Solangi, M. \& Kuczaj, S. A. (1997). All mothers are not the same: Maternal styles in bottlenose dolphins (Tursiops truncatus). International Journal of Comparative Psychology, 20, 35-54.

Hogg, J. T., Hass, C. C. \& Jenni, D. A. (1992). Sex-biased maternal expenditure in Rocky Mountain bighorn sheep. Behavioral Ecology and Sociobiology, 31, 243-251.

Illius, A. W. \& Gordon, I. J. 1987. The allometry of food intake in grazing ruminants. Journal of Animal Ecology, 56, 989-999.

Jaremovic, R. V. \& Croft, D. B. (1991). Social organization of the eastern grey kangaroo (Macropodidae, Marsupialia) in southeastern New South Wales. 1. Groups and group home ranges. Mammalia, 55, 169-185.

Jarman, P. J.(1987). Group size and activity in eastern grey kangaroos. Animal Behaviour, 35, 1044-1050.

Jarman, P. J., Jones, M. E., Johnson, C. N., Southwell, C. J., Stuart Dick, R. I., Higginbottom, K. B., et al.(1989). Macropod studies at Wallaby Creek. 8. Individual recognition of kangaroos and wallabies. Australian Wildlife Research, 16, 179-185.

Kaufmann, J. H. (1975). Field observations of the social behaviour of the eastern grey kangaroo, Macropus giganteus, Animal Behaviour, 23, 214-221. 
Kurvers, R., Prins, H., van Wieren, S., Van Oers, K., Nolet, B. \& Ydenberg, R. (2010). The effect of personality on social foraging: shy barnacle geese scrounge more. Proceedings of the Royal Society of London, Series B, 277, 601-607.

Lima, S. L. (1995). Back to the basics of anti-predatory vigilance: the group-size effect. Animal Behaviour, 49, 11-20.

Lima, S. L. \& Dill, L. M. (1990). Behavioral decisions made under the risk of predation: a review and prospectus. Canadian Journal of Zoology, 68, 619-640.

Lott, D. F. (1991). Intraspecific variation in the social systems of wild vertebrates. Cambridge: Cambridge University Press.

Martin, J. G. A., Nussey, D. H., Wilson, A. J. \& Réale, D. (2011). Measuring individual differences in reaction norms in field and experimental studies: a power analysis of random regression models. Methods in Ecology and Evolution, 2, 362-374.

Mathot, K. J., van den Hout, P. J., Piersma, T., Kempenaers, B., Réale, D. \& Dingemanse, N. J. (2011). Disentangling the roles of frequency-vs. state-dependence in generating individual differences in behavioural plasticity. Ecology Letters, 14, 1254-1262.

Mathot, K. J., Wright, J., Kempenaers, B. \& Dingemanse, N. J. (2012). Adaptive strategies for managing uncertainty may explain personality-related differences in behavioural plasticity. Oikos, 121, 1009-1020.

Montiglio, P. O., Ferrari, C. \& Réale, D. (2013). Social niche specialization under constraints: personality, social interactions and environmental heterogeneity. Philosophical Transaction of the Royal Society B, 368, 20120343.

Neuhaus, P. \& Ruckstuhl, K. E. (2002). The link between sexual dimorphism, activity budgets, and group cohesion: the case of the plains zebra (Equus burchelli). Canadian Journal of Zoology, 80, $1437-1441$.

Nielsen, B. L. (1999). On the interpretation of feeding behaviour measures and the use of feeding rate as an indicator of social constraint. Applied Animal Behavioural Sciences, 63, 79-91.

Nussey, D. H., Wilson, A. J. \& Brommer, J. E. (2007). The evolutionary ecology of individual phenotypic plasticity in wild populations. Journal of Evolutionary Biology, 20, 831-844.

Pays, O., Jarman, P. J., Loisel, P. \& Gerard, J. F. (2007). Coordination, independence or synchronization of individual vigilance in the eastern grey kangaroo? Animal Behaviour, 73, 595-604.

Pays, O., Renaud, P. C., Loisel, P., Petit, M., Gerard, J. F. \& Jarman, P. J. (2007). Prey synchronize their vigilant behaviour with other group members. Proceedings of the Royal Society B, 274, 1287-1291.

Pays, O. \& Jarman, P. J. (2008). Does sex affect both individual and collective vigilance in social mammalian herbivores: the case of the eastern grey kangaroo? Behavioral Ecology and Sociobiology, 62, 757-767. 
Pays, O., Blanchard, P., Valeix, M., Chamaillé-Jammes, S., Duncan, P., Périquet, S., et al. (2012). Detecting predators and locating competitors while foraging: an experimental study of a medium-sized herbivore in an African savanna. Oecologia, 169, 419-430.

Peterson, R. O., Woolington, J. D. \& Bailey, T. N. 1984. Wolves of the Kenai Peninsula, Alaska. Wildlife Monographs, 88, 3-52.

Pinheiro, J. C. \& Bates, D. M. (2000). Mixed-effects models in S and S-Plus. New York: Springer.

Pinheiro, J. C., Bates, D. M., DebRoy, S., Sarkar, D. and the R Development Core Team. (2013). nlme: Linear and Nonlinear Mixed Effects Models. R package version 3.1-113.

Randler, C. 2005. Coots Fulica atra reduce their vigilance under increased competition. Behavioural Processes, 68, 173-178.

Rieucau, G. \& Giraldeau, L. A. (2009). Group size effect caused by food competition in nutmeg mannikins (Lonchura punctulata). Behavioural Ecology, 20, 421-425.

Rieucau, G., Morand-Ferron, J. \& Giraldeau, L. A. (2010). Group size effect in nutmeg mannikin: between-individual behavioral differences but same plasticity. Behavioral Ecology, 21, 684689.

Robbins, C. T.1983. Food resources and their utilization. London: Academic Press.

Ruckstuhl, K. E., Festa-Bianchet, M. \& Jorgenson, J. T. (2003). Bite rates in Rocky Mountain bighorn sheep (Ovis canadensis): effects of season, age, sex and reproductive status. Behavioural Ecology and Sociobiology, 54, 167-173.

Shipley, L. A., Gross, J. E., Spalinger, D. E., Hobbs, N. T. \& Wunder, B. A. (1994). The scaling of intake rate in mammalian herbivores. American Naturalist, 134, 1055-1082.

Short, J.1985. The functional response of kangaroos, sheep and rabbits in an arid grazing system. Journal of Applied Ecology, 22, 435-447.

Sih, A., Bell, A. M., Johnson, J. C. \& Ziemba, R. E. (2004). Behavioral syndromes: An integrative overview. The Quarterly Review of Biology, 79, 241-277.

Spalinger, D. E. \& Hobbs, N. T. (1992). Mechanisms of foraging in mammalian herbivores: New models of functional response. The American Naturalist, 140, 325-348.

Stamps, J. A. \& Groothuis, T. G. G. (2010). Developmental perspectives on personality: implications for ecological and evolutionary studies of individual differences. Philosophical Transaction of the Royal Society B, 365, 4029-4041.

Stuart-Dick, R. I. (1987). Parental investment and rearing schedules in the eastern grey kangaroo. Ph.D. thesis. University of New England, Armidale, NSW.

Watson, D. N. \& Dawson, T. J. (1993). The Effects of age, sex, reproductive status and temporal factors on the time-use of free-ranging red kangaroos (Macropus rufus) in western New South Wales. Wildlife Research, 20, 785-801.

Webster, M. M. \& Ward, A. J. (2011). Personality and social context. Biological Review, 86, 769773. 
Wilmshurst, J. F., Fryxell, J. M. \& Colucci, P. E.(1999). What constrains daily intake in Thomson's gazelles? Ecology, 80, 2338-2347. 


\section{Figure legends}

Figure 1. Relationships between female eastern grey kangaroos' vigilance and bite rates and group size $(N=34)(a, b)$, food patch richness $(N=34)(c, d)$, and reproductive state $(N=30)(e, f)$. The black line represents the average effect for all observations and each grey line show an individual's relationship.

Figure 2. Population-level changes in the trade-off between bite rate and the time spent in vigilance in relation to (a) group size, (b) patch richness, and (c) reproductive state for female eastern grey kangaroos. In (a) and (b), intercepts were not significantly different under the different conditions; therefore the lines represent the population's change in bite rates in relation to the level of vigilance.

Figure 3. Trade-offs between bite rate and the time spent in vigilance for female eastern grey kangaroos (a) in small groups $(N=34)$, (b) in rich food patches $(N=34)$, and (c) having a youngat-foot $(N=30)$. Each line represents an individual's adjustment of its bite rate in relation to its level of vigilance. 


\section{Figures and Tables}

\section{Figure 1.}
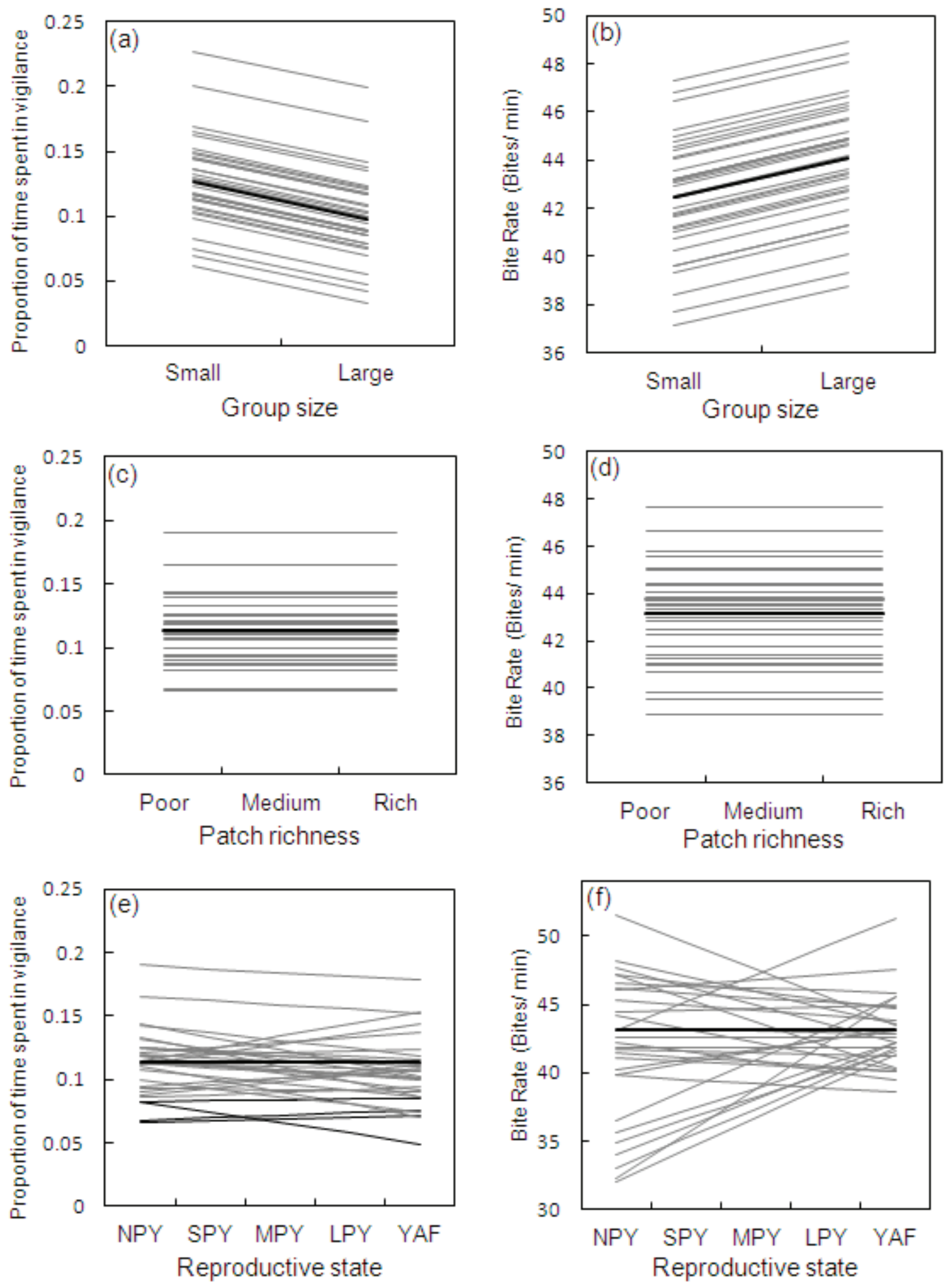
Figure 2.
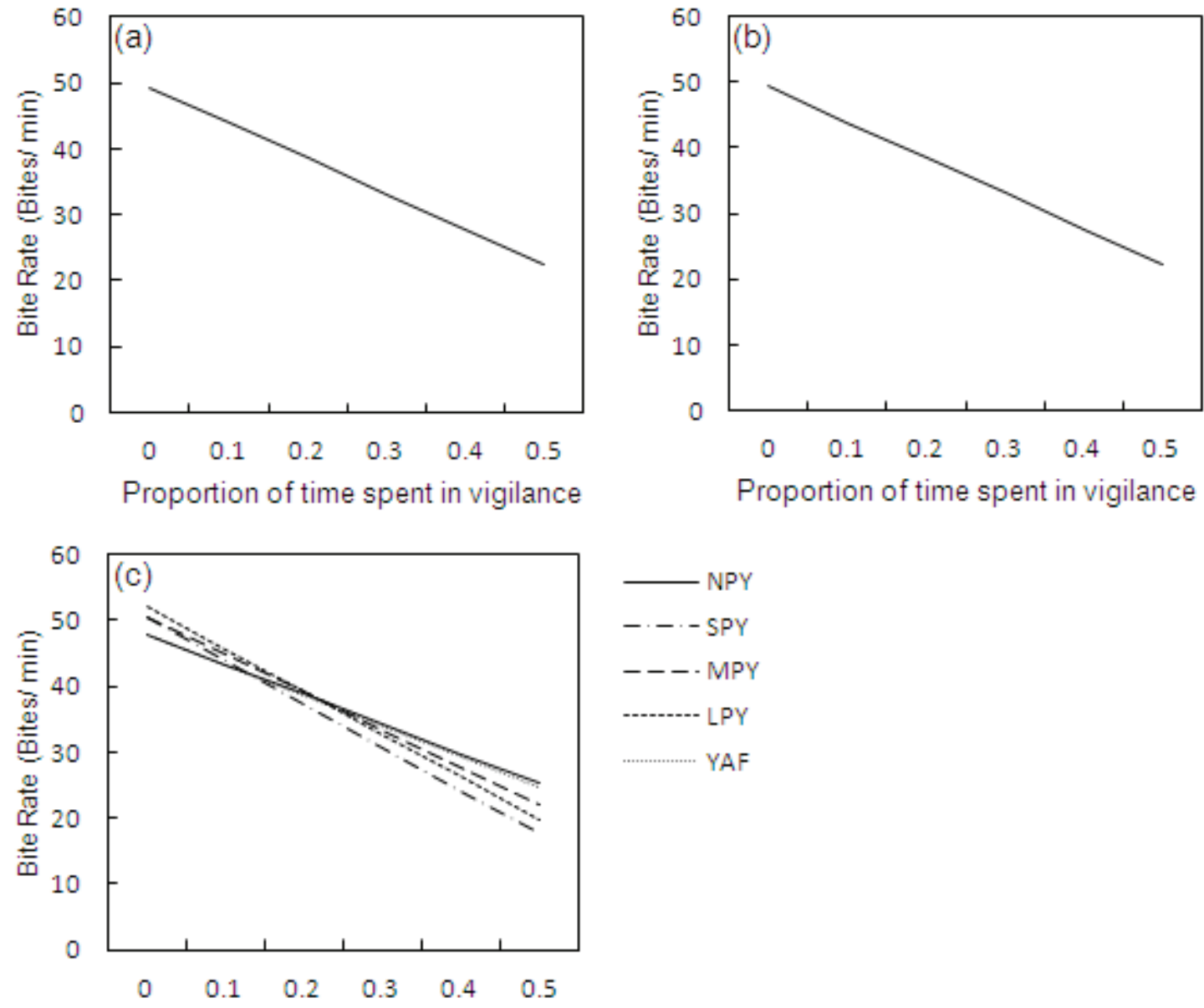

Proportion of time spent in vigilance 
Figure 3.
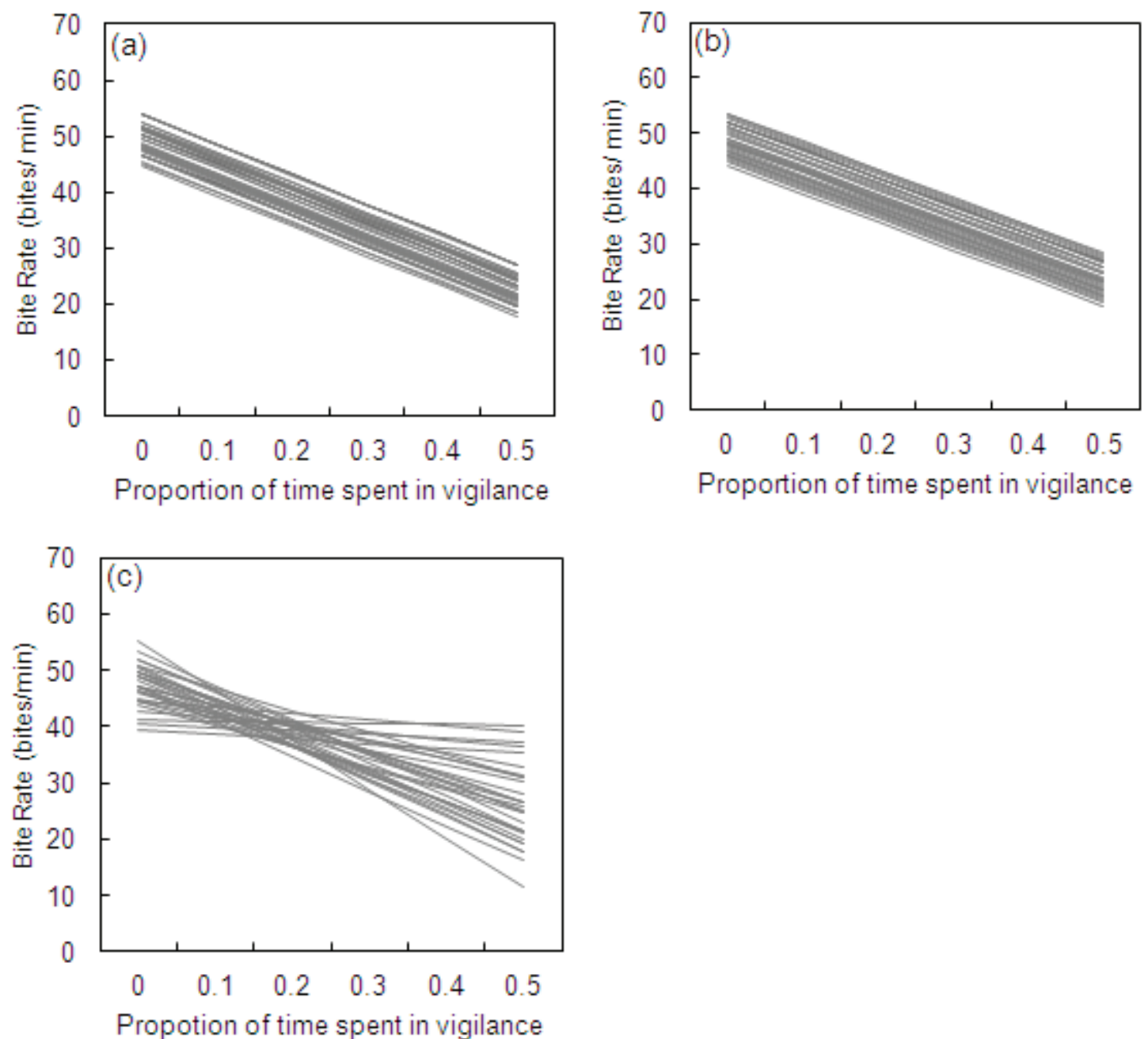
Table 1. Table of patch quality indices for short grass grazers in relation to patch biomass and greenness.

\begin{tabular}{|c|c|c|c|c|c|c|c|}
\hline \multirow{2}{*}{$\begin{array}{l}\text { Biomass } \\
\text { (g.m-2) }\end{array}$} & \multicolumn{7}{|c|}{ Percentage of green grass } \\
\hline & $0-40 \%$ & $>40-50 \%$ & $>50-60 \%$ & $>60-70 \%$ & $>70-80 \%$ & $>80-90 \%$ & $>90-100 \%$ \\
\hline $0-5$ & poor & poor & med & med & med & med & med \\
\hline$>5-10$ & poor & poor & med & rich & rich & rich & rich \\
\hline$>10-15$ & poor & med & med & rich & rich & rich & rich \\
\hline$>15-20$ & poor & med & rich & rich & rich & rich & rich \\
\hline$>20-25$ & poor & med & rich & rich & rich & rich & rich \\
\hline$>25-30$ & poor & med & rich & rich & rich & rich & rich \\
\hline$>30-35$ & poor & med & rich & rich & rich & rich & rich \\
\hline$>35-40$ & poor & med & med & rich & rich & rich & rich \\
\hline$>40-45$ & poor & poor & med & rich & rich & rich & rich \\
\hline$>45-50$ & poor & poor & poor & med & med & rich & rich \\
\hline$>50-55$ & poor & poor & poor & med & med & med & med \\
\hline$>55-60$ & poor & poor & poor & med & med & med & med \\
\hline
\end{tabular}

"Poor" means poor patch quality; "med" means medium patch quality and "rich" means rich patch quality. Values for optimal patches are highlighted in grey.

Table 2. Effects of group size, patch richness and reproductive state on (A) the proportion of time spent in vigilance (ArcSinSqRoot transformed), and (B) the bite rates of female kangaroos.

Factors numDF denDF F-value p-value $\quad$ Coeff \pm SE

\section{(A) Vigilance}

$\begin{array}{lrrrrr}\text { Intercept } & 1 & 1094 & 1900.363 & <0.001 & 0.352 \pm 0.017 \\ \text { Group size } & 1 & 1094 & 33.079 & <0.001 & -0.045 \pm 0.007 \\ \text { Patch richness } & 2 & 1094 & 0.850 & 0.427 & \\ \text { Reproductive state } & 4 & 1094 & 1.545 & 0.186\end{array}$

\section{(B) Bite rates}

$\begin{array}{lrrrrr}\text { Intercept } & 1 & 1094 & 16265.240 & <0.001 & 41.436 \pm 0.868 \\ \text { Group size } & 1 & 1094 & 15.594 & <0.001 & 1.681 \pm 0.419 \\ \text { Patch richness } & 2 & 1094 & 1.472 & 0.230 & \end{array}$

$\begin{array}{lllll}\text { Reproductive state } & 4 & 1094 & 1.293 & 0.270\end{array}$

Group size (small, large), patch richness (poor, medium, rich) and reproductive state (NPY, SPY, MPY, LPY, YAF) were categorical (classes used as references are italicized). Individual identity was included as a random factor. 
Table 3. Comparison of linear models with different random factors for the effects of group size, patch richness and reproductive state on (A) the proportion of time spent in vigilance (ArcSinSqRoot transformed), and (B) the bite rate of female kangaroos, based on Log-likelihood ratio tests (LRT).

\begin{tabular}{|c|c|c|c|c|c|c|}
\hline Factors & Models & Log-lik & df & $\begin{array}{l}\text { Models } \\
\text { compared }\end{array}$ & LRT & \\
\hline \multicolumn{7}{|l|}{ (A) Vigilance } \\
\hline \multirow[t]{3}{*}{ Group size } & M1-1: without ID & 653.662 & 3 & & & \\
\hline & M1-2: with ID & 674.887 & 4 & M1-1 vs M1-2 & 42.450 & $<0.001$ \\
\hline & M1-3: with ID × Group size & 676.259 & 6 & M1-2 vs M1-3 & 2.745 & 0.254 \\
\hline \multirow[t]{3}{*}{ Patch richness } & M2-1: without ID & 636.441 & 4 & & & \\
\hline & M2-2: with ID & 656.308 & 5 & M2-1 vs M2-2 & 39.734 & $<0.001$ \\
\hline & M2-3: with ID $\times$ Patch richness & 658.934 & 10 & M2-2 vs M2-3 & 5.252 & 0.386 \\
\hline \multirow[t]{3}{*}{ Reproductive state } & M3-1: without ID & 633.324 & 6 & & & \\
\hline & M3-2: with ID & 652.065 & 7 & M3-1 vs M3-2 & 37.481 & $<0.001$ \\
\hline & M3-3: with ID $\times$ Reproductive state & 665.702 & 21 & M3-2 vs M3-3 & 27.275 & 0.018 \\
\hline
\end{tabular}

\section{(B) Bite rate}

Group size

M4-1: without ID

\begin{tabular}{|c|c|c|c|c|c|c|}
\hline \multirow[t]{3}{*}{ Group size } & M4-1: without ID & -3835.287 & 3 & & & \\
\hline & M4-2: with ID & -3824.498 & 4 & M4-1 vs M4-2 & 21.579 & $<0.001$ \\
\hline & M4-3: with ID × Group size & -3823.255 & 6 & M4-2 vs M4-3 & 2.484 & 0.289 \\
\hline \multirow[t]{3}{*}{ Patch richness } & M5-1: without ID & -3841.080 & 4 & & & \\
\hline & M5-2: with ID & -3830.187 & 5 & M5-1 vs M5-2 & 21.786 & $<0.001$ \\
\hline & M5-3: with ID $\times$ Patch richness & -3828.934 & 10 & M5-2 vs M5-3 & 2.506 & 0.776 \\
\hline \multirow[t]{3}{*}{ Reproductive state } & M6-1: without ID & -3838.758 & 6 & & & \\
\hline & M6-2: with ID & -3828.001 & 7 & M6-1 vs M6-2 & 21.513 & $<0.001$ \\
\hline & M6-3: with ID $\times$ Reproductive state & -3805.029 & 21 & M6-2 vs M6-3 & 45.944 & $<0.001$ \\
\hline
\end{tabular}

Patch richness

M4-2: with ID

M4-3: with ID $\times$ Group size

0.018 
Table 4. Comparison of linear models with different random factors for the effects of the proportion of time spent in vigilance (ArcSinSqRoot transformed) on the bite rates of female kangaroos in relation to group size, patch richness and reproductive state based on Log-likelihood ratio tests (LRT).

\begin{tabular}{|c|c|c|c|c|c|c|}
\hline Factors & Models & Log-lik & df & $\begin{array}{l}\text { Models } \\
\text { compared }\end{array}$ & LRT & $P$ \\
\hline \multirow[t]{3}{*}{ Group size } & M7-1: without Group size & -3504.471 & 3 & & & \\
\hline & M7-2: with Group size & -3504.471 & 4 & M7-1 vs M7-2 & 0.000 & 0.999 \\
\hline & M7-3: with Group size $\times$ vigilance & -3504.45 & 6 & M7-2 vs M7-3 & 0.043 & 0.979 \\
\hline \multirow[t]{3}{*}{ Patch richness } & M8-1: without Patch richness & -3504.471 & 3 & & & \\
\hline & M8-2: with Patch richness & -3504.45 & 4 & M8-1 vs M8-2 & 0.042 & 0.838 \\
\hline & M8-3: with Patch richness $\times$ vigilance & -3503.086 & 6 & M8-2 vs M8-3 & 2.726 & 0.256 \\
\hline \multirow{3}{*}{$\begin{array}{l}\text { Reproductive } \\
\text { state }\end{array}$} & M9-1: without Reproductive state & -3504.471 & 3 & & & \\
\hline & M9-2: with Reproductive state & -3498.736 & 4 & M9-1 vs M9-2 & 11.469 & $<0.001$ \\
\hline & M9-3: with Reproductive state $\times$ vigilance & -3489.11 & 6 & M9-2 vs M9-3 & 19.251 & $<0.001$ \\
\hline
\end{tabular}

For each factor, the first comparison compares models of the relationship between bite rates and the proportion of time spent in vigilance, including the factor considered as a random effect, with those where the factor considered was excluded (testing for consistent variation between factor modalities, i.e. differences in intercepts), and the second comparison compares models with an interaction between the proportion of time spent in vigilance and the factor considered as a random effect with models with only the factor considered as a random effect (testing for variation in plasticity between the factor modalities, i.e. differences in slopes). Significant differences are in bold. 
Table 5. Comparison of linear models with different random factors for the effects of the proportion of time spent in vigilance (ArcSinSqRoot transformed) on the bite rates of female kangaroos in different conditions, based on Log-likelihood ratio tests (LRT).

\begin{tabular}{|c|c|c|c|c|c|c|c|}
\hline Factors & Condition & Models & Log-lik & df & Models compared & LRT & $P$ \\
\hline \multirow[t]{6}{*}{ Group size } & Small & M10-1: without ID & -1968.040 & 3 & & & \\
\hline & & M10-2: with ID & -1965.624 & 4 & M10-1 vs M10-2 & 4.832 & 0.028 \\
\hline & & M10-3: with ID $\times$ vigilance & -1963.414 & 6 & M10-2 vs M10-3 & 4.435 & 0.109 \\
\hline & Large & M11-1: without ID & -1533.716 & 3 & & & \\
\hline & & M11-2: with ID & -1531.935 & 4 & M11-1 vs M11-2 & 3.561 & 0.059 \\
\hline & & M11-3: with ID $\times$ vigilance & -1531.928 & 6 & M11-2 vs M11-3 & 0.014 & 0.993 \\
\hline \multirow{9}{*}{$\begin{array}{l}\text { Patch } \\
\text { richness }\end{array}$} & Poor & M12-1: without ID & -1207.876 & 3 & & & \\
\hline & & M12-2: with ID & -1207.876 & 4 & M12-1 vs M12-2 & 0 & 1 \\
\hline & & M12-3: with ID $\times$ vigilance & -1207.823 & 6 & M12-2 vs M12-3 & 0.105 & 0.948 \\
\hline & Medium & M13-1: without ID & -527.530 & 3 & & & \\
\hline & & M13-2: with ID & -527.530 & 4 & M13-1 vs M13-2 & 0 & 1 \\
\hline & & M13-3: with ID $\times$ vigilance & -525.092 & 6 & M13-2 vs M13-3 & 3.281 & 0.194 \\
\hline & Rich & M14-1: without ID & -1759.600 & 3 & & & \\
\hline & & M14-2: with ID & -1756.676 & 4 & M14-1 vs M14-2 & 5.846 & 0.016 \\
\hline & & M14-3: with ID $\times$ vigilance & -1754.267 & 6 & M14-2 vs M14-3 & 2.901 & 0.236 \\
\hline \multirow{15}{*}{$\begin{array}{l}\text { Reproductive } \\
\text { states }\end{array}$} & NPY & M15-1: without ID & -348.895 & 3 & & & \\
\hline & & M15-2: with ID & -345.290 & 4 & M15-1 vs M15-2 & 7.211 & 0.010 \\
\hline & & M15-3: with ID $\times$ vigilance & -345.290 & 6 & M15-2 vs M15-3 & 0.010 & 0.999 \\
\hline & SPY & M16-1: without ID & -493.326 & 3 & & & \\
\hline & & M16-2: with ID & -490.046 & 4 & M16-1 vs M16-2 & 6.561 & 0.001 \\
\hline & & M16-3: with ID $\times$ vigilance & -488.857 & 6 & M16-2 vs M16-3 & 2.378 & 0.305 \\
\hline & MPY & M17-1: without ID & -808.662 & 3 & & & \\
\hline & & M17-2: with ID & -806.770 & 4 & M17-1 vs M7-2 & 7.383 & 0.041 \\
\hline & & M17-3: with ID $\times$ vigilance & -805.937 & 6 & M17-2 vs M17-3 & 1.667 & 0.434 \\
\hline & LPY & M18-1: without ID & -378.928 & 3 & & & \\
\hline & & M18-2: with ID & -374.379 & 4 & M18-1 vs M18-2 & 9.099 & 0.002 \\
\hline & & M18-3: with ID $\times$ vigilance & -374.054 & 6 & M18-2 vs M18-3 & 0.649 & 0.723 \\
\hline & YAF & M19-1: without ID & -1428.068 & 3 & & & \\
\hline & & M19-2: with ID & -1422.063 & 4 & M19-1 vs M19-2 & 12.009 & $<0.001$ \\
\hline & & M19-3: with ID $\times$ vigilance & -1414.209 & 6 & M19-2 vs M19-3 & 7.787 & 0.020 \\
\hline
\end{tabular}

For each factor, the first comparison compares models including the identity of the focal female as a random effect with those where ID was excluded (testing for consistent variation among individuals, i.e. differences in intercepts) and the second comparison compares models with an interaction between the factor tested and ID as a random effect with models with only ID as a random effect (testing for inter-individual variation in plasticity, i.e. differences in slopes). Significant differences are in bold. 


\section{Chapter 6:}

\section{General discussion}

\section{1 - Overview}

The main objective of my PhD was to study different aspects of the trade-off between foraging and vigilance in gregarious herbivores using the common impala and the eastern grey kangaroos as model species. The different studies that I conducted allowed me to use both experimental and empirical approaches to study this trade-off in two different species, at both population and individual levels and at different temporal scales. First, the experimental study conducted in Zimbabwe made it possible to compare the behavioural responses of prey to predators' and conspecifics' vocalizations, which would have required longer observation times under natural conditions. Second, the focal observations of kangaroos over 10 minute periods and impalas over 6 minute periods gave me information about behavioural decisions involving this trade-off made on relatively short temporal scales by the animals. Third, the opportunity to follow the kangaroo population in Sundown National Park over a year allowed me to study this trade-off over a longer temporal scale and to investigate how they adjust their behaviour in relation to seasonal variation in ecological, social and physiological conditions. Finally, the study of identified individuals allowed me to highlight the existence of different adjustments to this trade-off at the individual level. Even though the foraging/vigilance trade-off has been well studied in the literature, my $\mathrm{PhD}$ research has led to novel findings on this subject and raises many questions about this pattern and its complexity.

As I already discussed my results from each separate study in the previous chapters of this thesis, I have tried below to integrate my results and highlight the main findings in order to have a better understanding of this trade-off in a more general context. I have therefore divided this general discussion into four different parts. I first discuss how food resources, predation risk, social context and individual traits can drive individual adjustments in the trade-off between foraging and vigilance, and how these drivers are likely to affect population dynamics either directly or indirectly. Second, I discuss my finding that between-individual behavioural variation may be more or less expressed depending on particular conditions. Third, I discuss how prey adjust their behaviour at different temporal scales (i.e. within a year, between seasons, and on a minute to minute basis) and how considering these different scales can allow us to identify different mechanisms. Finally, I discuss the potential foraging costs of vigilance and how herbivorous prey can adjust their behaviour to limit these costs. 


\section{2 - Causes and consequences of behavioural adjustments of the trade-off between foraging and vigilance in herbivores}

Herbivore populations are regulated by two main forces: food resources ("bottom-up" process) and predation ("top-down" process), with the strength of each process depending on a species' body size and the community of predators present in the ecosystem (Sinclair et al. 2003, Hopcraft et al. 2010). Impalas and eastern grey kangaroos are medium-sized herbivores and their populations should therefore be regulated mainly by predation (if predators are present), and then by food quality and to a lesser extent by food availability (Hopcraft et al. 2010). The hypothesis here is that macropods follow similar ecological rules as African medium-size herbivores. In addition to regulating their abundance, food and predation are also crucial in shaping herbivores' behaviours, which in turn can affect population size and dynamics (Frid and Dill 2002, Creel and Christianson 2008).

Because food acquisition and safety from predation are crucial to herbivores for maximising survival, growth, reproduction and therefore fitness (Lima and Dill 1990, Illius et al. 2002), the trade-off between foraging and vigilance provides a useful focus for investigating how individuals cope with different constraints in order to achieve these goals. The constraints (or factors) affecting this trade-off that I identified in the different parts of my PhD were of different types and acted at different temporal scales. As we could have expected, the two main components that I found to affect individual adjustments in foraging (via feeding rates), vigilance and their trade-off were food resources and predation risk. I also observed that other ecological as well as social factors modulated this trade-off in different ways, for example by changing the predation risk perceived by prey, by inducing competition, and by affecting foraging strategies. Finally, although I only tested for one of them, reproductive state, I observed that individuals' traits can also shape the trade-off between foraging and vigilance. I detail below how these factors affected behavioural adjustments, according to my observations, and then discuss the implications that these could have at the population level.

\section{2-1 Food resources and ecological influences}

Food resources relate directly to animals' fitness as these determine their net intake rate and body condition, which in turn can affect growth, survival, and reproductive abilities (Illius et al. 2002). Variations in the quantity and quality of food differentially affect herbivores, depending on their body size; while large herbivores are limited by forage quantity, smaller ones such as the ones studied in my PhD are more limited by forage quality (Hopcraft et al. 2010). In seasonally- 
driven ecosystems, temporal variation in food supply is known to affect the foraging behaviours of herbivores (Senft et al. 1987, Owen-Smith 2008). In summer (or the wet season), food resources are usually abundant and nutritious, allowing individuals to select high quality food items, whereas in winter (or the dry season), vegetation becomes depleted, scarce, dry or fibrous, constraining foragers to ingest low quality food (Owen-Smith 2008). By modifying foraging behaviour, variation in food resources also affects vigilance patterns and the trade-off between vigilance and feeding. In this PhD I studied behavioural responses of kangaroos to their resources in Sundown National Park. I worked at different spatial scales by investigating their behavioural adjustments at the food patch and habitat levels, and different temporal scales by studying both their immediate and seasonal adjustments to their resources.

I observed that in Sundown National Park, variation in patch richness during the year of my study was mainly driven by variation in quality (greenness) rather than quantity (biomass) (see Figure 1 in Chapter 2). Because medium-sized herbivores in general and eastern grey kangaroos in particular usually select for food items of high quality (Bell 1973, Clarke et al. 1989, Bradbury et al. 1996), we expected that our index of patch richness would be related to variation in feeding rates. When I did not take into account seasonal variation in feeding rates, I did not observe any effect of patch richness on the feeding rates of kangaroos (Chapter 5). However, controlling for seasonal variation revealed that this effect occurred but acted indirectly by affecting habitat use and group size (Chapter 2). Female kangaroos increased their feeding rates in open habitats, which seemed to be their preferred habitats year round and contained a higher biomass of plants. Also, they decreased their vigilance and consequently increased their feeding time as group size increased, and group sizes were larger in open habitats containing more food and increased seasonally with plant greenness. Altogether, these results indicate that over short temporal scales (here 10 minute observation periods), patch richness did not appear to affect feeding rates, whereas over longer temporal scales food resources did affect this behaviour, albeit indirectly.

The fact that the effect of food on feeding rates of kangaroos was not directly obvious seems quite surprising but may be explained by the fact that intake rates of herbivores are not only controlled by feeding rates but also by bite sizes, which are inversely related (Spalinger and Hobbs 1992). In my PhD research, I did not take into account bite sizes; therefore, the absence of a direct relationships between bite rates and patch characteristics could have arisen because kangaroos may have taken large bites in rich food conditions, which would have required longer chewing times, and in poor food condition they probably increased their searching time to select for the most profitable food items. Alternatively, as we argued in Chapter 5 , the range of variation in patch quality present during our study may not have been extreme enough for individuals to be forced to alter their bite rates. Therefore, the effect of patch characteristics might have been much stronger if I had been able to estimate intake rates more precisely or if the variation in resources had been greater. 
In addition to indirectly affecting feeding rates, food resources altered the vigilance patterns of kangaroos in different ways. As previously described, I observed that seasonal variation in patch characteristics indirectly modified the time spent in vigilance through variation in group sizes (Chapter 2). Although I did not observe any direct effect of patch richness on the time invested in total vigilance activity (Chapter 5), the different types of vigilance engaged in by kangaroos (in terms of functions and costs) were partially driven by patch characteristics, with this influence varying seasonally (Chapter 4).

These results indicated that, despite the effect of food resources not always being obvious and direct, resources clearly appear to be the main driving force behind behavioural adjustments of the trade-off between vigilance and foraging in this kangaroo population, particularly at the annual temporal scale. As highlighted in Chapter 2, the apparent low predation risk for adult individuals in the study area may have contributed to making this effect stronger compared to populations subject to a higher predation pressure. It would thus be useful to compare these results with data from other populations to identify to what extent food resources affect the trade-off when predation risk is greater than at Sundown National Park.

\section{2-2 Predation risk and safety in number}

Although predators can affect prey populations through predation (a direct effect of predation), prey also adjust their behaviours to predation risk in order to increase their survival (an indirect effect of predation) (Creel and Christianson 2008). As detailed in the General Introduction, prey can adopt very different antipredator behaviours in response to predation risk. Although these behaviours have a positive effect on survival by reducing the chance of being captured, they are also often time consuming and reduce individuals' investments in other fitness-enhancing activities such as food acquisition, which can in turn affect survival and reproduction (Hik 1995, Lima 1998, Frid and Dill 2002). Predation risk is therefore recognized as one of the major drivers determining animals' behaviour, and particularly the trade-off between vigilance and foraging (Lima and Dill 1990). In this PhD, I was able test the effect of apparent predator presence on the behavioural responses of prey with the playback experiment on impalas (Chapter 3), but also investigated behavioural adjustments of prey to different proxies of predation risk and group size when studying female kangaroos (Chapters 2, 4, and 5).

When I investigated the effects of lions' vocalizations on the behaviour of impalas by simulating their presence, female impalas reacted strongly. During the three minutes following the playbacks, I observed that they increased their vigilance by $40.0 \%$, principally due to an increase in exclusive vigilance. This confirms that exclusive vigilance is important in risky situations, probably because it allows a better perception of risk by enhancing hearing and vision compared to vigilance while chewing (Blanchard and Fritz 2007). Also, female impalas decreased their bite rates by 
$21.5 \%$ in response to lions' vocalizations. Although it is difficult to assess whether this reduction in feeding rates would have affected individuals' conditions (discussed in point 5 of this General Discussion), this result shows that predator presence altered food intake, albeit for a very short time. Finally, although I did not record the directions of their movements, females increased their step rates by $59.0 \%$ in response to lions' vocalizations, which we interpreted as another antipredator response. Altogether, these results highlight that predator presence not only affected the vigilance of impala, as has already been observed in other prey species (e.g. Lung and Childress 2007, Périquet et al. 2010), but also other behaviours including individuals' adjustments to the trade-off between foraging and vigilance.

Even when the risk of predation is minimal, prey have been shown to adjust their behaviours to environmental proxies of predation risk, and in relation to characteristics of the groups in which they were foraging. When I studied the kangaroo population, I investigated the effects of different proxies of predation risk known to affect vigilance behaviour (i.e. grass height, distance to cover, and habitat), and the kangaroos' behavioural adjustments to group size and the distance to their nearest neighbours. Contrary to other studies that observed that vigilance increased with grass height, presumably because it can reduce visibility (e.g. Burger et al. 2000, Pays et al. 2012), I did not observe any relationship between grass height and the vigilance of kangaroos. I also did not observe any relationship between distance to cover and the antipredator vigilance of kangaroos, maybe because the risk of being more or less close to cover varies with different predators' hunting strategies, as discussed in Chapter 4, or because predation risk appeared relatively low for adults in this population. Despite habitat structure not being the main factor affecting vigilance behaviour, groups were larger in open habitats and vigilance decreased with group size (Chapter 2). It has often been observed that herbivores form larger groups in open habitats (Gérard and Loisel 1995) and the formation of large groups has been reported to be an antipredator strategy, including in eastern grey kangaroos (Jarman 1974, Heathcote 1987, Jarman and Wright 1993). Indeed, habitat structure is often associated with predation risk as the openness of a habitat can enhance the conspicuousness of prey but also improve predator detection (Underwood 1982, Metcalfe 1984). However, because in our study open habitats had the most food and because group sizes also increased with food quality, we believe that the increase in group sizes in open habitats is explained primarily by the attraction of foragers to food resources rather than by protection from predators.

Even though our measured proxies of predation risk did not appear to strongly affect the behaviour of kangaroos, probably due to the low predation risk, and group formation did not seem to occur primarily because of predation risk, group size and the distance between foragers appeared to be major components of antipredator behavioural adjustments. I tested the relationship between the distance to nearest neighbours and antipredator vigilance and observed that proximity between foragers decreased the use of exclusive antipredator vigilance. This result is in accordance with the idea that proximity between foragers increases safety, allowing 
individuals to increase their foraging efforts (e.g. Fernandez-Juricic and Kacelnik 2004, Mooring et al. 2004). I also tested the relationships between group size and vigilance and feeding rates. Group size strongly affected the trade-off between vigilance and foraging in the kangaroos. Vigilance was negatively affected by group size in all my studies, including when I compiled all my observations on kangaroos, when I focused on antipredator vigilance in specific seasons (i.e. summer and winter), and when I studied seasonal variation in vigilance. The effect of group size was present at both the individual and the population level and at the different temporal scales considered. The "group size effect" is one of the most common relationships reported in the study of vigilance behaviour and has been observed in many species of birds and mammals (Elgar 1989, Roberts 1996). As detailed in the General Introduction, this pattern may arise because of detection (Pulliam 1973), dilution (Hamilton 1971) and/or confusion effects (Landeau and Terborgh 1986). This pattern has already been observed in eastern grey kangaroos and allows individuals to increase their safety and maximize food acquisition (Heathcote 1987, Jarman 1987, Jarman and Wright 1993, Pays et al. 2007, Favreau et al. 2010), as I also observed in Chapter 5. Nevertheless, it should be mentioned here that, despite most studies agreeing with the idea that the reduction in vigilance and increase in feeding rates in large group results from increasing safety, others have argued that these patterns could arise because an increasing level of competition between foragers in larger groups could cause individuals to increase their foraging effort at the expense of vigilance in order to ingest the available food before other individuals do so (e.g. Rieucau and Giraldeau 2009). Regardless of whether these patterns arise because of increasing safety or competition or probably a combination of both, my results confirm that group size is one of the major drivers of the trade-off between the foraging and vigilance of prey.

\section{2-3 Social context}

Group living is a common phenomenon across the animal kingdom and occurs in most taxa. Individuals of gregarious species often interact with each other in a wide variety of ways, and the intensity and complexity of social interactions often define the extent to which a species is considered more or less social. Social interactions can vary from behaviours such as simple avoidances to the maintenance of strong dominance hierarchies, and these interactions can lead to various different behavioural responses. Many aspects of animals' sociality have already been investigated but its effect on vigilance, foraging and their trade-off remain largely unexplored and often underestimated, especially in non-primate mammals. During my $\mathrm{PhD}, \mathrm{I}$ explored the effect of sociality on the behavioural adjustments of gregarious prey to better understand (1) how social stimuli can affect vigilance and foraging activities (Chapter 3) and (2) the importance and use of social vigilance (Chapter 4). 
The effect of vocal social signals other than alarm calls on the vigilance/foraging trade-off could allow us to identify whether the presence of particular conspecifics can cause equivalent foraging costs to the presence of predators. In my study of impalas, I observed that male impalas' roars affected females' activities but in an unexpected way, by causing a decrease in vigilance and an increase in movements but no effect on feeding rates. This result suggested that females sacrificed some time devoted to vigilance when they heard males' roars and used that time to increase their movements. Although our study provided different results to the few studies that have investigated behavioural responses to social vocalizations, which reported increases in vigilance in such conditions (e.g. McComb 1991, Smith et al. 2009, Bro-Jørgensen et al. 2010, Townsend et al. 2011), it confirms that social vocalizations can affect different aspects of behaviour and need to be considered more in future studies. Many studies have investigated the responses of foragers to alarm calls (e.g. Bachman 1993) or other auditory signals indicating the presence of predators, such as foot thumps in marsupials (e.g. Blumstein et al. 2000) with such signals usually found to cause an increase in vigilance and a decrease in foraging activity. However, the effects of social vocalizations on the behaviours of gregarious species remain poorly explored. Social vocalizations vary and serve different functions such as maintaining group cohesion (e.g. Townsend et al. 2011), coordinating activities (Harcourt et al. 1993), signalling the discovery of new food sites (Dittus 1984), signalling the ownership of a territory (Jarman 1979) or attracting females during the mating period (McComb 1991). Therefore they are expected to affect individuals' behaviours including vigilance activity (mainly social vigilance) and foraging tactics, although the effects of the different types of vocalizations would be expected to differ.

Another aspect of animal behaviour that arises from grouping and sociality is social vigilance. As detailed in the General Introduction, while antipredator vigilance is assumed to have a single function, social vigilance can be used for many purposes (Caro 2005). This activity has been recognized to occur in many taxa but mainly investigated in primates, in which it has been shown to vary according to sex, as well as reproductive state and dominance status (e.g. Caine and Marra 1988, McNelis and Boatright-Horowitz 1998, Kutsukake 2006). While many studies have recognized that non-primate mammals also monitor each other, studies of social vigilance have been fairly rare in these species. In Chapter 4, I found that the increase in social vigilance with group size that I previously observed during my Master's study (Favreau et al. 2010) only involved vigilance while chewing, and I identified new factors affecting social vigilance. My results suggest that in kangaroos social vigilance is involved in the assessment of the food patches discovered by others (i.e. scrounging), which is dependent on the season (and therefore overall food quality) and the quality of the patch exploited, and also the distance between foragers. In addition, although more studies are necessary, my results suggest that social vigilance probably serves in monitoring mates, young, and competitors. My results also showed that, when foraging in a rich patch, females increased their vigilance while chewing (probably as a result of bigger bites being taken), and used this "low-cost" form of vigilance mainly for social rather than antipredator vigilance. 
Finally, I observed that, even though social vigilance accounted for only on average $10 \%$ of total vigilance, it could vary greatly and even reach $100 \%$ of total vigilance on some occasions. The monitoring of conspecifics is therefore not uncommon and can even take a large amount of time for kangaroos, as is probably the case for many other gregarious species. Whatever its function, vigilance disturbs foraging activity, and therefore social vigilance should usually involve a cost to foraging activities in the same way as antipredator vigilance is assumed to do. Even if this foraging cost of social vigilance is likely to be lower than that of antipredator vigilance, which involves more time in exclusive vigilance, it should nonetheless affect how individuals adjust their trade-off. Therefore, the presence of conspecifics and the social context have consequences for individuals' behavioural decisions and these have to be considered as drivers of the trade-off between vigilance and foraging.

\section{2-4 Individuals' traits}

Individual characteristics of animals can also affect the trade-off between foraging and vigilance. In my PhD, I investigated whether females' reproductive states affected this pattern. Despite not detecting any effect of reproductive states on vigilance and feeding rates at the population level, reproductive states did affect these behaviours differently for different individuals, showing that individuals exhibit different strategies. In addition, the relationship between vigilance and feeding rates of females, representing their trade-off, varied among the different reproductive states. Although I was not able to study these, other characteristics such as age, sex, or body size, which can cause variation in vulnerability to predators and foraging patterns, should also affect the trade-off (e.g. Ginnett and Demment 1997, Pays and Jarman 2008).

\section{2-5 How the vigilance/foraging trade-off and its main drivers might affect population dynamics}

To maximize food acquisition and safety, gregarious herbivores have to adjust their behavioural responses to spatial and temporal variation in food resources and to the risk of predation. While these adjustments are classically studied at larger scales, I focused on a relatively fine scale by investigating the main drivers shaping the trade-off between foraging and vigilance. I observed that many factors affected the two components and ultimately this trade-off but that the main drivers were the characteristics of food resources and predation risk, as expected. In my study on impalas, the simulated presence of predators strongly influenced their behavioural adjustments, but I did not measure the effect of food resources. However, in my study on kangaroos in SNP I observed that both vigilance and feeding rates were mainly affected by patch quality through the effects of this on group size and habitat use, and that predation risk was not the 
main driver of these behaviours. This suggests that in this study system the main driver of the trade-off over the year was seasonal variation in food resources and that predation risk appeared to be the secondary driver. I believe that this pattern was due to the low predation risk for adults at the study site and that this population is therefore more regulated by food than by predation. However, predation risk is often higher in natural populations and may drive behavioural adjustments as strongly as food resources or even become the primary driver. For example, in African savanna ecosystems, small and medium-sized herbivores can be subject to a large number of predators and predation is assumed to be the primary driver of their population regulation (Hopcraft et al. 2010). The relative strengths of the effects of resources and risk on herbivores' behavioural adjustments may therefore vary under different conditions, in different systems and according to the species considered.

The left part of Figure 1 illustrates how the different drivers detailed previously affected the trade-off between vigilance and feeding rates (to describe the general context in this figure, we considered that predation and food resources have similar strengths of effects and are the two major drivers). As major drivers, food resources and predation (or predation risk) can directly or indirectly affect vigilance, feeding rates and consequently their trade-off. First, food resources can directly affect feeding rates of herbivores due to vegetation structure and seasonal variation, but also indirectly influence feeding rates and vigilance through individuals' habitat use and group sizes. Second, predation risk can directly affect vigilance, and also indirectly influence vigilance and feeding rates via group sizes and distances between foragers, but an increase in vigilance can also reduce predation rate (see Creel and Christianson 2008). Factors associated with ecological or social influences and individual traits can also directly affect these behaviours and thus the trade-off, although to a lesser extent, and thus act as additional drivers.

Therefore, multiple drivers can affect behavioural adjustments to the trade-off between vigilance and foraging, with these drivers acting simultaneously and interacting with each other. These drivers may be more or less influential depending on the ecosystem studied, the local abundance of predators and the species considered (Hopcraft et al. 2010). 


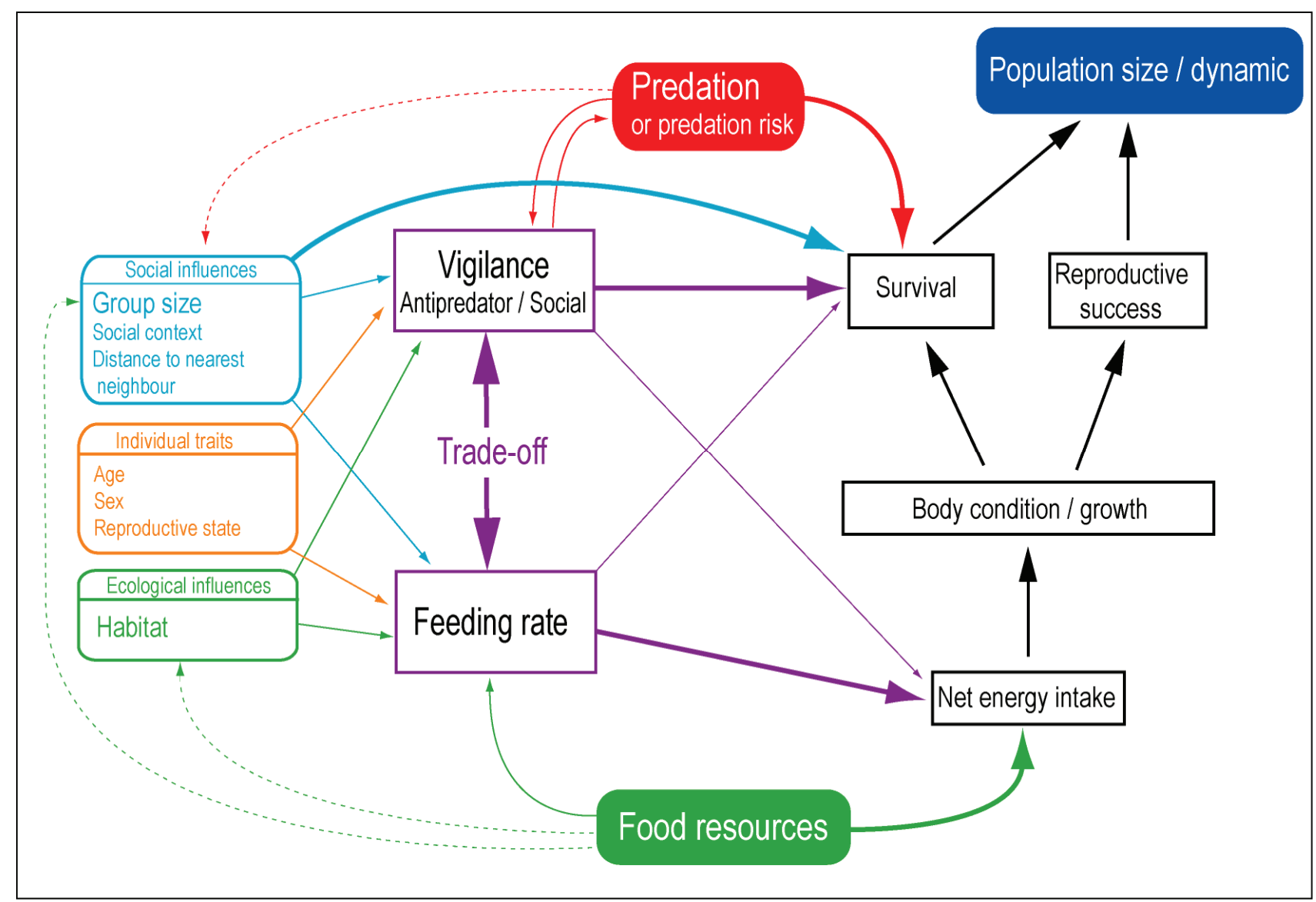

Figure 1: Direct (fine plain arrows) and indirect (fine dashed arrows) effects of the identified drivers affecting the trade-off between vigilance and feeding rates, and effects (thick arrows) of the drivers and the trade-off on population sizes and dynamics of herbivores through energy intake and/or survival.

Whatever the system studied and the drivers identified as being the most influential, the consequences of behavioural adjustments to this trade-off can indirectly affect population dynamics (as described in the General Introduction). These effects are presented in the middle and right parts of Figure 1. At first sight, this figure suggests that the factors influencing vigilance are more likely to affect individuals' survival, and the factors affecting feeding rate to affect body condition and therefore reproductive success and survival (Lima and Dill 1990, Saether 1997, Caro 2005). However, antipredator behaviour such as vigilance can have physiological consequences such as increasing stress, but also energetic consequences by reducing food intake leading to decreased individual body condition and growth, which can in turn affect reproductive success and survival, finally affecting population size and dynamics (Hik 1995, Lima 1998, Frid and Dill 2002, Creel and Christianson 2008). Food acquisition can also decrease survival as non-vigilant animals are the main targets of predators (FitzGibbon, 1989). In addition, population size and dynamics can be directly affected by food resources and predation via their effects on survival and energy intake. For instance, food supply can increase starvation or lead to a decline in reproductive success when overall food quality or availability is not sufficient (Langvatn et al. 1996). As previously stated, predators can directly affect the survival of prey and therefore their population dynamics, 
abundance, and even their distribution (Sinclair et al. 2003). Finally, social factors can also directly affect survival through the dilution effect of group size (Hamilton 1971) or through antipredator signals received from group mates (e.g. acoustic signals or information on predator detection via others members' alert behaviour). Therefore population sizes and dynamics can be affected by different drivers both directly and indirectly, making the system extremely complex.

\section{3 - Personality and plasticity can vary across contexts.}

Within-population behavioural variation has been receiving increasing attention since the establishment of the field of research on animal personality. In addition, the "behavioural reaction norm" approach proposed by Dingemanse et al. (2010) to study between-individual variations in personality and plasticity within a single framework has received lots of interest in recent studies. In Chapter 5, I first used this framework to study how different individuals adjusted their vigilance and their feeding rates in relation to variation in group sizes, food patch richness and reproductive states. I showed that female kangaroos exhibited different levels of vigilance and bite rates in relation to variation in these factors, as well as different adjustments of these behaviours as their reproductive states varied. These results highlight that even when individuals live in the same population and face similar constraints, they can adopt different behavioural strategies.

In the second part of this study, I investigated whether between-individual behavioural variation was repeatable across different contexts to highlight which factors shape individual variation. I adapted the behavioural norm approach framework to study whether the relationship between vigilance and bite rates of different identified female eastern grey kangaroos differed in different specific situations (i.e. in different group sizes, patches of different richness, and reproductive states). I observed that females exhibited consistent behavioural differences in small groups but not in large ones, in rich food patches but not in medium or poor ones, and in all reproductive states. In addition, females having a young-at-foot also exhibited different plasticity (adjustment of bite rates as vigilance increased). I was not able to compare my results with those of any other studies, as a similar approach has not previously been used, but these results suggest that behavioural consistency and plasticity are not necessarily repeatable across contexts (i.e. in different situations), at least for the relationship studied. Here I choose to discuss only the results relating to the patterns observed in different group sizes and food patch qualities, because in these conditions only between-individual behavioural consistency (or personality) was found, which is the area that has received the most attention in other studies.

My results suggest that the expression of consistent behavioural differences is context dependant and occurs particularly in relatively favourable conditions in terms of food access (good food patches) and competition (small group sizes), while being more limited in stressful conditions 
(poor food availability and higher levels of competition). Personality traits have been assumed by definition to be consistent across time and contexts (Sih et al. 2004); however, a few recent studies have provided evidence that the expression of personality types can be constrained under specific contexts, in accordance with my results. For example, as discussed in Chapter 5, Webster and Ward's review (2011) suggested that grouping could affect the expression of personality traits because conformity and facilitation increase with group size, possibly because of increasing competition. They stated that at the time they wrote their paper, no studies had investigated the effect of group sizes on the expression of personality traits, but that such studies are crucial for understanding the significance of individual behavioural variation under natural conditions. Kurvers et al. (2011) investigated how the boldness of individuals could affect collective decisions in barnacle geese (Branta leucopsis) in groups of different sizes. They observed that in pairs boldness strongly affected individual decisions, but that in groups of four boldness did not have any effect on decision-making, highlighting that behavioural differences became less important as group size increased. Both studies (i.e. Kurvers et al. 2011, Webster and Ward 2011) concluded by saying that most studies done on personality were conducted in groups smaller than natural groups, so that studies on bigger groups are required.

Food availability has also been suggested to affect the expression of personality type, but to our knowledge this has not been tested. In their "Opinion paper" on the effect of environmental stressors on the relationship between physiology and behaviour, Killen et al. (2013) stated that several factors including extreme temperature and food deprivation could cause adverse physiological effects, leading to a reduction in the expression of activity, boldness and aggression. Our results agree with this statement as we observed no consistent behavioural differences among individuals in poor and medium food patches but consistent differences in rich ones. Finally, recent studies highlighted that the expression of individual personalities could vary in relation to the risk of predation and breeding behaviour. First, Frost et al. (2013) showed that bold and shy rainbow trout (Oncorhynchus mykiss) responded to predation risk by becoming more intermediate in their behaviour and stated that acting too boldly or too shyly could be maladaptive when predation risk is unpredictable. Second, Haage et al. (2013) showed that in European mink (Mustela lutreola), the expression of boldness and exploration changed between the breeding and non-breeding seasons. Therefore, an increasing number of studies seem to show that the expression of personality can be altered among environmental and social contexts, probably because individual differences may be adaptive in some contexts but not in others (van Oers et al. 2005).

The patterns observed during my study suggest that food limitation, caused either by reduced food availability or high levels of competition, could impose constraints on kangaroos, forcing all individuals to adopt a similar strategy that could be viewed as the "optimal" or "more advantageous" strategy in terms of intake and safety. A reduction in these constraints would allow individuals to exhibit different behavioural strategies. These observations agreed with the suggested and/or observed patterns in the studies presented above in relation to other factors. 
However, more research is needed to confirm these trends in different species and for different behavioural traits. The existence of different behavioural strategies or personality types is often viewed as adaptive because it should allow individuals to cope with different environmental conditions or facilitate a population's response to environmental changes (Sih et al. 2012). We can thus wonder what could happen if environmental changes induce more foraging constraints on organisms, leading them to decrease the expression of individual behavioural variation.

\section{4 - The significance of considering different temporal scales in the study of the trade-off between vigilance and foraging}

In my PhD, I focussed on fine-scale behavioural adjustments of herbivores by investigating the trade-off between vigilance and feeding rates. Most behavioural studies done at this fine observation scale have been conducted over relatively short temporal scales such as a few weeks or months. However, vigilance and feeding rates are clearly affected by factors that often vary over time but not necessarily at the same temporal scales, making the understanding of the trade-off more complex.

For instance, foraging strategies and especially intake rates can vary over relatively short temporal scales in response to immediate food patch characteristics (e.g. Wilmshurst et al. 1999), but also over larger temporal scales in response to seasonal and/or annual variation in the availability and quality of the food supply (e.g. Bradbury et al. 1996, Lamoot et al. 2005). For example, Bradbury et al. (1996) showed that the relationship between bite rate and food resources varied seasonally in Thomson's gazelles. Using protein density as a measure of patch characteristics, they observed positive, negative and flat relationships between bite rates and protein densities in the dry, early wet and late wet seasons, respectively (Bradbury et al. 1996). In addition, Lamoot et al. (2005) observed that donkeys adjusted their bite rates seasonally according to variation in food supply. Although variation in intake rates can be a direct consequence of seasonal variation in food resources, the temporal scale at which the animal is observed can uncover different behavioural patterns since the mechanisms responsible for intake rates vary at different temporal scales as a result of different intrinsic constraints peculiar to the animal (Hobbs 2003). When an animal is observed foraging over a short time interval (e.g., less than one hour), its intake rate is mainly regulated by bite mass, bite rate, and plant encounter rate; when the time scale is extended (e.g. from one hour to one day), intake rate is regulated by the animal's digestion and excretion abilities, which relate to plants' cellular properties. Finally, at larger time scales (e.g., the lifetime of the animal), intake rate is regulated by genetic characteristics (see Hobbs 2003). The physiological needs of individuals also affect their feeding rates and can vary over different temporal scales. For example, the energetic needs of reproducing females vary during their 
reproductive cycles; lactating females usually increase their feeding rates gradually with the lactation demands of their offspring (e.g. Ruckstuhl et al. 2003, Gélin et al. 2013). The physiological states of animals also vary with age as they mature (Nielsen 1999); for example, the feeding rate of a growing individual has been shown to increase with time because of changes in body size and the capacity of the mouth in terms of bite sizes (Illius and Gordon 1987, Shipley et al. 1994). However, feeding rates of older animals often decrease as tooth wear increases, reducing their ability to process food efficiently (Kojola et al. 1998).

Vigilance levels are also affected by factors that vary over time, especially predation risk. The risk of predation is often not constant and may vary over multiple temporal scales that affect how prey animals adjust their antipredator strategies over time (Lima and Bednekoff 1999a). Predation risk can vary from minute to minute during an encounter between prey and predators (Lima and Bednekoff 1999a). Therefore, vigilance can vary at a short temporal scale when a prey animal detects the presence of a predator in the surrounding area, as I observed during the playback study on female impala (Chapter 3). The level of predation risk and ultimately vigilance may also vary over a day according to predators' hunting preferences. Meer et al. (2012) observed that kudu spent much more time in exclusive vigilance at waterholes during the early morning compared to the rest of the day, as the risk of predation was the highest in the morning due to an overlap in hunting times of both nocturnal and diurnal predators. Eastern grey kangaroos have also been observed to be more vigilant in the morning compared to the afternoon, probably because of the temporal patterns of activity of their predators (Edwards et al. 2013). Finally, although this is less documented, predation risk can also vary seasonally and lead to variation in antipredator responses. For instance, Rasmussen (2005) observed that brown lemurs (Eulemur fulvus) and mongoose lemurs (Eulemur mongoz) shifted from diurnal to more crepuscular activity cycles in the dry season when predation risk from raptors increased due to lower vegetative cover. This shift probably allowed them to increase their vigilance during the day during this riskier season. Some authors have thus argued that prey should continually adjust their behavioural responses according to immediate, intermediate, and long-term patterns of predation risk, and that ignoring the significance of temporal variation in risk could misestimate the impact of risk in nature (Lima and Bednekoff 1999a, Brown et al. 2009). While predation risk appears to be mainly correlated with predator presence and activity, it also varies in relation to the vulnerability of prey, which changes during their lifespan. Younger individuals are usually slower, less able to defend themselves and less experienced with predators, which could increase their vulnerability (Mech 1970). Therefore an individual's vulnerability is assumed to decrease with its age but can also increase after a certain age for old animals, in which body condition decreases, reducing flight speed during attacks (e.g. Peterson et al. 1984). Finally, group size, which is often viewed as a response to predation risk (Krause and Ruxton 2002), can change at very short temporal scales in highly dynamic fission-fusion species, but also over a day, between or within seasons and even among years (Gower et al. 2009a). 
In the different studies conducted during this $\mathrm{PhD}, \mathrm{I}$ also observed that prey responded to the immediate risk of predation by modifying their vigilance activity as well as their bite rates (Chapter 3), and that vigilance showed seasonal variation, correlated with group size variation across the year (Chapter 2). While group size varied through the year, I also observed that the amount of antipredator vigilance varied between winter and summer (Chapter 4), which was not the case for social vigilance, although this has been shown to vary with group size (Favreau et al. 2010). However, my results from this chapter showed that even though the average level of social vigilance remained relatively stable across seasons, the factors affecting social vigilance varied seasonally. This illustrates that different patterns can be identified when more than one temporal scale is investigated. The points presented above show that vigilance and foraging behaviours can be affected by multiple factors that vary over different temporal scales. As stated by Gower et al. (2009a), behavioural responses are temporally dependent and the temporal scale at which the response is observed may yield different insights. Therefore, the understanding of the trade-off between vigilance and foraging could be much improved if different temporal scales were incorporated or even combined in further studies.

\section{5 - Questioning the foraging cost of vigilance}

Vigilance activity is assumed to be costly as it is time consuming and reduces foraging time, feeding rates and probably intake rates (Underwood 1982, McNamara and Houston 1992), although vigilance can be incorporated within feeding bouts to reduce the loss of foraging time (Illius and FitzGibbon 1994, Fortin et al. 2004). According to the literature, a decrease in food intake could diminish individuals' body condition and in turn reduce survival and fecundity (FitzGibbon and Lazarus 1995, Watson et al. 2007). The reduction of feeding rates as vigilance increases has been observed in birds and mammals and provides an indicator of the foraging cost of vigilance (Fritz et al. 2002, Ruckstuhl et al. 2003, Cowlishaw et al. 2004). I investigated this relationship in eastern grey kangaroos and observed that this pattern occurs in this species, but that the strength of the relationship can vary between individuals under certain conditions (Chapter 5). However, even though vigilance clearly decreases the numbers of bites taken by foragers, part of my results and earlier studies indicate that foragers can use multiple strategies to reduce the cost of vigilance and that the fitness consequences of feeding deficits are difficult to demonstrate (Lind and Cresswell 2005, Gower et al. 2009b). We can thus wonder to what extent the foraging cost of vigilance really affects animals' survival and reproduction. I address below several points relating to this issue, focussing on herbivores.

First, prey species can adopt several different strategies to reduce their predation risk in order to diminish their time devoted to vigilance and therefore maximise their foraging effort. One of these strategies consists of limiting their exposure to predators. Predator exposure can be 
reduced by avoiding areas or feeding sites with high predator densities (Caro 2005, Fortin et al. 2005), by temporarily leaving feeding sites where predators have recently been active (Gower et al. 2009b), or by increasing movements in order to remain unpredictable in space for predators (i.e. predator-prey shell game, Mitchell and Lima 2002). Other strategies to reduce predation risk can be to choose feeding sites in which escape tactics are more effective (Lima 1992, White et al. 2002), or to adjust group sizes temporally with variation in predation risk (Lima and Bednekoff 1999a).

Second, herbivores are able to moderate and significantly reduce the cost of vigilance by being vigilant while processing their food during "spare time" (Fortin et al. 2004). Illius and FitzGibbon (1994) theoretically proposed that large herbivores could spend as much as $50 \%$ of their vigilance time without reducing their food intake (i.e. in "cost-free" vigilance). Fortin et al. (2004) investigated the potential feeding cost of vigilance in bison and elk and showed that vigilance while chewing could reduce this cost by as much as $35 \%$. Studies investigating individuals' investment in exclusive vigilance and vigilance while chewing reported that the time invested in each particular vigilance type varied with predation risk (or perceived predation risk), group size, and food characteristics (e.g. Benhaeim et al. 2008, Pays et al. 2012, Périquet et al. 2012). All of the studies differentiating these two types of vigilance in large herbivores observed that the time spent in vigilance while chewing was the always greater than for exclusive vigilance and comprised between 75 and 84\% of vigilance time (e.g. Pays et al. 2012, Périquet et al. 2012). My observations on both impala and eastern grey kangaroos agreed with these findings, with impalas spending on average $74 \%$ (during control observations) and kangaroos $72 \%$ of their vigilance time in vigilance while chewing (Chapters 3 and 4 ). In addition, during the impala study, females increased their vigilance levels after being exposed to lions' vocalizations, mainly due to an increase in exclusive vigilance, and they decreased their vigilance after being exposed to the male impalas' roars, mainly due to a decrease in vigilance while chewing. Despite these changes, time spent in vigilance while chewing remained proportionally higher than for exclusive vigilance, representing $63 \%$ and $60 \%$ of vigilance time after lion and male impala playbacks, respectively. While the vigilance of kangaroos varied seasonally, the proportion of time spent in vigilance while chewing was always higher than the proportion of time spent in exclusive vigilance (F-RF unpublished data). During my observations of kangaroos over a year, I noticed that for $20 \%$ of the observations, kangaroos spent $100 \%$ of their vigilance time in vigilance while chewing (based on 1135 focal observations; F-RF, unpublished data). Therefore, kangaroos, impalas and probably most large herbivores adjust their vigilance behaviour in order to pay the minimum possible foraging cost. However, even though the investment in exclusive vigilance represented less than $40 \%$ of vigilance time, it appeared to be quite seasonally stable at least for kangaroos, suggesting that prey have to maintain a certain level of exclusive vigilance. This is not surprising given that, although though this vigilance type is more costly, it has also been assumed to be more effective for predator detection (Lima and Bednekoff 1999b, Blanchard and Fritz 2007). 
Finally, we can wonder to what extent a decrease in feeding rates due to vigilance can alter herbivores' body conditions. It is difficult to assess the threshold of bite rates under which a forager's intake would be deficient and impose a real physiological cost for an animal. To investigate to what extent vigilance can incur physiological costs in zebras, Barnier et al. (submitted) established a critical threshold for bite rates by using data on horses of similar body size that were not subject to predation. They estimated that because horses never took less than 15 bites per minutes, bite rates could be considered as deficient under this limit. This method provides an easy way to investigate the strength of the cost of vigilance. I was unable to find data on bite rate ranges for impalas and eastern grey kangaroo that were not subject to predation but I could compare them with species similar in body size. Female impalas' body weights range between 40 and $53 \mathrm{~kg}$ (Estes 1991) and female eastern grey kangaroos' between 20 and $36 \mathrm{~kg}$ (Yom-Tov 1986). Therefore to have an idea of the threshold below which a low intake could be considered as critical for impalas and kangaroos, we could compare impalas with white-tailed deer (Odocoileus virginianus) (body weight: $40-60 \mathrm{~kg} /$ bite rates: 10-70 bites per minute, Gross et al. 1993), and kangaroos with Thomson's gazelles (body weight: $15-25$ kg / bite rates: 19-73 bite per minutes (Hofmann 1989, Wilmshurst et al. 1999). We can thus consider that below 10 and 15 bites per minutes, respectively, feeding rates of impalas and kangaroos could be deficient. During my observations on impalas, females averaged 50.7 bites per minutes during control periods with a minimum and a maximum of 24.6 and 70.6 bites per minutes, respectively, and were therefore far from the threshold of 10 bites per minutes below which intake could be considered as deficient. After hearing lions' vocalizations, they decreased their feeding rates to an average of 40.1 bites per minutes and a minimum of 10.4 bites per minutes. Kangaroos took on average 43.2 bites per minute with the minimum observed during winter being 18.3 bites per minutes and thus they also never reached costly values of feeding rates. In addition, in herbivores bite rate is known to decrease with increasing bite sizes as biomass increases (Gross et al. 1993); therefore, herbivores should be able to increase their bite size as vigilance increases to compensate for the loss of feeding time, which may be possible if the quality of food resources is sufficiently high to remain digestible by these medium sized herbivores.

There is no doubt that vigilance incurs foraging costs as it decreases intake rate; however, these issues provide serious doubts that the cost incurred by vigilance could lead to a deficient intake and reduce the body condition and survival of herbivores. To our knowledge, the investment in vigilance has never been clearly demonstrated to affect individual fitness, probably because herbivores use multiple antipredator tactics to avoid spending too much time not foraging, and because they can manage the cost of this activity by chewing their food while being vigilant. Herbivores probably also rely on other senses such as olfaction and hearing and should be able to remain at least somewhat aware of potential risks while foraging. As stated by Gower et al. (2009b), large herbivores seem to have evolved to live and forage efficiently in the presence of predators. Studies focusing on the foraging cost of vigilance are therefore needed to investigate 
whether vigilance can incur costs that could alter individuals' survival, reproduction and consequently fitness over the long term.

\section{6 - Conclusion}

Herbivores foraging under a risk of predation face multiple constraints and have to adjust their behaviour accordingly to maximize food acquisition and safety. These constraints can alter population dynamics either directly or indirectly via these behavioural adjustments. The trade-off between vigilance and foraging on which I focused in this $\mathrm{PhD}$ only represents a small part of herbivores' behavioural adjustments. Depending on the scale at which their behaviour is investigated, other constraints (e.g. human activities, parasitism or disease, or climate change) could play a role and influence these adjustments. Future work is therefore needed using broader spatial and temporal scales to improve our knowledge on the link between population dynamics, ecological constraints and behavioural responses.

\section{7 - References}

Bachman G.C. 1993. The effect of the body condition on the trade-off between vigilance and foraging in Belding's ground squirrels. Animal Behaviour, 46, 233-244.

Bell H.L. 1973. The ecology of three macropod marsupial species in an area of open forest and savannah woodland in north Queensland, Australia. Mammalia, 37, 537-544.

Benhaiem S., Delon M., Lourtet B., Cargnelutti B., Aulagnier S. Hewison J.M., Morellet N. \& Verheyden H. 2008. Hunting increases vigilance levels in roe deer and modifies feeding site selection. Animal Behaviour, 76, 611-618.

Blanchard P. \& Fritz H. 2007. Induced or routine vigilance while foraging. Oikos, 116, 1603-1608.

Blumstein D.T., Daniel J.C., Griffin A.S. \& Evans C.S. 2000. Insular tammar wallabies (Macropus eugenii) respond to visual but not acoustic cues from predators. Behavioral Ecology, 11, 528535.

Bradbury J.W., Vehrencamp S.L., Clifton K.E. \& Clifton L.M. 1996. The relationship between bite rate and local forage abundance in wild Thomson's gazelles. Ecology, 77, 2237-2255.

Bro-Jørgensen J., Pangle W.M. 2010. Male topi antelopes alarm snort deceptively to retain females for mating. American Naturalist, 176, 33-39.

Brown G.E., Macnaughton C.J., Elvidge C.K., Ramnarine I. \& Godin J.G.J. 2009. Provenance and threat-sensitive predator avoidance patterns in wild-caught Trinidadian guppies. Behavioral Ecology and Sociobiology, 63, 699-706. 
Burger J., Safina C. \& Gochfeld M. 2000. Factors affecting vigilance in springbok: importance of vegetative cover, location in herd, and herd size. Acta ethologica, 25, 97-104.

Caine N.G. \& Marra S.L. 1988. Vigilance and social organization in two species of primates. Animal Behaviour, 36, 897-904.

Caro T. 2005. Antipredator defenses in birds and mammals. University of Chicago Press, Chicago.

Clarke J.L., Jones M.E. \& Jarman, P.J.1989. A day in the life of a kangaroo: activities and movements of eastern grey kangaroos Macropus giganteus at Wallaby Creek. In: Kangaroos, wallabies and rat-kangaroos. (Ed. by G. Grigg, P. Jarman \& I. Hume), pp. 611-618. Chipping Norton, United Kingdom: Surrey Beatty.

Cowlishaw G., Lawes M.J., Lightbody M., Martin A., Pettifor R. \& Rowcliffe J.M. 2004. A simple rule for the costs of vigilance: empirical evidence from a social forager. Proceedings of the Royal Society of London B, 271, 27-33.

Creel S. \& Christianson D. 2008. Relationships between direct predation and risk effects. Trends in Ecology and Evolution, 23, 194-201.

Dingemanse N.J., Kazem A.J.N., Réale D. \& Wright J. 2010. Behavioural reaction norms: where animal personality meets individual plasticity. Trends in Ecology and Evolution, 25, 81-89.

Dittus, W.P.J. 1984. Toque macaque food calls: semantic communication concerning food distribution in the environment. Animal Behaviour, 32, 470-477.

Edwards A.M., Best E.C., Blomberg S.P. \& Goldizen A.W. 2013. Individual traits influence vigilance in wild female eastern grey kangaroos. Australian Journal of Zoology, 61, 332-341.

Elgar M.A. 1989.Predator vigilance and group size in mammals and birds: a critical review of the empirical evidence. Biological Reviews, 64, 13-33.

Estes R.D. 1991. The behavior guide to African mammals. Halfway House, Russel Friedman Books, South Africa.

Favreau F-R., Goldizen A.W. \& Pays O. 2010. Interactions among social monitoring, anti-predator vigilance and group size in eastern grey kangaroos. Proceedings of the Royal Society $B, 277$, 2089-2095.

Fernàndez-Juricic E., Kacelnik A. 2004. Information transfer and gain in flocks: the effects of quality and quantity of social information at different neighbour distances. Behavioral Ecology and Sociobiology, 55, 502-51.

FitzGibbon C.D. 1989. A cost to individuals with reduced vigilance in groups of thomson's gazelles hunted by cheetahs. Animal Behaviour, 37, 508-510.

FitzGibbon C.D. \& Lazarus J. 1995. Antipredator behavior of Serengeti ungulates. In: Serengeti II: Dynamics, Conservation and Management of an Ecosystem (Ed. by A. R. E. Sinclair \& P. Arcese), pp. 274-296. Chicago: University of Chicago Press.

Fortin D., Boyce M.S., Merrill E.H. \& Fryxell J.M. 2004. Foraging costs of vigilance in large mammalian herbivores. Oikos, 107, 172-180. 
Fortin D., Bayer H.L., Boyce H.S., Smith D.W., Duchesne T. \& Mao J.S. 2005. Wolves influence elk movements: behavior shapes a trophic cascade in Yellowstone National Park. Ecology, 86, 1320-1330.

Frid A. \& Dill L. 2002. Human-caused disturbance stimuli as a form of predation risk. Conservation Ecology, 6, 11-26.

Fritz H., Guillemain M. \& Durant D. 2002. The cost of vigilance for intake rate in the mallard (Anas platyrhynchos): an approach through foraging experiments. Ethology, Ecology and Evolution, 14, 91-97.

Frost A.J., Thomson J.S., Smith C., Burton H.C., Davis B., Watts P.C. \& Sneddon L.U. 2013. Environmental change alters personality in the rainbow trout, Oncorhynchus mykiss. Animal Behaviour, 85, 1199-1207.

Gélin U., Wilson M.E., Coulson G.M. \& Festa-Bianchet M. 2013. Offspring sex, current and previous reproduction affect feeding behaviour in wild eastern grey kangaroos. Animal Behaviour, 86, 885-891.

Gérard J.F. \& Loisel P. 1995. Spontaneous emergence of a relationship between habitat openness and mean group size and its possible evolutionary consequences in large herbivores. Journal of Theoretical Biology, 176, 511-522.

Ginnett T.F. \& Demment M.W. 1997. Sex differences in giraffes foraging behavior at two spatial scales. Oecologia, 110, 291-300.

Gower C.N., Garrott R.A., White P.J., Cherry S. \& Yoccoz N.G. 2009a. Elk group size and predation: a flexible strategy when faced with variable risk. In: The Ecology of Large Mammals in Central Yellowstone: Sixteen Years of Integrated Field Studies (eds R.A. Garrott, P.J.White \& F.G.R.Watson), pp. 401-422. Elsevier/Academic Press, California, USA.

Gower C.N., Garrott R.A. \& White P.J. 2009b.) Elk foraging behavior: does predation risk reduce time for food acquisition? In: The Ecology of Large Mammals in Central Yellowstone: Sixteen Years of Integrated Field Studies (eds R.A. Garrott, P.J. White \& F.G.R. Watson), pp. 424 450. Elsevier, San Diego, CA, USA.

Gross J.E., Shipley L.A., Hobbs N.T., Spalinger D.E. \& Wunder B.A. 1993. Functional response of herbivores in food-concentrated patches: tests of a mechanistic model. Ecology, 74, 778-791.

Haage M., Bergvall U.A., Maran T., Kiik K. \& Angerbjörn A. 2013. Situation and context impacts the expression of personality: The influence of breeding season and test context. Behavioural Processes, 100, 103-109.

Hamilton W.D. 1971. Geometry for the selfish herd. Journal of Theoretical Biology, 31, 295-311.

Heathcote C.F. 1987. Grouping of eastern grey kangaroos in open habitat. Australian Wildlife Research, 14, 343-348.

Hik D.S. 1995. Does risk of predation influence population dynamics? Evidence from the cyclic decline of snowshoe hares. Wildlife Research, 22, 115-129. 
Hobb, N.T. 2003. Challenges and opportunities in integrating ecological knowledge across scales. Forest Ecology and Management, 181, 223-238.

Hofmann R.R. 1989. Evolutionary steps of ecophysiological adaptation and diversification of ruminants: a comparative view of their digestive system. Oecologia, 78, 443-457.

Hopcraft J.G.C., Olff H. \& Sinclair A.R.E. 2010. Herbivores, resources and risks: alternating regulation along primary environmental gradients in savannas. Trends in Ecology and Evolution, 25, 119-128.

Illius A.W. \& FitzGibbon C.1994. Costs of vigilance in foraging ungulates. Animal Behaviour, 47, 481-484.

Illius A.W. \& Gordon I.J. 1987. The allometry of food intake in grazing ruminants. Journal of Animal Ecology, 56, 989-999.

Illius A.W., Tolkamp B.J. \& Yearsley J. 2002. Symposium on 'Perspectives in the study of food intake' The evolution of the control of food intake. Proceedings of the Nutrition Society, 61, 465-472.

Jarman M.V. 1979. Impala social behaviour: territory, hierarchy, mating, and the use of space. Zeitschrift für Tierpsychologie, 21, 1-92.

Jarman P.J. 1974. The social organisation of antelope in relation to their ecology. Behaviour, 48, 215-267.

Jarman P.J. 1987. Group-size and activity in eastern grey kangaroos. Animal Behaviour, 35, 10441050.

Jarman P.J. \& Wright S. 1993. Macropod studies at Wallaby Creek. IX. Exposure and responses of eastern grey kangaroos to dingoes. Wildlife research, 20, 833-843.

Killen S.S., Marras S., Metcalfe M.B., McKenzie D.J. \& Domenici P. 2013. Environmental stressors alter relationships between physiology and behaviour. Trends in Ecology \& Evolution, 28, 651658.

Kojola I., Hella T., Hutha E. \& Niva A. 1998. Foraging conditions, tooth wear and herbivore body reserves: a study of female reindeer. Oecologia, 117, 26-30.

Krause J. \& Ruxton G.D. 2002. Living in groups. Oxford University Press, Oxford

Kurvers R.H.J.M., Adamczyk V.M.A.P., van Wieren S.E. \& Prins H.H.T. 2011. The effect of boldness on decision-making in barnacle geese is group-size-dependent. Proceedings of the Royal Society Biological Sciences B, 278, 2018-2024.

Kutsukake N. 2006 The context and quality of social relationships affect vigilance behaviour in wild chimpanzees. Ethology, 112, 581-591.

Lamoot I., Callebauta J., Demeulenaerea E., Vandenberghea C. \& Hoffmann M. 2005. Foraging behaviour of donkeys grazing in a coastal dune area in temperate climate conditions. Applied Animal Behaviour Science, 92, 93-112.

Landeau L. \& Terborgh J. 1986. Oddity and the 'confusion effect' in predation. Animal Behaviour, 34, 1372-1380. 
Langvatn R., Ablon S.D., Burkey T. \& Clutton-Brock T.H. 1996. Climate, plant phenology and variation in age of first reproduction in a temperate herbivore. Journal of Animal Ecology, 65, 653-670.

Lima S.L. 1992. Strong preferences for apparently dangerous habitats? A consequence of differential escape from predators. Oikos, 64, 597-600.

Lima S.L. 1998. Nonlethal effects in the ecology of predator-prey interactions. BioScience, 48, 2534.

Lima S.L. \& Bednekoff P.A. 1999a. Temporal variation in danger drives antipredator behavior: the predation risk allocation hypothesis. The American Naturalist, 153, 649-659.

Lima S.L. \& Bednekoff P.A. 1999b. Back to the basics of antipredatory vigilance: can nonvigilant animals detect attack? Animal Behaviour, 58, 537-543.

Lima S.L. \& Dill L.M.1990. Behavioral decisions made under the risk of predation: a review and prospectus. Canadian Journal of Zoology, 68, 619-640.

Lind J. \& Cresswell W. 2005. Determining the fitness consequences of anti-predation behaviour. Behavioral Ecology, 16, 945- 956.

Lung M.A. \& Childress L.J. 2007. The influence of conspecifics and predation risk on the vigilance of elk (Cervus elaphus) in Yellowstone National Parc. Biological Reviews, 18, 12-20.

McComb K.E. 1991. Female choice for high roaring rates in red deer, Cervus elaphus. Animal Behaviour, 41, 79-88.

McNamara J.M. \& Houston A.I. 1992. Evolutionarily stable levels of vigilance as a function of group size. Animal Behaviour, 43, 641-658.

McNelis N.L. \& Boatright-Horowitz S.L. 1998. Social monitoring in a primate group: the relationship between visual attention and hierarchical ranks. Animal Cognition, 1, 65-69.

Mech L.D. 1970. The wolf: ecology and behavior of an endangered species. Natural History Press, Garden City, New York, USA.

Meer E., Pays O. \& Fritz H. 2012. The effect of simulated African wild dog presence on antipredator behaviour of kudu and impala. Ethology, 118, 1018-1027.

Metcalfe N.B. 1984. The effects of habitat on the vigilance of shorebirds: is visibility important? Animal Behaviour, 32, 981-985.

Mitchell W.A. \& Lima S.L. 2002. Predator-prey shell games: large scale movement and its implications for decision-making by prey. Oikos, 99, 249-259.

Mooring M.S., Fitzpatrick T.A., Nishihira T.T. \& Reisig D.D. 2004. Vigilance, predation risk, and the allee effect in desert bighorn sheep. Journal of Wildlife management, 68, 519-532.

Nielsen B.L. 1999. On the interpretation of feeding behaviour measures and the use of feeding rate as an indicator of social constraint. Applied Animal Behavioural Sciences, 63, 79-91.

van Oers K., Klunder M. \& Drent P.J. 2005. Context dependence of personalities: risk taking behavior in a social and non-social context. Behavioral Ecology, 16, 716-723. 
Owen-Smith, N. 2008. Effects of temporal variability in resources on foraging behaviour. In: Resource ecology: spatial and temporal dynamics of foraging. Edited by H.H.T. Prins and F. Van Langevelde. Springer-Verlag, Dordrecht, the Netherlands. pp. 159-181.

Pays O. \& Jarman P.J. 2008. Does sex affect both individual and collective vigilance in social mammalian herbivores: the case of the eastern grey kangaroo? Behavioral Ecology and Sociobiology, 62, 757-767.

Pays O., Jarman P.J. \& Gerard J.F. 2007. Coordination, independence or synchronisation of individual vigilance in the eastern grey kangaroo? Animal Behaviour, 73, 595-604.

Pays O., Blanchard P., Valeix M., Chamaillé-Jammes S., Duncan P., Périquet S., Lombard M., Ncube G., Tarakini T., Makuwe E. \& Fritz H. 2012. Detecting predators and locating competitors while foraging: an experimental study of a medium-sized herbivore in an African savanna. Oecologia, 169, 419-430.

Périquet S.. Valeix M., Loveridge A.J., Madzikanda H., Macdonald D.W. \& Fritz H. 2010. Individual vigilance of African herbivores while drinking: the role of immediate predation risk and context. Animal Behaviour, 79, 665-671.

Périquet S., Todd-Jones L., Valeix M., Stapelkamp B., Elliot N., Wijers M., Pays O., Fortin D., Madzikanda H., Fritz H., Macdonald D.W. \& Loveridge A.J. 2012. Influence of immediate predation risk by lions on the vigilance of prey of different body size. Behavioral Ecology, 23, 970-976.

Peterson R.O., Woolington J.D. \& Bailey T.N. 1984. Wolves of the Kenai Peninsula, Alaska. Wildlife Monographs, 88, 3-52.

Pulliam H.R. 1973. On the avantages of flocking. Journal of theoretical Biology, 38, 419-422.

Rasmussen M. 2005. Seasonality in predation risk: Varying activity periods in lemurs and other primates. In: Primate Seasonality: Implications for Human Evolution (Eds, Brockman, D., and van Schaik, C.), pp. 105-128. Cambridge, Cambridge University Press.

Rieucau G. \& Giraldeau L.A. 2009. Group size effect caused by food competition in nutmeg mannikins (Lonchura punctulata). Behavioural Ecology, 20, 421-425.

Roberts G. 1996. Why individual vigilance declines as group size increases. Animal Behaviour, 51, 1077-1086.

Ruckstuhl K.E., Festa-Bianchet M. \& Jorgenson J.T. 2003. Bite rates in rocky mountain bighorn sheep (Ovis canadensis): effects of season, age, sex and reproductive status. Behavioural Ecology and Sociobiology, 54, 167-173.

Sæther B.E. 1997. Environmental stochasticity and population dynamics of large herbivores: a search for mechanisms. Trends in Ecology and Evolution, 12, 143-149.

Senft R.L., Coughenour M.B., Bailey D.W., Ritten-house L.R., Sala O.E., Swift D.M. 1987. Large herbivore foraging and ecological hierarchies. BioScience, 37, 789-799.

Shipley L.A., Gross J.E., Spalinger D.E., Hobbs N.T. \& Wunder B.A. 1994. The scaling of intake rate in mammalian herbivores. American Naturalist, 134, 1055-1082. 
Sih A., Bell A.M., Johnson J.C. \& Ziemba R.E. 2004. Behavioral syndromes: An integrative overview. The Quarterly Review of Biology, 79, 241-277.

Sih A. Cote J., Evans M., Fogarty S. \& Pruitt J. 2012. Ecological implications of behavioural syndromes. Ecology Letter, 15, 278-289.

Sinclair A., Mduma S. \& Brashares J. 2003. Patterns of predation in a diverse predator-prey system. Nature, 425, 288-290.

Smith A., Birnie A.K., Lane K.R. \& French J.A. 2009. Production and perception of sex differences in vocalizations of wied's black-tufted-ear marmosets (Callithrix kuhlii). American Journal of Primatology, 71, 324-332.

Spalinger D.E. \& Hobbs N.T. 1992. Mechanisms of foraging in mammalian herbivores: new models of functional response. The American Naturalist, 140, 325-348.

Townsend S.W., Allen C. \& Manser M.B. 2011. A simple test of vocal individual recognition in wild meerkats. Biology Letter, 8, 179-182.

Underwood R. 1982. Vigilance behaviour in grazing African antelopes. Behaviour, 79, 81-107.

Watson M., Aebischer N.J. \& Cresswell W. 2007. Vigilance and fitness in Grey Partridges Perdix perdix: the effects of group size and foraging-vigilance trade-offs on predation mortality. Journal or Animal Ecology, 76, 211-221.

Webster M.M. \& Ward A.J. 2011. Personality and social context. Biological Review, 86, 769-773.

White C.A., Feller M.C. \& Bayley S. 2003. Predation risk and the functional response of elk-aspen herbivory. Forest Ecology and Management, 181, 77-98.

Wilmshurst J.F., Fryxell J.M., Colucci P.E. 1999. What constrains daily intake in Thomson's gazelles? Ecology, 80, 2338-2347.

Yom-Tov Y. 1986. Climatological correlates for body size of five species of Australian mammals. Biological Journal of the Linnean Society, 29, 245-262. 